\title{
On the Lathrobium fauna of China V. New species and additional records from Yunnan (Coleoptera: Staphylinidae: Paederinae)
}

\author{
With 347 figures and 8 maps
}

VOLKER ASSING ${ }^{1}$

${ }^{1}$ Gabelsberger Straße 2, 30163 Hannover, Germany. - vassing.hann@t-online.de Published on 2013-06-14

\section{Summary}

Material of the paederine genus Lathrobium Gravenhorst, 1802 from the Chinese province Yunnan is examined. Fifty-nine species are identified, nine of them described previously and fifty undescribed. Forty species are described and illustrated for the first time, all of them micropterous and locally endemic: Lathrobium abscisum sp. n. (Gaoligong Shan), L. acre sp. n. (Gaoligong Shan), L. acutapicale sp. n. (mountain range ESE Zhongdian), L. amputatum sp. n. (Gaoligong Shan), L. bidigitulatum sp. n. (Gaoligong Shan), L. bifasciatum sp. n. (mountain range SSE Zhongdian), L. bihamulatum sp. n. (Ertaipo Shan E Mangshi), L. biseriatum sp. n. (Xue Shan), L. breviseriatum sp. n. (mountain range E Weishan), L. curvatissimum sp. n. (Jizu Shan), L. desectum sp. n. (Gaoligong Shan), L. elevatum sp. n. (Ailao Shan), L. exspoliatum sp. n. (Xue Shan), L. fortehamatum sp. n. (Xue Shan), L. fortespinosum sp. n. (mountain range N Zhongdian), L. glandulosum sp. n. (Gaoligong Shan), L. grandispinosum sp. n. (Zhemo Shan), L. hirsutum sp. n. (Diancang Shan), L. iaculatum sp. n. (Gaoligong Shan), L. incurvatum sp. n. (mountain range SSE Zhongdian), L. magnispinosum sp. n. (Wuliang Shan), L. nuicum sp. n. (Nu Shan), L. puetzi sp. n. (Nu Shan), L. rastellatum sp. n. (Ailao Shan), L. rastratum sp. n. (Wuliang Shan), L. rectissimum sp. n. (Gaoligong Shan), L. resectum sp. n. (Gaoligong Shan), L. restinctum sp. n. (mountain range ESE Zhongdian), L. reticolle sp. n. (Haba Shan), L. schuelkei sp. n. (Laobie Shan), L. secans sp. n. (Gaoligong Shan), L. sectum sp. n. (Gaoligong Shan), L. seriespinosum sp. n. (Yulongxue Shan), L. sexspinosum sp. n. (Yulongxue Shan), L. squamosum sp. n. (Ertaipo Shan E Mangshi), L. stipiferum sp. n. (Haba Shan), L. tentaculatum sp. n. (Ailao Shan), L. tricuspidatum sp. n. (Haba Shan), L. triquetrum sp. n. (Bangma Shan), L. zhemoicum sp. n. (Zhemo Shan). Ten probably undescribed species remain unnamed, since only females have become available. Seven previously described species and the previously unknown female sexual characters of L. yulongense PENG \& Li, 2012 are fully redescribed and illustrated. The Lathrobium fauna of Yunnan currently comprises fifty-eight described species and is thus far more diverse than those of other Chinese provinces. The total number of species recorded from mainland China now amounts to 156. All the Lathrobium records from Yunnan are from the west of the province, with the greatest diversity in the Gaoligong Shan (18 species). The known distribution of the genus in Yunnan and the individual distributions of 48 species are mapped. The examined material from Yunnan was collected primarily from leaf litter in various forest and shrub habitats at elevations between 2100 and $4100 \mathrm{~m}$. The sex ratio of four species is strongly biased in favour of females, at least in one species apparently a result of different, sex-related life expectancies. Primarily based on their male and female sexual characters, the examined species are attributed to eight species groups, with one of them subdivided into eleven subgroups. Only three of these species groups also include species from other provinces (Sichuan, Chongqing); the distributions of the remainder are confined to Yunnan. 


\section{Key words}

Coleoptera, Staphylinidae, Paederinae, Lathrobiina, Lathrobium, Palaearctic region, China, Yunnan, taxonomy, new species, descriptions, redescriptions, species groups, endemism, glands, sex ratio, life history.

\section{New species}

Lathrobium abscisum sp. n., L. acre sp. n., L. acutapicale sp. n., L. amputatum sp. n., L. bidigitulatum sp. n., L. bifasciatum sp. n., L. bihamulatum sp. n., L. biseriatum sp. n., L. breviseriatum sp. n., L. curvatissimum sp. n., L. desectum sp. n., L. elevatum sp. n., L. exspoliatum sp. n., L. fortehamatum sp. n., L. fortespinosum sp. n., L. glandulosum sp. n., L. grandispinosum sp. n., L. hirsutum sp. n., L. iaculatum sp. n., L. incurvatum sp. n., L. magnispinosum sp. n., L. nuicum sp. n., L. puetzi sp. n., L. rastellatum sp. n., L. rastratum sp. n., L. rectissimum sp. n., L. resectum sp. n., L. restinctum sp. n., L. reticolle sp. n., L. schuelkei sp. n., L. secans sp. n., L. sectum sp. n., L. seriespinosum sp. n., L. sexspinosum sp. n., L. squamosum sp. n., L. stipiferum sp. n. (Haba Shan), L. tentaculatum sp. n., L. tricuspidatum sp. n., L. triquetrum sp. n., L. zhemoicum sp. n.

\section{Zusammenfassung}

Eine Untersuchung von umfangreichem Material der Gattung Lathrobium GravenHorst, 1802 aus der chinesischen Provinz Yunnan ergab 59 Arten, davon neun bereits beschrieben und 50 unbeschrieben. Vierzig Arten, allesamt brachypter und lokalendemisch, werden erstmals beschrieben und abgebildet: Lathrobium abscisum sp. n. (Gaoligong Shan), L. acre sp. n. (Gaoligong Shan), L. acutapicale sp. n. (Berge ESE Zhongdian), L. amputatum sp. n. (Gaoligong Shan), L. bidigitulatum sp. n. (Gaoligong Shan), L. bifasciatum sp. n. (Berge SSE Zhongdian), L. bihamulatum sp. n. (Ertaipo Shan E Mangshi), L. biseriatum sp. n. (Xue Shan), L. breviseriatum sp. n. (Berge E Weishan), L. curvatissimum sp. n. (Jizu Shan), L. desectum sp. n. (Gaoligong Shan), L. elevatum sp. n. (Ailao Shan), L. exspoliatum sp. n. (Xue Shan), L. fortehamatum sp. n. (Xue Shan), L. fortespinosum sp. n. (Berge N Zhongdian), L. glandulosum sp. n. (Gaoligong Shan), L. grandispinosum sp. n. (Zhemo Shan), L. hirsutum sp. n. (Diancang Shan), L. iaculatum sp. n. (Gaoligong Shan), L. incurvatum sp. n. (Berge SSE Zhongdian), L. magnispinosum sp. n. (Wuliang Shan), L. nuicum sp. n. (Nu Shan), L. puetzi sp. n. (Nu Shan), L. rastellatum sp. n. (Ailao Shan), L. rastratum sp. n. (Wuliang Shan), L. rectissimum sp. n. (Gaoligong Shan), L. resectum sp. n. (Gaoligong Shan), L. restinctum sp. n. (Berge ESE Zhongdian), L. reticolle sp. n. (Haba Shan), L. schuelkei sp. n. (Laobie Shan), L. secans sp. n. (Gaoligong Shan), L. sectum sp. n. (Gaoligong Shan), L. seriespinosum sp. n. (Yulongxue Shan), L. sexspinosum sp. n. (Yulongxue Shan), L. squamosum sp. n. (Ertaipo Shan E Mangshi), L. stipiferum sp. n. (Haba Shan), L. tentaculatum sp. n. (Ailao Shan), L. tricuspidatum sp. n. (Haba Shan), L. triquetrum sp. n. (Bangma Shan), L. zhemoicum sp. n. (Zhemo Shan). Zehn vermutlich unbeschriebene Arten werden nicht benannt, da keine Männchen verfügbar waren. Sieben bereits beschriebene Arten sowie die weiblichen Sexualmerkmale von L. yulongense Peng \& LI, 2012 werden redeskribiert und abgebildet. Einschließlich der neuen Arten umfasst die Lathrobium-Fauna von Yunnan derzeit 58 beschriebene Arten und ist damit weit artenreicher als die Faunen anderer chinesischer Provinzen. Die Artenzahl der insgesamt aus China nachgewiesenen, beschriebenen Arten erhöht sich auf 156. Alle bisherigen Lathrobium-Nachweise stammen aus dem Westen Yunnans. Mit 18 Arten ist der Gaoligong Shan das Gebirge mit der höchsten Diversität. Die bekannte Verbreitung der Gattung in Yunnan sowie die individuellen Verbreitungsgebiete von 48 Arten werden anhand von Karten illustriert. Soweit bekannt, leben die Lathrobium-Arten Yunnans in der Bodenstreu unterschiedlicher Wald- und Strauchbiotope in Höhenlagen zwischen 2100 und $4100 \mathrm{~m}$. Bei vier Arten war das Geschlechterverhältnis, zumindest bei einer Art offenbar bedingt durch geringere Lebenserwartung der Männchen, zugunsten der Weibchen verschoben. Vor allem auf der Grundlage ihrer männlichen und weiblichen Geschlechtsmerkmale werden die untersuchten Arten acht Artengruppen zugeordnet; eine davon wird in elf Untergruppen unterteilt. Nur drei dieser Artengruppen umfassen auch Arten aus anderen Provinzen (Sichuan, Chongqing); die Verbreitung der übrigen Gruppen beschränkt sich offenbar auf Yunnan. 


\section{Contents}

1 Introduction 56

2 Material and methods ............. 56

3. The Lathrobium fauna of Yunnan .............................. 56

3.1 Diversity and distribution ........................................... 56

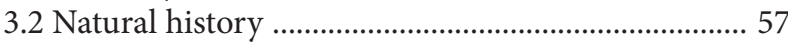

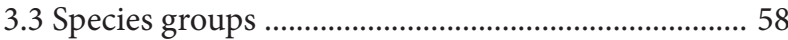

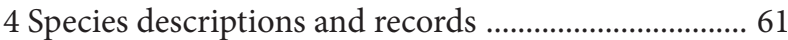

4.1 The species of the L. daliense group ........................ 61

4.1.1 The L. daliense subgroup .

61

4.1.1.1 Lathrobium daliense Watanabe \& XiaO, 1994

4.1.1.2 Lathrobium breviseriatum sp. $\mathrm{n}$.

4.1.1.3 Lathrobium zhemoicum sp. n.

4.1.1.4 Lathrobium schuelkei sp. n.

4.1.1.5 Lathrobium rastellatum $\mathrm{sp} . \mathrm{n}$.

4.1.1.6 Lathrobium rastratum sp. n.

4.1.2 The L. aokii subgroup

4.1.2.1 Lathrobium aokii WATANABE \& XIAO, 2000

4.1.2.2 Lathrobium elevatum sp. n.

4.1.2.3 Lathrobium jizushanense WATANABE \& XIAO,

1997

4.1.3 The L. magnispinosum subgroup ........................... 73

4.1.3.1 Lathrobium magnispinosum sp. n. ..................... 73

4.1.3.2 Lathrobium grandispinosum sp. n. .................... 75

4.1.3.3 Lathrobium nuicum sp. n. ................................... 75

4.1.3.4 Lathrobium iaculatum sp. n. ............................... 77

4.1.4 The L. exspoliatum subgroup .................................. 77

4.1.4.1 Lathrobium exspoliatum sp. n. ............................ 77

4.1.4.2 Lathrobium triquetrum sp. n. ............................. 79

4.1.5 The L. acutapicale subgroup ................................... 80

4.1.5.1 Lathrobium acutapicale sp. n. ............................ 80

4.1.5.2 Lathrobium restinctum sp. n. .............................. 82

4.1.5.3 Lathrobium biseriatum sp. n. ................................ 83

4.1.5.4 Lathrobium bifasciatum sp. n. ............................. 85

4.1.5.5 Lathrobium reticolle sp. n. .................................. 86

4.1.6 The L. puetzi subgroup ........................................ 87

4.1.6.1 Lathrobium puetzi sp. n. ..................................... 87

4.1.7 The L. rectissimum subgroup ..................................... 88

4.1.7.1 Lathrobium rectissimum sp. n. ............................. 88

4.1.7.2 Lathrobium xiei WatANABE \& XIAO, 2000 ....... 90

4.1.8 The L. fortehamatum subgroup ............................. 91

4.1.8.1 Lathrobium fortehamatum sp. n. ...................... 91

4.1.8.2 Lathrobium tricuspidatum sp. n. ........................ 93
4.1.8.3 Lathrobium fortespinosum sp. n. ......................... 93

4.1.9 The L. lijiangense subgroup ................................... 95

4.1.9.1 Lathrobium lijiangense WATANABE \& XIAO,

1997 95

4.1.9.2 Lathrobium seriespinosum sp. n. ....................... 96

4.1.9.3 Lathrobium sexspinosum sp. n. .......................... 98

4.1.10 The L. yulongense subgroup ................................ 98

4.1.10.1 Lathrobium yulongense PENG \& LI, 2012 ........ 98

4.1.11 The L. hirsutum subgroup ................................... 99

4.1.11.1 Lathrobium hirsutum sp. n. .............................. 99

4.1.11.2 Lathrobium baizuorum WaTANABE \& XiaO, 2000

101

4.2 The L. tentaculatum species group ........................ 102

4.2.1 Lathrobium tentaculatum sp. n. ............................ 102

4.3 The L. celere species group ....................................... 103

4.3.1 Lathrobium glandulosum sp. n. .............................. 103

4.3.2 Lathrobium secans sp. n. ....................................... 105

4.3.3 Lathrobium acre sp. n. ............................................ 106

4.3.4 Lathrobium bidigitulatum sp. n. .......................... 108

4.4 The L. curvatissimum species group ....................... 109

4.4.1 Lathrobium curvatissimum sp. n. ........................ 109

4.4.2 Lathrobium yinae WATANABE \& XIAO, 1997 ..... 110

4.4.3 Lathrobium stipiferum sp. n. ................................ 111

4.4.4 Lathrobium incurvatum sp. n. .............................. 113

4.5 The L. squamosum species group ............................ 113

4.5.1 Lathrobium squamosum sp. n. .............................. 113

4.6 The L. bihamulatum species group ......................... 115

4.6.1 Lathrobium bihamulatum sp. n. .......................... 115

4.7 The $L$. desectum species group ................................ 116

4.7.1 Lathrobium desectum sp. n. ..................................... 116

4.7.2 Lathrobium sectum sp. n. ....................................... 118

4.7.3 Lathrobium amputatum sp. n. ............................. 118

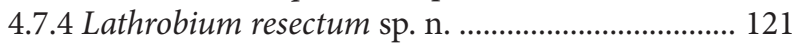

4.7.5 Lathrobium abscisum sp. n. .................................. 121

4.8 The L. lobrathiforme species group ....................... 122

4.8.1 Lathrobium lobrathiforme Assing, 2012 ............ 122

4.9 Unnamed species .................................................. 122

5 Updated checklist of the Lathrobium species of mainland China and Taiwan ................................... 124

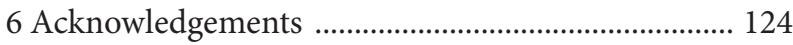

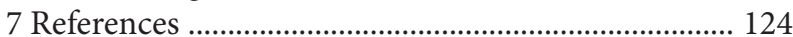




\section{Introduction}

The Holarctic paederine genus Lathrobium GravenHORST, 1802 is currently represented in the Palaearctic region by more than 430 species. In all, 116 described species, the vast majority of them micropterous and locally endemic, had been reported from mainland China (Assing in press b, c). Thus, in China, the diversity of Lathrobium is significantly greater than that of any other genus of the Paederinae.

While four previous contributions to the Lathrobium fauna of China have addressed the species of the Qinling Shan, the Daba Shan, and adjacent mountain ranges (Assing in press a), of the Emei Shan (Assing et al.2013), of various provinces exclusive of Yunnan (Assing 2013), and of Sichuan (Assing in press b), the present paper exclusively focuses on the fauna of Yunnan. Previously, the province with the greatest diversity were Sichuan (31 species), followed by Shaanxi (20 species), Yunnan (18 species), and Zhejiang (17 species). However, Yunnan had already been suspected earlier to host far more species than any of the other Chinese provinces (Assing in press b).

Less than twenty years ago, Watanabe \& Xiao (1994) were the first to describe two micropterous Lathrobium species from Yunnan. Sixteen additional species, all of them micropterous and locally endemic, were subsequently reported from this province by WATANABE \& Xiao (1996, 1997, 2000), Peng et al.(2012), and Assing (2012b). All eighteen species were described from western Yunnan: from the Gaoligong Shan (seven species), the Diancang Shan (four species), the Yulongxue Shan (four species), the Jizu Shan (two species), and the Ailao Shan (one species). Some of the species have been attributed to the Lathrobium pollens/brachypterum and L. monticola groups, respectively, by WatanABE \& XiaO (1994, 1996, 1997, 2000). For a discussion of this artificial species group concept see Assing (in press a).

The present paper is based primarily on recently collected and amazingly rich material compiled and made available to me by Michael Schülke (Berlin), Aleš Smetana (Ottawa), and Andreas Pütz (Eisenhüttenstadt). Additional specimens were found in the collections of three public institutions.

\section{Material and methods}

The material examined in this study is deposited in the following public institutions and private collections:

CAS Chinese Academy of Sciences, Beijing

NHMB Naturhistorisches Museum Basel

(M. Geiser, I. Zürcher)

NHMW Naturhistorisches Museum Wien

(H. Schillhammer)

SMNS Staatliches Museum für Naturkunde, Stuttgart (W. Schawaller)

cAss author's private collection

cPüt private collection Andreas Pütz, Eisenhüttenstadt

cSch private collection Michael Schülke, Berlin

cSme private collection Aleš Smetana, Ottawa

The morphological studies were conducted using a Stemi SV 11 microscope (Zeiss Germany) and a Jenalab compound microscope (Carl Zeiss Jena). A digital camera (Nikon Coolpix 995) was used for the photographs. The maps were created using MapCreator 2.0 (primap) software.

Body length was measured from the anterior margin of the mandibles (in resting position) to the abdominal apex, the length of the forebody from the anterior margin of the mandibles to the posterior margin of the elytra, head length from the anterior margin of the frons to the posterior margin of the head, elytral length at the suture from the apex of the scutellum to the posterior margin of the elytra (at the sutural angles), and the length of the aedeagus from the apex of the ventral process to the base of the aedeagal capsule. The "parameral" side (i.e., the side where the sperm duct enters) is referred to as the ventral, the opposite side as the dorsal aspect.

The names of the mountain ranges are primarily based on Nelles Map Southern China. Unless specified otherwise, the term "Shan" generally refers to mountain ranges rather than individual mountains.

\section{The Lathrobium fauna of Yunnan}

\subsection{Diversity and distribution}

The material examined in the course of the present study is composed of fifty-nine species, nine of them previously described, forty newly described, and ten unnamed. The latter probably represent undescribed entities, but are not named because only females have become available. Thus, with a total of fifty-eight described species, the Lathrobium fauna of Yunnan is far more diverse than that of any 
other Chinese province and nearly twice as high as that of Sichuan, which previously had the greatest number of species. All the species, named and unnamed, are micropterous, flightless, and apparently locally endemic. Without exception, the Lathrobium records from Yunnan are from the west of the province, records from the eastern half are unknown (Map 1). The Gaoligong Shan alone hosts as many as eighteen described species. The remaining described species are endemic to the Yulongxue Shan (6 species), the Diancang Shan (5), the mountain ranges to the north, south-southeast, and east-southeast of Zhongdian (5), the Ailao Shan (4), the Jizu Shan (3), the Haba Shan (3), the Ertaipo Shan E Mangshi (2), the Zhemo Shan (2), the Wuliang Shan (2), the Nu Shan (2), the Xue Shan to the south of Zhongdian (2), the Laobie Shan (1), the Bangma Shan (1), the Wulao (=Xue) Shan to the east-northeast of Lincang (1), and the Daque Shan to the east of Weishan (1).

For several reasons the Lathrobium fauna of Yunnan can be expected to be significantly more diverse than presently known. Not only did the examined material include ten probably undescribed species. Also, numerous species were collected only once. Moreover, ten out of eighteen previously described species were not recorded in the present paper, although material from the respective mountain ranges was available. Finally, numerous regions, mountains, or habitats/elevations, particularly the northeastern parts of Yunnan, have not been investigated using appropriate methods (sifting), probably because they are less easily accessible.

\subsection{Natural history}

The examined material with labels specifying information on the habitat and the method of collection was sifted from leaf litter in various forest (deciduous, mixed, coniferous) and shrub habitats. The altitudes range from 2100 to $4100 \mathrm{~m}$, with the vast majority of records between 2300 and $3900 \mathrm{~m}$. Two species groups seem to be confined to high-altitude habitats at elevations of $3500-4100 \mathrm{~m}$ (see the following section). On numerous occasions, two or more species, occasionally of the same species group, were found syntopically (i.e., in the same sample). Similar observations were made in other regions of China, e.g., the Qinling Shan and the Daba Shan (Assing in press a).

In four species (L. aokii, L. exspoliatum, L. fortespinosum, L. glandulosum), the observed sex ratios were strongly biased in favour of females. In L. aokii, the sex ratio was biased only in spring-collected material, whereas it was

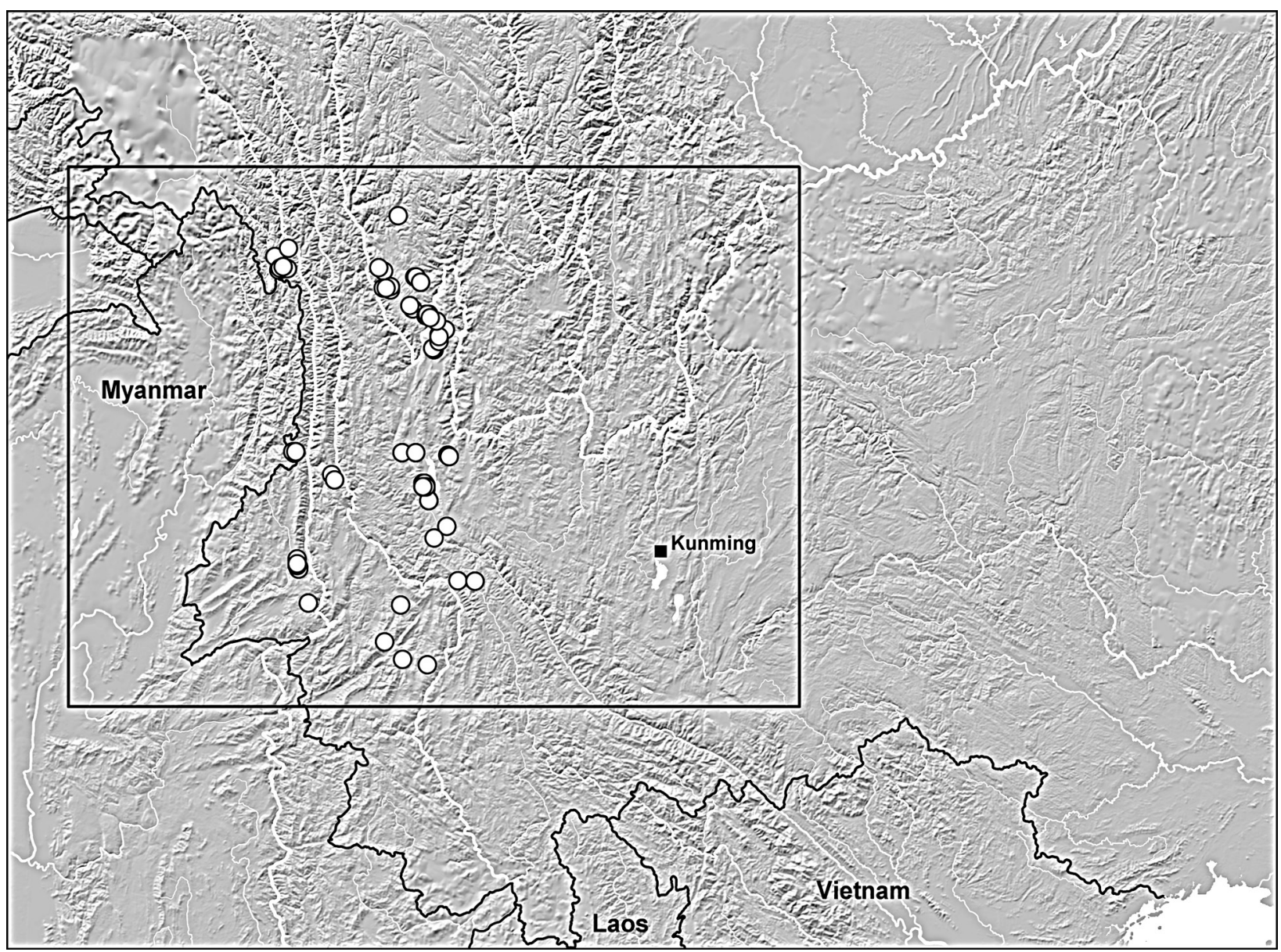

Map 1: Pooled Lathrobium records from Yunnan, based on examined material. The frame marks the limits of Maps 2-8. 
balanced in material collected in summer, when the new generation of the adults appears (as can be inferred from the presence of teneral specimens during this period). These observations suggest that such biased sex ratios may be a result different, sex-related life expectancies (shorter in males than in females). Teneral adults were collected primarily in August and September (twenty species), suggesting oviposition in spring and pre-imaginal development in spring and summer. Teneral adults of six species were exclusively found in May and June, which may indicate pre-imaginal development during winter.

\subsection{Species groups}

Based on morphological evidence, primarily the male and female sexual characters, the Lathrobium fauna of Yunnan can be subdivided into several species groups, four of them apparently represented only by single species. Aside from the male sexual characters, the structure of the female tergites IX and X seems to be of particular significance. The antero-median portion of the female tergite IX may be completely divided (thus forming two separate hemi-tergites connected only by the anterior tergal margin) or very short with a distinct median suture, allowing for a long tergite $\mathrm{X}$. In many species groups, however, the antero-median portion is much longer, undivided, and without suture, which in turn allows for a much shorter tergite X. An anteriorly divided anteromedian portion, or the presence of a median suture, appear to be the derived conditions. Among West Palaearctic Lathrobium, these conditions form exceptions. In the Central European fauna, for instance, a completely divided tergite IX is known only from one (L. brunnipes (FABricius, 1793)) and a median suture from two species (L. pallidum NordmanN, 1837, L. dilutum ERICHson, 1839) (Assing 2012a). Similarly, just one out of ten species groups known from the Himalaya has the female tergite IX completely divided, and a median suture is present in only one other group (Assing 2012c). In most regions of China, too, species groups with an anteriorly divided tergite IX seem to be rarer. Most of the species and species groups known from the Qinling Shan, the Daba Shan, and adjacent mountain ranges have an anteriorly undivided female tergite IX (AssING in press a). In Yunnan, three out of eight species groups, which include the majority of species, have a short antero-median portion with a median suture (or, rarely, a completely divided antero-median portion). However, many of the species described from China have not been comprehensively studied in this respect. This also applies to those species from Yunnan, of which no material was available. The descriptions by Watanabe \& Xiao (1994, 1996, 1997, 2000) do not provide many phylogenetically relevant details, such as the morphology of the female tergites IX and $\mathrm{X}$, or the internal structures of the aedeagus. Interestingly, nearly all the species examined have a ring-shaped membranous structure in the internal sac of the aedeagus. The phylogenetic significance of this structure is unknown, mostly because it has not been studied in previous contributions.

As has been observed earlier (Assing in press a), closely related species, particularly hypothesized adelphotaxa, are at the same time geographically close, suggesting that the separation of gene pools and subsequent speciation were - at least primarily - initiated by local geological and climatic events.

The L. daliense group represents, by far, the most diverse lineage in Yunnan. It comprises more than 30 species in at least eleven subgroups and is characterized by a female tergite IX with a short antero-median portion with a median suture, a long female tergite $\mathrm{X}$, a posteriorly more or less distinctly, convexly produced female sternite VIII, symmetric male sternites VII and VIII with, at most, weakly modified pubescence, a male sternite VIII without, or with small posterior excision, a symmetric aedeagus with a slender, usually curved, and apically acute ventral process, and with pairs of (series of) spines and/ or dark membranous structures in the internal sac.

The $L$. daliense subgroup is represented by six species (L. daliense, L. breviseriatum, L. zhemoicum, L. schuelkei, L. rastellatum, L. rastratum) found at moderately high elevations (2100-3000 m) and distributed in the region extending from the Diancang Shan in the north to the Laobie Shan in the south. They are characterized particularly by the similar morphology of the aedeagus (short to moderately short, laterally more or less distinctly compressed ventral process of the aedeagus; see, e.g., Figs 4, $11,19,24)$ and additionally by the similar secondary sexual characters, rather uniform, moderately large body size (length of forebody 2.7-3.5 mm), a large, stout, and distinctly convex pronotum, and dark coloration. Sister species relationships are hypothesized for $L$. daliense + L. breviseriatum, L. zhemoicum + L. schuelkei, and L. rastellatum $+L$. rastratum. For details see the respective species sections.

The L. aokii subgroup comprises three of the examined species (L. aokii, L. elevatum, L. jizushanense) and, based on the illustrations provided in the original description, also L. yunnanum Watanabe \& XIAO, 1994. The species of this lineage are distributed in the mountains around the Er Hai lake (Map 3) and were collected at altitudes of $2450-4060 \mathrm{~m}$. They are characterized by relatively large body size (length of forebody 3.3-4.3 mm), dark coloration, a strongly transverse male sternite VII (e.g., Figs 42, 50 ), an aedeagus with a slender, weakly curved (lateral view), and apically acute ventral process (e.g., Figs 44, 52), a transverse female sternite VIII (e.g., Figs 46, 54), a female tergite IX with a very short antero-median portion (e.g., Figs 47, 55), and a female tergite $\mathrm{X}$ with a median elevation (e.g., Figs 46, 54). Lathrobium aokii and 
L. elevatum may represent adelophotaxa (see the respective species sections).

The L. magnispinosum subgroup is composed of four species (L. magnispinosum, L. grandispinosum, L. nuicum, L. iaculatum) distributed in the south of western Yunnan (Map 3) with altitudes ranging from 2100 to $2970 \mathrm{~m}$. The monophyly of this lineage is supported by the synapomorphic presence of a large and long sclerotized basal spine (in addition to pairs of smaller spines and membranous structures) in the internal sac of the aedeagus (e.g., Figs 68-69, 76-77). Other characters defining this subgroup are the large body size (length of forebody 4.2$5.3 \mathrm{~mm}$ ), blackish coloration, a distinctly transverse head (e.g., Figs 64, 73), a broad pronotum (e.g., Figs 64, 73), short elytra (approximately 0.5 times as long as pronotum), a strongly transverse male sternite VII (e.g., Fig. 65), the small, but distinct posterior excision of the male sternite VIII, usually with modified pubescence at its margins (e.g., Figs 66-67, 74-75), and particularly a long and conspicuously flattened female tergite X (Figs 72, 85, 91). The similar aedeagal morphology suggests that L. magnispinosum and L. grandispinosum represent adelphotaxa (see the respective species sections).

The L. exspoliatum subgroup contains two species (L. exspoliatum, L. triquetrum) distributed in the south of western Yunnan (Map 4) and collected at elevations of $2210-2510 \mathrm{~m}$. This lineage is characterized by unmodified pubescence of the male sternites VII and VIII (Figs 94-95, 103-104), a small aedeagus with a short and stout, laterally more or less compressed ventral process and with a weakly sclerotized dorsal plate, the presence of a pair of spines and the absence of long membranous structures in the internal sac of the aedeagus (Figs 96-97, 105-107), and a posteriorly weakly produced female sternite VIII (Figs 99, 108). Externally, both species are similar to the representatives of the L. daliense subgroup. At least the shared modifications of the aedeagus probably represent synapomorphies.

The L. acutapicale subgroup includes five species (L. acutapicale, L. restinctum, L. biseriatum, L. bifasciatum, $L$. reticolle) distributed in the north of western Yunnan and apparently confined to high-altitude habitats $(2970-3900 \mathrm{~m})$. The species of this lineage are rather small (length of forebody 2.3-2.8 mm), of dark coloration, and have a moderately slender pronotum. They are particularly characterized by stout antennae (Figs 110, 138), small eyes (composed of 15-30 ommatidia), a pronotum with shallow microculpture (unique, though often nearly obsolete in part of the species), an aedeagus with a slender and apically pointed ventral process (e.g., Figs 114, 120) (exception: L. reticolle), with a very short, weakly sclerotized basal portion of the dorsal plate, and with a pair (of series) of spines in the internal sac (e.g., Figs 127, 135), and a short to very short antero-median portion of the female tergite IX (e.g., Figs 117, 122). Primarily based on the sexual characters, the following phylogenetic affiliations are hypothesized: ((L. acutapicale + L. restinctum $)+$ $(L$. biseriatum + L. bifasciatum $))+L$. reticolle. For details see the respective species sections.

The L. puetzi subgroup is represented by a single species, L. puetzi, from the Nu Shan (Map 4). The morphology of its aedeagus (shape of ventral process and of dorsal plate, internal structures; see Figs 147-148) somewhat resembles that of the L. acutapicale subgroup. However, the species differs in many other character, particularly the absence of microsculpture on the pronotum, larger body size (length of forebody $3.0-3.3 \mathrm{~mm}$ ), a less slender pronotum with weakly convex lateral margins in dorsal view (Fig. 144), larger eyes, longer and more slender antennae, and a posteriorly distinctly produced female sternite VIII (Fig. 150).

The L. rectissimum subgroup is composed of two examined species (L. rectissimum, L.xiei) and probably also L. baihualingense WATANABE \& XIAO, 2000, all of them distributed in the Gaoligong Shan (Map 5). The examined species were collected at elevations of 2100-3000 m. They are characterized by relatively small to moderate body size (length of forebody 2.5-3.3 mm), a slender habitus, reddish to brown coloration, small eyes composed of 25-30 ommatidia, a pronounced sexual dimorphism of protarsomeres I-IV, a slender (as broad as long or oblong) and in the middle narrowly non-pubescent male sternite VIII with a small posterior excision (Figs 155, 163), an aedeagus with a conspicuously long and slender ventral process and with two or three long series of distinctly sclerotized spines (Figs 156-157, 164-165), and a long female tergite X (Figs 159, 167).

The L.fortehamatum subgroup includes three species (L. fortehamatum, L. tricuspidatum, L. fortespinosum) distributed in the north of western Yunnan (Map 5), apparently confined to high-altitude habitats (3800$4070 \mathrm{~m}$ ), and sharing the following differential characters: body rather small (length of forebody 2.5-3.1 mm) and of reddish coloration; eyes reduced, without pigmentation, and composed of approximately 10 ommatidia; antennae stout, antennomeres $\mathrm{V}$-X not oblong; pronotum slender (approximately 1.3 times as long as broad; e.g., Figs 169, 175); elytra with very shallow punctation; male sternite VII strongly transverse and with extensive median impression (e.g., Figs 170, 176); male sternite VIII with $\mathrm{V}$-shaped posterior excision, posterior margin produced on either side of this excision (e.g., Figs 171, 177); aedeagus large in relation to body size, dorsal plate with apical portion long, distinctly sclerotized, and distinctly convex to roof-shaped in cross-section, internal sac with large and strongly sclerotized spines (e.g., Figs 172, 178). At least the adaptive reduction of the eyes, as well as the shared modifications of the aedeagus and the male sternite VIII evidently represent synapomorphies. The similar male and female sexual characters suggest that 
L. fortehamatum and L. tricuspidatum are adelphotaxa. For details see the respective species sections.

The L. lijiangense subgroup comprises three species (L. lijiangense, L. seriespinosum, L. sexspinosum) distributed in the Yulongxue Shan and its environs (Maps 6-7), and apparently confined to high altitude habitats (3000$4100 \mathrm{~m}$ ). These species differ from other subgroups of the L. daliense group by the following character combination: body of dark coloration and small to moderate body size (length of forebody 2.7-3.5 mm); head weakly oblong (e.g., Figs 191, 199); sexual dimorphism of protarsomeres I-IV weakly pronounced; male sternite VIII with very shallow posterior excision or concavity (e.g., Figs 193, 201); dorsal plate of aedeagus with long apical and short basal portion; internal sac of aedeagus with pair of conspicuous apical spines and with additional pairs of series of basal spines (e.g., Figs 194, 196, 202-203); female tergite IX with completely divided or very short anteromedian portion (e.g., Figs 198, 205); female tergite X distinctly convex or sharply elevated in cross-section. At least the shared modifications of the male sternite VIII, the aedeagus, and the female tergites IX and X probably represent synapomorphies.

Like the species of the L. lijiangense subgroup, Lathrobium yulongense is endemic to the Yulongxue Shan (Map 6) and belongs to the L. daliense group. However, the male and female sexual characters do not suggest closer affiliations to any of the other subgroups. The species is characterized by a derived morphology of the aedeagus (ventral process and dorsal plate of conspicuous shape, internal sac without distinct spines), a broadly convex and in the middle weakly concave posterior margin of the female sternite VIII, a very short antero-median portion of the female tergite IX (Fig. 188), and a long female tergite X (Fig. 189). For illustrations of the external and male sexual characters see Peng et al.(2012).

The L. hirsutum subgroup comprises two species (L. hirsutum, L. baizuorum) distributed in the Diancang Shan (Map 6) and collected at elevations of 2700-3100 m. This subgroup is characterized by small body size (length of forebody 2.2-2.6 $\mathrm{mm}$ ), reddish coloration, a male sternite VIII without posterior excision (posterior weakly concave in the middle at most) and a non-pubescent middle at least in posterior half (Figs 214, 222), an aedeagus with a slender and apically very acute ventral process and with series of sclerotized spines in the internal sac (Figs 215$217,223-224$ ), a posteriorly convexly produced female sternite VIII (Figs 218, 225), and rather short posterolateral processes of the female tergite IX (Figs 219, 226).

The L. tentaculatum group includes a single species (L. tentaculatum) distributed in the Ailao Shan (Map 6), where it was found at an elevation of $2300 \mathrm{~m}$. It shares the morphology of the female tergite IX (antero-median portion very short and with suture) and the long female tergite $\mathrm{X}$ with the species of the L.daliense group, but differs from them in so many respects that it is hypothesized to represent a distinct species group. It is characterized by a large and robust body (length of forebody 4.5-4.8 mm; Fig. 227), a large and distinctly transverse head with relatively large eyes, long antennae, dense and defined punctation of the elytra (Fig. 228), a posteriorly triangularly produced tergite VIII (Fig. 233), the absence of a median projection at the anterior margin of the male sternite VII (Fig. 229), a distinctly transverse and posteriorly broadly concave male sternite VIII with modified pubescence at its posterior margin (Fig. 230), and an aedeagus (Figs 231-232) of highly derived morphology (slightly asymmetric and dorso-ventrally flattened; ventral process apically with two long processes; dorsal plate with short, slightly asymmetric apical portion and with short basal portion; internal sac without spines or other dark structures, except for the ring-shaped membranous structure).

The L. celere group currently includes five species, one (L. celere Assing, 2013) from the Gongga Shan in Sichuan, and four (L.glandulosum, L. secans, L. acre, L. bigitulatum) from the Gaoligong Shan (Maps 5-7) in western Yunnan, where they were collected at altitudes between approximately 3000 and $3400 \mathrm{~m}$. On several occasions, two or more species of this group (in various combinations) were found in the same locality. The monophyly of this species group is constituted by a conspicuous synapomorphy, the presence of a more or less defined cluster of hypothesized gland openings on the male sternite VIII (Figs 241, 249, 257, 264). In three species, such gland openings are present also on the male sternite VII (e.g., Fig. 239). In addition, the species of this species group are characterized by a slender habitus (e.g., Fig. 236), a subquadrate or oblong head with pronounced microreticulation, a slender pronotum (1.25-1.35 times as long as broad; e.g., Figs 237, 246), long legs and antennae, the (near) absence of a sexual dimorphism of the protarsomeres I-IV, a distinctly transverse male sternite VII with unmodified pubescence (e.g., Figs 238, 247), a compact aedeagus (Figs 242-243, 250, 258-259, 265-266) with a relatively short, often laterally strongly compressed ventral process, a dorsal plate with a broad apical portion, and a short antero-median portion of the female tergite IX with a median suture (Figs 245, 252, 269). The similarly blade-shaped ventral process of the aedeagus in L. secans and L. acre suggests that these two species represent adelphotaxa.

The L. curvatissimum group is composed of four species (L. curvatissimum, L. yinae, L. stipiferum, L. incurvatum), which were collected at altitudes of 2180-3200 m), all of them distributed in the north of western Yunnan. It seems likely that three species from Sichuan, L. diffissum Assing, in press from the Luoji Shan, L. aspinosum Assing, 2013 from the Erlang Shan, and an undescribed species from Shimian County (PENG et al. in prep), too, 
belong to this species group. The species of this lineage are distinguished from all the preceding species by the fused antero-median portion of the female tergite IX (Figs 275, 282, 289). In addition, they are characterized by moderately large to large body size (length of forebody 3.4-4.9 mm), a long aedeagus (Figs 273, 280, 287, 293) with an elongated and curved ventral process, a long apical portion of the dorsal plate of the aedeagus (at least in the species from Yunnan), and by the absence of a distinct posterior excision of the male sternite VIII (Figs 272, 279, 286, 292) (exception: L. aspinosum). For illustrations of L. aspinosum and L. diffissum see Assing (2013) and Assing (in press b), respectively.

Like the species of the L. curvatissimum group, L. squamosum from the south of western Yunnan (Map 7) (collected at $2280 \mathrm{~m}$ ) has a female tergite IX with an undivided antero-median portion (Fig. 301). The male and female sexual characters (Figs 295-300) do not suggest closer affiliations to any of the other species groups known from Yunnan.

Lathrobium bihamulatum, which was collected in the same locality as L. squamosum (Map 8), is the only species known from Yunnan with an asymmetrically bisinuate posterior margin of the male sternite VIII (Fig. 305). In addition, it differs in so many other respects, particularly the morphology of the aedeagus (massive apical portion of the internal sac, extremely long dorsal plate, presence of a pair of two long and hook-shaped apical spines and of additional basal spines of different sizes in the internal sac; see Figs 306-307), the absence of a median projection at the anterior margin of the male sternite VII (Fig. 304), and the slender elytra (not broader than the pronotum; a unique character among Lathrobium from Yunnan) that it is not possible to attribute it to any of the other species groups.

The L. desectum group comprises five species (L. desectum, L. sectum, L. amputatum, L. resectum, L. abscisum) from the Gaoligong Shan (Map 8), where they were found in high-altitude habitats $(2940-3320 \mathrm{~m})$. The monophyly of this lineage is supported particularly by the morphology of the aedeagus, which has a pair of large basal spines and additional series of sclerotized spines in the internal sac (Figs 311, 313, 319, 323, 325, $331-333,340-342,344-345)$ and a dorsal plate with a sharply pointed and elongated apex (Figs 312, 324, 343). In addition, the species of this group are characterized by moderate size (length of forebody 3.1-4.1 mm), a transverse and usually somewhat wedge-shaped head, a short and broad pronotum $(<1.2$ times as long as broad and distinctly broader than head), a moderately transverse male sternite VII with unmodified pubescence, a distinctly transverse male sternite VIII with a more or less truncate posterior margin without median excision, a slender and smoothly curved ventral process of the aedeagus, a broad female sternite VIII (as long as broad at most), and by the undivided antero-median portion of the female tergite IX.

The L. lobrathiforme group is currently represented by one species from the Gaoligong Shan and one (L. lobrathioides Assing, 2012) from Chongqing. These two species differ so significantly from all other species of Palaearctic Lathrobium (see Assing 2012b) that their generic placement will have to be re-examined.

\section{Species descriptions and records}

\subsection{The species of the L. daliense group}

\subsubsection{The L. daliense subgroup}

\subsubsection{Lathrobium daliense WATANABE \& XIAO, 1994 (Figs 1-6, Map 2)}

\section{Material examined:}

China: Yunnan: $45 o^{\star} o^{\star}, 36$ ㅇ 우 [17 exs. teneral], Dali Bai Nat. Aut. Pref., Diancang Shan, $3 \mathrm{~km}$ W Dali old town, pine forest at "Cloud Road", right upper chairlift station, $25^{\circ} 41^{\prime} \mathrm{N}, 100^{\circ} 07^{\prime} \mathrm{E}, 2650-2750 \mathrm{~m}$, pine needles, leaf litter, and dry moss in ditches sifted, 1.IX.2003, leg. Schülke, Smetana \& Wrase (cSch, cSme, cAss); $350^{\star} o^{\star}, 42$ 우 우 [15 exs teneral], same data, but 30.VIII.2003 (cSch, cAss); 1 甲, data, but 29.VIII.2003, leg. Smetana (cSme); 2 o $^{\top} \mathrm{o}^{\star}, 12$ 우 우, same data, but 17.VI.2005, leg. Schülke \& Smetana (cSch, cSme, cAss); $4 o^{x} o^{x}, 7$ ㅇ 우, same data, but 3.IX.2003 (cSch, cAss); 4 o $^{\star}$, 5 우 우 [4 exs teneral], Dali Bai Nat. Aut. Pref., Diancang Shan, 4 km W Dali old town, pine forest at "Cloud Road", right upper chairlift station, $25^{\circ} 41^{\prime} \mathrm{N}, 100^{\circ} 07^{\prime} \mathrm{E}, 2900-3000 \mathrm{~m}$, E-slope with degraded forest and old pine forest, 31.VIII.2003, leg. Schülke \& Smetana (cSch, cSme, cAss); 4 o o o , 3 ㅇ 우, Dali Bai Nat. Aut. Pref., Diancang Shan, 5 km SSW Dali, $25^{\circ} 39^{\prime} \mathrm{N}, 100^{\circ} 08^{\prime} \mathrm{E}, 2800 \mathrm{~m}$, E-slope with degraded forest and old pine forest, 26.VIII.2003, leg. Smetana (cSme, cAss); $10^{7}, 1$ 오 , Dali Bai Nat. Aut. Pref., Diancang Shan, $3 \mathrm{~km}$ E Dali, $25^{\circ} 41^{\prime} \mathrm{N}, 100^{\circ} 07^{\prime} \mathrm{E}, 2700 \mathrm{~m}$, 29.VIII.2003, leg. Smetana (cSme, cAss); $30^{\top} 0^{\star}, 4$ 우 우, Dali Bai Nat. Aut. Pref., Diancang Shan, W Dali, $25^{\circ} 42^{\prime} \mathrm{N}, 100^{\circ} 07^{\prime} \mathrm{E}$, $2860 \mathrm{~m}$, pine forest, litter and moss sifted, 28.V.2007, leg. Schülke \& Pütz (cPüt, cSch, cAss); $3 \sigma^{\top} o^{\star}$, Dali Bai Nat. Aut. Pref., Diancang Shan, $25^{\circ} 40^{\prime} \mathrm{N}, 100^{\circ} 08^{\prime} \mathrm{E}, 2730 \mathrm{~m}$, sifted, 9.V.2010, leg. Grebennikov (CAS, cSme, cAss); $10^{\star}$, same data, but 11.V.2010 (cSme); 2 우, Dali Bai Nat. Aut. Pref., Diancang Shan, W Dali, $25^{\circ} 42^{\prime} \mathrm{N}, 100^{\circ} 06^{\prime} \mathrm{E}$, $2960 \mathrm{~m}$, sifted from litter, moss, and flood debris, 6.IX.2009, leg. Schülke (cSch, cAss); $4 o^{\star} o^{x}, 2$ ㅇ 우, Dali Bai Nat. Aut. Pref., Diancang Shan, E-slope of Zhonghe Shan, $25^{\circ} 41^{\prime} \mathrm{N}, 100^{\circ} 08^{\prime} \mathrm{E}, 2650 \mathrm{~m}$, mixed forest with pine 
and rhododendron, litter and humus sifted, 13.VI.2007, leg. Hájek \& Ružička (cSch, cAss); 1 o , 1 \%, Dali Bai Nat. Aut. Pref., Diancang Shan, same data, but 2.VI.2007 (cSch, cAss); 1 + , Dali Bai Nat. Aut. Pref., Diancang Shan, $4 \mathrm{~km}$ W Dali old town, $25^{\circ} 41^{\prime} \mathrm{N}, 100^{\circ} 07^{\prime} \mathrm{E}, 2900-3000 \mathrm{~m}$, E-slope with Salix, sifted, 22.VI.2005, leg. Wrase (cSch);
2 o $^{\pi}, 1$ 웅, above Dali, 2000-2200 m, 4.-17.IV.1999, leg. Schawaller (SMNS).

Comment:

The original description of $L$. daliense is based on eleven type specimens from "Zhonghe Feng (2,620 m alt.),
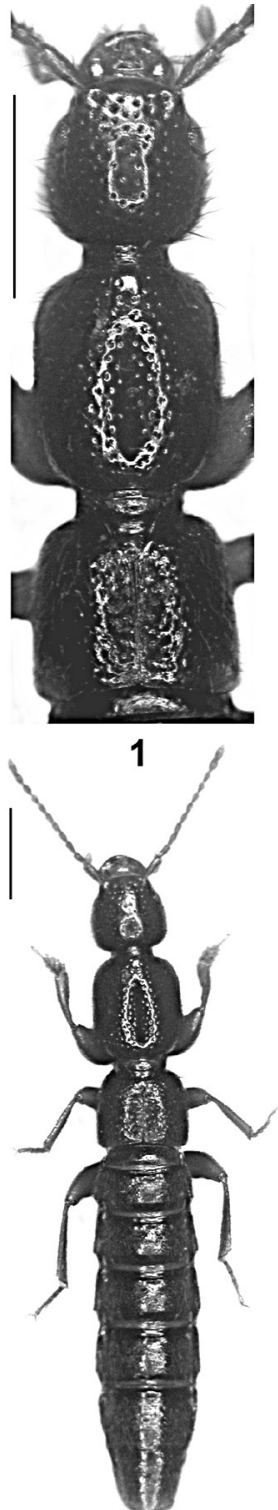

7

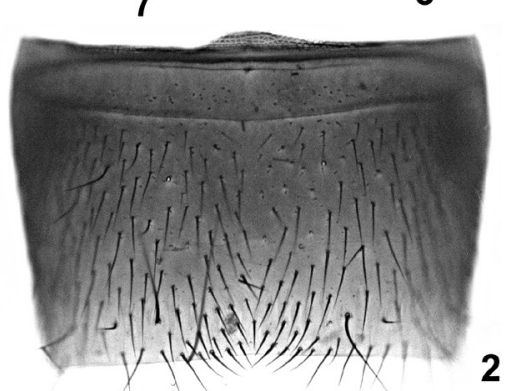

8

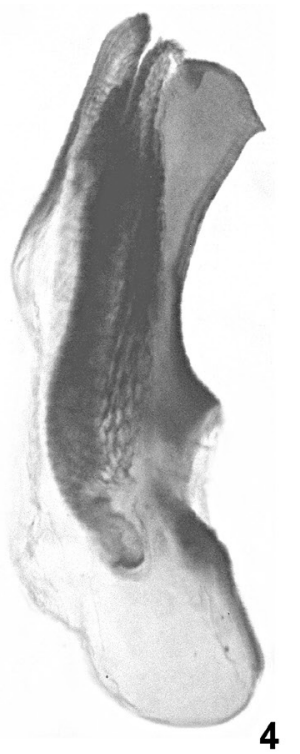

4
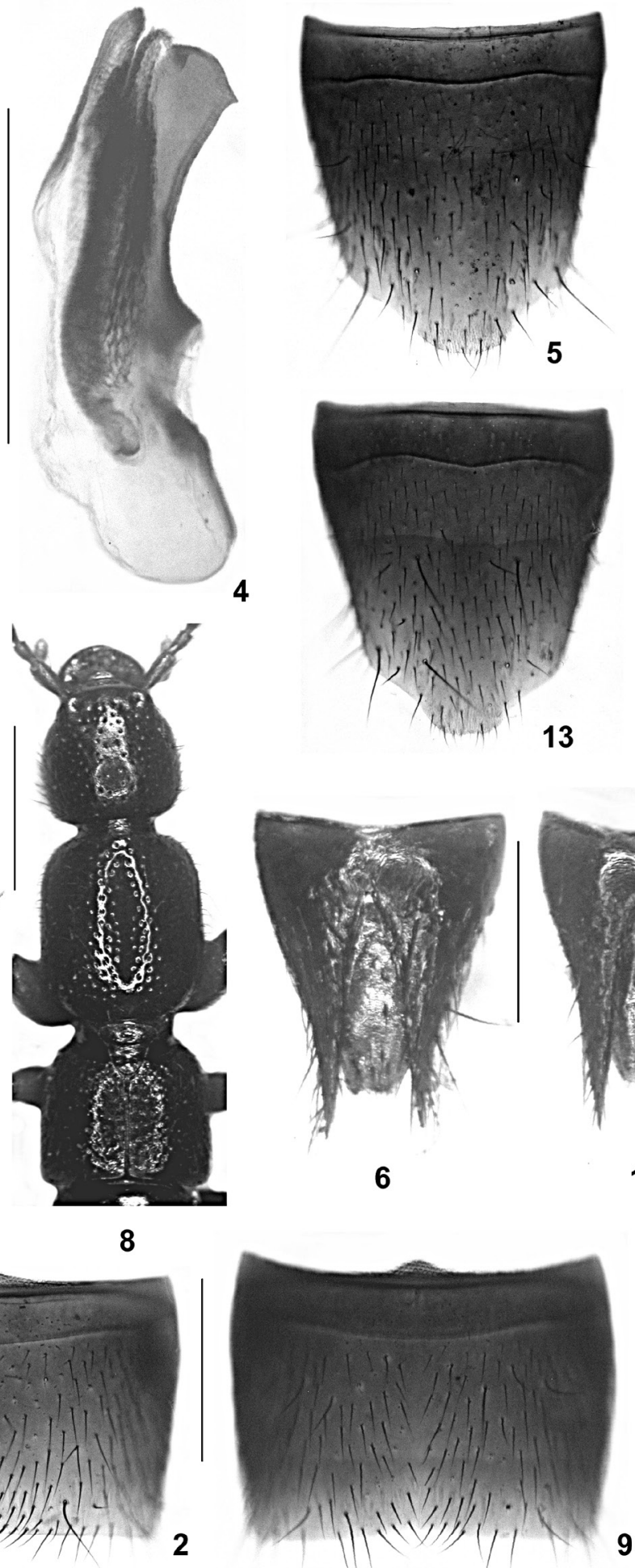

13

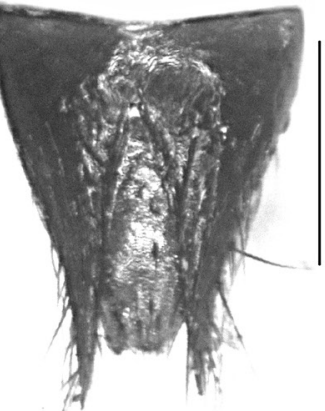

6

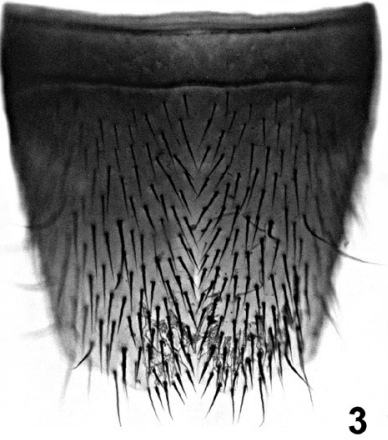

3

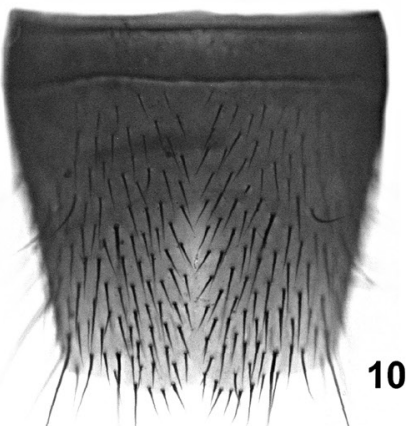

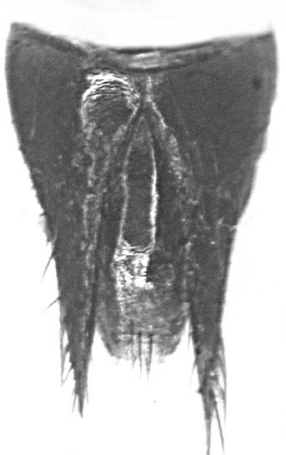

14

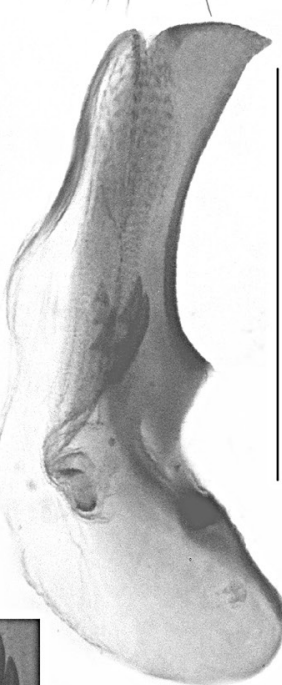

11

Figs 1-14: Lathrobium daliense (1-6) and L. breviseriatum (7-14): forebody (1,8); male sternite VII $(2,9)$; male sternite VIII $(3,10)$; aedeagus in lateral view $(4,11)$; female sternite VIII $(5,13)$; female tergites IX-X $(6,14)$; habitus $(7)$; internal structures of aedeagus (12). Scale bars: 1, 7-8: $1.0 \mathrm{~mm}$; 2-6, 9-11, 13-14: $0.5 \mathrm{~mm}$; 12: $0.1 \mathrm{~mm}$. 
Diancang Shan Mountains, Dali Shi” (Watanabe \& XIAO 1994). The illustrations of the aedeagus provided in the original description leave no doubt that the above specimens are conspecific with the types.

\section{Redescription:}

Species of moderate size; body length 5.9-7.2 mm; length of forebody 2.7-3.2 mm. Coloration: body dark-brown to blackish-brown; legs and antennae reddish to darkbrown.

Head (Fig. 1) approximately as long as broad; punctation variable, relatively fine to moderately coarse, moderately dense, sparser in median dorsal portion; interstices with fine, but distinct microsculpture. Eyes rather large, approximately half as long as postocular region in dorsal view, composed of $>50$ defined ommatidia. Antennae 1.6-1.8 mm long.

Pronotum (Fig. 1) relatively broad, approximately 1.2 times as long as broad, 1.10-1.15 times as broad as head, and distinctly convex in cross-section; punctation similar to that of head; interstices without microsculpture; impunctate midline moderately broad.

Elytra (Fig. 1) broad and short, approximately 0.520.53 times as long as pronotum; punctation rather fine and shallow. Hind wings completely reduced. Protarsomeres with distinct sexual dimorphism.

Abdomen 1.05-1.10 times as broad as elytra; punctation fine and rather dense; interstices with shallow microsculpture; posterior margin of tergite VII without palisade fringe; posterior margin of tergite VIII convex to indistinctly pointed in the middle, without sexual dimorphism.

$o^{\top}$ : sternites III-VI unmodified; sternite VII (Fig. 2) moderately transverse, in posterior median portion with relatively sparse and weakly modified dark setae, posterior margin weakly concave; sternite VIII (Fig. 3) approximately as long as broad or indistinctly transverse, symmetric, and with weakly modified dark setae in posterior half, posterior excision small and shallow; aedeagus (Fig. 4) 0.8-0.9 mm long, symmetric, and with stout ventral process of highly distinctive shape; dorsal plate with moderately long and convex (cross-section) apical portion, and with short and semi-transparent basal portion; internal sac with two long membranous structures with weakly sclerotized spines.

ㅇ: sternite VIII (Fig. 5) 0.8-0.9 mm long and approximately as long as broad, posteriorly distinctly, convexly produced in the middle; tergite IX (Fig. 6) with short

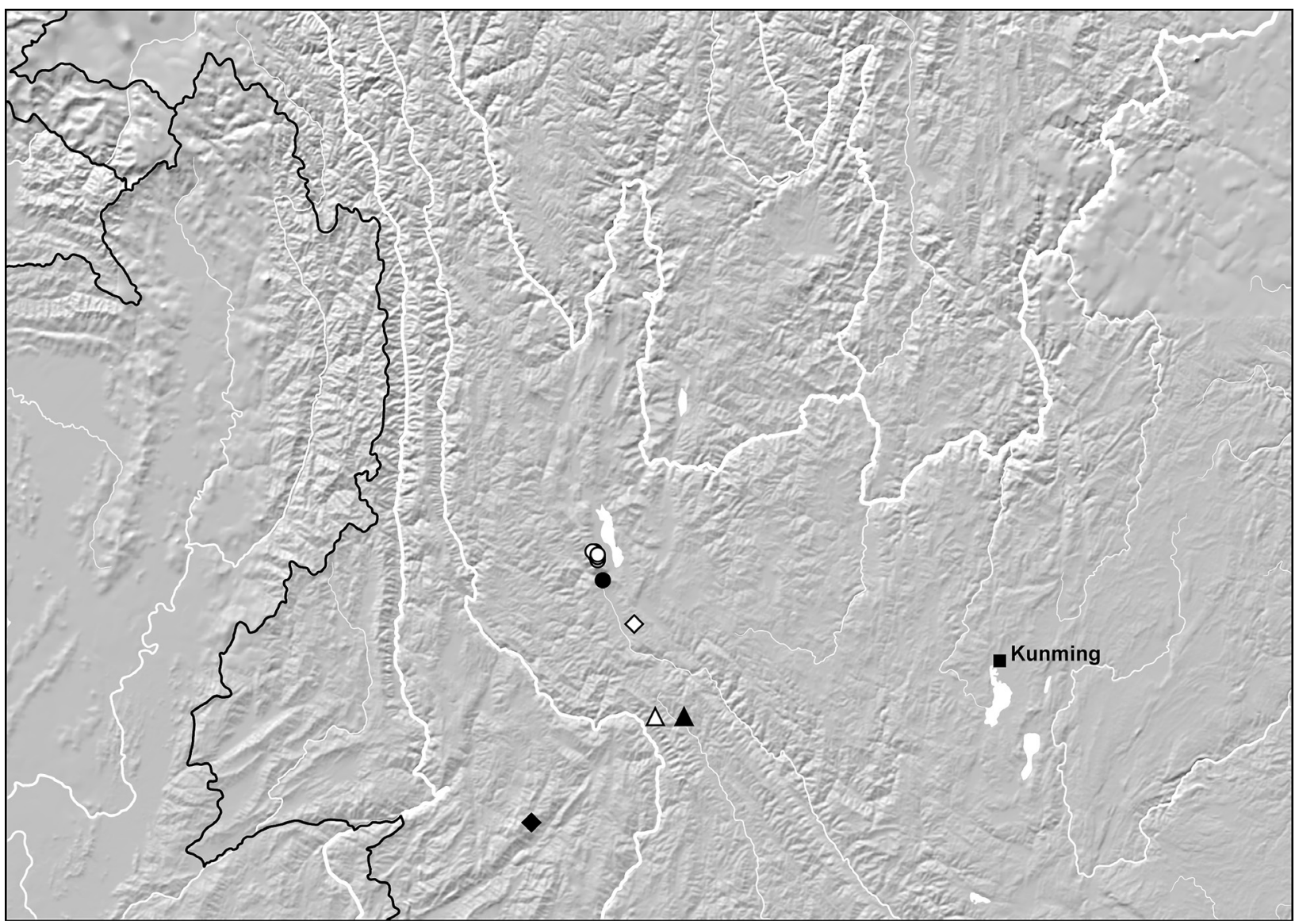

Map 2: Distribution of the species of the L. daliense subgroup: L. daliense (white circles); L. breviseriatum (white diamond); L. zhemoicum (black circle); L. rastratum (white triangle); L. rastellatum (black triangle); L. schuelkei (black diamond). 
antero-median portion and with long and slender postero-lateral processes, median portion with median suture; tergite X flattened, even somewhat concave in cross-section, approximately four times as long as anteromedian portion of tergite IX (Fig. 6).

\section{Distribution and natural history:}

Lathrobium daliense is probably endemic to the Diancang Shan, where it is evidently rather common. Numerous specimens were sifted from leaf litter and moss at altitudes between approximately 2100 and $3000 \mathrm{~m}$. Several specimens collected at the end of August and in the beginning of September are teneral.

\subsubsection{Lathrobium breviseriatum sp. n. (Figs 7-14, Map 2)}

\section{Type material:}

Holotype o": "CHINA: Yunnan, Dali Bai Aut. Pref., mount. range E Weishan, $12 \mathrm{~km}$ NE Weishan, $25^{\circ} 17^{\prime} 02$ $15^{\prime \prime} \mathrm{N}, 100^{\circ} 22^{\prime} 23-30 " \mathrm{E}, 2630-2660 \mathrm{~m}$, scrub with pines and bamboo, litter sifted, 15.IX.2009, leg. M. Schülke [CH0954] / Holotypus o Lathrobium breviseriatum sp. n. det. V. Assing 2013” (cSch). Paratypes: $7 \sigma^{*} \sigma^{*}, 10$ 우 우 [3 teneral]: same data as holotype (cSch, cAss); $20^{\star} 0^{\star}, 3$ 우 우: same data, but leg. Wrase (cSch, cAss).

\section{Etymology:}

The specific epithet (Latin, adjective) refers to the short series of spines in the internal sac of the aedeagus.

\section{Description:}

External characters (Figs 7-8) as in L. daliense, except for the on average slightly darker (reddish to dark-brown) legs.

$0^{\star}$ : sternites III-VI unmodified; sternite VII (Fig. 9) moderately transverse, in posterior median portion with relatively sparse and very weakly modified dark setae, posterior margin weakly concave in the middle; sternite VIII (Fig. 10) approximately as long as broad or indistinctly transverse, symmetric, and with weakly modified dark setae in posterior half, middle of sternite narrowly without setae; posterior excision small and shallow; aedeagus (Fig. 11) approximately $0.8 \mathrm{~mm}$ long, symmetric, and with stout ventral process of highly distinctive shape; dorsal plate with moderately long and not very strongly sclerotized apical portion, and with short and semi-transparent basal portion; internal sac with two short membranous structures with few sclerotized spines (Fig. 12), basally with a circular membranous structure.

o : sternite VIII (Fig. 13) approximately $0.8 \mathrm{~mm}$ long and weakly oblong, posteriorly distinctly, convexly produced in the middle; tergite IX (Fig. 14) with short anteromedian portion and with long and slender postero-lateral processes, antero-median portion with median suture; tergite $\mathrm{X}$ weakly convex in cross-section anteriorly and flattened posteriorly, nearly four times as long as anteromedian portion of tergite IX (Fig. 14).

\section{Comparative notes:}

The highly similar external morphology and particularly the similar male and female sexual characters, above all the shape and internal structures of the aedeagus, suggest that $L$. breviseriatum is very closely related to, and probably the sister species of $L$. daliense. Both species are best distinguished by the shape of the apex of the ventral process and by the internal structures of the aedeagus.

\section{Distribution and natural history:}

The type locality is situated in the Daque Shan in a mountain range to the northeast of Weishan in Yunnan (Map 2). The specimens were sifted from leaf litter in a shrub habitat with pine and bamboo at an altitude of 2630-2660 m. Three paratypes are teneral.

\subsubsection{Lathrobium zhemoicum sp. n. (Figs 15-21, Map 2)}

\section{Type material:}

Holotype ơ : "CHINA: Yunnan, Dali Bai Aut. Pref., Zhemo

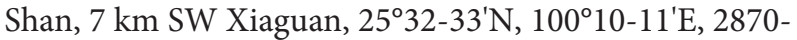
2970 m, scrub with bamboo, oaks \& Rhododendr., litter sifted, 18.IX.2009, leg. M. Schülke [CH09-60] / Holotypus o Lathrobium zhemoicum sp. n. det. V. Assing 2013" (cSch). Paratypes: $1 \mathrm{o}^{\top}$ : same data as holotype (cAss); $10^{\top}$ : same data, but leg. Wrase (cSch).

\section{Etymology:}

The specific epithet (Latin, adjective) is derived from the name of the mountain where the type locality is situated.

\section{Description:}

External characters (Figs 15-16) as in L. daliense.

$\sigma^{*}$ : sternites III-VI unmodified; sternite VII (Fig. 17) distinctly transverse, in posterior median portion with relatively sparse and very weakly modified dark setae, posterior margin weakly concave in the middle; sternite VIII (Fig. 18) moderately transverse, symmetric, and with weakly modified dark setae in posterior portion, posterior excision distinct and nearly semi-circular; aedeagus (Fig. 19) approximately $0.9 \mathrm{~mm}$ long, symmetric, and with stout, apically acute ventral process of distinctive shape; dorsal plate with moderately long and distinctly sclerotized apical portion, and with reduced, very short basal portion; internal sac with two long membranous structures apically extending into long sclerotized spines (Figs 20-21) and basally extending into a circular membranous structure.

ㅇ: unknown. 
Comparative notes:

The highly similar external morphology, as well as the similar male and female sexual characters, above all the shape and internal structures of the aedeagus, suggest that $L$. zhemoicum is very closely related to the species pair L. daliense + L. breviseriatum. It is distinguished from both species by the more strongly transverse male sternites VII and VIII, the pronounced posterior excision of the male sternite VIII, the shape of the ventral process of the aedeagus, and by the more strongly reduced basal portion of the dorsal plate of the aedeagus.

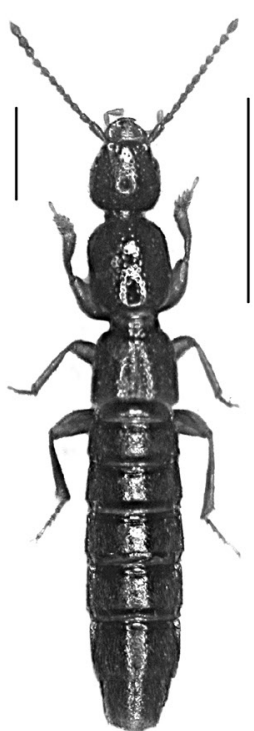

15

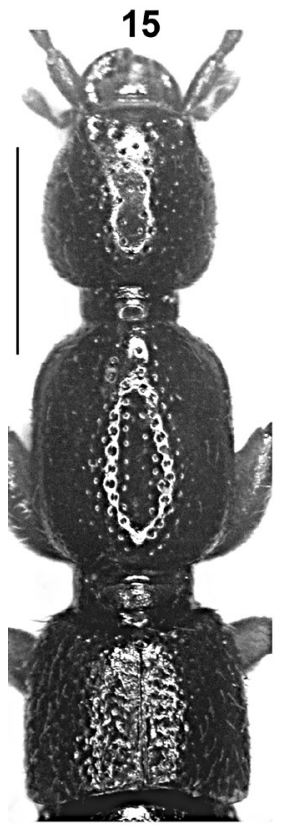

22

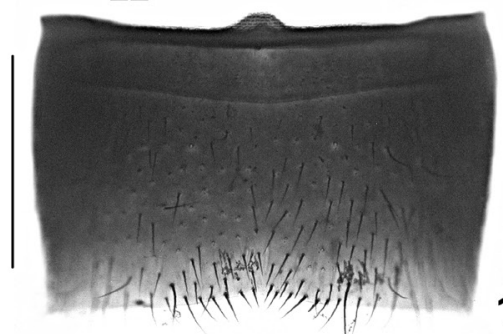

17
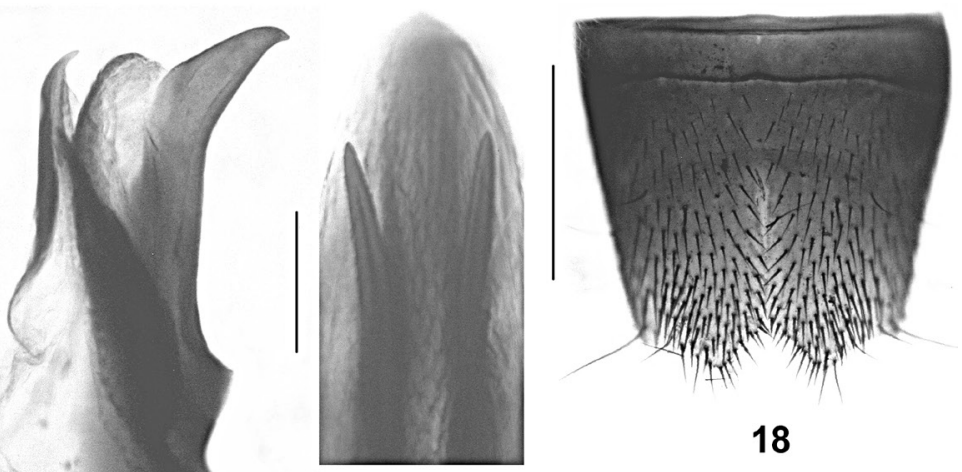

18

21
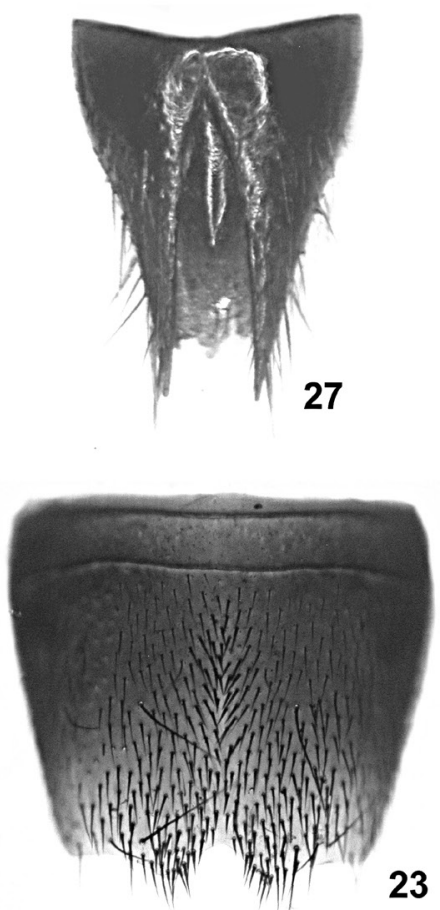

25

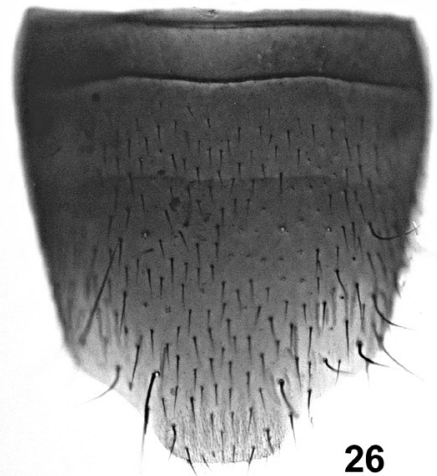

Figs 15-27: Lathrobium zhemoicum (15-21) and L. schuelkei (22-27): habitus (15); forebody (16, 22); male sternite VII (17); male sternite VIII $(18,23)$; aedeagus in lateral view $(19,24)$; internal structures of aedeagus in lateral view $(20)$; internal structures of aedeagus in dorsal view (21); aedeagus in ventral view (25); female sternite VIII (26); female tergites IX-X (27). Scale bars: 15-16, 22: $1.0 \mathrm{~mm} ; 17-19,23-27: 0.5 \mathrm{~mm}$; 20-21: $0.1 \mathrm{~mm}$. 
Distribution and natural history:

The type locality is situated in the Zhemo Shan in the northern Ailao Shan range, to the southwest of Xiaguan in Yunnan (Map 2). The specimens were sifted from leaf litter in a shrub habitat with oak, bamboo, and rhododendron at an altitude of 2870-2970 m, together with the holotype of L. magnispinosum. One of the types is slightly teneral.

\subsubsection{Lathrobium schuelkei sp. n. (Figs 22-27, Map 2)}

\section{Type material:}

Holotype $0^{\top}$ : "CHINA: Yunnan, Lincang Pref., Laobie

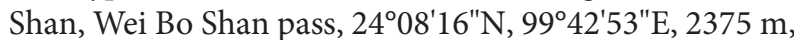
creek valley, devastated second. decid. forest, litter \& moss sifted, 8.IX.2009, leg. M. Schülke [CH09-35] / Holotypus o Lathrobium schuelkei sp. n. det. V. Assing 2013" (cAss). Paratypes: 4 i + [2 teneral]: same data as holotype (cSch, cAss).

\section{Etymology:}

The species is dedicated to my friend and colleague Michael Schülke, whose outstanding material the present paper is largely based on.

\section{Description:}

Body length 6.0-7.5 mm; length of forebody 3.1-3.5 mm. Other external characters (Fig. 22) as in L. daliense.

$\sigma^{\top}$ : sternites III-VI unmodified; sternite VII moderately transverse, in posterior median portion with few weakly modified dark setae, posterior margin weakly concave; sternite VIII (Fig. 23) moderately transverse, symmetric, and with weakly modified dark setae in posterior portion and along middle, posterior excision distinct; aedeagus (Figs 24-25) approximately $1.0 \mathrm{~mm}$ long, symmetric, and with stout, apically acute ventral process; dorsal plate with moderately long, apically truncate (dorsal view), and distinctly sclerotized apical portion, and with long lamellate basal portion; internal sac with two long membranous structures with at least two pairs of moderately long sclerotized spines, basally with circular membranous structure.

ㅇ: sternite VIII (Fig. 26) approximately $1.0 \mathrm{~mm}$ long and weakly oblong, posterior margin distinctly, convexly produced in the middle; tergite IX (Fig. 27) with short anteromedian portion and with moderately long postero-lateral processes, antero-median portion with median suture; tergite $\mathrm{X}$ weakly convex, with small elevation at posterior third, and more than four times as long as antero-median portion of tergite IX (Fig. 27).

\section{Comparative notes:}

As can be inferred from the similar external and sexual characters, particularly the morphology of the aedeagus, the shapes and chaetotaxy of the male sternites VII and VIII, the shape of the female sternite VIII, and the morphology of the female tergites IX and X, L. schuelkei is a close relative of $L$. daliense and allied species. It is characterized above all by the morphology of the aedeagus, especially the shape of the ventral process and the conspicuously long basal portion of the dorsal plate. Based on the similar morphology of the aedeagus, L. schuelkei may be most closely related to L. zhemoicum.

\section{Distribution and natural history:}

The type locality is situated in the Laobie Shan range in Yunnan (Map 2). The specimens were sifted from leaf litter in a degraded deciduous forest at an altitude of $2375 \mathrm{~m}$. Two of the paratypes are teneral.

\subsubsection{Lathrobium rastellatum sp. n.} (Figs 28-35, Map 2)

\section{Type material:}

Holotype o : "CHINA: Yunnan, Pu'er Pref., Ailao Shan, $37 \mathrm{~km}$ NW Jingdong, $24^{\circ} 45^{\prime} 12^{\prime \prime} \mathrm{N}, 100^{\circ} 41^{\prime} 24.5^{\prime \prime} \mathrm{E}, 2300 \mathrm{~m}$, devastated forest remnant, litter \& dead wood sifted, 13.IX.2009, leg. M. Schülke [CH09-48] / Holotypus o Lathrobium rastellatum sp. n. det. V. Assing 2013" (cSch). Paratypes: 1 ㅇ: same data as holotype (cAss); $10^{\star}, 2$ ㅇ ㅇ: "CHINA (Yunnan) Pu'er Pref., Ailao Shan, $37 \mathrm{~km}$ NW Jingdong, $24^{\circ} 45^{\prime} 12^{\prime \prime} \mathrm{N}, 100^{\circ} 41^{\prime} 24.5^{\prime} \mathrm{E}, 2300 \mathrm{~m}$ (devastated forest remnant, litter, moss, grass roots sifted) 13.IX.2009 D.W. Wrase [48]" (cSch, cAss).

\section{Etymology:}

The specific epithet is an adjective derived from the Latin noun rastellus (small hatchet) and alludes to the shape of the ventral process of the aedeagus.

\section{Description:}

Body length 6.7-7.5 mm; length of forebody 3.0-3.5 mm. Other external characters (Figs 28-29) as in L. daliense.

$0^{*}$ : sternites III-VI unmodified; sternite VII (Fig. 30) distinctly transverse, in posterior median portion with sparse and very weakly modified dark setae, posterior margin broadly and weakly concave; sternite VIII (Fig. 31) moderately transverse, symmetric, and with weakly modified dark setae in posterior portion, posterior excision (Fig. 32) of nearly semi-circular shape, its margins furnished with moderately modified, short and stout black setae; aedeagus (Fig. 33) approximately $1.1 \mathrm{~mm}$ long, symmetric; ventral process slender, distinctly angled subapically (lateral view), and apically acute; dorsal plate with relatively short, broad, flat, and rather weakly sclerotized apical portion and with short, 
very weakly sclerotized basal portion; internal sac with two long and dark membranous structures containing at least two moderately long sclerotized spines and basally extending into a circular membranous structure.

ㅇ: sternite VIII (Fig. 34) approximately as broad as long, posterior margin distinctly and convexly produced in the middle; tergite IX (Fig. 35) with very short antero-median portion and moderately long postero-lateral processes, antero-median portion with suture; tergite $\mathrm{X}$ weakly convex in anterior half, with short roof-shaped elevation behind middle, flat in posterior fifth, and approximately eight times as long as antero-median portion of tergite IX (Fig. 35).

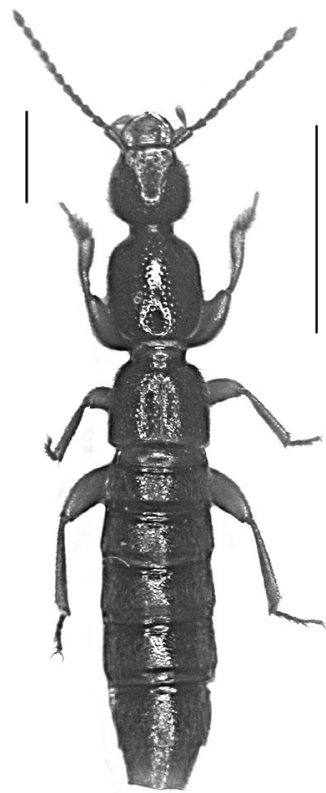

28

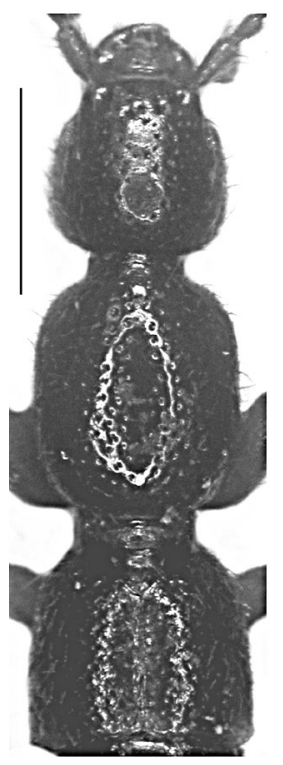

36

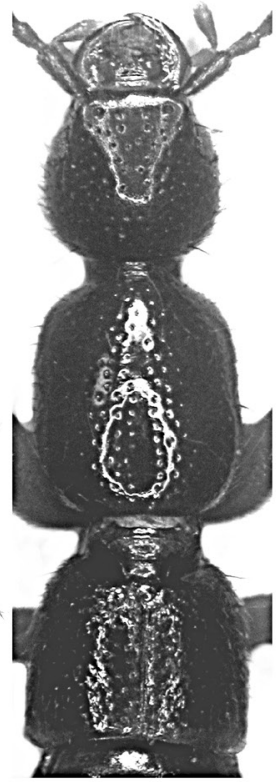

29

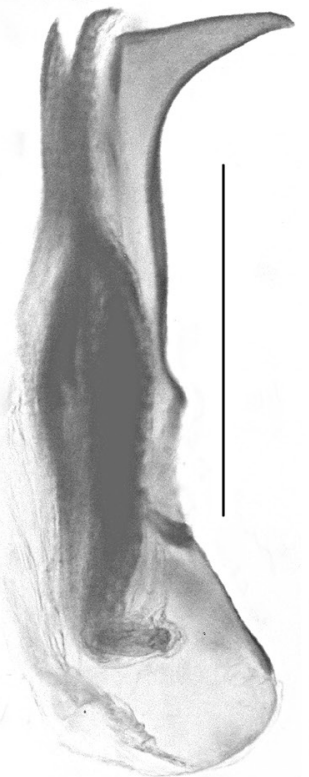

40

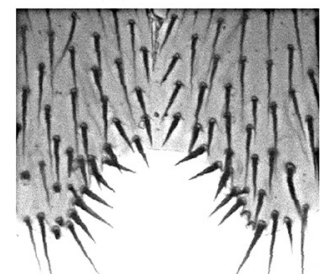

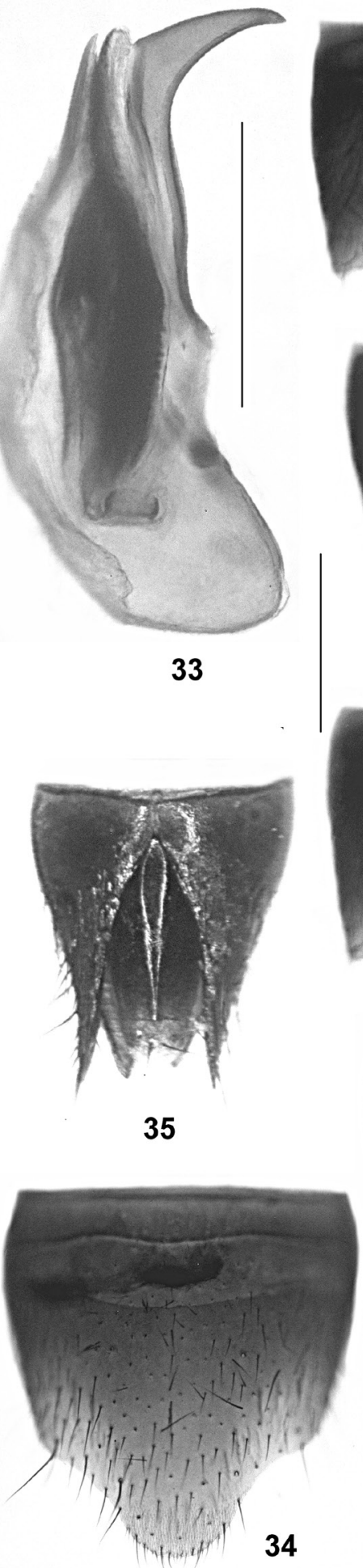

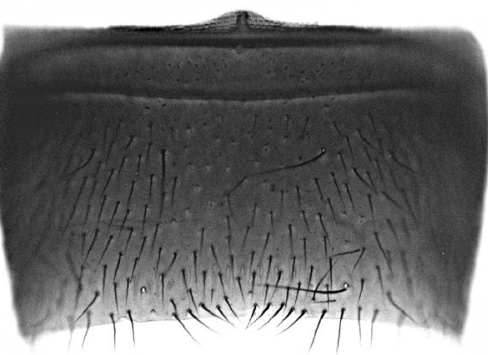

30
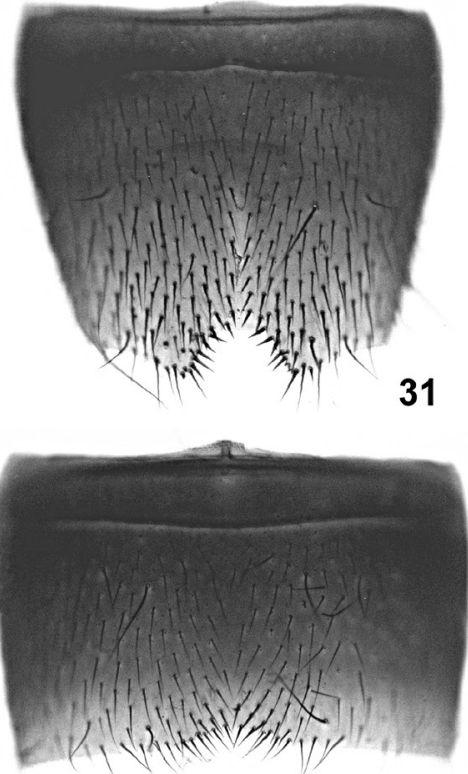

37

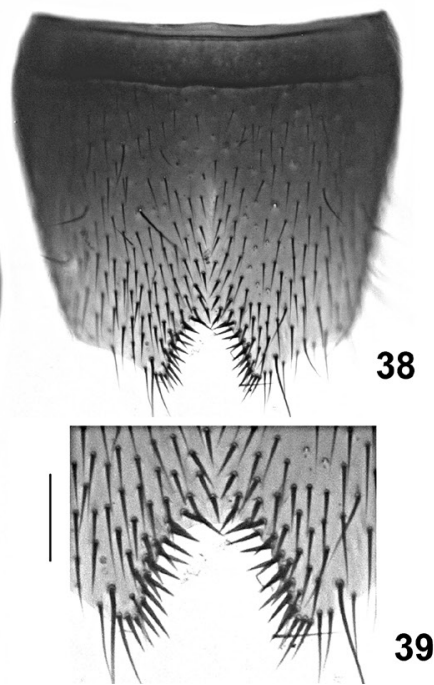

Figs 28-40: Lathrobium rastellatum (28-35) and L. rastratum (36-40): habitus (28); forebody $(29,36)$; male sternite VII (30, 37); male sternite VIII $(31,38)$; posterior excision of male sternite VIII $(32,39)$; aedeagus in lateral view $(33,40)$; female sternite VIII (34); female tergites IX-X (35). Scale bars: 28-29, 36: $1.0 \mathrm{~mm}$; 30-31, 33-35, 37-38, 40: $0.5 \mathrm{~mm}$; 32, 39: $0.1 \mathrm{~mm}$. 


\section{Comparative notes:}

The highly similar external morphology, as well as the similar male and female sexual characters suggest that $L$. rastellatum is closely related to $L$. daliense and allied species. It is distinguished from them by the morphology of the aedeagus (particularly the shape of the ventral process), the shape and chaetotaxy of the male sternite VIII, and the shapes of the female tergites IX and $\mathrm{X}$, from $L$. daliense additionally by the more transverse male sternite VII and by slightly larger average body size. Previously, the sole representative of Lathrobium known from the Ailao Shan was L. ailaoshanense Watanabe \& XiaO, 1997, which differs from L. rastellatum by the reddish-brown coloration and an aedeagus with a conspicuously long and slender ventral process. For illustrations of L. ailaoshanense see WATANABE \& XIAO (1997). According to the original description of L. ailaoshanense, the lengths of the body and the forebody are 4.9-5.2 $\mathrm{mm}$ and 2.1-2.2 $\mathrm{mm}$, respectively. However, like other measurements indicated in WATANABE \& XIAO (1997), these measurements are probably incorrect.

\section{Distribution and natural history:}

The type locality is situated in the Ailao Shan range to the northwest of Jingdong, Yunnan (Map 2). The specimens were sifted from leaf litter in a degraded forest remnant at an altitude of $2300 \mathrm{~m}$.

\subsubsection{Lathrobium rastratum sp. n. (Figs 36-40, Map 2)}

\section{Type material:}

Holotype $0^{*}$ : "CHINA: Yunnan, Lincang/Dali Pref., Wuliang Shan, old pass road, $\mathrm{N}$ pass, $24^{\circ} 45^{\prime} 16.4^{\prime \prime} \mathrm{N}$, $100^{\circ} 29^{\prime} 50.3^{\prime \prime} \mathrm{E}, 2350 \mathrm{~m}$, forest remnant \& tea plantation, litter, mushrooms, grass sifted, 16.IX.2009, leg. M. Schülke [CH09-55] / Holotypus ơ Lathrobium rastratum sp. n. det. V. Assing 2013" (cAss).

\section{Etymology:}

The specific epithet is an adjective derived from the Latin noun raster (hatchet) and alludes to the shape of the ventral process of the aedeagus.

\section{Description:}

External characters (Fig. 36) as in L. rastellatum.

$\sigma^{\star}$ : sternites III-VI unmodified; sternite VII (Fig. 37) distinctly transverse, in posterior median portion with moderately dense, weakly modified black setae, posterior margin weakly concave in the middle; sternite VIII (Fig. 38) moderately transverse, symmetric, with weakly modified dark setae in posterior portion, posterior margin somewhat produced on either side of posterior excision, posterior excision (Fig. 39) almost U-shaped, its margins densely furnished with moderately modified, short and stout black setae; aedeagus (Fig. 40) $1.05 \mathrm{~mm}$ long, symmetric; ventral process moderately slender, distinctly angled subapically (lateral view), and apically acute; dorsal plate with moderately long, broad, flat, and moderately sclerotized apical portion, and with very short, very weakly sclerotized basal portion; internal sac with two long and dark membranous structures containing at least two moderately long sclerotized spines and basally extending into a circular membranous structure.

ㅇ: unknown.

\section{Comparative notes:}

As can be inferred from the highly similar male sexual characters, L. rastratum is probably the adelphotaxon of L. rastellatum, from which it differs by the different shape and chaetotaxy of the male sternite VII (pubescence more distinctly modified in posterior median portion, posterior margin weakly concave in the middle), the shape and chaetotaxy of the male sternite VIII (posterior excision deeper, its margins more densely furnished with modified setae; posterior margin produced on either side of excision), and by the morphology of the aedeagus, particularly the stouter ventral process. From L. magnispinosum, the only other species known from the Wuliang Shan, L. rastratum is readily distinguished by much smaller size alone.

\section{Distribution and natural history:}

The type locality is situated in the Wuliang Shan, Yunnan (Map 2). The holotype was sifted from leaf litter in a forest remnant at an altitude of $2350 \mathrm{~m}$.

\subsubsection{The L. aokii subgroup}

\subsubsection{Lathrobium aokii WaTANABE \& XIA0, 2000 (Figs 41-47, Map 3)}

\section{Material examined:}

China: Yunnan: $190^{\top} o^{\top}, 14$ ㅇ ㅇ [4 teneral], Dali Bai Nat. Aut. Pref., Diancang Shan, $5 \mathrm{~km}$ SSW Dali, $25^{\circ} 39^{\prime} \mathrm{N}$, $100^{\circ} 08^{\prime} \mathrm{E}, 2800 \mathrm{~m}$, shrubs, bamboo, moss, and old flood debris sifted, 26.VIII.2003, $2800 \mathrm{~m}$, leg. Schülke, Smetana \& Wrase (cSch, cSme, cAss); 5 o $^{\star} \sigma^{\star}, 2$ 우 우 [2 teneral], Dali Bai Nat. Aut. Pref., Diancang Shan, 3 km W Dali old town, creek valley and pine forest at "Cloud Road", right upper chairlift station, $25^{\circ} 41^{\prime} \mathrm{N}, 100^{\circ} 07^{\prime} \mathrm{E}, 2650-2750 \mathrm{~m}$, litter and pine needles sifted, 29.VIII.2003, leg. Schülke, Smetana \& Wrase (cSch, cAss); $5 o^{*} o^{*}, 6$ 우 우, Diancang Shan, W Dali, $25^{\circ} 42^{\prime} \mathrm{N}, 100^{\circ} 07^{\prime} \mathrm{E}, 3016 \mathrm{~m}$, moist escarpment, litter sifted, 28.V.2007, leg. Schülke \& Pütz (cPüt, cSch, cAss); 4 우 우 [1 slightly teneral], Diancang Shan, $4 \mathrm{~km}$ W Dali old town, $25^{\circ} 41^{\prime} \mathrm{N}, 100^{\circ} 07^{\prime} \mathrm{E}, 2900-3000 \mathrm{~m}$, E-slope with degraded forest and old pine forest, sifted, 
31.VIII.2003, leg. Schülke \& Smetana (cSch, cSme); 1 ơ, 1 ㅇ, Diancang Shan, W Dali, $25^{\circ} 42^{\prime} \mathrm{N}, 100^{\circ} 06^{\prime} \mathrm{E}, 2960 \mathrm{~m}$, sifted from litter, moss, and flood debris, 6.IX.2009, leg. Schülke (cSch, cAss); $4 o^{\star} o^{\star}, 21$ 우 옹 Diancang Shan near Dali, $25^{\circ} 40^{\prime} \mathrm{N}, 100^{\circ} 08^{\prime} \mathrm{E}, 2710 \mathrm{~m}$, sifted, 10.V.2010, leg. Grebennikov (CAS, cSme, cAss); $10^{\star}$, Diancang Shan near Dali, $25^{\circ} 40^{\prime} \mathrm{N} 100^{\circ} 06^{\prime} \mathrm{E}, 4060 \mathrm{~m}$, sifted, 15.V.2010, leg. Grebennikov (cAss); $10^{*}$, Diancang Shan near Dali, $25^{\circ} 40^{\prime} \mathrm{N}, 100^{\circ} 06^{\prime} \mathrm{E}, 3890 \mathrm{~m}$, sifted, 19.V.2010, leg.
Grebennikov (cAss); $30^{\star} o^{\star}, 7$ ㅜㅇ, Diancang Shan near Dali, $25^{\circ} 40^{\prime} \mathrm{N}, 100^{\circ} 08^{\prime}, 2660 \mathrm{~m}$, sifted, 18.V.2010, leg. Grebennikov (CAS, cSme, cAss); $10^{\star}$, above Dali, 25002700 m, 8.-18.IV.1999, leg. Schawaller (SMNS).

\section{Comment:}

The original description is based on numerous specimens from "Xueren Feng" and "Yuzhu Feng" in the Diancang Shan. The illustration of the ventral aspect of the male

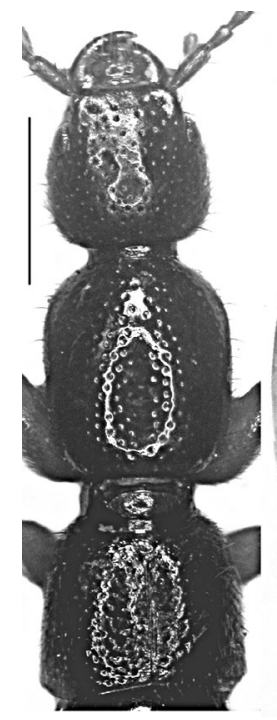

41

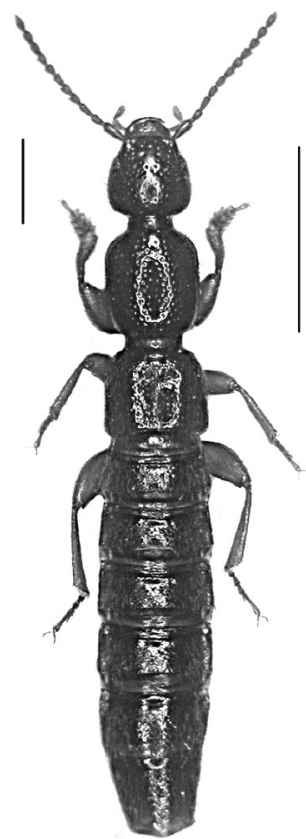

48

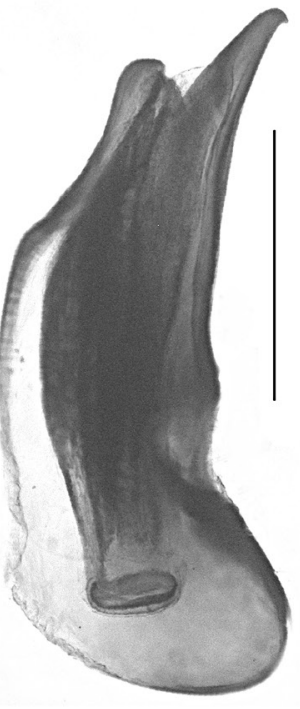

44

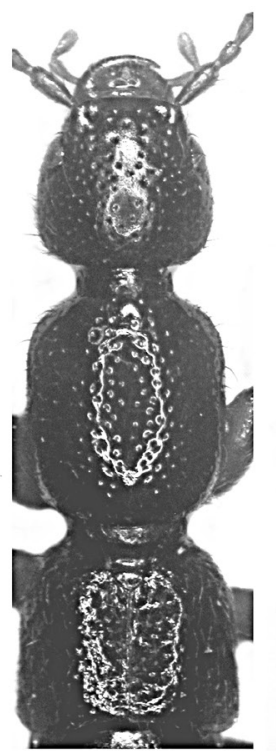

49

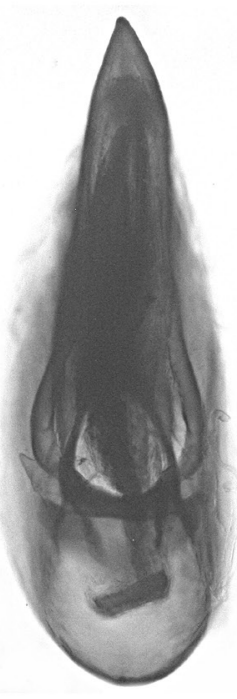

45

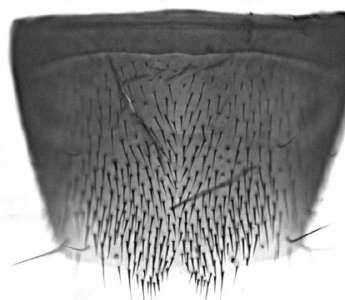

43

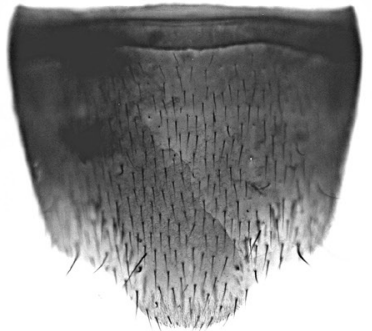

46

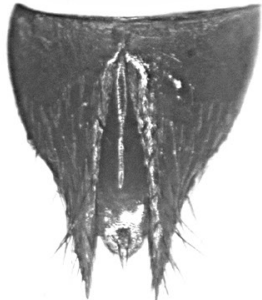

47

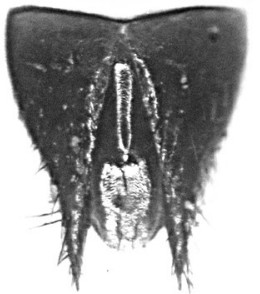

55

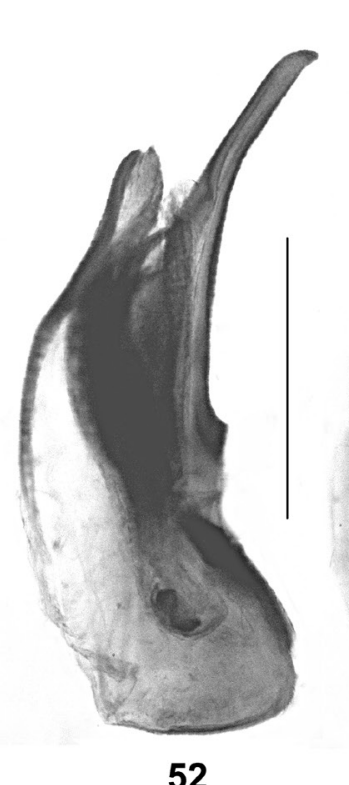

52

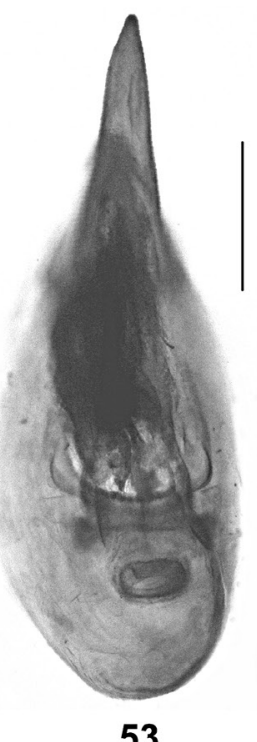

53
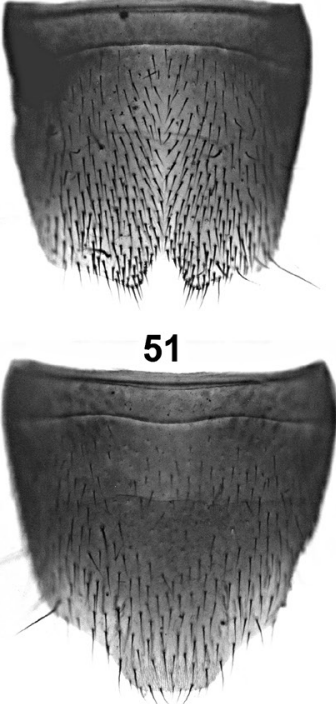

54
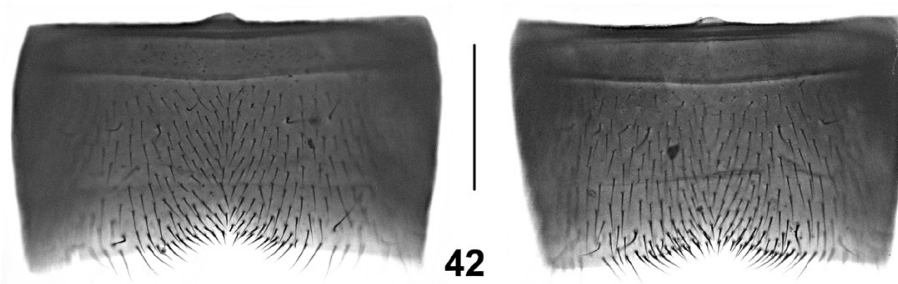

50

Figs 41-55: Lathrobium aokii (41-47) and L. elevatum (48-55): forebody (41, 49); male sternite VII (42, 50); male sternite VIII $(43,51)$; aedeagus in lateral and in ventral view $(44-45,52-53)$; female sternite VIII $(46,54)$; female tergites IX-X $(47,55)$; habitus (4). Scale bars: 41, 48-49: $1.0 \mathrm{~mm}$; 42-47, 50-55: $0.5 \mathrm{~mm}$. 
abomen in Watanabe \& XiaO (2000) is evidently confused: L. aokii is illustrated in figure 2, not in figure 4 as indicated in the caption. In view of the similarity with the following species, a full redescription is provided below.

\section{Redescription:}

Relatively large species of rather variable body size (but without sexual size dimorphism) and stout habitus; body length 7.5-9.5 mm; length of forebody 3.5-4.3 mm. Coloration: body blackish-brown to blackish; legs reddish to dark-brown with paler tarsi; antennae reddish to brown.

Head (Fig. 41) approximately as long as broad, more or less distinctly dilated posteriad; punctation not particularly coarse and moderately dense, sparser in median dorsal portion; interstices with fine, but distinct microreticulation. Eyes relatively large, approximately half the length of postocular region in dorsal view and composed of numerous (> 50) defined ommatidia. Antenna 2.0 $2.3 \mathrm{~mm}$ long.

Pronotum (Fig. 41) large, broad, and strongly convex in cross-section, approximately 1.2 times as long as broad and 1.1 times as broad as head; punctation similar to that of head; interstices without microsculpture and very glossy; impunctate midline moderately broad.
Elytra (Fig. 41) short, approximately 0.53 times as long as pronotum; punctation shallow and rather fine. Hind wings completely reduced. Protarsi with distinct sexual dimorphism.

Abdomen 1.15-1.20 times as broad as elytra; punctation fine and rather dense; interstices with very shallow microsculpture; posterior margin of tergite VII without palisade fringe; tergite VIII without appreciable sexual dimorphism, posterior margin convex to indistinctly pointed in the middle.

$\sigma^{*}$ : sternites III-VI unmodified; sternite VII (Fig. 42) strongly transverse, symmetric, with shallow median impression posteriorly, this impression with weakly modified black setae, posterior margin broadly concave; sternite VIII (Fig. 43) symmetric, distinctly transverse, with weakly modified black setae in posterior portion, and with small posterior excision; aedeagus (Figs 44-45) approximately $1.3 \mathrm{~mm}$ long, symmetric, and with moderately slender, apically not abruptly narrowed ventral process; dorsal plate with strongly convex (cross-section) and moderately long apical portion, basal portion nearly as long as apical portion; internal sac with pair of series of moderately sclerotized spines.

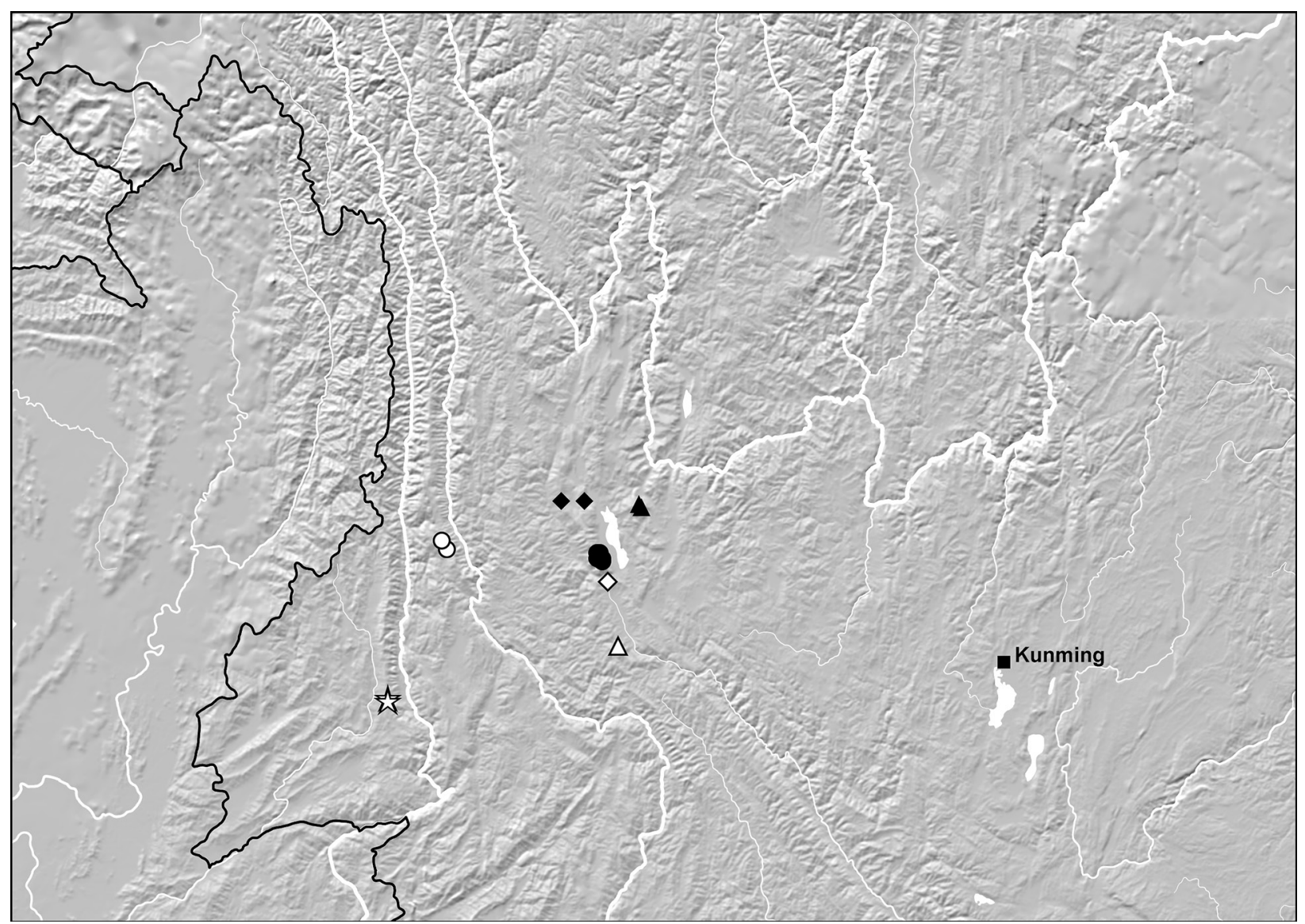

Map 3: Distribution of the species of the L. aokii (filled symbols) and L. magnispinosum (open symbols) subgroups: L. aokii (black circles); L. elevatum (black diamonds); L. jizushanense (black triangles); L. grandispinosum (white diamond); L. magnispinosum (white triangle); L. nuicum (white circles); L. iaculatum (white stars). 
ㅇ: sternite VIII (Fig. 46) weakly transverse, posterior margin distinctly, convexly produced in the middle; tergite IX (Fig. 47) with very short median portion and moderately long postero-lateral processes, median portion with suture; tergite X (Fig. 47) with pronounced, almost roof-shaped median elevation in anterior two thirds, this elevation abruptly sloping downwards at posterior third, anterior portion of tergite $\mathrm{X}$ nearly reaching anterior margin of tergite IX.

\section{Comparative notes:}

The similar external morphology and particularly the similar male and female sexual characters suggest that L. aokii is closely allied to L. yunnanum WATANABE \& XIAO, 1994 from the Laohu Shan $\left[25^{\circ} 43^{\prime} \mathrm{N}, 99^{\circ} 54^{\prime} \mathrm{E}\right]$ in the same mountain range. Lathrobium yunnanum differs from L. aokii by the less small posterior excision of the male sternite VIII, the more slender ventral process of the aedeagus (particularly in ventral view), and the less convex and apically differently shaped dorsal plate of the aedeagus.

\section{Distribution and natural history:}

Lathrobium aokii is probably endemic to the southern part of the Diancang Shan, to the west and southwest of Dali old town (Map 3). The specimens were sifted primarily from leaf litter in various forest habitats at altitudes between approximately 2600 and $4060 \mathrm{~m}$, in some localities together with L. daliense or L. baizuorum. Several specimens collected at the end of August are teneral. While the sex ratio of the material collected in summer is balanced, that of the material found in spring is strongly biased in favour of females $\left(90^{*} o^{*}\right.$ : 28 우 우).

\subsubsection{Lathrobium elevatum sp. n. (Figs 48-55, Map 3)}

\section{Type material:}

Holotype ơ: "CHINA (Yunnan) Dali Bai Aut. Pref., Diancang Shan E pass, $43 \mathrm{~km}$ NW Dali, $2700 \mathrm{~m}$, (secondary pine forest, litter, moss sifted) $25^{\circ} 59^{\prime} 50^{\prime \prime} \mathrm{N}$, 10000'30"E, 23.VIII.2009 D.W. Wrase [02] / Holotypus o Lathrobium elevatum sp. n. det. V. Assing 2013" (cSch). Paratypes: $10^{\star}, 1$ : : same data as holotype (cSch, cAss); 1 ㅇ: same data, but leg. Schülke (cSch); $10^{\star}, 1$ ㅇ: "CHINA: Yunnan [CH07-08], Dali Bai Auton. Pref.,

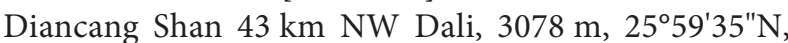
99 52'06"E, W pass, Rhodod., oaks, bamboo, sifted, 29.V.2007, M. Schülke” (cAss).

Etymology:

The specific epithet (Latin, adjective) alludes to the anteriorly elevated female tergite $\mathrm{X}$.

\section{Description:}

Relatively large species; body length 7.2-9.0 mm; length of forebody 3.5-3.8 mm. External characters (Figs 48-49) as in L. aokii.

$\sigma^{*}$ : sternites III-VI unmodified; sternite VII (Fig. 50) strongly transverse, symmetric, with shallow median impression posteriorly, this impression with rather weakly modified black setae, posterior margin broadly concave, in the middle more distinctly concave; sternite VIII (Fig. 51) symmetric, rather weakly transverse, with weakly modified black setae in posterior portion, and with moderately small posterior excision; aedeagus (Figs 52-53) approximately $1.25 \mathrm{~mm}$ long, symmetric, and with slender, apically acute ventral process; dorsal plate with distinctly sclerotized, strongly convex (crosssection), and moderately long apical portion, basal portion nearly as long as apical portion; internal sac with pair of series of moderately sclerotized spines.

ㅇ: sternite VIII (Fig. 54) approximately 1.0-1.1 mm long, transverse, posterior margin distinctly, convexly produced in the middle; tergite IX (Fig. 55) with very short anteromedian portion and moderately long postero-lateral processes, antero-median portion with suture; tergite $\mathrm{X}$ (Fig. 55) with convex (cross-section) median elevation in anterior two thirds, this elevation sloping downwards at posterior third, anterior portion of tergite X nearly reaching anterior margin of tergite IX.

\section{Comparative notes:}

Lathrobium elevatum is undoubtedly closely allied to L. yunnanum and particularly L. aokii, as can be inferred not only from the highly similar external morphology, but also by the similarly derived sexual characters (shapes and chaetotaxy of the male sternites VII and VIII; shapes of the ventral process and of the dorsal plate of the aedeagus; presence of a pair of series of spines in internal sac of aedeagus; female sternite VIII transverse; antero-median portion of female tergite IX very short and with median suture; female tergite $\mathrm{X}$ elevated in anterior two thirds).

\section{Distribution and natural history:}

Lathrobium elevatum is known only from two geographically close localities to the northwest of Dali old town in the Diancang Shan (Map 3). The specimens were sifted from leaf litter in a pine forest and an oak forest at altitudes of 2700 and $3080 \mathrm{~m}$, together with L. hirsutum.

\subsubsection{Lathrobium jizushanense WATANABE \& XIA0, 1997 (Figs 56-63, Map 3)}

Material examined:

China: Yunnan: $12 \sigma^{\star} o^{\star}, 15$ 우 +6 teneral], Dali Bai Aut. Pref., 37 km NE Dali, Jizu Shan, summit plateau, 25⒌' N, $100^{\circ} 22^{\prime} \mathrm{E}, 3150 \mathrm{~m}$, mixed forest, sifted from litter and 
moss, 5.IX.2009, leg. Schülke \& Wrase (cAss); $10^{\star}, 2$ ㅇ ㅇ, Shanzhi env., Jizu Shan, along the path to the summit, “27 $57.7-8^{\prime} \mathrm{N}$ " [evidently erroneous; recte $25^{\circ}$ ], 100.22.123.6'E, 2180-2580 m, dense mixed forest with dominant Quercus, Pinus and Rhododendron, near stream, sifted, 22.-24.VI.2007, leg. Hájek \& Růžička (cSch, cAss); 1 ㅇ [teneral], Dali Bai Aut. Pref., 37 km NE Dali, Jizu Shan, path to cable car, $25^{\circ} 58^{\prime} \mathrm{N}, 100^{\circ} 23^{\prime} \mathrm{E}, 2450 \mathrm{~m}$, mixed forest, sifted from litter, moss \& pine apples, 5.IX.2009, leg. M. Schülke [CH09-29]" (cSch).

\section{Etymology:}

The specific epithet (Latin, adjective) alludes to the anteriorly elevated female tergite $\mathrm{X}$.

\section{Comment:}

The original description is based on 15 type specimens from "Mt. Jizu Shan, Binchuan Xian" (WATAnABE \& XIAO 1997). According to the description, the length of the body is $4.8-5.8 \mathrm{~mm}$, and the length of the forebody 2.3-2.5 $\mathrm{mm}$. Moreover, the drawings of the aedeagus are not identical to the aedeagal morphology of the examined material. However, the measurements of other species described by Watanabe \& XiaO (1997) were found to be erroneous, too, and the other details indicated in the description indicate that the species belongs to the L. aokii group, whose species are distinctly larger. Finally, the illustrations provided by Watanabe \& XiaO (1997) are schematic and partly somewhat inaccurate. Therefore, until the type material has been revised, the above material is attributed to L. jizushanense.

\section{Redescription:}

Relatively large species; body length 7.2-8.8 mm; length of forebody 3.3-3.7 mm. External characters (Figs 56-57) as in L. aokii.

$\sigma^{\star}$ : sternites III-VI unmodified; sternite VII (Fig. 58) strongly transverse, symmetric, with shallow median impression posteriorly, this impression with weakly modified black setae, posterior margin broadly concave; sternite VIII (Fig. 59) symmetric, moderately transverse, with weakly modified black setae in posterior portion, and with moderately small posterior excision; aedeagus (Figs 60-61) approximately $1.2 \mathrm{~mm}$ long, symmetric, and with slender, apically acute ventral process; dorsal plate with distinctly sclerotized, strongly convex (crosssection), and short apical portion, basal portion weakly separated from apical portion; internal sac with pair of long membranous structures with moderately sclerotized spines.

ㅇ: sternite VIII (Fig. 62) approximately $1.1 \mathrm{~mm}$ long, weakly transverse, posterior margin distinctly, con-

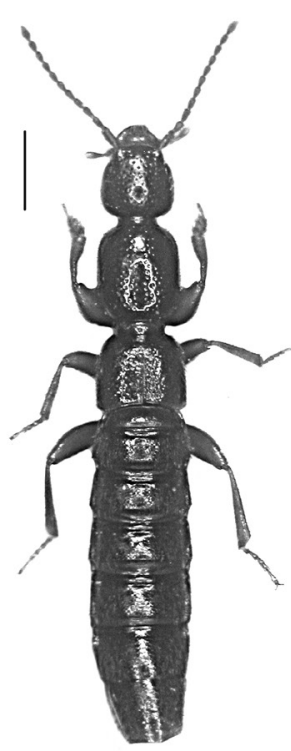

56

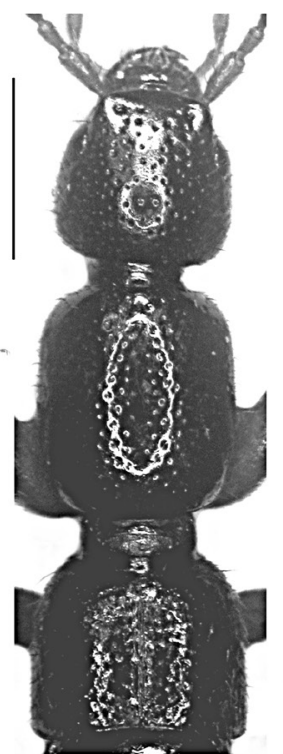

57

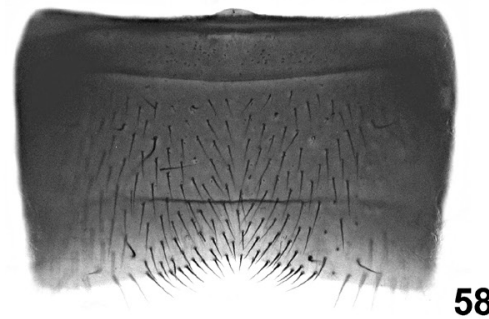

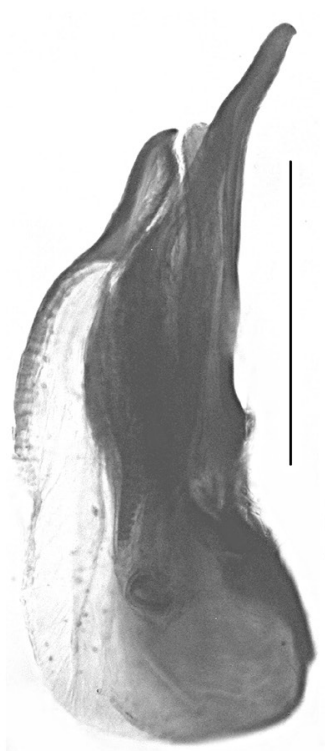

60

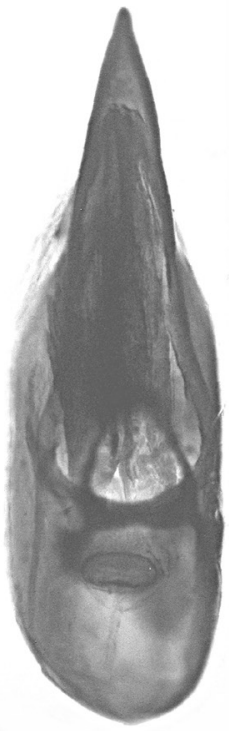

61

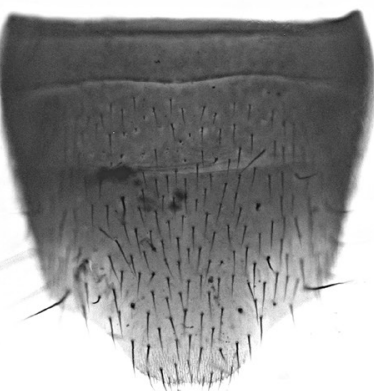

62

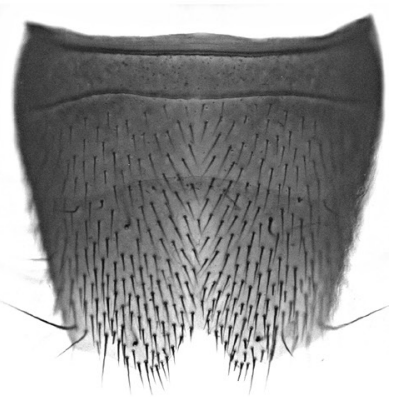

59

Figs 56-63: Lathrobium jizushanense: habitus (56); forebody (57); male sternite VII (58); male sternite VIII (59); aedeagus in lateral and in ventral view (60-61); female sternite VIII (4); female tergites IX-X (63);. Scale bars: 56-57: 1.0 mm; 58-63: 0.5 mm. 
vexly produced in the middle; tergite IX (Fig. 63) with very short antero-median portion and moderately long postero-lateral processes, median portion with suture; tergite X (Fig. 63) with narrowly convex (cross-section) median elevation in anterior half, in posterior half depressed, nearly reaching anterior margin of tergite IX.

\section{Comparative notes:}

The similar external characters and above all the similar male and female sexual characters suggest that L. jizushanense is closely allied to L. yunnanum and L. aokii, from which it differs particularly by the shape and internal structures of the aedeagus and by the morphology of the female tergite $\mathrm{X}$. The only other previously described species of Lathrobium known from the Jizu Shan is L. zhangi WatANABE \& XIAO, 1997. For illustrations of the differently shaped aedeagus of this species see WATANABE \& XIAO (1997). For characters distinguishing L. jizushanense from the sympatric L. curvatissimum see the comparative notes in the section on L. curvatissimum.

\section{Distribution and natural history:}

Lathrobium jizushanense is known only from the Jizu Shan (Map 3), where it is probably endemic. The examined specimens were sifted from leaf litter in a pine for est and an oak forest at altitudes of 2450-3080 m, in one locality together with L. curvatissimum. Several specimens collected in September are teneral.

\subsubsection{The L. magnispinosum subgroup}

\subsubsection{Lathrobium magnispinosum sp. $\mathrm{n}$. (Figs 64-72, Map 3)}

\section{Type material:}

Holotype ơ: "CHINA: Yunnan [CH07-35], Dali Bai Auton. Pref., Wuliang Shan, $9 \mathrm{~km}$ SW Weishan, 2450$2500 \mathrm{~m}, 25^{\circ} 10^{\prime} 14^{\prime \prime} \mathrm{N}, \mathrm{W}$ slope, $100^{\circ} 14^{\prime} 22^{\prime \prime} \mathrm{E}$, oaks and pines, sifted, 13.VI.2007, M. Schülke / Holotypus o Lathrobium magnispinosum sp. n. det. V. Assing 2013" (cAss). Paratypes: 1 9 : same data as holotype (cSch); $10^{*}$, 1 : : same data, but leg. Pütz (cPüt, cAss); 1 : "China: Yunnan, Wuliang Shan, $9 \mathrm{~km}$ SW Weishan, $25^{\circ} 10.15 .5^{\prime \prime} \mathrm{N}$, $100^{\circ} 14^{\prime} 21.8^{\prime \prime} \mathrm{E}, 2480 \mathrm{~m}$, scrub with (oak, alder, pine), litter \& mushrooms sifted, 14.IX.2009, leg. M. Schülke [CH09-51]" (cSch).

\section{Etymology:}

The specific epithet (Latin, adjective) alludes to the presence of a large spine in the internal sac of the aedeagus.

\section{Description:}

Large species; body length $9.0-10.5 \mathrm{~mm}$; length of forebody 4.4-4.7 mm. Coloration: body black; legs darkbrown to blackish-brown; antennae brown.
Head (Fig. 64) transverse, 1.05-1.10 times as broad as long, slightly dilated posteriad; punctation moderately coarse and moderately dense, rather sparse in median dorsal portion; interstices with fine and shallow microreticulation. Eyes moderately small, 0.3-0.4 times as long as postocular region in dorsal view and composed of > 50 defined ommatidia. Antenna 2.3-2.5 mm long.

Pronotum (Fig. 64) moderately convex in cross-section, short and broad, approximately 1.2 times as long as broad and 1.1 times as broad as head; punctation similar to that of head, but slightly denser; impunctate midline moderately broad; interstices without microsculpture and glossy.

Elytra (Fig. 64) broad and short, approximately 0.50 times as long as pronotum; punctation rather fine and dense. Hind wings completely reduced. Protarsi with moderately pronounced sexual dimorphism.

Abdomen 1.05-1.10 times as broad as elytra; punctation fine and dense; interstices with shallow microsculpture; posterior margin of tergite VII without palisade fringe; tergite VIII without appreciable sexual dimorphism, posterior margin convex to indistinctly pointed in the middle.

$\sigma^{7}$ : sternites III-VI unmodified; sternite VII (Fig. 65) distinctly transverse, symmetric, with shallow median impression posteriorly, this impression with weakly modified black setae, posterior margin broadly concave; sternite VIII (Fig. 66) symmetric, moderately transverse, with dense and weakly modified black setae in posterior portion, posterior excision (Fig. 67) small, but distinct; aedeagus (Figs 68-69) $1.5 \mathrm{~mm}$ long, symmetric, with rather stout ventral process; apical portion of dorsal plate strongly sclerotized, long, somewhat convex in cross-section, and apically pointed in lateral view, basal portion lamellate and much shorter than apical portion; internal sac with pair of membranous structures with short spines and with additional very large spine (Fig. 70).

ㅇ: sternite VIII (Fig. 71) approximately $1.3 \mathrm{~mm}$ long and approximately as long as broad, posterior margin distinctly, convexly produced in the middle; tergite IX (Fig. 72) with short median portion and moderately long postero-lateral processes, antero-median portion with suture; tergite VIII (Fig. 72) long and flat, nearly six times as long as antero-median portion of tergite IX.

\section{Comparative notes:}

Lathrobium magnispinosum is distinguished from L. aokii and allied species by its larger body size and by the morphology of the aedeagus. In addition, it is characterized by the distinctly transverse head, the broad pronotum, the short elytra (not longer than 0.5 times the length of pronotum), the shape and chaetotaxy of the male 
sternite VIII, the shape of the female sternite VIII, and the conspicuously long and flat female tergite $\mathrm{X}$.

Distribution and natural history:

Lathrobium magnispinosum was collected in two geographically close localities in the Wuliang Shan, to the southwest of Weishan (Map 3). The specimens were sifted from leaf litter in a mixed oak and pine forest and in a shrub habitat at an altitude of 2450-2500 m.

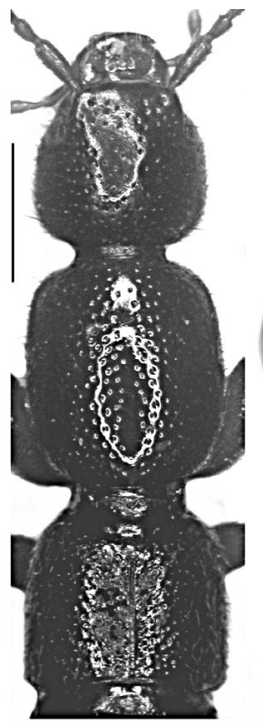

64

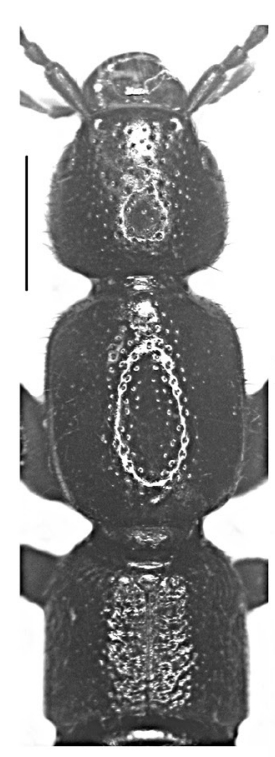

73

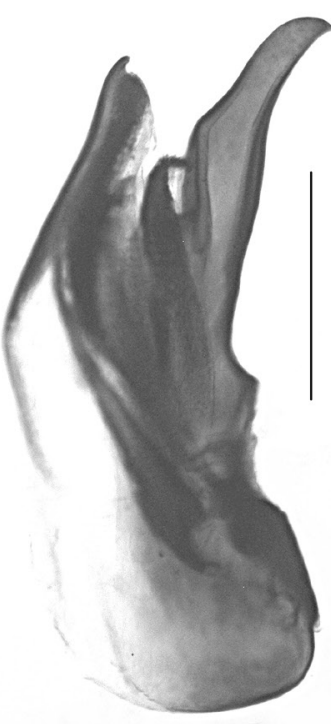

68

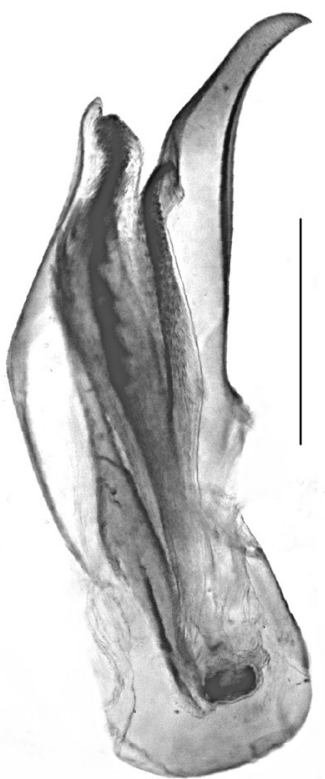

76

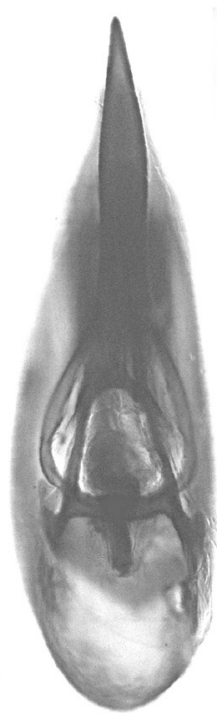

69

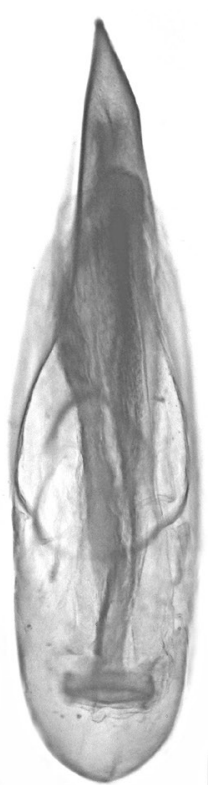

77
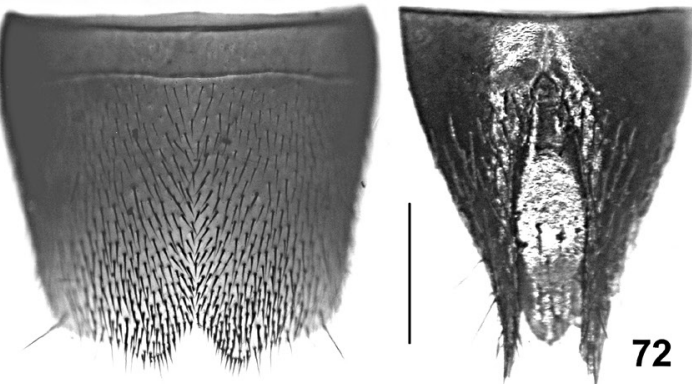

66

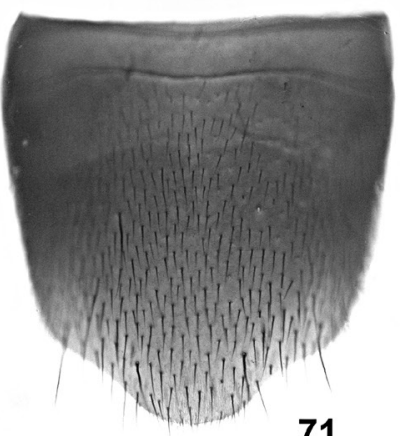

71

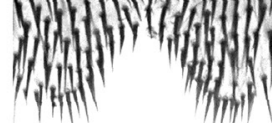

67

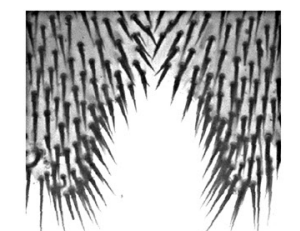

75

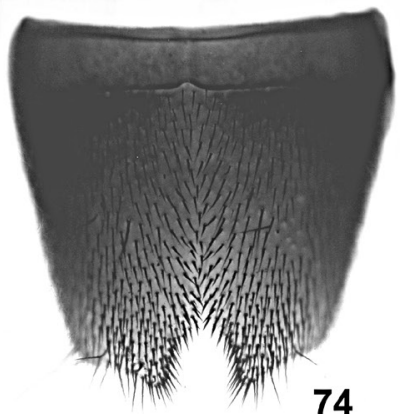

74
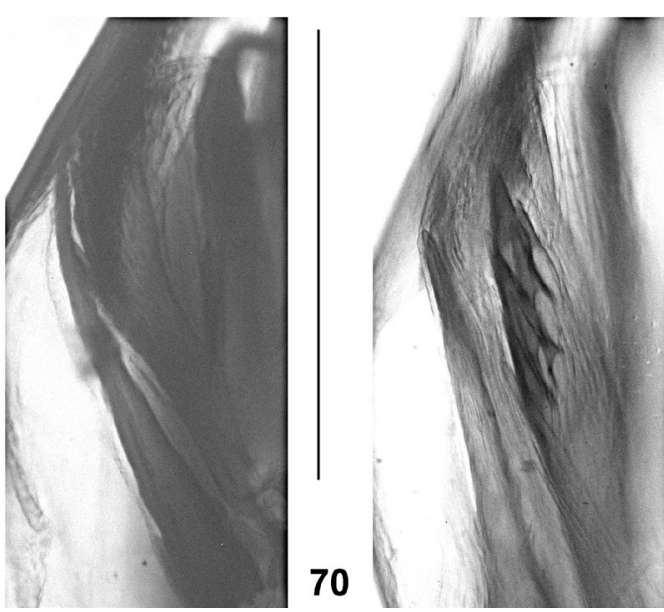

78

Figs 64-78: Lathrobium magnispinosum (64-72) and L. grandispinosum (73-78): forebody (64, 73); male sternite VII (65); male sternite VIII $(66,74)$; posterior excision of male sternite VIII $(67,75)$; aedeagus in lateral and in ventral view $(68-69,76-77)$; internal structures of aedeagus in lateral view $(70,78)$; female sternite VIII (71); female tergites IX-X (72). Scale bars: 64, 73: $1.0 \mathrm{~mm}$; 65-72, 74-78: $0.5 \mathrm{~mm}$. 


\subsubsection{Lathrobium grandispinosum sp. n. (Figs 73-78, Map 3 )}

Type material:

Holotype $0^{*}$ : "CHINA: Yunnan, Dali Bai Aut. Pref., Zhemo Shan, $7 \mathrm{~km}$ SW Xiaguan, $25^{\circ} 32-33^{\prime} \mathrm{N}, 100^{\circ} 10-11^{\prime} \mathrm{E}, 2870$ 2970 m, scrub with bamboo, oaks \& Rhododendr., litter sifted, 18.IX.2009, leg. M. Schülke [CH09-60] / Holotypus $\sigma^{*}$ Lathrobium grandispinosum sp. n. det. V. Assing 2013" (cAss).

\section{Etymology:}

The specific epithet (Latin, adjective) alludes to the presence of a large spine in the internal sac of the aedeagus.

\section{Description:}

Large species; body length $10.7 \mathrm{~mm}$; length of forebody $4.7 \mathrm{~mm}$. Coloration: body black; legs dark-brown to blackish-brown; antennae reddish-brown. External characters (Fig. 73) as in L. magnispinosum.

$0^{*}$ : sternites III-VI unmodified; sternite VII distinctly transverse, symmetric, with shallow median impression posteriorly, this impression with weakly modified black setae, posterior margin broadly concave; sternite VIII (Fig. 74) symmetric, weakly transverse, with dense and weakly modified black setae in posterior portion, posterior excision (Fig. 75) rather deep and U-shaped; aedeagus (Figs 76-77) $1.65 \mathrm{~mm}$ long, symmetric, with rather stout ventral process; apical portion of dorsal plate moderately long and weakly convex in crosssection, basal portion lamellate and slightly shorter than apical portion; internal sac with pair of membranous structures with short spines and with additional very large spine (Fig. 78).

\section{ᄋ: unknown.}

\section{Comparative notes:}

As can be inferred from the similar external morphology and above all by the similar male sexual characters (presence of a large spine in the internal sac of the aedeagus, shape of ventral process, shape and chaetotaxy of the male sternites VII and VIII), L. grandispinosum is probably the sister species of L. magnispinosum, from which it is distinguished particularly by the less transverse male sternite VIII with a much deeper and differently shaped posterior excision, as well as by the larger aedeagus with an apically more slender ventral process, a differently shaped dorsal plate, and slightly different internal structures.

Distribution and natural history:

The type locality is situated in the Zhemo Shan in the northern Ailao range, to the southwest of Xiguan (Map 3). The holotype was sifted from leaf litter in a shrub habitat with oak, bamboo, and rhododendron at an altitude of 2870-2970, together with L. zhemoicum.

\subsubsection{Lathrobium nuicum sp. $\mathrm{n}$. (Figs 79-85, Map 3)}

Type material:

Holotype $\sigma^{\top}$ : “CHINA: Yunnan [CH07-30], Nujiang Lisu Aut. Pref., Nu Shan, 7 km NNW Coajian [Caojian], $25^{\circ} 43^{\prime} 29^{\prime \prime} \mathrm{N}, 9^{\circ} 07^{\prime} 57^{\prime \prime} \mathrm{E}, 2420 \mathrm{~m}$, second. pine forest with shrubs, litter, bark sifted, 11.VI.2007, M. Schülke / Holotypus ơ Lathrobium nuicum sp. n. det. V. Assing 2013" (cAss). Paratypes: 1 : same data as holotype (cSch); 4 o $^{\star}$ o $^{*}$ : same data, but leg. Pütz (cPüt, cSch, cAss); 1 ㅇ: "P.R. CHINA, Yunnan, E slope S Nushan at Liuku, $\mathrm{N} 25^{\circ} 45.782^{\prime}, \mathrm{E} 98^{\circ} 06.067^{\prime}$ [evidently incorrect; recte: $99^{\circ}$ ], $2534 \mathrm{~m}$, sifting09, V. Grebennikov" (cAss).

\section{Etymology:}

The specific epithet is an adjective derived from $\mathrm{Nu}$ Shan, the name of the mountain range where the species is probably endemic.

\section{Description:}

Very large species; body length $11.0-13.0 \mathrm{~mm}$; length of forebody 4.7-5.3 mm. Head (Fig. 79) strongly transverse, 1.10-1.15 times as broad as long. Abdomen with extremely fine and extremely dense punctation. Protarsomeres I-IV with moderately pronounced sexual dimorphism. Tergite VIII with weakly pronounced sexual dimorphism. Other external characters as in L. magnispinosum.

$\sigma^{*}$ : posterior margin of tergite VIII weakly convex; sternites III-VI unmodified; sternite VII (Fig. 80) strongly transverse, symmetric, with extensive, but shallow postero-median impression, this impression with dense, moderately modified short black setae, posterior margin broadly concave; sternite VIII (Fig. 81) symmetric, weakly transverse, with dense and weakly modified short black setae, posterior excision rather deep and almost U-shaped; aedeagus (Figs 82-83) 1.85 mm long, symmetric; ventral process nearly straight and apically hooked in lateral view, ventrally with pair of carinae; apical portion of dorsal plate lamellate, distinctly sclerotized, weakly curved and apically slightly hooked in lateral view, basal portion long, longer than apical portion, lamellate, and almost straight in lateral view; internal sac with long, massive, and strongly sclerotized spine, with additional smaller apical spines, and with pair of dark membranous structures.

१: sternite VIII (Fig. 84) approximately $1.6 \mathrm{~mm}$ long and transverse, posterior margin distinctly, convexly produced in the middle; tergite IX (Fig. 85) with very short antero-median portion and moderately long posterolateral processes, antero-median portion with median suture; tergite X (Fig. 85) flattened, very long, approximately ten times as long as antero-median portion of tergite IX. 


\section{Comparative notes:}

The similar external and particularly the male sexual characters (shapes and chaetotaxy of the male sternites VII and VIII; morphology of the aedeagus: internal sac with a long and large sclerotized spine) suggest that L. nuicum is closely related to L. magnispinosum and allied species. It is readily distinguished from all geographically close species by its distinctly larger body size alone. In addi- tion, it is characterized by the extremely dense and fine punctation and by the sexual characters, particularly the morphology of the aedeagus.

\section{Distribution and natural history:}

The species was found in two localities in the southern $\mathrm{Nu}$ Shan range near Caojian, Yunnan (Map 3). The specimens were sifted from leaf litter, partly in a secondary

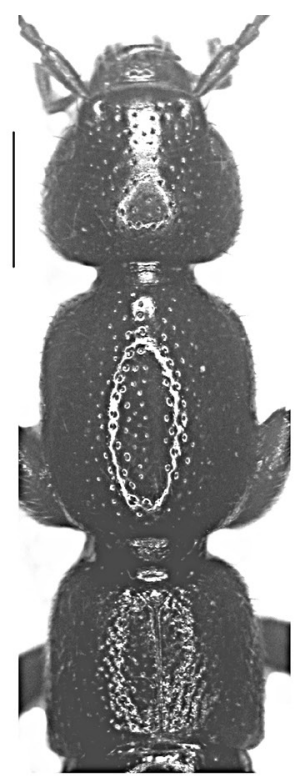

79

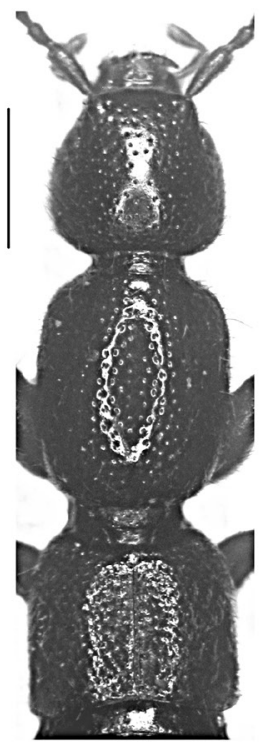

86

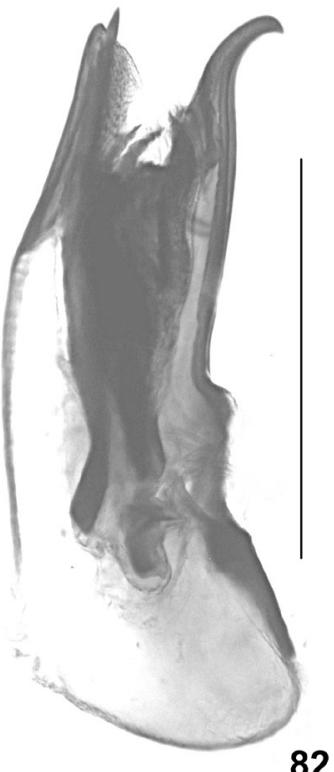

82
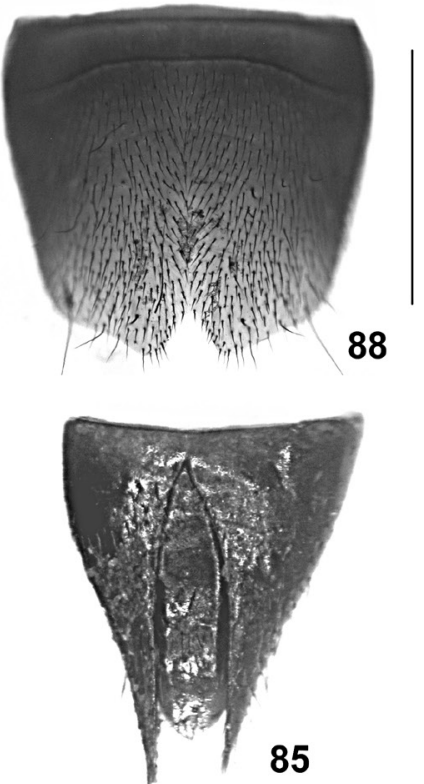

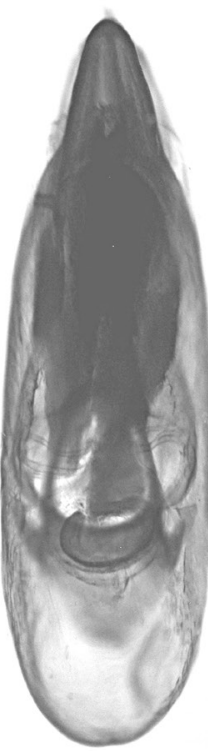

83

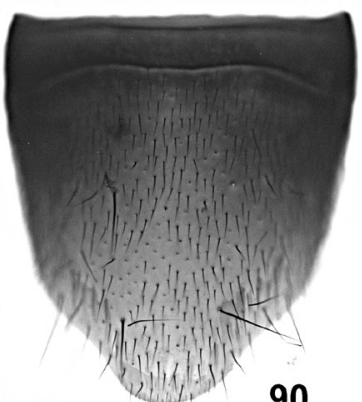

90

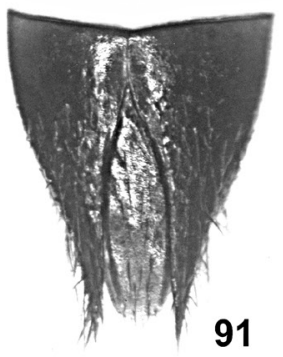

91

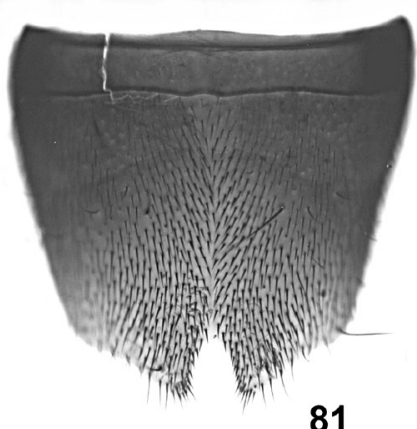

81

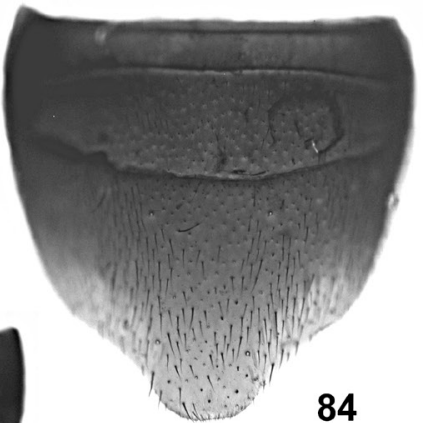

84

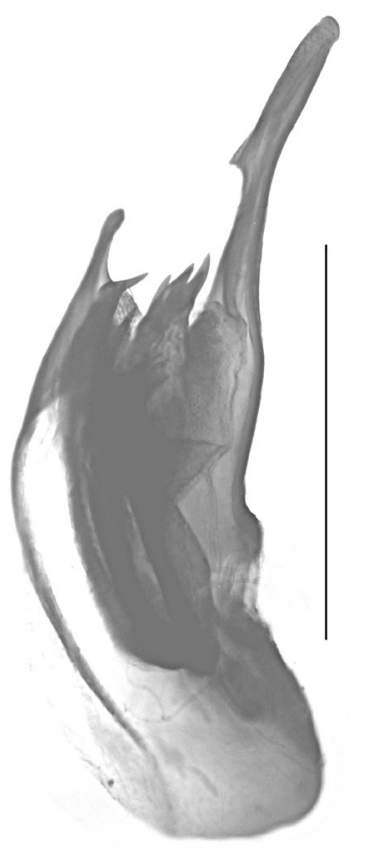

89

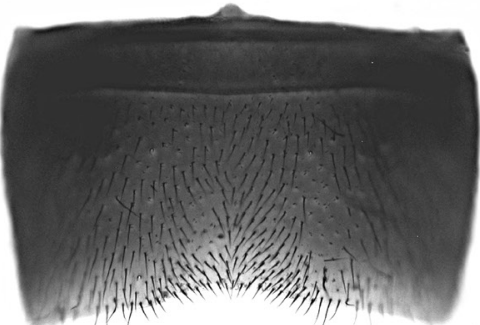

87

Figs 79-91: Lathrobium nuicum (79-85) and L. iaculatum (86-91): forebody (79, 86); male sternite VII (80, 87); male sternite VIII (81,

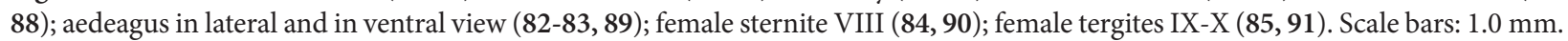


pine forest with shrubs, at altitudes of 2420 and approximately $2530 \mathrm{~m}$, together with $L$. puetzi and an unnamed, probably undescribed species.

\subsubsection{Lathrobium iaculatum sp. n. (Figs 86-91, Map 3)}

\section{Type material:}

Holotype ơ: "CHINA: Yunnan, Baoshan Pref., Gaoligong Shan $33 \mathrm{~km}$ SE Tengchong, $2150 \mathrm{~m}, 24^{\circ} 51^{\prime} 22^{\prime \prime} \mathrm{N}$, $98^{\circ} 45^{\prime} 36^{\prime \prime} \mathrm{E}$, devast. primery [sic] deciduous forest, litter, wood, mushrooms sifted, 28.VIII.2009, leg. M. Schülke [CH09-08a] / Holotypus o Lathrobium iaculatum sp. n. det. V. Assing 2013" (cSch). Paratypes: $2 o^{\star} o^{\star}, 2$ 우 우 [1 $\sigma^{\star}$, 2 우 우 slightly teneral]: same data as holotype (cSch, cAss); $1 \sigma^{*}$ [teneral]: same data, but 26.VIII.2009 (cSch); $1 \sigma^{*}$ : "CHINA: Yunnan [CH07-14], Baoshan Pref., Gaoligong Shan, $33 \mathrm{~km}$ SE Tengchong, 2100-2200 m, 2451'22"N, $98^{\circ} 45^{\prime} 36^{\prime \prime} \mathrm{E}$, decid. forest, litter, wood, fungi sifted, 31.V.2007, M. Schülke” (cSch); 1 ㅇ: same data, but leg Wrase (cSch); 1 o , 1 \%: "CHINA (Yunnan) Baoshan Pref., Gaoligong Shan, W Pass 35 km SE Tengchong $2100 \mathrm{~m}$ (devast. prim. dec. forest, litter sifted) $24^{\circ} 50^{\circ} 18^{\prime \prime} \mathrm{N}$, 98 ${ }^{\circ} 45^{\prime} 43^{\prime \prime E}$, 25.-28.VIII.2009 D.W. Wrase [06]” (cSch, cAss); 1 ㅇ: "CHINA: Yunnan [CH07-13], Baoshan Pref., Gaoligong Shan, E pass, $36 \mathrm{~km}$ SE Tengchong, $2200 \mathrm{~m}$, $24^{\circ} 49^{\prime} 32^{\prime \prime} \mathrm{N}, 98^{\circ} 46^{\prime} 06^{\prime} \mathrm{E}$, decid. forest, litter, wood, fungi sifted, 31.V.2007, M. Schülke" (cAss).

\section{Etymlogy:}

The specific epithet is an adjective derived from the Latin noun iaculum (harpoon, spear) and alludes to the shape of the ventral process of the aedeagus.

\section{Description:}

Large species; body length $8.5-10.7 \mathrm{~mm}$; length of forebody $4.2-4.7 \mathrm{~mm}$. Coloration: body black; legs dark-brown to blackish-brown; antennae reddish to reddish-brown. External characters (Fig. 86) as in L. magnispinosum.

Protarsomeres with weakly pronounced sexual dimorphism. Tergite VIII without sexual dimorphism, weakly convex or indistinctly pointed in the middle.

$\sigma^{\pi}$ : sternites III-VI unmodified; sternite VII (Fig. 87) distinctly transverse, symmetric, with shallow median impression posteriorly, this impression with dense weakly modified black setae, posterior margin broadly concave; sternite VIII (Fig. 88) symmetric, weakly transverse, with dense and weakly modified black setae, posterior excision distinct and moderately deep; aedeagus (Fig. 89) 2.1$2.2 \mathrm{~mm}$ long, symmetric, with conspicuously long ventral process of distinctive shape; apical portion of dorsal plate moderately long, lamellate, distinctly sclerotized, and api- cally pointed in dorsal view, basal portion lamellate, and conspicuously long, much longer than apical portion; internal sac with pair of membranous structures, with several apical sclerotized spines, and with additional very large spine.

क : sternite VIII (Fig. 90) approximately $1.4 \mathrm{~mm}$ long and indistinctly oblong, posterior margin convexly produced in the middle; tergite IX (Fig. 91) with short anteromedian portion and moderately long postero-lateral processes, antero-median portion with median suture; tergite X (Fig. 91) conspicuously flattened, very long, more than four times as long as antero-median portion of tergite IX.

\section{Comparative notes:}

As can be inferred from the similar external morphology and above all by the similar male sexual characters (presence of a large spine in the internal sac of the aedeagus, shapes and chaetotaxy of the male sternites VII and VIII), L. iaculatum is closely allied to L. magnispinosum and L. grandispinosum, from which it is distinguished particularly by the conspicuous shape of the ventral process of the aedeagus.

\section{Distribution and natural history:}

The species was found in several geographically close localities in the southern Gaoligong Shan, to the southeast of Tengchong (Map 3). The specimens were sifted from leaf litter in deciduous forests at altitudes of 2100$2200 \mathrm{~m}$. Several specimens collected in August are teneral.

\subsubsection{The L. exspoliatum subgroup}

\subsubsection{Lathrobium exspoliatum sp. $\mathrm{n}$. (Figs 92-100, Map 4)}

\section{Type material:}

Holotype $o^{\text {*: }}$ "CHINA: Yunnan, Lincang Pref., Xue Shan, $11 \mathrm{~km}$ ENE Lincang, $2510 \mathrm{~m}, 23^{\circ} 55^{\prime} 01 \mathrm{~N}, 100^{\circ} 11^{\prime} 17.5^{\prime \prime E}$, second. pine forest with Rhodod., small cleft with water, litter \& mushrooms sifted, 10.IX.2009, leg. M. Schülke [CH09-39] / Holotypus o Lathrobium exspoliatum sp. n. det. V. Assing 2013" (cSch). Paratypes: $10^{*}, 12$ ㅇ ㅇ: same data as holotype (cSch, cAss); $10^{*}$ : same data, but leg. Wrase (cAss).

\section{Etymology:}

The specific epithet is the past participle of the Latin verb exspoliare (to rob) and refers to the absence of modified setae on the male sternites VII and VIII. 


\section{Description:}

Body length 6.7-8.5 mm; length of forebody 3.4-3.7 mm. Habitus and forebody as in Figs 92-93. External characters highly similar to those of L. rastellatum and L. daliense.
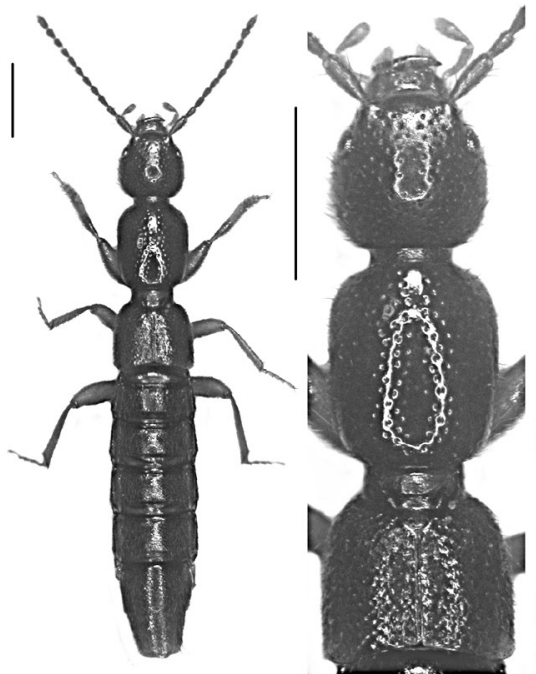

92

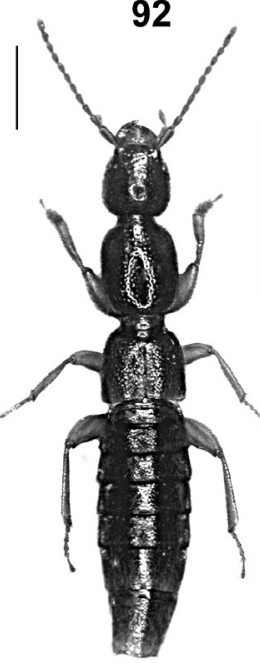

101

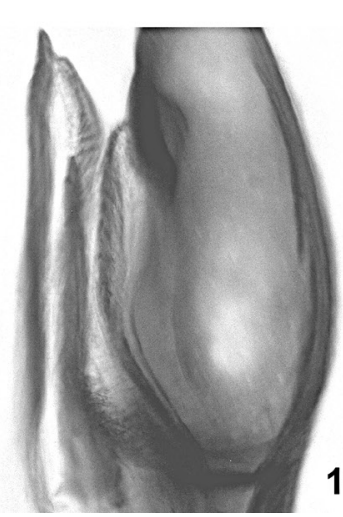

93

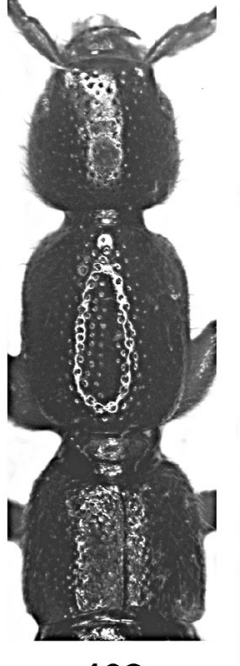

102

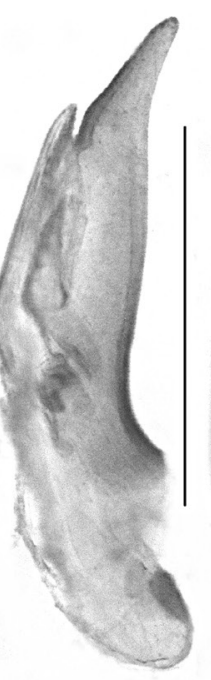

96 $o^{\star}$ : sternites III-VI unmodified; sternite VII (Fig. 94) moderately transverse and with unmodified pubescence, posterior margin broadly and very weakly concave; sternite VIII (Fig. 95) weakly transverse, with unmodified pubescence, posterior margin convex, only in the middle weakly concave; aedeagus (Figs 96-97) rather weakly

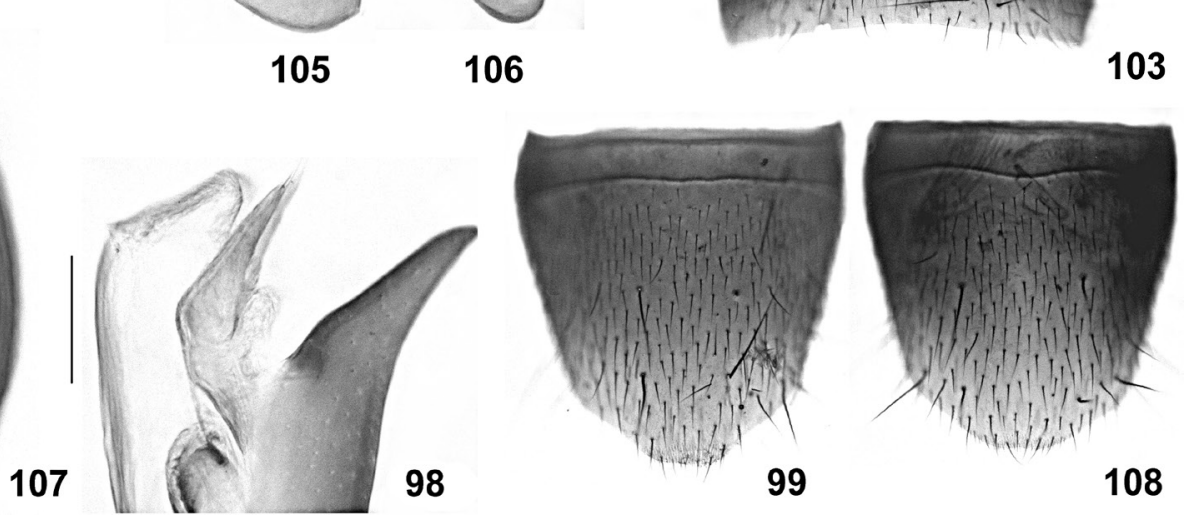

Figs 92-109: Lathrobium exspoliatum (92-100) and L. triquetrum (101-109): habitus (92, 101); forebody (93, 102); male sternite VII $(94,103)$; male sternite VIII $(95,104)$; aedeagus in lateral and in ventral view $(96-97,105-106)$; internal structures of aedeagus in lateral view $(98,107)$; female sternite VIII $(\mathbf{9 9}, 108)$; female tergites IX-X $(100,109)$. Scale bars: 92-93, 101-102: 1.0 mm; 94-97, 99-100, 103-106, 108-109: 0.5 mm; 98, 107: $0.1 \mathrm{~mm}$. 
sclerotized and small in relation to body size, approximately $0.8 \mathrm{~mm}$ long; ventral process laterally compressed and relatively short; dorsal plate very weakly sclerotized, almost semi-membranous, with moderately long and very thin apical portion, and with short basal portion; internal sac with pair of short semi-transparent spines (Fig. 98).

오 : sternite VIII (Fig. 99) approximately $1.0 \mathrm{~mm}$ long, about as broad as long, weakly modified, posterior margin strongly convex; tergite IX (Fig. 100) with very short antero-median portion and with moderately long postero-lateral processes, median portion with suture; tergite $\mathrm{X}$ (Fig. 100) moderately convex in anterior half and flat in posterior half, nearly ten times as long as median portion of tergite IX.

\section{Comparative notes:}

The similar external characters, the similar morphology of the female tergites IX and X, as well as the similar general morphology of the aedeagus (ventral process relatively short, laterally compressed, and symmetric; presence of pair of spines in internal sac; shape of dorsal plate) suggest that L. exspoliatum is related to L. daliense and allied species. It is characterized particularly by the weakly pronounced male secondary sexual characters (absence of modified pubescence on the male sternite VII and VIII), the shape of the male sternite VIII, and by the distinctive morphology of the aedeagus.

\section{Distribution and natural history:}

The type locality is situated in the Wulao (synonym: Xue) Shan to the east-northeast of Lincang, Yunnan (Map 4). The specimens were sifted from litter in a secondary pine forest at an altitude of $2510 \mathrm{~m}$. Seven paratypes are slightly to distinctly teneral. The sex ratio is strongly biased in favour of females $\left(3 o^{\top} o^{\top}: 12\right.$ 우 우).

\subsubsection{Lathrobium triquetrum sp. n. (Figs 101-109, Map 4)}

\section{Type material:}

Holotype $0^{*}$ : "CHINA: Yunnan, Lincang Pref., Bangma Shan, $20 \mathrm{~km}$ NW Lincang, $2210 \mathrm{~m}, 23^{\circ} 58^{\prime} 25^{\prime \prime} \mathrm{N}$, $99^{\circ} 54^{\prime} 36^{\prime \prime} \mathrm{E}$, water reservoir, devast. forest with ferns, litter \& ferns sifted, reservoir bank, 9.IX.2009, leg. M. Schülke [CH09-37] / Holotypus ơ Lathrobium triquetrum sp. n. det. V. Assing 2013” (cSch). Paratypes: $20^{\star} 0^{\star}, 3$ 우 우 [1 slightly teneral]: same data as holotype (cSch, cAss).

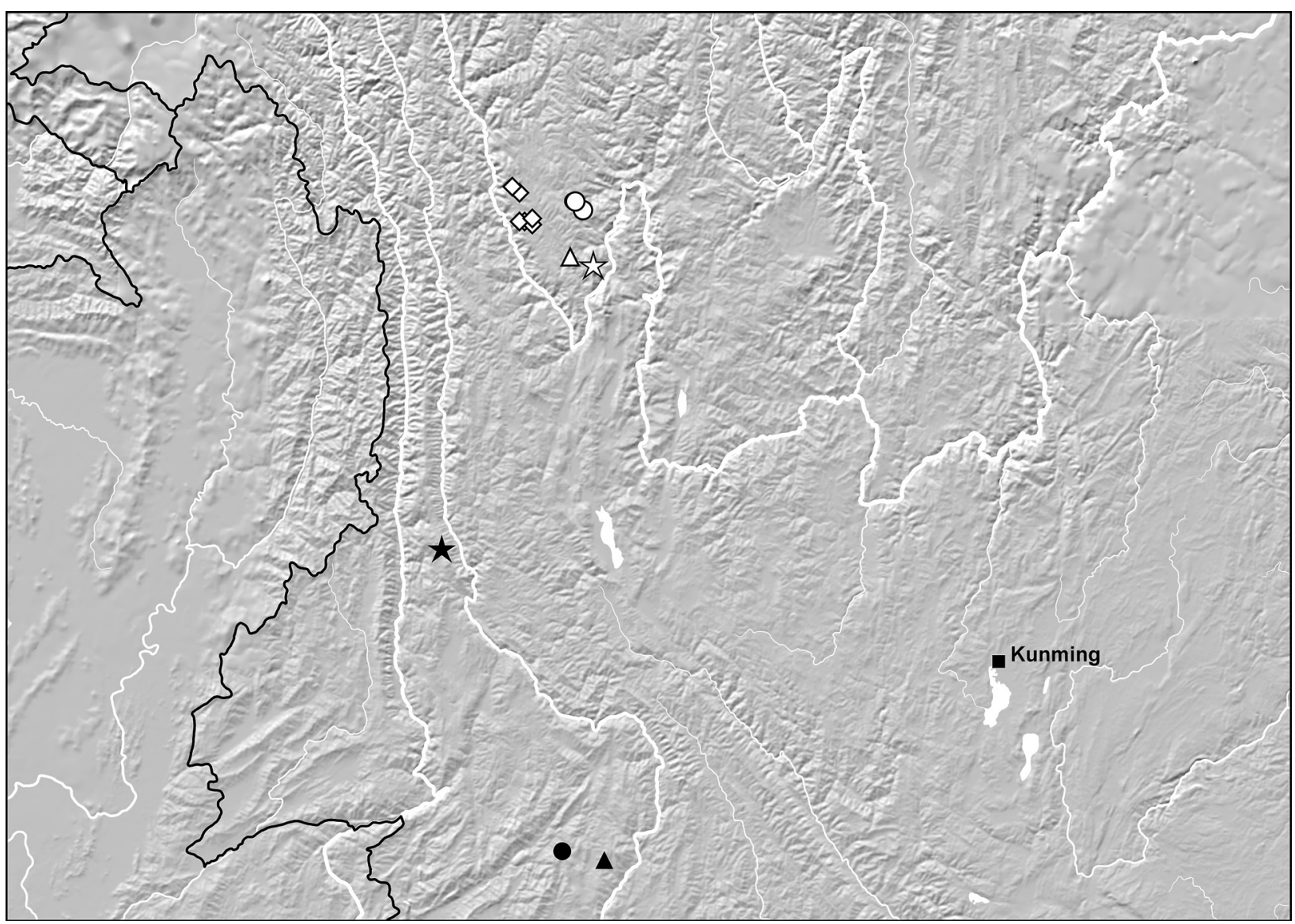

Map 4: Distribution of the species of the L. puetzi (filled star), the L. exspoliatum (other filled symbols), and the L. acutapicale (open symbols) subgroups: L. puetzi (black star); L. triquetrum (black circle); L. exspoliatum (black triangle); L. acutapicale (white circles); L. biseriatum (white diamonds); L. bifasciatum (white triangle); L. reticolle (white star). 


\section{Etymology:}

The specific epithet (Latin, adjective: three-sided) alludes to the voluminous, apically in cross-section triangular ventral process of the aedeagus.

\section{Description:}

Body length 6.3-7.5 mm; length of forebody 3.3-3.5 mm. Habitus and forebody as in Figs 101-102. Externally highly similar to L. rastellatum, L. daliense, and L. exspoliatum.

$0^{\star}$ : sternites III-VI unmodified; sternite VII (Fig. 103) moderately transverse and with unmodified pubescence, posterior margin broadly and weakly concave; sternite VIII (Fig. 104) weakly transverse, with unmodified pubescence, posterior excision broadly and rather deeply concave; aedeagus (Figs 105-106) approximately $1.0 \mathrm{~mm}$ long, symmetric; ventral process of highly distinctive shape, short, stout, voluminous, in cross section apically triangular and basally quadrangular; dorsal plate with moderately long, relatively weakly sclerotized, lamellate, and straight (lateral view) apical portion and with distinctly shorter, hardly sclerotized basal portion; internal sac with one moderately long spine (Fig. 107).

: sternite VIII (Fig. 108) approximately $1.0 \mathrm{~mm}$ long, about as broad as long, weakly modified, posterior margin strongly convex; tergite IX (Fig. 109) with very short antero-median portion and with moderately long postero-lateral processes, median portion with suture; tergite X (Fig. 109) weakly convex in anterior two fifths and flat in posterior three fifths, nearly ten times as long as median portion of tergite IX.

\section{Comparative notes:}

The similar external characters, the similar morphology of the female tergites IX and X, the female sternite VIII, the nearly unmodified pubescences of the male sternites VII and VIII, and the morphology of the aedeagus (weakly sclerotized dorsal plate; presence of spines in internal sac) suggest that L. triquetrum is most closely related to L. exspoliatum. It differs from this species and other representatives of the genus particularly by the highly distinctive morphology of the aedeagus, as well as by the shape and chaetotaxy of the male sternite VIII.

\section{Distribution and natural history:}

The type locality is situated in the Fengchui Shan in the Bangma Shan range to the northwest of Lincang, Yunnan (Map 4). The specimens were sifted from litter in a degraded forest at an altitude of $2210 \mathrm{~m}$. One of the male paratypes is somewhat teneral.

\subsubsection{The L. acutapicale subgroup}

\subsubsection{Lathrobium acutapicale sp. n. (Figs 110-117, Map 4)}

\section{Type material:}

Holotype ơ: "CHINA: N-Yunnan [C03-13], Zhongdian [today: Shangri-La] Co., $36 \mathrm{~km}$ ESE Zhongdian, overgrown rock hillside with old mixed forest, bamboo, dead wood, mushrooms, $27^{\circ} 40.9^{\prime} \mathrm{N}, 100^{\circ} 01.5^{\prime} \mathrm{E}, 3500-3550 \mathrm{~m}$, 23.VIII.2003, leg. M. Schülke / Holotypus ơ Lathrobium acutapicale sp. n. det. V. Assing 2013" (cSch). Paratypes: $6 o^{\star} o^{\star}, 2$ ㅇ ㅇ [2 teneral]: same data as holotype (cSch, cAss); $3 \sigma^{\star} \sigma^{*}, 3$ ㅇ ㅇ [1 teneral]: same data, but leg. Wrase (cSch, cAss); $7 o^{\star} o^{\star}, 3$ 우 $\circ$ : “China: N-Yunnan Zhongdian Co. $36 \mathrm{~km}$ ESE Zhongdian $27^{\circ} 40.9^{\prime} \mathrm{N} 100^{\circ} 01.5 \mathrm{E}, 3500$ 3550 m 23.VIII.2003 A. Smetana [C133]" (cSme, cAss); $24 o^{\star} o^{\star}, 22$ 우 ㅇ: “CHINA: N-Yunnan [C03-12], Zhongdian Co., pass $28 \mathrm{~km}$ ESE Zhongdian, devastated primary forest with young Abies, Larix, Betula, Rhodod., $27^{\circ} 43.9^{\prime} \mathrm{N}, 99^{\circ} 58.2^{\prime} \mathrm{E}, 3700-3750 \mathrm{~m}, 22 . V I I I .2003$, leg. M. Schülke" (cSch, cAss); $4 o^{\star} o^{\star}, 4$ 우 우 :CHINA: N-Yunnan [C2005-01], Diqing Tibet. Aut. Pref., Zhongdian Co., Bitai Hai Lake area, $29 \mathrm{~km}$ ESE Zhongdian, $27^{\circ} 43.65^{\prime} \mathrm{N}$, $99^{\circ} 58.97^{\prime} \mathrm{E}, 3540 \mathrm{~m}$, creek valley, devast. mixed forest, litter, moss, dead wood, 1.VI.2005, M. Schülke [C200501]" (cSch, cAss); 1 \% : same data, but leg. Wrase (cSch); $80^{\star} o^{\star}, 8$ ㅇ 우 :CHINA: N-Yunnan Zhongdian Co. pass $28 \mathrm{~km}$ ESE Zhongdian $27^{\circ} 43.9^{\prime} \mathrm{N}$ 99 $58.2^{\prime} \mathrm{E}$ 3700-3750 m 22.VIII.2003 A. Smetana [C131]" (cSme, cAss); 1 ơ: "CHINA (N-Yunnan) Diqing Tibet Aut. Pref., Zhondian Co., $35 \mathrm{~km}$ ESE Zhongdian, $3450 \mathrm{~m}, 27^{\circ} 41.00^{\prime} \mathrm{N}$, $100^{\circ} 01.47^{\prime} \mathrm{E}$, (devastaded [sic] mixed forest near small creek, sifted from litter, moss, dead wood), 3.VI.2005 D.W. Wrase [03]" (cAss).

\section{Etymology:}

The specific epithet (Latin, adjective: with acute apex) alludes to the slender and acute apex of the ventral process of the aedeagus.

\section{Description:}

Small species; body length 5.5-7.0 mm; length of forebody $2.5-2.8 \mathrm{~mm}$. Habitus as in Fig. 110. Coloration: body dark-brown to blackish-brown; legs and antennae reddish.

Head (Fig. 111) approximately as broad as long; punctation moderately coarse and rather sparse; interstices with distinct microreticulation. Eyes small, approximately 0.3 times as long as postocular region and composed of approximately 25-30 relatively large ommatidia. Antenna short and stout, approximately $1.4 \mathrm{~mm}$ long; antennomeres VI-X weakly transverse.

Pronotum (Fig. 111) approximately 1.2 times as long as broad and 1.05 times as broad as head, lateral margins straight and parallel; punctation similar to that of head; 
impunctate midline rather broad; interstices with very shallow microreticulation at least in anterior, posterior, and lateral portions.

Elytra (Fig. 111) approximately 0.55 times as long as pronotum; punctation sparse. Hind wings completely reduced. Protarsomeres I-IV with moderately pronounced sexual dimorphism.
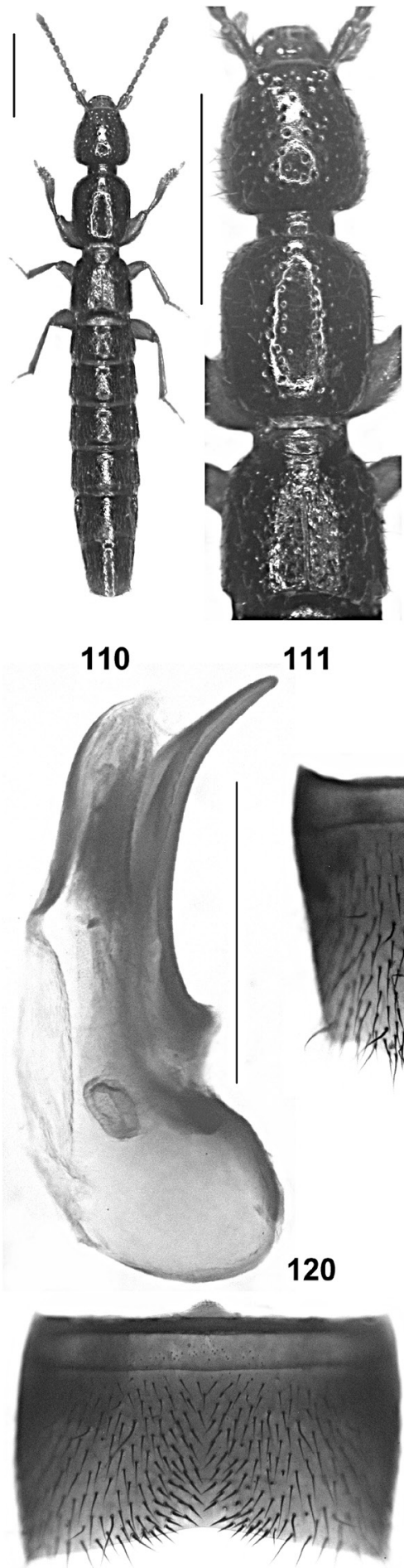

Abdomen 1.05-1.10 times as broad as elytra; punctation moderately dense and fine; interstices with shallow microsculpture; posterior margin of tergite VII without palisade fringe; posterior margin of tergite VIII convex to indistinctly pointed in the middle, without sexual dimorphism. 
$\sigma^{7}$ : sternites III-VI unmodified; sternite VII (Fig. 112) moderately transverse, pubescence sparse and not distinctly modified, except for a small area without setae in postero-median portion, posterior margin broadly and weakly concave, slightly more distinctly concave in the middle; sternite VIII (Fig. 113) weakly transverse, pubescence weakly modified, middle of posterior half narrowly without setae, posterior excision distinct, moderately deep; aedeagus (Figs 114-115) approximately $1.0 \mathrm{~mm}$ long and symmetric; ventral process smoothly curved, with long, slender, and acute apex; apical portion of dorsal plate moderately long, lamellate, and moderately sclerotized, basal portion of dorsal plate fine, short, and not distinctly sclerotized; internal sac with pair of moderately long series of numerous short dark spines.

ㅇ: sternite VIII (Fig. 116) 0.8-0.9 mm long, very weakly oblong, posterior margin strongly convex; tergite IX (Fig. 117) with very short antero-median portion and moderately long postero-lateral processes, antero-median portion with suture; tergite X (Fig. 117) distinctly convex (cross-section) in anterior three fourths and flat in posterior fourth, nearly reaching anterior margin of tergite IX.

\section{Comparative notes:}

Together with the following four externally extremely similar species, L. acutapicale forms a complex of very close relatives, all of which are distinguished from other representatives of Lathrobium known from Yunnan particularly by the presence of shallow traces of microsculpture (sometimes reduced) on the pronotum and the similar sexual characters, as well as additionally by the combination of relatively small body size and dark coloration. It differs from other members of this subgroup particularly by the conspicuously slender and acute apex of the ventral process of the aedeagus. For additional characters distinguishing it from its close relatives see the comparative notes in the following sections.

\section{Distribution and natural history:}

The species was collected in five geographically close localities near the Gongzhanmu Shan in a mountain range to the east-southeast of Zhongdian (Map 4). The specimens were sifted in large numbers from leaf litter in mixed primary and secondary forests at altitudes of 3450 $3750 \mathrm{~m}$, partly together with the closely related $L$. restinctum. Three of the paratypes are teneral.

\subsubsection{Lathrobium restinctum sp. $\mathrm{n}$. (Figs 118-122, Map 5)}

\section{Type material:}

Holotype ơ: "CHINA: N-Yunnan [C2005-03], Diqing Tibet. Aut. Pref., Zhongdian [today: Shangri-La] Co., $35 \mathrm{~km}$ ESE Zhongdian, $3450 \mathrm{~m}, / 27^{\circ} 41.00^{\prime} \mathrm{N}, 100^{\circ} 01.47^{\prime} \mathrm{E}$, devastaded [sic] mixed forest nr. small creek, litter, moss, dead wood sifted, 3.VI.2005, M. Schülke / Holotypus o Lathrobium restinctum sp. n. det. V. Assing 2013" (cSch). Paratypes: $2 \sigma^{\star} o^{*}, 4$ 우 : same data as holotype (cSch, cAss); 1 i : same data, but leg. Wrase (cSch); $20^{*} \sigma^{*}$, 2 우: "CHINA: N-Yunnan Diqing Tibet. Aut. Pr. Zhongdian Co. $35 \mathrm{~km}$ ESE Zhongdian $27^{\circ} 41.00^{\prime} \mathrm{N}, 100^{\circ} 01.47^{\prime} \mathrm{E}$ 3450 m 3.VI.2005 A. Smetana (cSme, cAss); 6 o ๙ $^{\star}, 5$ 우 우: "CHINA: N-Yunnan [C03-13], Zhongdian Co., 36 km ESE Zhongdian, overgrown rock hillside with old mixed forest, bamboo, dead wood, mushrooms, $27^{\circ} 40.9^{\prime} \mathrm{N}$, $100^{\circ} 01.5^{\prime} \mathrm{E}, 3500-3550 \mathrm{~m}, 23$.VIII.2003, leg. M. Schülke" (cSch, cAss); 1 \% : same data, but leg. Wrase (cSch); $10^{\text {t, }}$ 1 \%: same data, but "[C03-13B] ... 24.VIII.2003" (cSch, cAss).

\section{Etymology:}

The specific epithet (Latin, past participle of the verb restinguere: to extinguish, to delete) alludes to the usually practically obsolete microsculpture of the pronotum.

\section{Description:}

Small species; body length 5.5-7.0 mm; length of forebody 2.3-2.8 mm. Pronotum with nearly or completely obsolete microreticulation, even in anterior and posterior portions. Posterior margin of tergite VIII with sexual dimorphism. Other external characters as in L. acutapicale.

$0^{*}$ : posterior margin of tergite VIII weakly, obtusely pointed in the middle; sternites III-VI unmodified; sternite VII (Fig. 118) distinctly transverse and with rather distinct postero-median impression, this impression with dense and moderately modified black setae, posterior margin broadly concave; sternite VIII (Fig. 119) moderately transverse, with moderately modified black setae in the oblong median impression, middle of impression narrowly without setae, posterior excision small and shallow; aedeagus (Fig. 120) 0.9-1.0 mm long and symmetric; ventral process strongly and smoothly curved in lateral view; dorsal plate with lamellate, moderately long, sinuate (lateral view), and apically acute (dorsal view) apical portion, and with very short, not distinctly sclerotized basal portion; internal sac with pair of moderately long structures with weakly sclerotized, barely noticeable spines.

+ : posterior margin of tergite VIII produced, obtusely angled in the middle; sternite VIII (Fig. 121) 0.8-0.9 mm long, distinctly oblong and with strongly convex posterior margin; tergite IX (Fig. 122) completely divided in the middle, or nearly so, with moderately long and slender postero-lateral processes; tergite X (Fig. 122) reaching anterior margin of tergite IX (or nearly so), strongly convex in anterior three fourths, this elevation abruptly sloping ventrad at posterior fourth, thus forming an angle in lateral view. 


\section{Comparative notes:}

Lathrobium restinctum is undoubtedly very closely related to the syntopic L. acutapicale, as can be inferred particularly from the similar male and female sexual characters, but also from the similar external morphology. It is distinguished from L. acutapicale by the shapes of the female tergite VIII (more strongly and more angularly produced posteriorly) and sternite VIII, by the more transverse male sternite VIII with denser and more distinctly modified setae in the deeper posteromedian impression, by the smaller posterior excision of the male sternite VIII, the (especially apically) stouter ventral process of the aedeagus, the differently shaped dorsal plate, and the shorter structures with much less distinctly sclerotized spines in the internal sac of the aedeagus. In addition, it differs by the less distinct and often practically obsolete microsculpture of the pronotum.

\section{Distribution and natural history:}

The species was found in two geographically close localities near the Gongzhanmu Shan in a mountain range to the east-southeast of Zhongdian (Map 5). The specimens were sifted from leaf litter in mixed forests at altitudes of 3450-3550 m, together with L. acutapicale.

\subsubsection{Lathrobium biseriatum sp. $\mathrm{n}$. (Figs 123-129, Map 4)}

\section{Type material:}

Holotype $0^{\star}$ : "CHINA (N-Yunnan) Zhongdian [today: Shangri-La] Co., Xue Shan, $10 \mathrm{~km}$ SW Zhongdian, 3700$3800 \mathrm{~m}, 27^{\circ} 46.5^{\prime} \mathrm{N}, 99^{\circ} 36.5^{\prime} \mathrm{E}$ (primary mixed forest, leaf litter sifted) 20.VIII.2003 Wrase [10A] / Holotypus o Lathrobium biseriatum sp. n. det. V. Assing 2013" (cSch). Paratypes: $2 \sigma^{\star} \sigma^{\star}, 1$ ㅇ: same data as holotype (cSch, cAss); $4 \circlearrowleft^{\star} \sigma^{\star}, 1$ : $:$ "CHINA: N-Yunnan [C2005-05], Diqing Tibet Aut. Pref., Zhongdian Co., Xue Shan near lake $23 \mathrm{~km}$ S Zhongdian, $3895 \mathrm{~m} / 27^{\circ} 37.1^{\prime} \mathrm{N}, 9^{\circ} 38.5^{\prime} \mathrm{E}$, devast. mixed forest, meadows, lake border, leaf litter, dead wood sifted, 5.VI.2005, leg. M. Schülke [C2005-05]" (cSch, cAss); $1 o^{*}$ : same data, but leg. Wrase (cSch); $10^{*}$, 1 ㅇ: same data, but "[C2005-05] ... 6.VI.2005" (cAss); 1 ㅇ: same data, but leg. Wrase (cSch); $20^{\star} o^{\star}:$ "CHINA: N-Yunnan [C2005-02], Diqing Tibet Aut. Pref., Zhongdian Co., Xue Shan, 23 km S Zhongdian, 3675-3725 m / $27^{\circ} 36.3^{\prime} \mathrm{N}, 99^{\circ} 41.5^{\prime} \mathrm{E}$, devastated mixed forest, sifted from leaf litter, dead wood, 2.VI.2005, leg. M. Schülke [C200502]" (cSch, cAss); $2 o^{*} o^{*}$ [1 slightly teneral]: same data, but leg. Wrase (cSch); 1 \% 4 우 ㅇ: "CHINA: N-Yunnan, Diqing Tibet Aut. Pr. Zhongdian Co. Xue Shan near lake, $23 \mathrm{~km}$ S Zhongdian, $27^{\circ} 37.1^{\prime} \mathrm{N}, 99^{\circ} 38.5^{\prime} \mathrm{E} 3895 \mathrm{~m}$, 5.VI.2005 A. Smetana [C152]" (cSme, cAss); 1 i : same

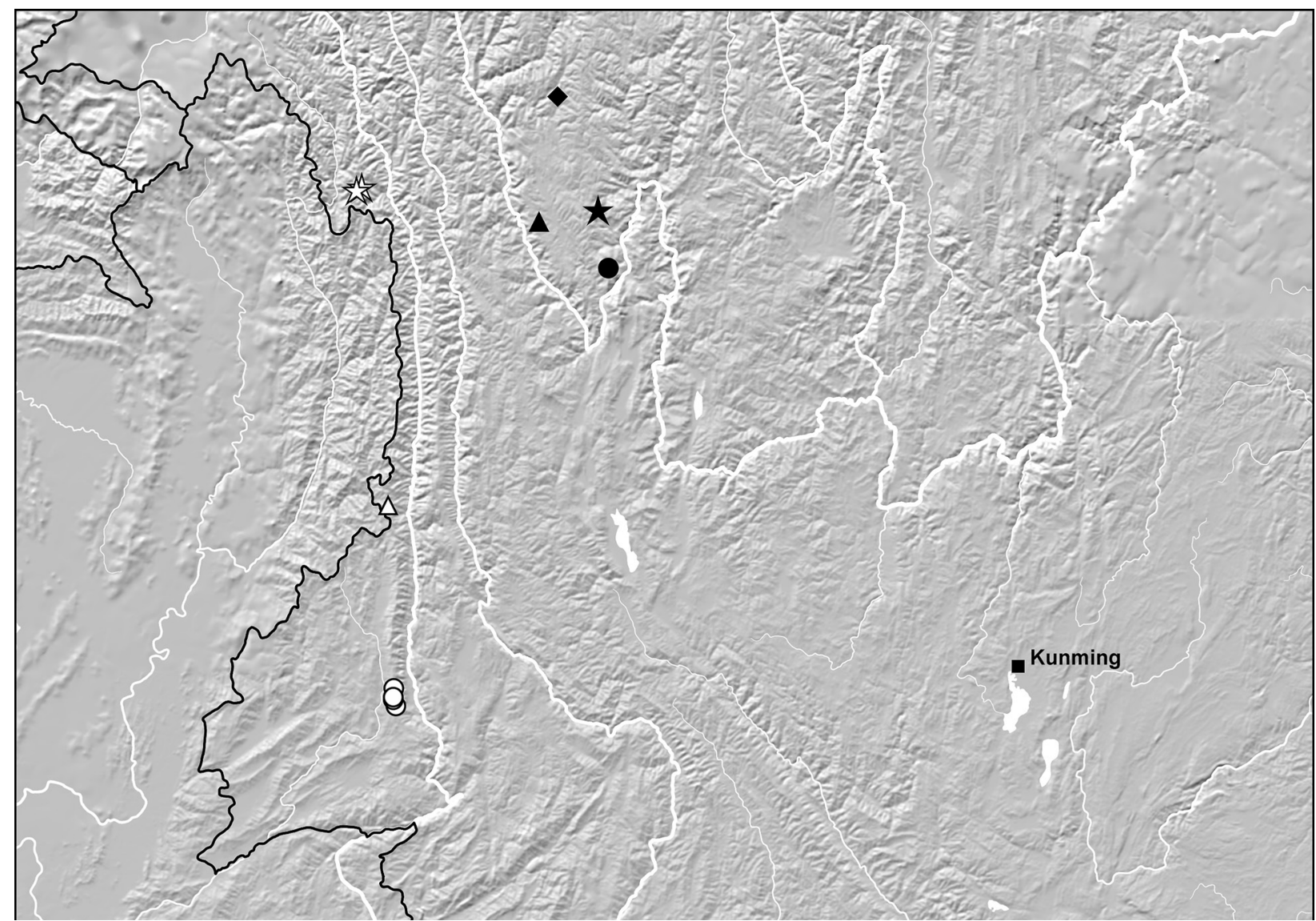

Map 5: Distribution of the species of the L. celere (open stars), the L. rectissimum (other open symbols), the L. acutapicale (filled star), and the L. fortehamatum (other filled symbols) (sub-)groups: L. restinctum (black star); L. rectissimum (white triangle); L. xiei (white circles); L. fortehamatum (black triangle); L. tricuspidatum (black circle); L. fortespinosum (black diamond); L. secans (white stars). 
data, but "15.VI.2005 ... [C161]" (cSme); 2 ○` o, 4 우 우: "CHINA: N-Yunnan, Diqing Tibet Aut. Pr. Zhongdian Co. Xue Shan nr. lake, $23 \mathrm{~km} \mathrm{~S}$ Zhongdian, $27^{\circ} 37.1^{\prime} \mathrm{N}$, 99³6.5'E 3850 m, 6.VI.2005 A. Smetana (C153a)" (cSme, cAss); 2 o $^{\top}$ o $^{\top} 1$ + [2 teneral]: same data, but "(C153b)" (cSme, cAss); 2 o $^{\star}, 4$ 우: "CHINA: N-Yunnan, Diqing
Tibet Aut. Pr. Zhongdian Co. Xue Shan 23 km S Zhongdian, $27^{\circ} 38.3^{\prime} \mathrm{N}, \quad 99^{\circ} 41.5^{\prime} \mathrm{E} \quad 3675-3725 \mathrm{~m}, 2 . \mathrm{VI} .2005$ A. Smetana [C149]" (cSme, cAss); 3 o $^{\star}, 2$ 우 ㅇ :CHINA: N-Yunnan, Diqing Tibet Aut. Pr. Zhongdian Co. $10 \mathrm{~km}$ SW Zhongdian, Xue Shan $27^{\circ} 46.5^{\prime} \mathrm{N}, 99^{\circ} 36.5^{\prime} \mathrm{E} 3800 \mathrm{~m}$, 20.VIII.2003 A. Smetana [C129]" (cSme, cAss); 1 o $^{\text {, }}$
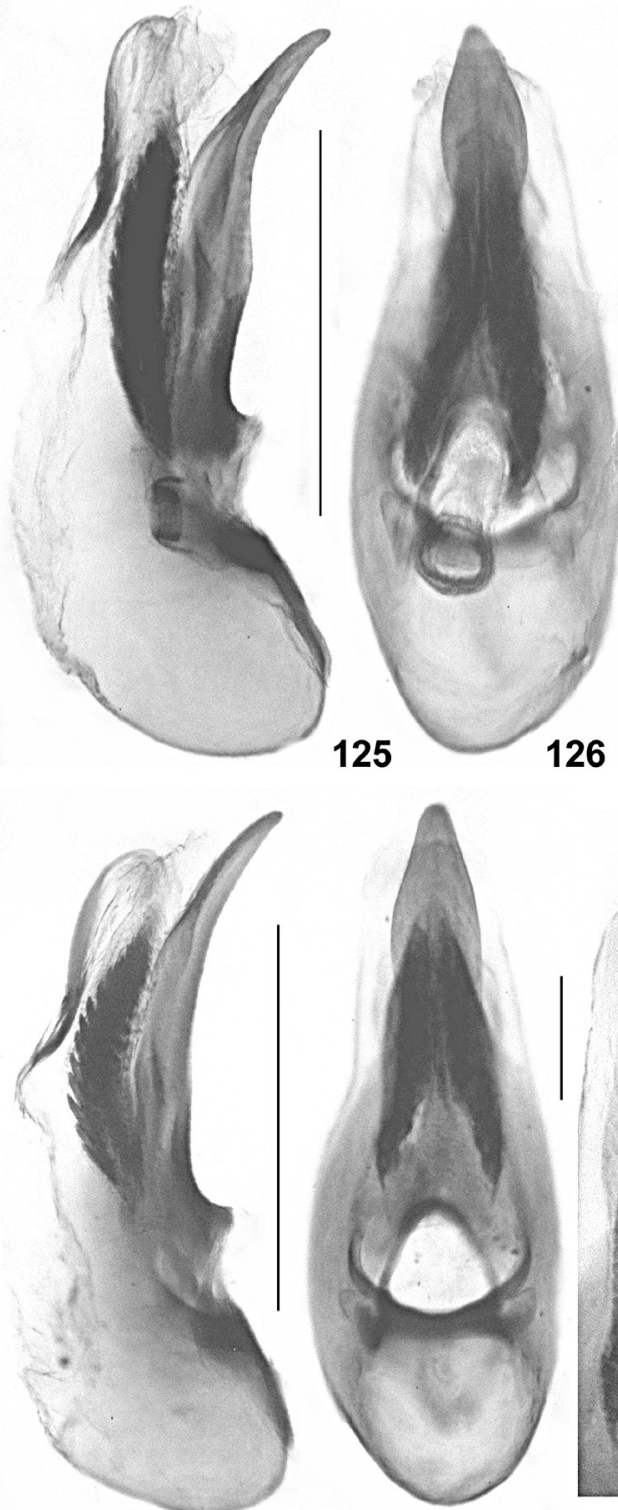

132

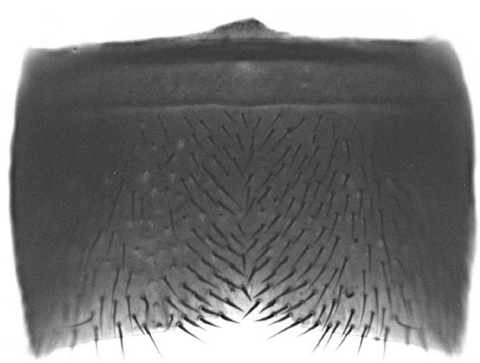

133

123

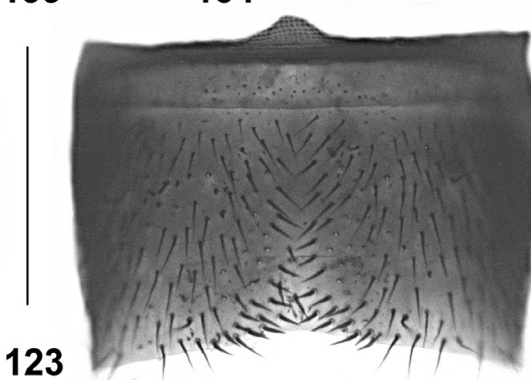

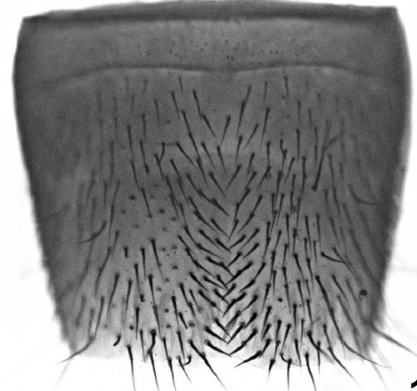

124
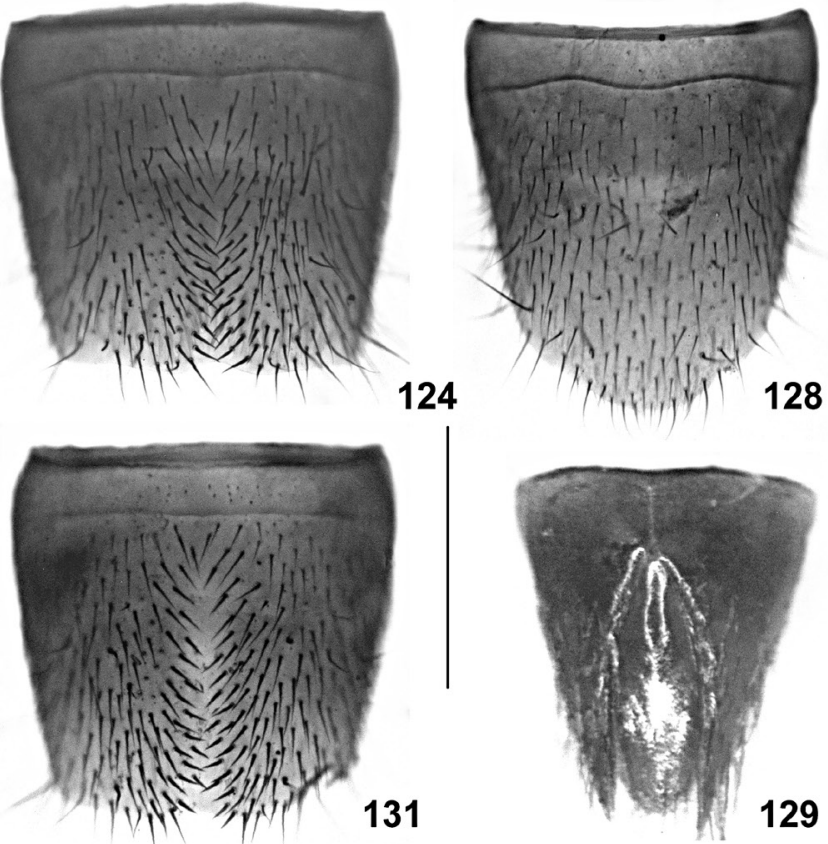

129
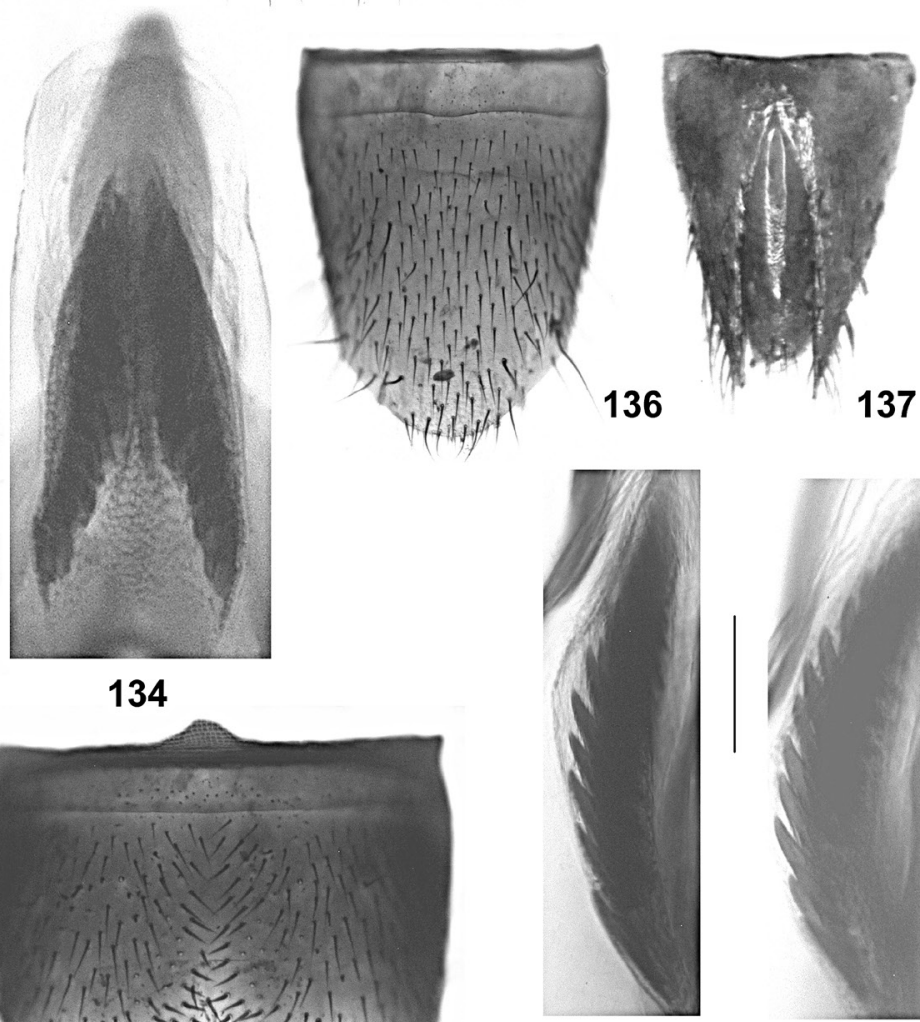

127

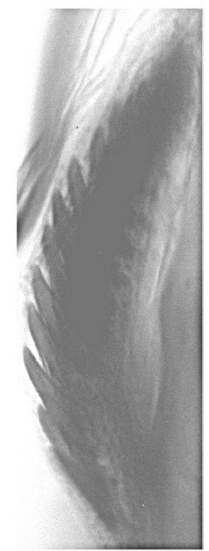

135

Figs 123-137: Lathrobium biseriatum (123-129) and L. bifasciatum (130-137): male sternite VII (123, 130); male sternite VIII (124, 131); aedeagus in lateral and in ventral view (125-126, 132-133); internal structures of aedeagus in lateral view (127, 135); female sternite VIII $(128,136)$; female tergites IX-X $(129,137)$; internal structures of aedeagus in ventral view (134). Scale bars: 123-126, 128-133, 136-137: $0.5 \mathrm{~mm} ; 127,134-135: 0.1 \mathrm{~mm}$. 
2 우: “CHINA N Yunnan, Xue Shan nr. Zhongdian $3900 \mathrm{~m}, 25 . \mathrm{VI} .199627^{\circ} 49 \mathrm{~N} 99^{\circ} 34 \mathrm{E}$ C41 / collected by A. Smetana, J. Farkač and P. Kabátek" (cSme, cAss); $30^{\star} o^{\star}$, 2 우 우 [1 teneral]: same data, but "3800 m ... 26.VI.1996 ... C43" (cSme, cAss).

\section{Etymology:}

The specific epithet (Latin, adjective) alludes to the pair of compact series of spines in the internal sac of the aedeagus.

\section{Description:}

Microsculpture of pronotum extremely shallow or completely obsolete. Other external characters as in L. acutapicale.

$0^{\star}$ : sternites III-VI unmodified; sternite VII (Fig. 123) moderately transverse and with distinct postero-median impression, this impression with moderately dense and moderately modified black setae, posterior margin broadly and weakly concave, in the middle slightly more distinctly concave; sternite VIII (Fig. 124) moderately transverse, oblong median impression (including midline) with weakly modified dark setae; posterior excision small and very shallow; aedeagus (Figs 125-126) 0.90 $0.95 \mathrm{~mm}$ long; ventral process apically acute, ventral margin bisinuate in lateral view; apical portion of dorsal plate moderately long, moderately sclerotized, and somewhat convex in cross-section; basal portion of dorsal plate short and very weakly sclerotized; internal sac with pair of relatively long series of numerous distinctly sclerotized spines (Fig. 127).

i : sternite VIII (Fig. 128) approximately $0.8 \mathrm{~mm}$ long, very weakly oblong and with moderately convex posterior margin; tergite IX (Fig. 129) with moderately short antero-median portion and moderately long posterolateral processes, antero-median portion with median suture; tergite X (Fig. 129) evenly and relatively weakly convex in cross-section, approximately three times as long as antero-median portion of tergite IX.

\section{Comparative notes:}

Lathrobium biseriatum belongs to the L.acutapicale subgroup, as can be inferred both from the similar sexual characters and from the similar external morphology (small eyes with approximately 25 relatively large ommatidia; presence of shallow traces of microsculpture on the pronotum; small body size). Among the species of this group, it is evidently most closely related to L. bifasciatum, with which it shares the presence of two series of strongly sclerotized spines in the internal sac of the aedeagus, the very shallow posterior excision of the male sternite VIII, and the similar morphology of the female tergites IX and X. Lathrobium biseriatum differs from other species of the L. acutapicale subgroup particularly by the shape of the ventral process of the aedeagus (ventral margin bisinuate in lateral view), the long and distinctly sclerotized series of spines in the internal sac of the aedeagus, and the weakly oblong female sternite VIII.

\section{Distribution and natural history:}

The species is probably endemic to the Xue Shan range to the south of Zhongdian, where it was found near the Shika Shan and the Zhujiemu Shan (Map 4). The specimens were sifted from leaf litter in mixed forests at altitudes of 3675-3900 m, in some localities together with L. fortehamatum. Some of the specimens collected in June are teneral.

\subsubsection{Lathrobium bifasciatum sp. $\mathrm{n}$. (Figs 130-137, Map 4)}

\section{Type material:}

Holotype $0^{*}$ : "CHINA: N-Yunnan Zhongdian [today: Shangri-La] Co. $51 \mathrm{~km}$ SSE Zhongdian $27^{\circ} 25.3^{\prime} \mathrm{N}$ 9956.5'E $2970 \mathrm{~m}$ 26.VIII.2003 A. Smetana [C123] / Holotypus ơ Lathrobium bifasciatum sp. n. det. V. Assing 2013" (cAss). Paratypes: 1 ơ, 2 ㅇ 우 [2 teneral]: “CHINA (N-Yunnan) Zhongdian Co., $51 \mathrm{~km}$ SSE Zhongdian, $2970 \mathrm{~m}, 27^{\circ} 25.3^{\prime} \mathrm{N} 99^{\circ} 56.5^{\prime} \mathrm{E}$ (creek valley, mixed conif. forest with shrubby veget., bamboo) 16.VIII.2003 Wrase [04]" (cSch, cAss).

\section{Etymology:}

The specific epithet (Latin, adjective: with two bundles) alludes to the pair of compact series of spines in the internal sac of the aedeagus.

\section{Description:}

Small and slender species; body length $5.0-5.7 \mathrm{~mm}$; length of forebody $2.4-2.5 \mathrm{~mm}$. Head weakly oblong, approximately 1.05 times as long as broad. Pronotum approximately 1.25 times as long as broad. Tergite VIII with sexual dimorphism. Other external characters as in L. acutapicale.

$\sigma^{*}$ : posterior margin of tergite VIII weakly, obtusely pointed in the middle; sternites III-VI unmodified; sternite VII (Fig. 130) relatively weakly transverse and with oblong median impression, this impression with rather sparse and moderately modified black setae, posterior margin broadly and weakly concave, in the middle slightly more distinctly concave; sternite VIII (Fig. 131) weakly transverse and with oblong impression, this impression with moderately modified dark setae on either side of the non-pubescent middle, posterior excision conspicuously small and shallow; aedeagus (Figs 132-133) approximately $0.9 \mathrm{~mm}$ long and symmetric; ventral process weakly curved in lateral view; dorsal plate with lamellate, relatively short, sinuate (lateral view), and apically acute (dorsal view) apical portion, and with very short, very weakly sclerotized basal por- 
tion; internal sac with pair of compact series of numerous distinctly sclerotized spines (Figs 134-135).

क: posterior margin of tergite VIII somewhat produced and distinctly angled in the middle; sternite VIII (Fig. 136) approximately $0.8 \mathrm{~mm}$ long, distinctly oblong and with strongly convex posterior margin; tergite IX (Fig. 137) with moderately short antero-median portion and moderately long postero-lateral processes, anteromedian portion with median suture; tergite X (Fig. 137) evenly and moderately convex in cross-section, approximately three times as long as antero-median portion of tergite IX.

\section{Comparative notes:}

Lathrobium bifasciatum clearly belongs to the L. acutapicale subgroup, as is suggested not only by the similar sexual characters, but also by the similar external morphology (small eyes with approximately 25 relatively large ommatidia; presence of shallow traces of microsculpture on the pronotum; small body size). It is distinguished from other species of this group by the morphology of the aedeagus (shapes of ventral process and of internal structures), the shapes and chaetotaxy of the male sternites VII and VIII, and by the shapes of the female tergites IX and $\mathrm{X}$.

\section{Distribution and natural history:}

The type locality is situated near the Shanshenmiaohou Shan in a mountain range to the south-southeast of Zhongdian (Map 4). The specimens were sifted from leaf litter in a mixed coniferous forest at an altitude of nearly $3000 \mathrm{~m}$. Two of the four specimens are teneral.

\subsubsection{Lathrobium reticolle sp. n. (Figs 138-142, Map 4)}

\section{Type material:}

Holotype ơ: "CHINA, Yunnan, Haba Shan, N27 $21^{\prime} 42^{\prime}$, E10006'20", 24.vi.2012, 3508 m, sift30, V. Grebennikov / Holotypus ơ Lathrobium reticolle sp. n. det. V. Assing 2013" (CAS). Paratypes: $3 \sigma^{\star} \sigma^{\star}$ : same data as holotype (CAS, Sme, cAss).

\section{Etymology:}

The specific epithet (Latin, adjective: with reticulate pronotum) alludes to the presence of shallow microsculpture on the pronotum.

\section{Description:}

Small species; body length 4.8-5.7 $\mathrm{mm}$; length of forebody 2.3-2.6 mm. Habitus as in Fig. 138. Coloration: body brown to dark-brown; legs and antennae reddish.

Head (Fig. 139) distinctly oblong, 1.05-1.10 times as long as broad; punctation moderately coarse and moderately dense, sparser in median dorsal portion; interstices with distinct microreticulation. Eyes small, approximately 0.25 times as long as postocular region and composed of approximately 15 relatively large ommatidia. Antenna short and stout, approximately $1.4 \mathrm{~mm}$ long; antennomeres V-X noticeably transverse.

Pronotum (Fig. 139) approximately 1.25 times as long as broad and about as broad as head, lateral margins conspicuously straight and parallel; punctation rather dense and coarse, somewhat coarser than that of head; impunctate midline moderately broad; interstices with very shallow microreticulation at least in anterior, posterior, and lateral portions.

Elytra (Fig. 139) approximately 0.55 times as long as pronotum; punctation rather sparse and shallow. Hind wings completely reduced.

Abdomen 1.10-1.15 times as broad as elytra; punctation moderately dense and moderately fine; interstices with shallow microsculpture; posterior margin of tergite VII without palisade fringe; posterior margin of tergite VIII weakly convex to indistinctly pointed in the middle.

$\sigma^{\text {* }}$ : sternites III-VI unmodified; sternite VII (Fig. 140) distinctly transverse and with sparse, not distinctly modified pubescence, posterior margin broadly and weakly concave; sternite VIII (Fig. 141) weakly transverse, pubescence not distinctly modified, in posterior median portion with small semi-transparent area, posterior margin distinctly convex, without median excision; aedeagus (Fig. 142) approximately $0.7 \mathrm{~mm}$ long and symmetric; ventral process stout and laterally compressed; apical portion of dorsal plate short, lamellate, distinctly sclerotized, of subtriangular shape, and apically acute, basal portion of dorsal plate reduced, unsclerotized, barely noticeable; internal sac with pair of needle-shaped, moderately long, and distinctly sclerotized spines.

ㅇ: unknown.

\section{Comparative notes:}

The presence of shallow microsculpture on the pronotum, as well as the similar external characters suggest that $L$. reticolle belongs to the L. acutapicale subgroup, although it is distinguished from other representatives of this lineage by a rather different morphology of the aedeagus (short and laterally compressed ventral process, presence of a pair of spines (not series of spines) in the internal sac), and the absence of a posterior excision of the male sternite VIII.

\section{Distribution and natural history:}

The type locality is situated in Haba Shan (Map 4). The specimens were sifted from litter at an altitude of approximately $3500 \mathrm{~m}$. 
4.1.6 The L. puetzi subgroup

4.1.6.1 Lathrobium puetzi sp. $\mathrm{n}$.

(Figs 143-151, Map 4)
Type material:

Holotype $0^{7}$ : "CHINA: Yunnan [CH07-30], Nujiang Lisu Aut. Pref., Nu Shan, $7 \mathrm{~km}$ NNW Coajian [= Caojian], $25^{\circ} 43^{\prime} 29^{\prime \prime} \mathrm{N}, 99^{\circ} 07^{\prime} 57^{\prime \prime} \mathrm{E}, 2420 \mathrm{~m}$, second. pine forest with shrubs, litter, bark sifted, 11.VI.2007, leg. A. Pütz / Holo-

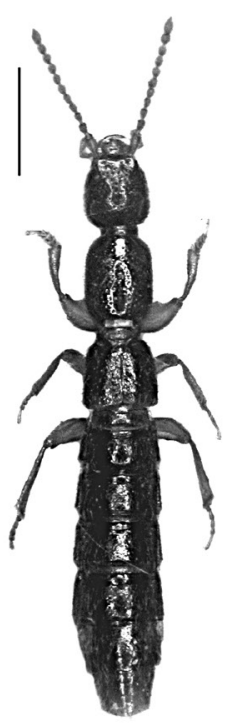

138

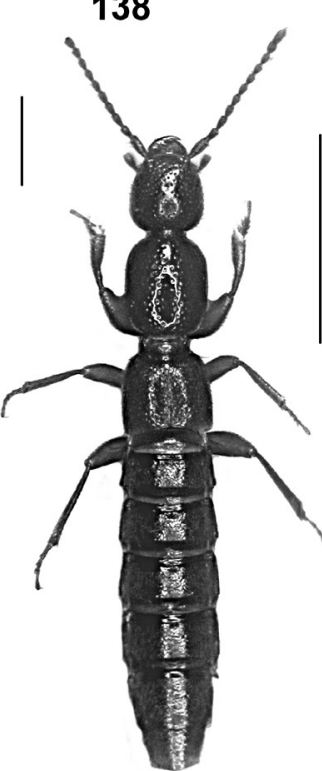

143

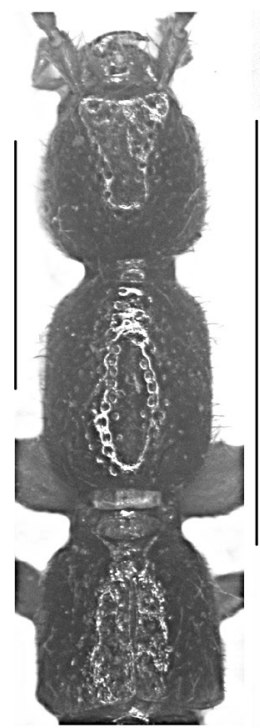

139

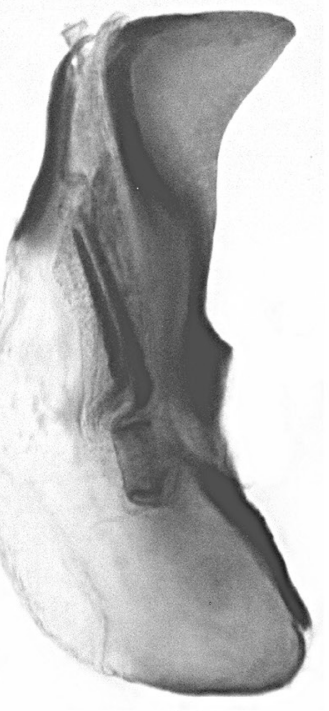

142
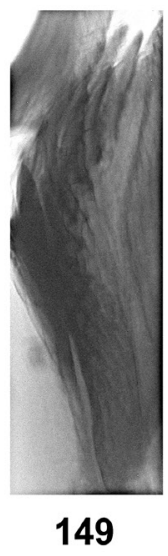

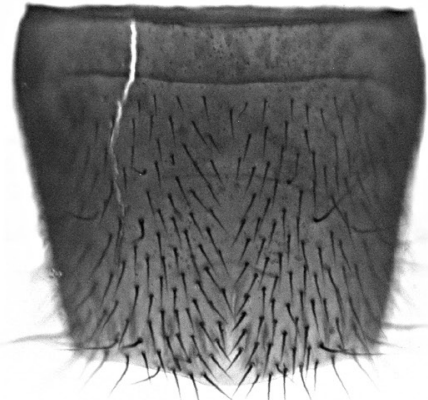

141
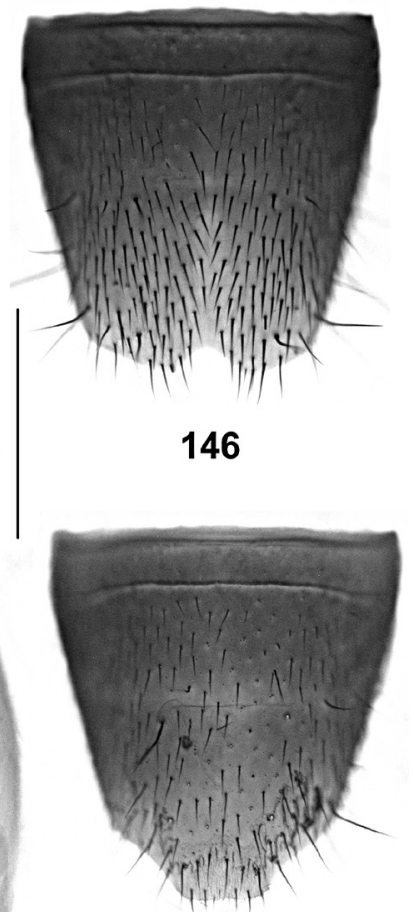

150

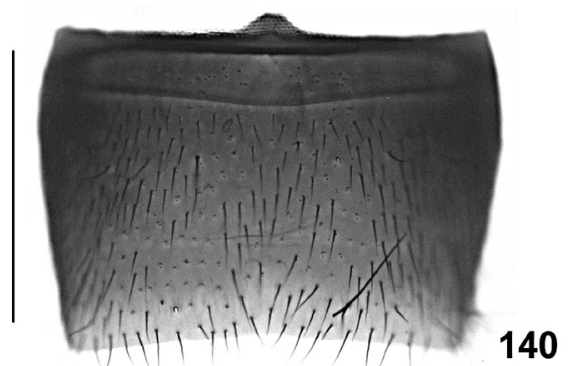

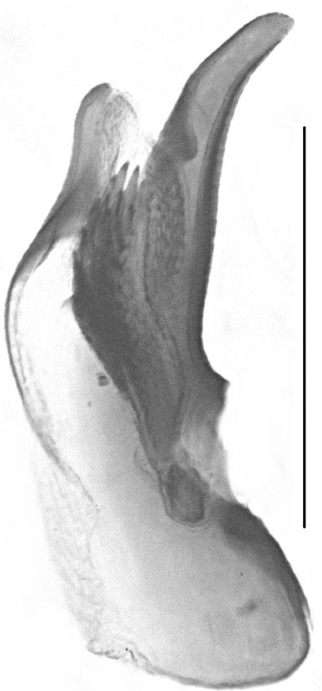

147

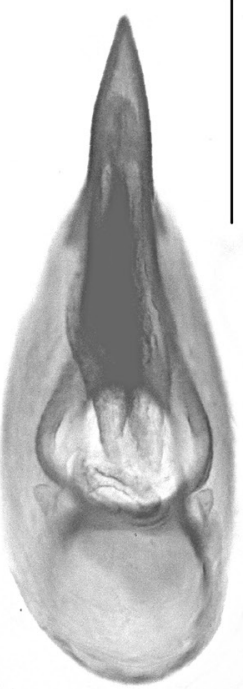

148

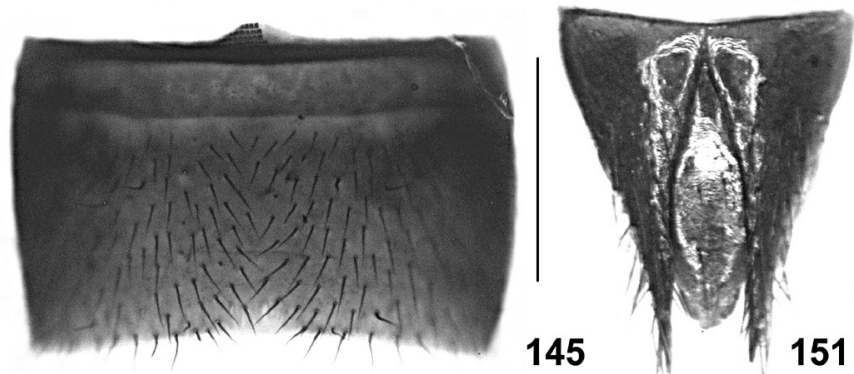

Figs 138-151: Lathrobium reticolle (138-142) and L. puetzi (143-151): habitus (138, 143); forebody (139, 144); male sternite VII $(140,145)$; male sternite VIII $(141,146)$; aedeagus in lateral and in ventral view $(142,147-148)$; internal structures of aedeagus in lateral view (149); female sternite VIII (150); female tergites IX-X (151). Scale bars: 138-139, 143-144: 1.0 mm; 140-142, 145-148, 150-151: $0.5 \mathrm{~mm}$; 149: $0.1 \mathrm{~mm}$. 
typus o Lathrobium puetzi sp. n. det. V. Assing 2013” (cAss). Paratypes: 1 \% : same data as holotype (cPüt).

\section{Etymology:}

This species is dedicated to Andreas Pütz, specialist of Byrrhidae, who collected the type specimens.

\section{Description:}

Relatively small species; body length 6.8-7.5 mm; length of forebody $3.0-3.3 \mathrm{~mm}$. Habitus as in Fig 143. Coloration: body dark-brown to blackish-brown; legs and antennae dark-reddish.

Head (Fig. 144) approximately as broad as long or weakly oblong; punctation moderately coarse and moderately dense, sparser in median dorsal portion; interstices with distinct microreticulation. Eyes moderately small, approximately $0.35-0.40$ times as long as postocular region and composed of approximately 50 small ommatidia. Antenna 1.7-1.9 mm long; antennomeres VI-X weakly oblong or as long as broad.

Pronotum (Fig. 144) approximately 1.2 times as long as broad and approximately 1.1 times as broad as head, punctation similar to that of head; impunctate midline rather narrow; interstices without microreticulation.

Elytra (Fig. 144) approximately 0.55 times as long as pronotum; punctation dense, shallow, and weakly defined. Hind wings completely reduced. Protarsomeres I-IV with moderately pronounced sexual dimorphism.

Abdomen 1.05-1.10 times as broad as elytra; punctation moderately dense and fine; interstices with shallow microsculpture; posterior margin of tergite VII without palisade fringe; posterior margin of tergite VIII weakly angled in the middle, without sexual dimorphism.

$0^{*}$ : sternites III-VI unmodified; sternite VII (Fig. 145) moderately transverse and with sparse unmodified pubescence, posterior margin broadly and weakly concave; sternite VIII (Fig. 146) nearly as long as broad and with oblong median impression, pubescence weakly modified in posterior half, posterior excision distinct, but small and not very deep; aedeagus (Figs 147-148) small in relation to body size, $0.85 \mathrm{~mm}$ long and symmetric; ventral process smoothly curved and moderately slender; apical portion of dorsal plate moderately long, lamellate, moderately sclerotized, and apically convex in cross-section, basal portion of dorsal plate approximately as long as apical portion, fine, and weakly sclerotized; internal sac with pair of moderately long series of moderately sclerotized spines (Fig. 149).

o : sternite VIII (Fig. 150) $0.9 \mathrm{~mm}$ long and approximately as long as broad, posterior margin distinctly produced and somewhat truncate in the middle; tergite IX (Fig. 151) with very short antero-median portion and moderately long postero-lateral processes, anteromedian portion with suture; tergite $X$ (Fig. 151) flat (cross-section) and approximately seven times as long as tergite IX.

\section{Comparative notes:}

The male and female sexual characters, above all the morphology of the aedeagus (shape of ventral process, dorsal plate, and internal structures) somewhat resemble those of the L. acutapicale subgroup, from which L. puetzi is distinguished by several external characters such as the larger body size, larger eyes, longer and more slender antennae, and a pronotum with weakly convex lateral margins in dorsal view.

\section{Distribution and natural history:}

The type locality is situated in the southern $\mathrm{Nu}$ Shan range, to the north of Caojian (Map 4). The specimens were sifted from leaf litter in a secondary pine forest with shrubs at an altitude of $2420 \mathrm{~m}$, together with L. nuicum and an unnamed, probably undescribed species.

\subsubsection{The L. rectissimum subgroup}

\subsubsection{Lathrobium rectissimum sp. $\mathrm{n}$. (Figs 152-159, Map 5)}

\section{Type material:}

Holotype ơ: "CHINA: Yunnan [CH07-28A], Nujiang Lisu Aut. Pref., Gaoligong Shan, side valley $19 \mathrm{~km}$ NW Liuku, $25^{\circ} 59^{\prime} 02^{\prime \prime} \mathrm{N}, 98^{\circ} 42^{\prime} 23^{\prime \prime} \mathrm{E}, 2730 \mathrm{~m}$, devast. prim. for., litter sifted, 10.VI.2007, M. Schülke / Holotypus ơ Lathrobium rectissimum sp. n. det. V. Assing 2013" (cSch). Paratypes: $10^{\top}$ : same data as holotype (cAss); $10^{\star}, 1$ 우 same data, but "[CH07-28] ... 9.VI.2007" (cSch); 4 o o $0^{*}$, 3 우 우 [2 teneral]: "CHINA: Yunnan, Nujiang Lisu Pref.,

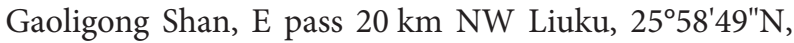
$98^{\circ} 41^{\prime} 48^{\prime \prime E}, 3000 \mathrm{~m}$, creek valley with devast. prim. forest, litter \& moss sifted, 3.IX.2009, leg. M. Schülke [CH0925]" (cSch, cAss); 2 o $^{\star}$ o $^{\star}, 3$ ㅇ ㅇ [ 2 teneral]: same data, but leg. Wrase (cSch, cAss).

\section{Etymology:}

The specific epithet (superlative of the Latin adjective rectus: straight) alludes to the conspicuously long and straight ventral process of the aedeagus.

\section{Description:}

Species of moderately small size and slender habitus (Fig. 152); body length 6.5-8.0 mm; length of forebody 2.9-3.3 mm. Coloration: body reddish-brown; legs and antennae reddish.

Head (Fig. 153) approximately as long as broad or weakly oblong; punctation moderately coarse and relatively 
sparse; interstices with fine and extremely shallow, barely noticeable microsculpture. Eyes relatively small, 0.250.30 times as long as postocular region in dorsal view and composed of 25-30 ommatidia. Antenna 1.7-1.9 mm long.
Pronotum (Fig. 153) approximately 1.2 times as long as broad and 1.05-1.10 times as broad as head, distinctly tapering posteriad, widest at anterior angles; punctation similar to that of head, relatively sparse; impunctate midline rather broad; interstices without microsculpture.

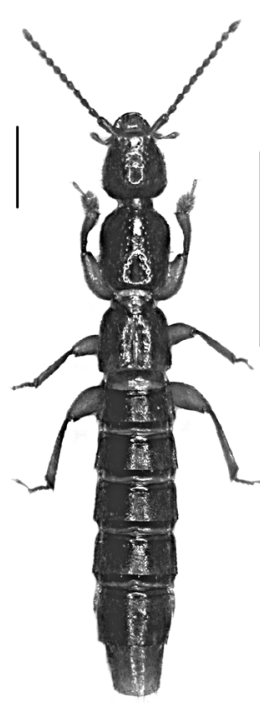

152

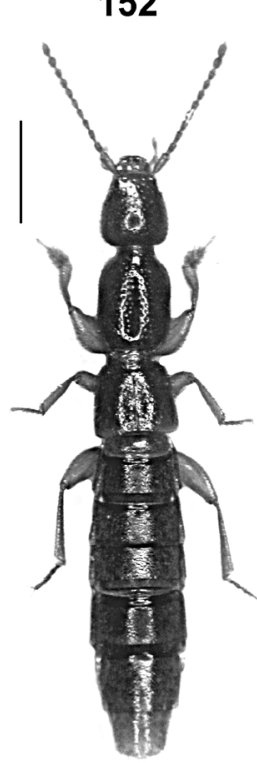

160

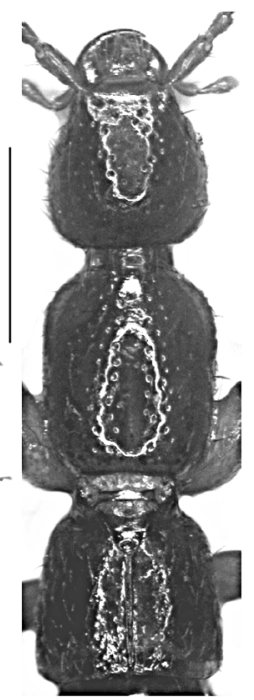

153

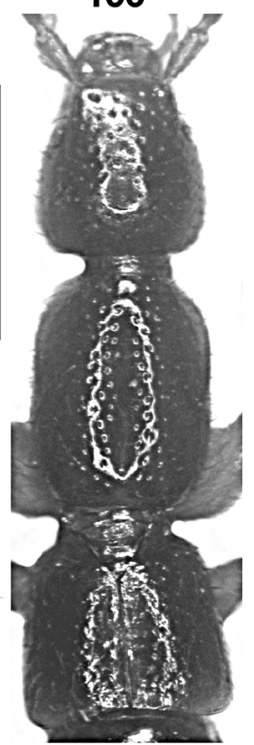

161

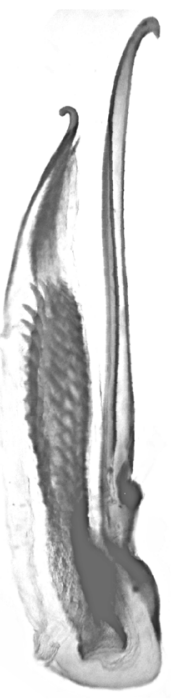

156

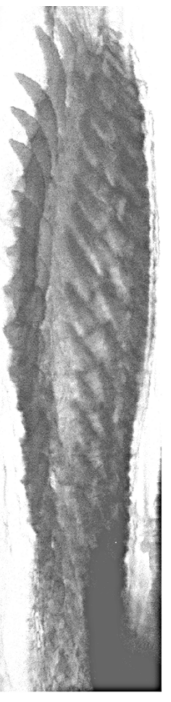

157
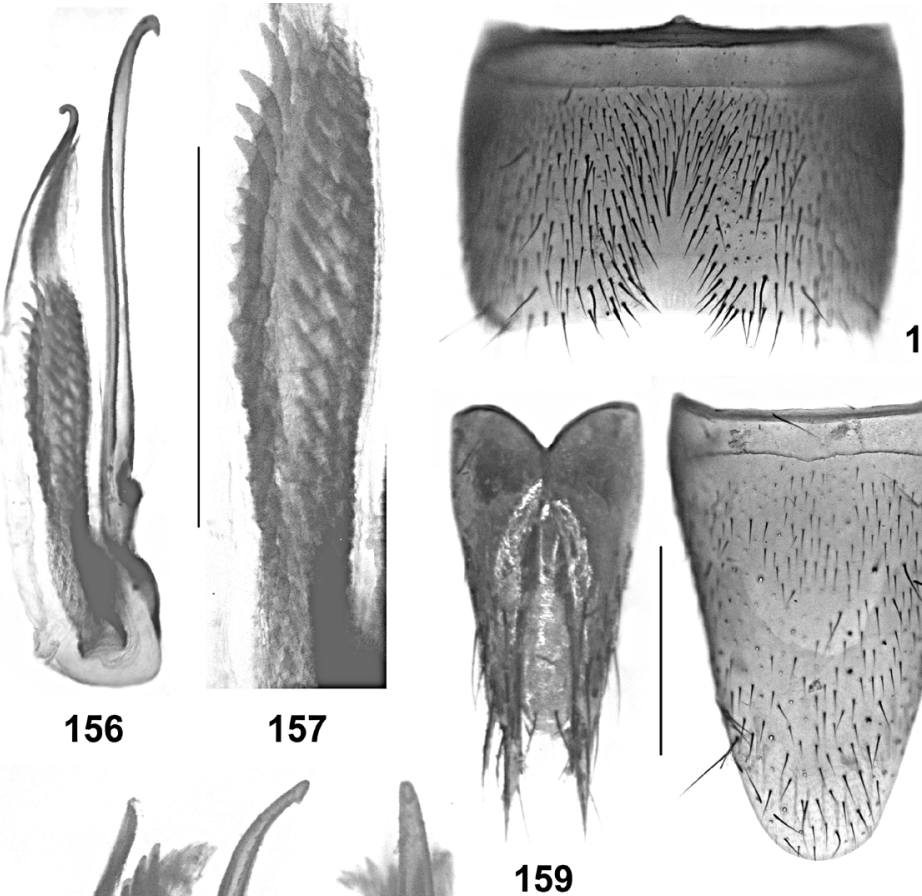

154

159

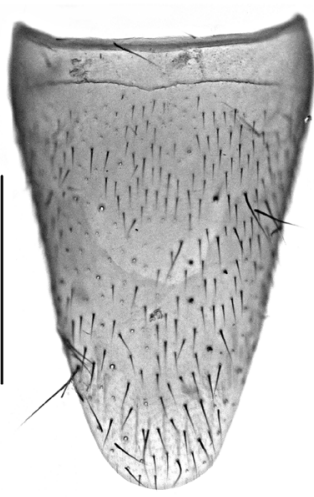

158

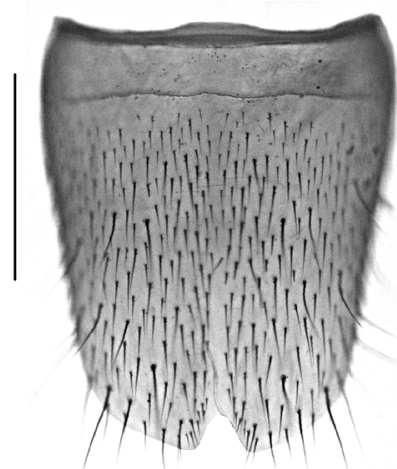

155

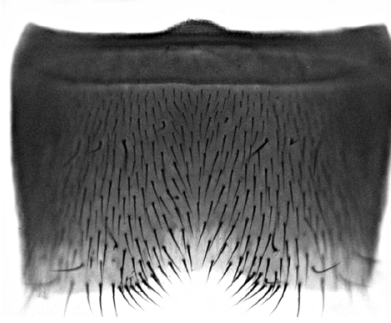

162

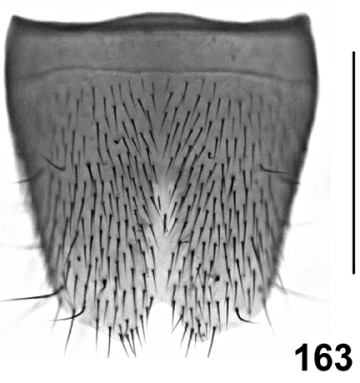

163

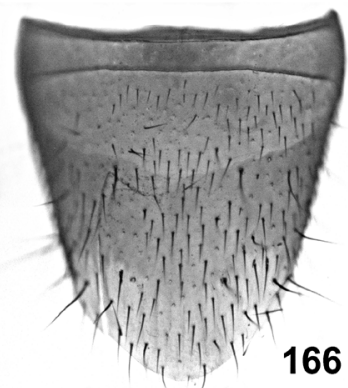

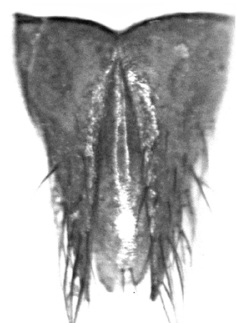

167

Figs 152-167: Lathrobium rectissimum (152-159) and L. xiei (160-167): habitus (152, 160); forebody (153, 161); male sternite VII (154, $162)$; male sternite VIII $(155,163)$; aedeagus in lateral and in ventral view $(156,164-165)$; internal structures of aedeagus in lateral view (157); female sternite VIII (158, 166); female tergites IX-X (159, 167). Scale bars: 152-153, 160-161: 1.0 mm; 154-159, 162-167: 0.5 mm. 
Elytra (Fig. 153) approximately $0.55-0.58$ times as long as pronotum; punctation fine, shallow, and rather sparse. Hind wings completely reduced. Protarsomeres I-IV with pronounced sexual dimorphism.

Abdomen slender, approximately 1.15 times as broad as elytra; punctation fine and very dense; interstices with shallow microsculpture; posterior margin of tergite VII without palisade fringe; tergite VIII with pronounced sexual dimorphism.

$0^{\star}$ : protarsomeres I-IV strongly dilated; posterior margin of tergite VIII weakly convex; sternites III-VI unmodified; sternite VII (Fig. 154) moderately transverse, symmetric, with moderately extensive postero-median impression, this impression with weakly modified black setae at the margins and without setae in the middle, posterior margin weakly concave; sternite VIII (Fig. 155) distinctly oblong, approximately 1.15 times as long as broad, middle narrowly without setae in posterior half, pubescence otherwise not distinctly modified, posterior margin distinctly convex, posterior excision small and V-shaped; aedeagus conspicuously long and slender (Fig. 156), approximately $2.0 \mathrm{~mm}$ long, and symmetric; ventral process remarkably long, straight, slender, and apically hooked in lateral view; dorsal plate with moderately long, lamellate, and apically hooked (lateral view) apical portion and with indistinct, strongly reduced basal portion; internal sac with pair of long series of numerous short and moderately sclerotized spines (Fig. 157).

ㅇ: protarsomeres I-IV moderately dilated, distinctly less so than in male; tergite VIII strongly and convexly produced posteriorly; sternite VIII (Fig. 158) approximately $1.1 \mathrm{~mm}$ long, strongly oblong, gradually tapering posteriad, and posteriorly strongly convex; tergite IX (Fig. 159) with short antero-median portion and long, slender postero-lateral processes, antero-median portion with median suture; tergite X (Fig. 159) almost flat, strongly oblong, and more than four times as long as anteromedian portion of tergite IX.

\section{Comparative notes:}

This species is distinguished from its congeners particularly by the conspicuous morphology of the aedeagus, the shape and chaetotaxy of the male sternite VIII, the pronounced sexual dimorphism of the protarsomeres I-IV and of tergite VIII, the conspicuously oblong female sternite VIII, and the long and slender female tergites IX and X. In addition, it is characterized by its slender habitus, the posteriorly tapering pronotum, the reddish-brown coloration, and the chaetotaxy of the male sternite VII. Based on the morphology of the aedeagus, this species may be allied to L. baihualingense WATANABE \& XIAO, 2000, which too is known only from the Gaoligong Shan.

\section{Distribution and natural history:}

The species was found in two geographically close localities in the Gaoligong Shan, to the northwest of Liuku (Map 5). The specimens were sifted from leaf litter in degraded primary forests at altitudes of 2730 and $3000 \mathrm{~m}$. Four specimens collected in the beginning of September are teneral.

\subsubsection{Lathrobium xiei WaTANABE \& XIA0, 2000 (Figs 160-167, Map 5)}

\section{Material examined:}

China: Yunnan: $4 o^{\star} \sigma^{\star}, 5$ 우 + , Baoshan Pref., Gaoligong Shan, $29 \mathrm{~km}$ ESE Tengchong, 24 $4^{\circ} 55^{\prime} 37^{\prime \prime} \mathrm{N}, 98^{\circ} 45^{\prime} 09^{\prime \prime} \mathrm{E}$, $2350 \mathrm{~m}$, degraded deciduous forest, litter sifted, 1.VI. 2007, leg. Pütz, Schülke, Wrase (cPüt, cSch, cAss); 1 ㅇ, Baoshan Pref., Gaoligong Shan, W pass $35 \mathrm{~km}$ SE Tengchong, $24^{\circ} 50^{\prime} 18^{\prime \prime} \mathrm{N}, 98^{\circ} 45^{\prime} 43^{\prime \prime} \mathrm{E}, 2100 \mathrm{~m}$, degraded primary deciduous forest, litter sifted, 25.-28.VIII.2009, leg. Wrase (cSch); 2 우 우 [1 teneral], Baoshan Pref., Gaoligong Shan, $32 \mathrm{~km}$ SE Tengchong, 24ำ $51-53^{\prime} \mathrm{N}, 9^{\circ} 45^{\prime} \mathrm{E}, 2150-$ $2250 \mathrm{~m}$, degraded primary and secondary forests, litter sifted, 26.VIII.2009, leg. Schülke (cSch); $10^{\star}$, Baoshan Pref., Gaoligong Shan, 31 km SE Tengchong, $24^{\circ} 53^{\prime} 11^{\prime \prime} \mathrm{N}$, $98^{\circ} 45^{\prime} 22^{\prime} \mathrm{E}, 2200-2250 \mathrm{~m}$, pasture in secondary forest, 26.VIII.2009, leg. Wrase (cAss).

\section{Comment:}

The original description is based on four type specimens, two males and two females, from "Dabei, Gaoligong Shan Mts., Tengchong Xian” (WATAnabe \& XiaO 2000). The illustration of the aedeagus provided in the original description is apparently somewhat inaccurate.

\section{Redescription:}

Species of rather small size; body length 5.0-6.8 mm; length of forebody $2.5-2.8 \mathrm{~mm}$. Tergite VIII without sexual dimorphism, posterior margin weakly angled in the middle. Other external characters (Figs 160-161) as in L. rectissimum.

$\mathrm{o}^{\star}$ : protarsomeres I-IV strongly dilated; sternites III-VI unmodified; sternite VII (Fig. 162) moderately transverse, symmetric, with moderately extensive posteromedian impression, posterior margin with shallow concavity in the middle, on either side of this concavity with ill-defined cluster of denser setae; sternite VIII (Fig. 163) approximately as long as broad, pubescence not distinctly modified, middle of sternite narrowly without setae in posterior half, posterior excision distinct, but relatively small; aedeagus (Figs 164-165) approximately $1.0 \mathrm{~mm}$ long, symmetric, with long, slender, and apically hooked ventral process; apical portion of dorsal plate almost flat, distinctly sclerotized, weakly curved in lateral view, and moderately long, basal portion approximately as long as apical portion, lamellate, and weakly sclero- 
tized; internal sac with a pair of basal series composed of numerous distinctly sclerotized spines and an additional apical series of spines.

ㅇ: protarsomeres I-IV moderately dilated, distinctly less so than in male; sternite VIII (Fig. 166) approximately $0.8 \mathrm{~mm}$ long, very weakly oblong, gradually tapering posteriad, and posteriorly strongly convex; tergite IX (Fig. 167) with very short antero-median portion and moderately long, slender postero-lateral processes, antero-median portion with median suture; tergite $\mathrm{X}$ (Fig. 167) weakly convex, approximately ten times as long as antero-median portion of tergite IX.

\section{Comparative notes:}

This species appears to be closely allied to L. rectissimum, a conclusion not only supported by the similar external morphology and coloration, but also by the pronounced sexual dimorphism of the protarsi, the similar shapes and chaetotaxy of the male sternites VII and VIII, the similar general morphology of the aedeagus (long, slender, and not distinctly curved ventral process; presence of series of distinctly sclerotized spines in internal sac), and by the shape of the female tergite IX. It is distinguished from L. rectissimum by smaller body size, the absence of a sexual dimorphism of tergite VIII, the shape and chaetotaxy of the male sternite VII, the shorter and posteriorly more distinctly excised male sternite VIII, the much shorter aedeagus with a differently shaped ventral process, dorsal plate, and internal structures, the much less oblong female sternite VIII, and the much less slender female tergites IX and $\mathrm{X}$.

\section{Distribution and natural history:}

The species is known from several geographically close localities in the Gaoligong Shan, to the southeast and east-southeast of Tengchong (Map 5). The examined specimens were sifted from leaf litter in degraded deciduous forests at altitudes of 2100-2350 m. One specimen collected in August is teneral.

\subsubsection{The L. fortehamatum subgroup}

\subsubsection{Lathrobium fortehamatum sp. $\mathrm{n}$. (Figs 168-174, Map 5)}

\section{Type material:}

Holotype $0^{\star}$ : “CHINA: N-Yunnan [C2005-05], Diqing Tibet Aut. Pref., Zhongdian [today: Shangri-La] Co., Xue Shan near lake $23 \mathrm{~km} \mathrm{~S}$ Zhongdian, $3895 \mathrm{~m} / 27^{\circ} 37.1^{\prime} \mathrm{N}$, $99^{\circ} 38.5^{\prime} \mathrm{E}$, devast. mixed forest, meadows, lake border, leaf litter, dead wood sifted, 5.VI.2005, leg. M. Schülke [C2005-05] / Holotypus o Lathrobium fortehamatum sp. n. det. V. Assing 2013" (cSch). Paratypes: $2 o^{\star} o^{\star}$ : same data as holotype (cSch, cAss); $10^{\star}, 2$ 우: same data, but
“[C2005-05A] ... 6.VI.2005” (cSch, cAss); 1 o", 2 우 우 "CHINA: N-Yunnan, Diqing Tibet Aut. Pr. Zhongdian Co. Xue Shan near lake, $23 \mathrm{~km}$ S Zhongdian, $27^{\circ} 37.1^{\prime} \mathrm{N}$, 99³8.5'E 3895 m, 5.VI.2005 A. Smetana [C152]" (cSme, cAss); 1 ㅇ: same data, but “15.VI.2005 ... [C161]” (cSme).

\section{Etymology:}

The specific epithet (Latin, adjective) alludes to the assortment of large and hook-like internal spines of the aedeagus.

\section{Description:}

Relatively small species; body length 5.1-7.2 mm; length of forebody 2.8-3.1 mm. Habitus as in Fig. 168. Coloration: body reddish; legs reddish-yellow; antennae reddish.

Head (Fig. 169) approximately 1.05 times as long as broad; punctation rather coarse and moderately dense, sparser in median dorsal portion; interstices with distinct microreticulation. Eyes very small and without pigmentation, smaller than antennomere $\mathrm{V}$ in cross-section and composed of approximately 10 weakly defined ommatidia. Antenna short and rather stout, approximately 1.6$1.7 \mathrm{~mm}$ long; antennomeres $\mathrm{V}$-X approximately as long as broad.

Pronotum (Fig. 169) slender, approximately 1.3 times as long as broad and about as broad as head; punctation similar to that of head, but somewhat denser; impunctate midline moderately broad; interstices without microreticulation.

Elytra (Fig. 169) approximately 0.6 times as long as pronotum; punctation very shallow and ill-defined. Hind wings completely reduced. Protarsomeres I-IV with pronounced sexual dimorphism.

Abdomen 1.10-1.15 times as broad as elytra; punctation moderately dense and fine; interstices with shallow microsculpture; posterior margin of tergite VII without palisade fringe; posterior margin of tergite VIII without distinct sexual dimorphism, weakly convex to indistinctly pointed in the middle.

$0^{\star}$ : sternites III-VI unmodified; sternite VII (Fig. 170) strongly transverse and with rather extensive median impression, this impression with weakly modified dark setae on either side of middle and anteriorly, without setae in the middle, posterior margin broadly and weakly concave; sternite VIII (Fig. 171) moderately transverse, with very weakly modified pubescence in posteromedian depression, posterior excision distinct and somewhat V-shaped, posterior margin produced on either side of posterior excision; aedeagus (Fig. 172) relatively large in relation to body size, approximately $1.1 \mathrm{~mm}$ long, and symmetric; ventral process curved and apically acute in lateral view; dorsal plate with long, distinctly sclerotized, 
and somewhat convex (cross-section) apical portion, basal portion nearly as long as apical portion and lamellate; internal sac with several large, strongly curved, and strongly sclerotized spines.

ㅇ: sternite VIII (Fig. 173) transverse, posterior margin produced and weakly concave to truncate in the middle; tergite IX (Fig. 174) with moderately short antero-median portion and with moderately slender postero-lateral processes, antero-median portion with median suture; tergite $\mathrm{X}$ (Fig. 174) distinctly convex in cross-section in anterior half and flat in posterior half, approximately three times as long as antero-median portion of tergite IX.

\section{Comparative notes:}

Lathrobium fortehamatum is undoubtedly closely allied to L. tricuspidatum, with which it shares the reddish coloration of the body, the very small eyes with few ommatidia and without pigmentation, the slender pronotum, the shallow punctation of the elytra, and particularly the male and female sexual characters (relatively large aedeagus with several large, curved, and strongly sclerotized internal spines; shapes and chaetotaxy of the male sternites VII and VIII; transverse female sternite VIII of similar shape; similar morphology of the female tergites IX and X). Lathrobium fortehamatum differs from L. tricuspidatum by larger body size, the less transverse male

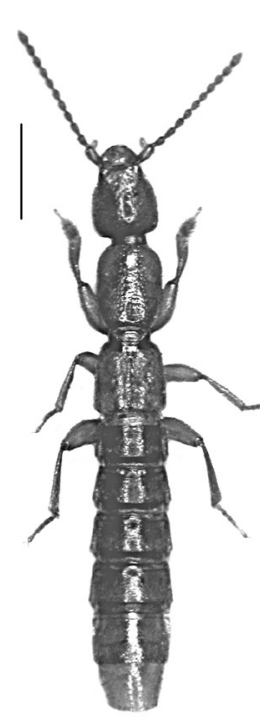

168

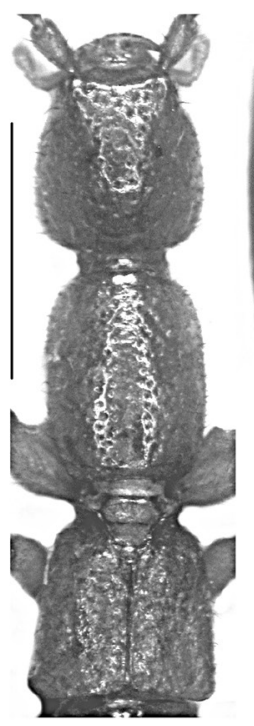

175

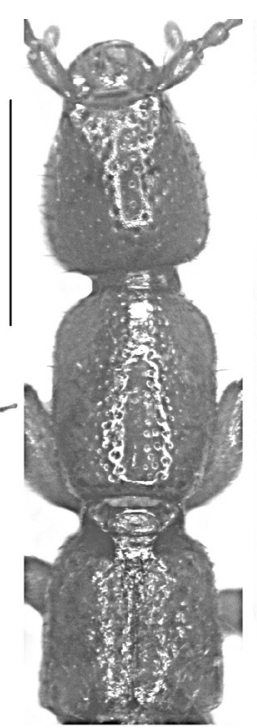

169

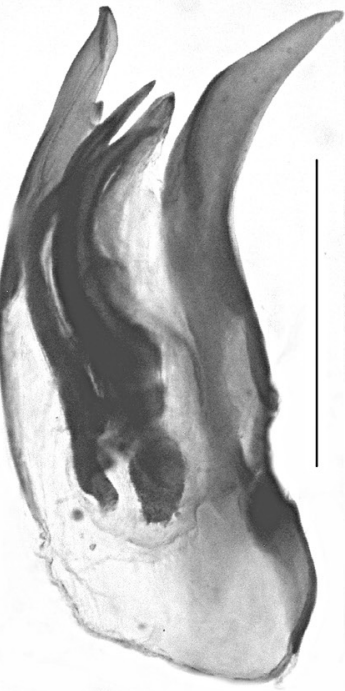

172

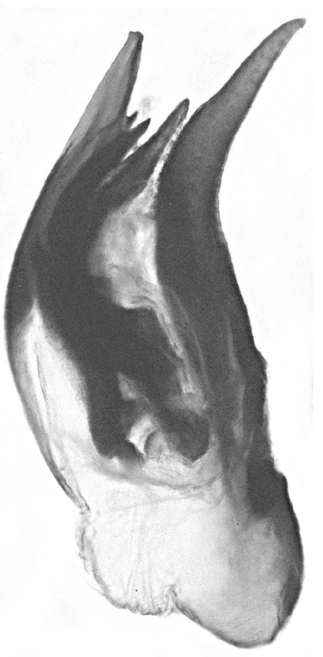

178
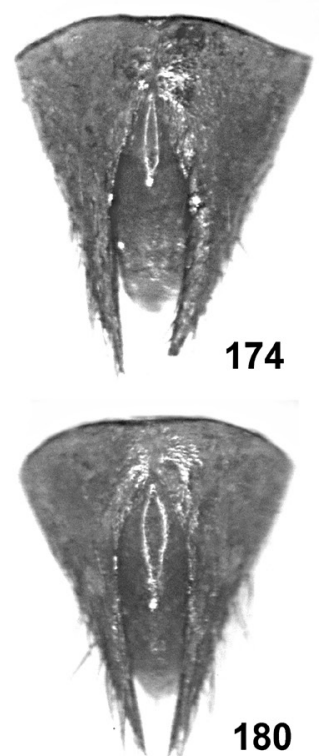

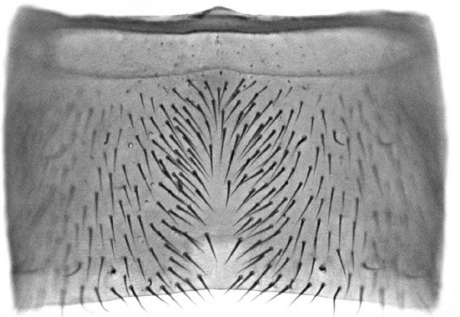

170

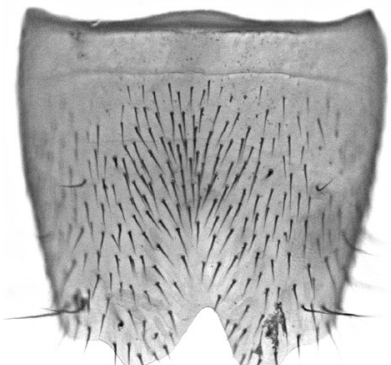

171

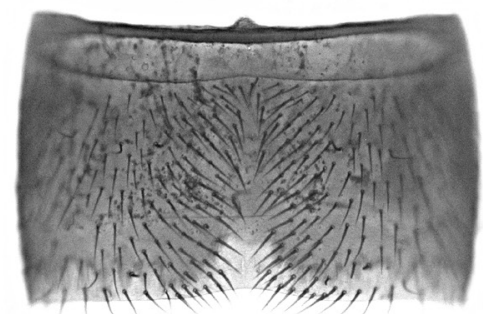

176

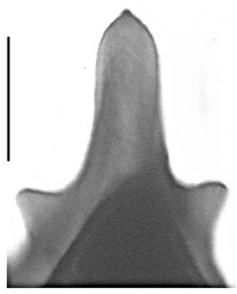

179

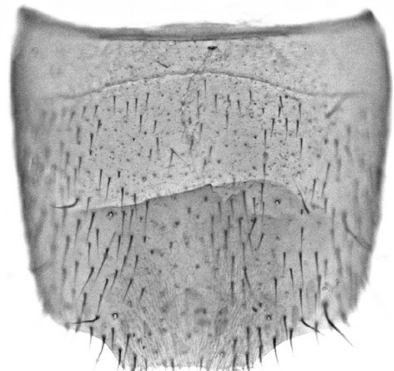

173

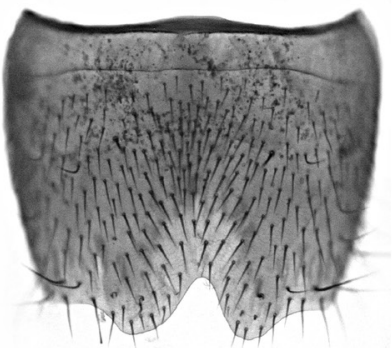

177

Figs 168-180: Lathrobium fortehamatum (168-174) and L.tricuspidatum (175-180): habitus (168); forebody (169, 175); male sternite VII $(170,176)$; male sternite VIII $(171,177)$; aedeagus in lateral view $(172,178)$; female sternite VIII $(173)$; female tergites IX-X $(174,180)$; apical portion of dorsal plate of aedeagus in dorsal view (179). Scale bars: 168-169, $175: 1.0 \mathrm{~mm}$; 170-174, 176-178, 180: $0.5 \mathrm{~mm}$; 179: $0.1 \mathrm{~mm}$. 
sternite VIII, the slightly larger aedeagus with differently shaped ventral process, dorsal plate, and internal structures, the truncate middle of the posterior margin of the female sternite VIII, the longer antero-median portion of the female tergite IX, and the shape of the female tergite $\mathrm{X}$.

\section{Distribution and natural history:}

The type locality is situated in Xue Shan range near Tianchi Lake and Zhujiemu Shan, to the south of Zhongdian (Map 5). The specimens were sifted from leaf litter in a mixed forest at an altitude of nearly $3900 \mathrm{~m}$, together with L. biseriatum.

\subsubsection{Lathrobium tricuspidatum sp. $\mathrm{n}$ (Figs 175-180, Map 5)}

Type material:

Holotype $0^{*}$ : "CHINA, Yunnan, Haba Shan, N2721'01", E10005'44", 21.vi.2012, 4072 m, sift26, V. Grebennikov / Holotypus o Lathrobium tricuspidatum sp. n. det. V. Assing 2013" (CAS). Paratypes + : same data as holotype (cAss).

\section{Etymology:}

The specific epithet (Latin, adjective) alludes to the apically trifid dorsal plate of the aedeagus.

\section{Description:}

Small species; body length 5.3-6.0 mm; length of forebody 2.5-2.6 mm. Coloration: body reddish; legs reddishyellow; antennae reddish.

Head (Fig. 175) distinctly oblong, 1.05-1.10 times as long as broad; punctation rather coarse and dense, only slightly sparser in median dorsal portion; interstices with distinct microreticulation. Eyes very small and without pigmentation, slightly smaller than antennomere $\mathrm{V}$ in cross-section and composed of approximately 10 weakly defined ommatidia. Antenna short and rather stout, approximately $1.4 \mathrm{~mm}$ long; antennomeres IV-VI approximately as long as broad and VII-X weakly transverse.

Pronotum (Fig. 175) slender, approximately 1.3 times as long as broad and 0.95-1.0 times as broad as head; punctation similar to that of head, but even denser; impunctate midline moderately broad; interstices without microreticulation.

Elytra (Fig. 175) approximately 0.55-0.60 times as long as pronotum; punctation rather shallow. Hind wings completely reduced. Protarsomeres I-IV with moderately pronounced sexual dimorphism.

Abdomen 1.10-1.15 times as broad as elytra; punctation moderately dense and fine; interstices with shallow microsculpture; posterior margin of tergite VII without palisade fringe; posterior margin of tergite VIII apparently with sexual dimorphism.

$o^{\star}$ : posterior margin of tergite VIII weakly convex; sternites III-VI unmodified; sternite VII (Fig. 176) strongly transverse and with rather extensive median impression, this impression with weakly modified dark setae on either side of middle, posterior margin broadly and weakly concave; sternite VIII (Fig. 177) moderately transverse, without distinctly modified pubescence, posterior excision distinct and somewhat $\mathrm{V}$-shaped, posterior margin produced on either side of posterior excision; aedeagus (Fig. 178) large in relation to body size, 1.0-1.1 mm long, and symmetric; ventral process curved and apically acute in lateral view; dorsal plate with large, distinctly sclerotized, somewhat convex (cross-section), and apically trifid apical portion (Fig. 179) and with fine, moderately long, lamellate basal portion; internal sac with large, strongly curved, and strongly sclerotized spines.

ㅇ: posterior margin of tergite VIII strongly convex in the middle; sternite VIII transverse, posterior margin convexly produced in the middle; tergite IX (Fig. 180) with short antero-median portion and with moderately slender postero-lateral processes, antero-median portion with median suture; tergite X (Fig. 180) distinctly convex in cross-section, approximately more than four times as long as antero-median portion of tergite IX.

\section{Comparative notes:}

The shapes of the female sternite VII and the female tergites IX and X, as well as the morphology of the symmetric aedeagus (spines in internal sac) and the chaetotaxy of the male sternites VII and VIII suggest that L. tricuspidatum is closely related to L. fortehamatum. For distinguishing characters see the comparative notes in the preceding section.

\section{Distribution and natural history:}

The type locality is situated in Haba Shan (Map 5). The specimens were sifted at an altitude of approximately $4070 \mathrm{~m}$.

\subsubsection{Lathrobium fortespinosum sp. n. (Figs 181-187, Map 5)}

\section{Type material:}

Holotype o": "CHINA (N-Yunnan) Zhongdian [today: Shangri-La] Co., $55 \mathrm{~km} \mathrm{~N}$ Zhongdian, $28^{\circ} 19.8^{\prime} \mathrm{N}$, $99^{\circ} 45.7^{\prime} \mathrm{E}, 3800 \mathrm{~m}$ (primary mixed forest, Rhodod., dead wood, leaf litter, mushrooms, moss) 18.VIII.2003, Wrase [07] / Holotypus o Lathrobium fortespinosum sp. n. det. V. Assing 2013" (cSch). Paratypes: $10^{\star}, 8$ 우 + : same data as holotype (cSch, cAss); 6 + + : same data, but leg. Schülke (cSch, cAss); 2 ㅇ ㅇ: "CHINA: N-Yunnan Zhong- 
dian Co. $55 \mathrm{~km}$ N Zhongdian, $28^{\circ} 19.8^{\prime} \mathrm{N}$, 99²45.7'E, 3800 m 18.VIII.2003 A. Smetana [C127]" (cSme, cAss).

\section{Etymology:}

The specific epithet (Latin, adjective) alludes to the large internal spines of the aedeagus.

\section{Description:}

External characters (Figs 181-182) as in L. fortehamatum.

$\sigma^{*}$ : sternites III-VI unmodified; sternite VII (Fig. 183) strongly transverse and with rather extensive median impression, this impression with weakly modified dark setae on either side of middle and anteriorly, without setae in the middle, posterior margin broadly and weakly concave; sternite VIII (Fig. 184) moderately transverse, with very weakly modified pubescence in postero-median depression, posterior excision deep and somewhat V-shaped, posterior margin produced on either side of posterior excision; aedeagus (Fig. 185) relatively large in relation to body size, approximately $1.2 \mathrm{~mm}$ long, and symmetric; ventral process curved and apically acute in lateral view; dorsal plate with long, distinctly sclerotized, roof-shaped (cross-section) apical portion, basal portion relatively long and lamellate; internal sac with three large, strongly sclerotized spines of characteristic shapes.

o : sternite VIII (Fig. 186) oblong, posterior margin produced and weakly concave to truncate in the middle; tergite IX (Fig. 187) with moderately short antero-median portion and with moderately slender postero-lateral processes, antero-median portion with median suture; tergite X (Fig. 187) distinctly convex in cross-section, more than three times as long as antero-median portion of tergite IX.

\section{Comparative notes:}

Lathrobium fortespinosum is closely allied to L. tricuspidatum and particularly L. fortehamatum. It differs from the latter only by the sexual characters, particularly the deeper posterior excision of the male sternite VIII, the larger aedeagus with the differently shaped ventral process, the large roof-shaped dorsal plate of the aedeagus, the shapes of the internal structures of the aedeagus, the oblong female sternite VIII, and the shape of the female tergite X. From L. tricuspidatum, it is distinguished by larger body size, the less transverse male sternite VIII with a deeper posterior excision, the morphology of the aedeagus (larger size; shapes of the ventral process, of the

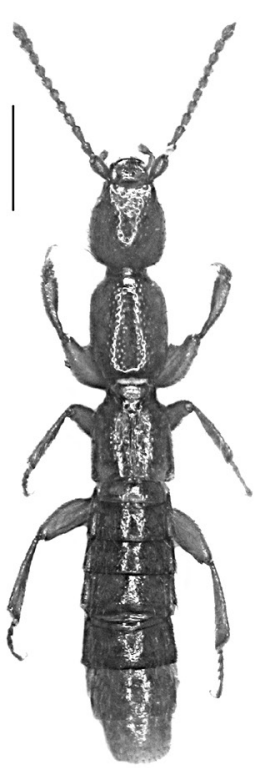

181

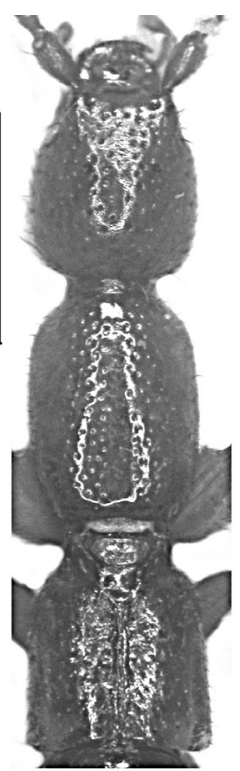

182

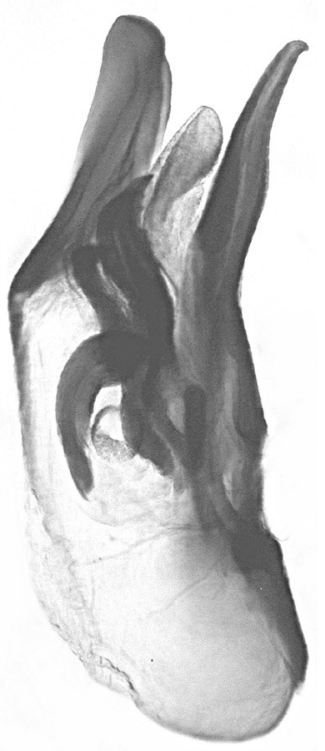

185

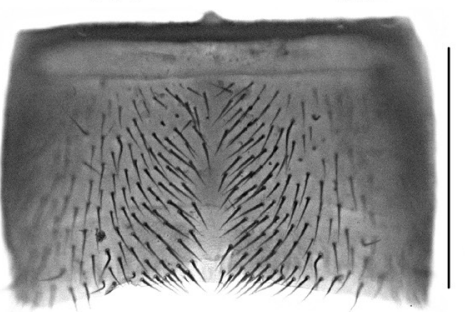

183

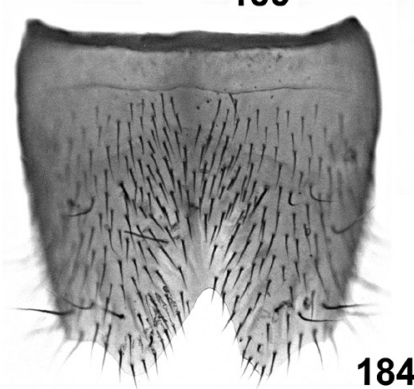

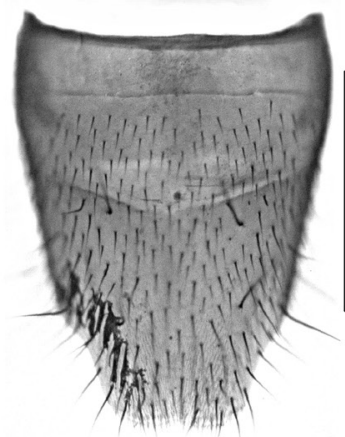

186

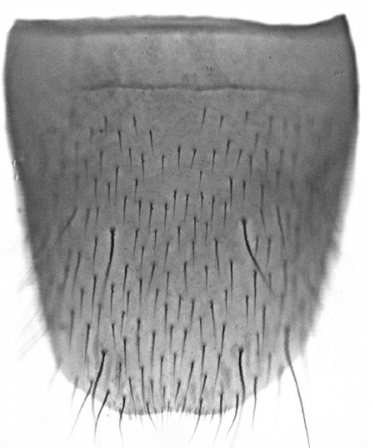

188

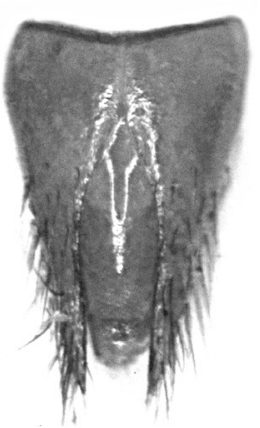

187

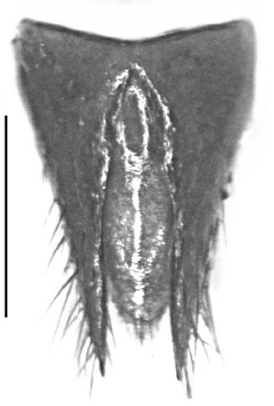

189

Figs 181-189: Lathrobium fortespinosum (181-187) and L. yulongense (188-189): habitus (181); forebody (182); male sternite VII (183); male sternite VIII (184); aedeagus in lateral view (185); female sternite VIII $(186,188)$; female tergites IX-X (187, 189). Scale bars: 181-182: $1.0 \mathrm{~mm}$; 183-189: $0.5 \mathrm{~mm}$. 
dorsal plate, and of the sclerotized internal structures), the oblong female sternite VIII, and the slightly longer antero-median portion of the female tergite IX.

\section{Distribution and natural history:}

The type locality is situated in the Xiaoxue Shan, $55 \mathrm{~km}$ to the north of Zhongdian (Map 5). The specimens were sifted from leaf litter in a primary forest at an altitude of $3800 \mathrm{~m}$. The sex ratio is strongly biased in favour of females $\left(20^{\top} o^{\top}: 16\right.$ 우 우 $)$.

\subsubsection{The L. lijiangense subgroup}

\subsubsection{Lathrobium lijiangense WATANABE \& XIA0, 1997 (Figs 190-198, Map 6)}

\section{Material examined:}

China: Yunnan: $20^{\top} o^{\star}, 2$ ㅇ ㅇ, $32 \mathrm{~km} N$ Lijiang, Maonioping, $27^{\circ} 10^{\prime} \mathrm{N}, 100^{\circ} 15^{\prime} \mathrm{E}, 3540 \mathrm{~m}$, wet mixed forest with pine, fir, and rhododendron, detritus, leaves and moss sifted, 21.VI.2007, leg. Hájek \& J. Růžička (cSch, cAss); 3 o $^{\star}$ [1 slightly teneral], Yulongxue Shan, $50 \mathrm{~km} \mathrm{~N}$ Lijiang, 24.-29.VI.1993, leg. Jendek \& Sausa (NHMW, cAss); $20^{\star} o^{*}, 3$ 우 우 , Yulongxue Shan N. P., ca. $30 \mathrm{~km} \mathrm{~N}$ Lijiang, Baishui env., 2900-3200 m, 7.-11.VII.1994, leg. Schillhammer (NHMW, cAss); $10^{*}$ [slightly teneral], Yulongxue Shan, $27^{\circ} 01^{\prime} \mathrm{N}, 100^{\circ} 12^{\prime} \mathrm{E}, 2900-3500 \mathrm{~m}, 24$.25.V.1993, leg. Kubáň (cAss).

\section{Comment:}

The original description is based on seven type specimens from the Yulongxue Shan. According to WATANABE \& XiAO (1997), the body length is 4.4-5.2 $\mathrm{mm}$ and the length of the forebody ranges from 1.9 to $2.1 \mathrm{~mm}$. However, the lengths of the body and the forebody of the above material, whose aedeagus is identical (also in size) to that illustrated in the original description, are 6.7-8.0 and 2.9-3.5 $\mathrm{mm}$, respectively, suggesting that the measurements in WATANABE \& XIAO (1997) are erroneous.

\section{Redescription:}

Species of moderate size; body length 6.7-8.0 mm; length of forebody 2.9-3.5 mm. Habitus as in Fig. 190. Coloration: body dark-brown to blackish; legs and antennae reddish.

Head (Fig. 191) 1.02-1.05 times as long as broad; punctation moderately dense and moderately coarse, sparser in median dorsal portion; interstices with distinct microreticulation and subdued shine. Eyes rather small, approximately 0.3 times as long as postocular region and composed of approximately 40 ommatidia. Antenna 1.5$1.7 \mathrm{~mm}$ long.
Pronotum (Fig. 191) 1.20-1.24 times as long as broad and approximately 1.05 times as broad as head; punctation similar to that of head; interstices without microsculpture and glossy; impunctate midline rather broad.

Elytra (Fig. 191) short, approximately 0.53 times as long as pronotum; punctation shallow and rather fine. Hind wings completely reduced. Protarsi with weakly pronounced sexual dimorphism.

Abdomen 1.05-1.10 times as broad as elytra; punctation fine and rather dense; interstices with shallow microsculpture; posterior margin of tergite VII without palisade fringe; tergite VIII without sexual dimorphism, posterior margin convex to indistinctly pointed in the middle.

$\sigma^{\top}$ : sternites III-VI unmodified; sternite VII (Fig. 192) moderately transverse, symmetric, with shallow median impression posteriorly, this impression with weakly modified black setae, posterior margin broadly concave; sternite VIII (Fig. 193) symmetric, weakly transverse, with weakly modified black setae in posterior portion, narrowly without setae along the middle, posterior margin weakly concave in the middle; aedeagus (Figs 194-195) approximately $1.0 \mathrm{~mm}$ long, symmetric; ventral process rather broad at base in ventral view and smoothly curved in lateral view; dorsal plate with long, strongly sclerotized apical portion and with very short, weakly sclerotized basal portion; internal sac with pair of long membranous structures, with pair of apical sclerotized spines, with two pairs of larger basal, short sclerotized spines (Fig. 196), and with one or two additional basal pairs of smaller and less strongly sclerotized spines (difficult to see).

오 : sternite VIII (Fig. 197) approximately $1.0 \mathrm{~mm}$ long and distinctly oblong, posterior margin distinctly and convexly produced in the middle; tergite IX (Fig. 198) with very short antero-median portion and with moderately long postero-lateral processes, antero-median portion with median suture; tergite X (Fig. 198) nearly reaching anterior margin of tergite IX, strongly, convexly elevated in anterior four fifths, this elevation abruptly sloping downwards at posterior fifth.

\section{Comparative notes:}

In external appearance (size, coloration, proportions, punctation, etc.) this species is similar to L. daliense, but distinguished by more slender elytra, smaller eyes, and the different sexual characters.

\section{Distribution and natural history:}

Lathrobium lijiangense is known only from the Yulongxue Shan (Map 6), where part of the above material was collected in a wet mixed forest and at altitudes between approximately 3000 and $3540 \mathrm{~m}$. Two specimens collected in May and June are slightly teneral. 
4.1.9.2 Lathrobium seriespinosum sp. $\mathrm{n}$. (Figs 199-205, Map 7)

Type material:

Holotype ơ: "YUNNAN 3600-4100 m, 27.02N 100.11E, Yulongshan mts. 27.5.1993 Vít Kubáň leg. / Holotypus o Lathrobium seriespinosum sp. n. det. V. Assing 2013” (NHMW). Paratype $9:$ same data as holotype (cAss).

\section{Etymology:}

The specific epithet is an adjective composed of the Latin noun series (row) and the Latin adjective spinosum (with
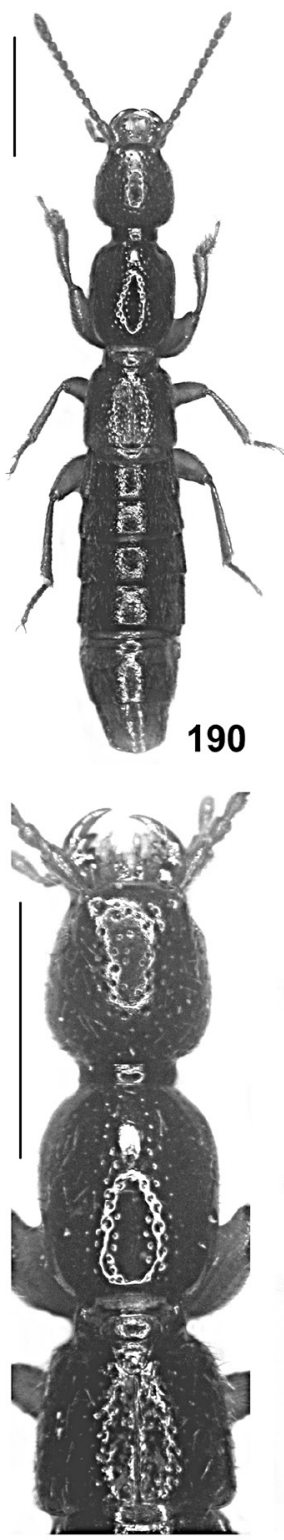

199

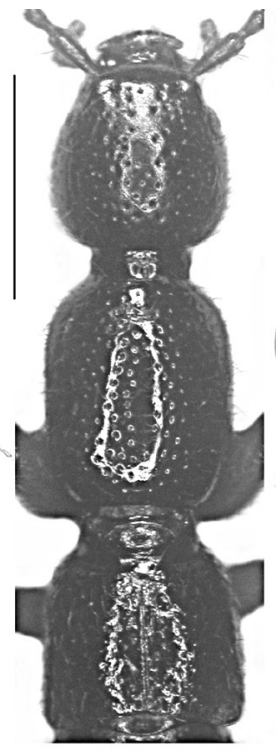

191

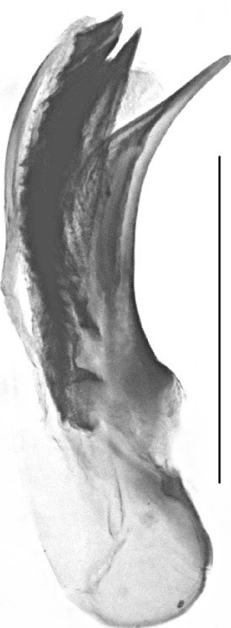

202
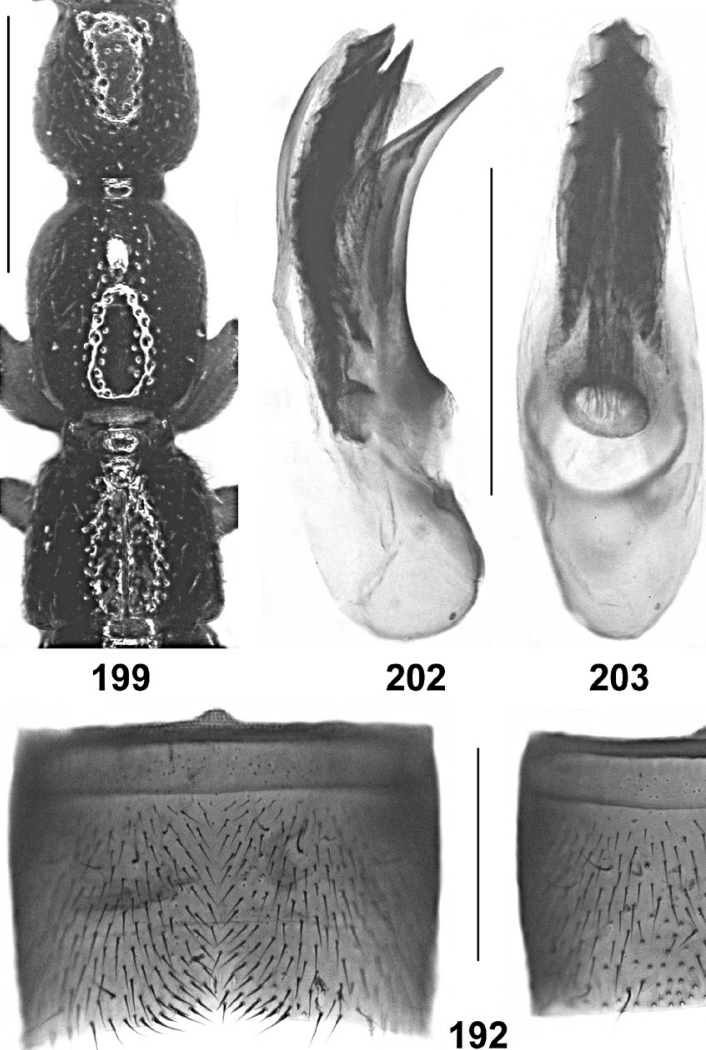

195

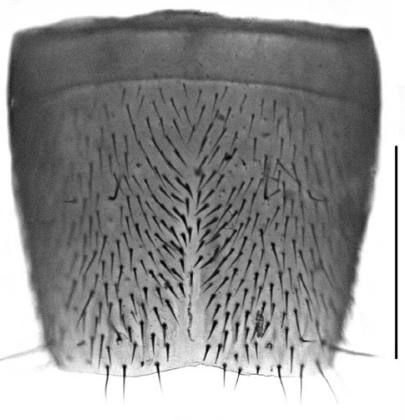

193

203
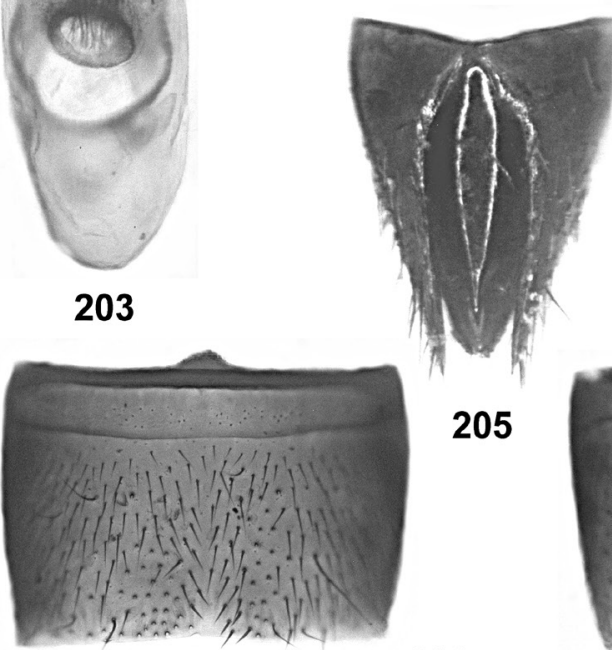

205

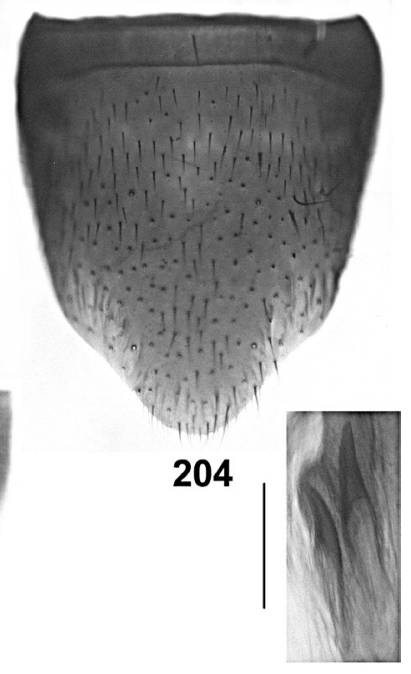

196

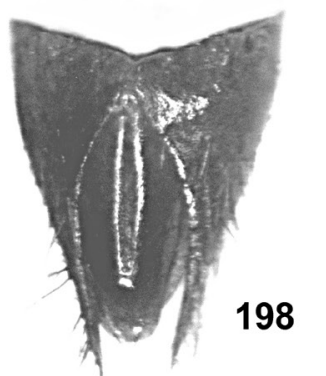

\section{7}

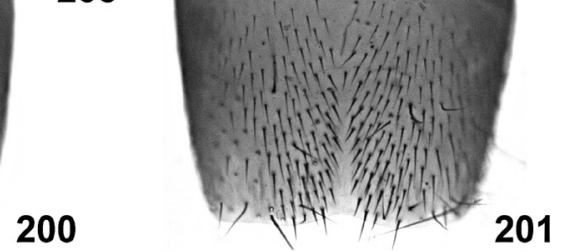

Figs 190-205: Lathrobium lijiangense (190-198) and L. seriespinosum (199-205): habitus (190); forebody (191, 199); male sternite VII (192, 200); male sternite VIII $(193,201)$; aedeagus in lateral and in ventral view (194-195, 202-203); internal structures of aedeagus in lateral view (196); female sternite VIII $(197,204)$; female tergites IX-X (198, 205). Scale bars: 190-191, 199: 1.0 mm; 192-195, 197-198, 200-205: 0.5 mm; 196: $0.1 \mathrm{~mm}$. 
spines). It alludes to the presence of two long series of spines in the internal sac of the aedeagus.

\section{Description:}

Species of relatively small size; body length 5.5-6.2 mm; length of forebody 2.7-3.0 mm. Apart from the smaller body size, external characters (Fig. 199) as in L. lijiangense.

$0^{\star}$ : sternites III-VI unmodified; sternite VII (Fig. 200) moderately transverse, symmetric, with shallow median depression posteriorly, this depression with weakly modified black setae, posterior margin only indistinctly concave; sternite VIII (Fig. 201) symmetric, weakly transverse, with weakly modified black setae in posterior portion, narrowly without setae along the middle, posterior margin weakly concave in the middle; aedeagus (Figs 202-203) $0.9 \mathrm{~mm}$ long, symmetric; ventral process strongly curved subapically and very acute apically in lateral view; dorsal plate with moderately long, lamellate, and moderately sclerotized apical portion and with short, weakly sclerotized basal portion; internal sac with pair of sclerotized apical spines and with pair of long series of numerous strongly sclerotized spines.
+ : sternite VIII (Fig. 204) approximately $1.0 \mathrm{~mm}$ long and distinctly oblong, posterior margin distinctly and convexly produced in the middle; tergite IX (Fig. 205) with completely divided antero-median portion; tergite $\mathrm{X}$ (Fig. 205) reaching anterior margin of tergite IX, posteriorly sharply elevated, this elevation nearly angled in lateral view.

\section{Comparative notes:}

Based on the similar male and female sexual characters, particularly the apical pair of internal spines of the aedeagus, L. seriespinosum is undoubtedly closely allied to the geographically close L. lijiangense, but distinguished by slightly smaller body size and particularly the shape of the ventral process of the smaller aedeagus (more strongly curved, apically longer and more acute), the different internal structures of the aedeagus, the shape of the female tergite VIII (anteriorly completely divided), and the sharp posterior elevation on the female tergite $\mathrm{X}$.

\section{Distribution and natural history:}

The species is probably endemic to the Yulongxue Shan (Map 7), where the specimens were collected at high altitudes (3500-4100 m), apparently together with L. sexspinosum.

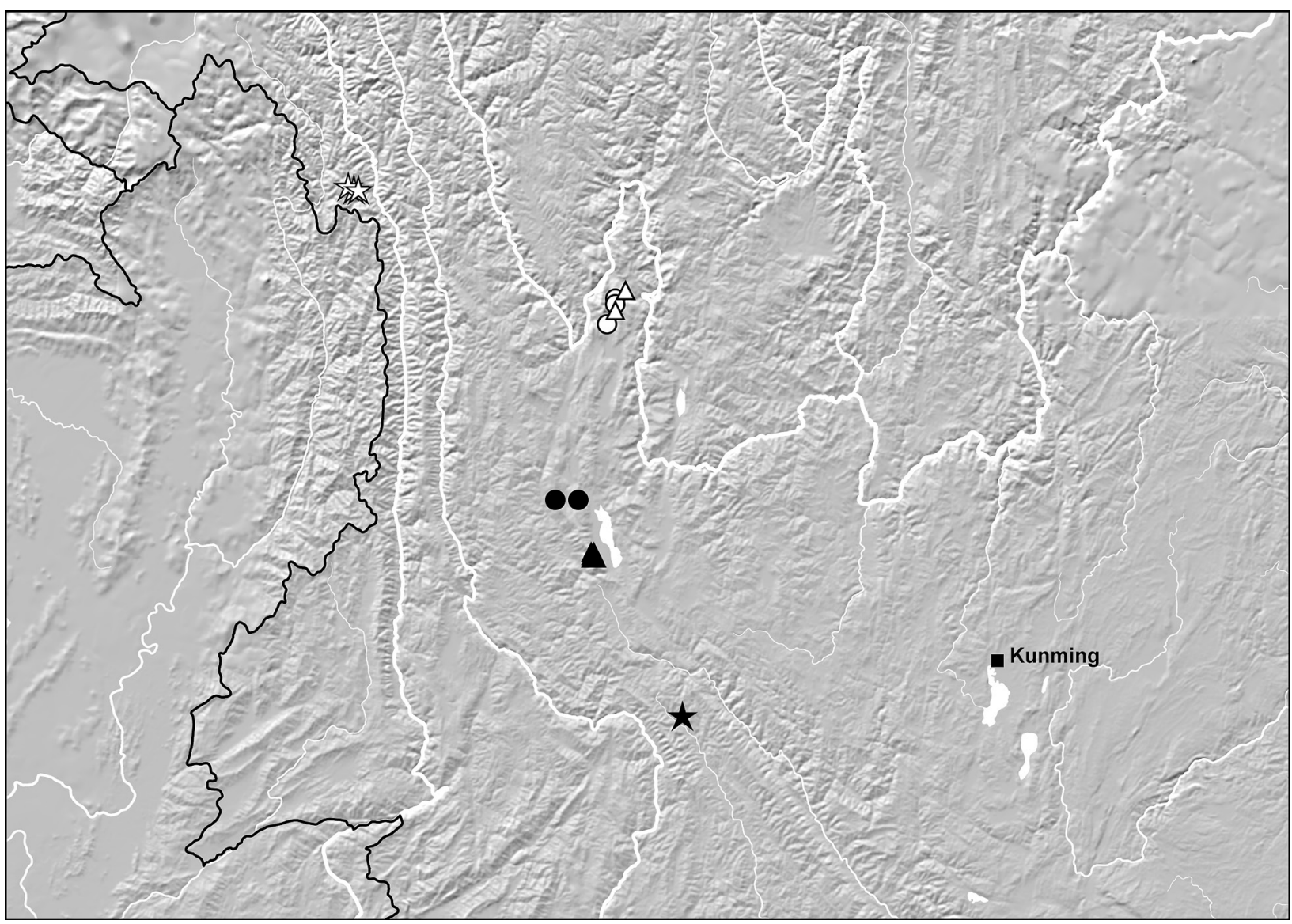

Map 6: Distribution of the species of the L. celere (open stars), the L. yulongense (open triangles), the L. lijiangense (open circles), the L. tentaculatum (black star), and the L. hirsutum (other filled symbols) (sub-)groups: L. lijiangense (white circles); L. yulongense (white triangles); L. tentaculatum (black star); L. hirsutum (black circles); L. baizuorum (black triangles); L. bidigitulatum (white stars). 


\subsubsection{Lathrobium sexspinosum sp. n. (Figs 206-210, Map 7)}

Type material:

Holotype ơ: "YUNNAN 3600-4100 m, 27.02N 100.11E, Yulongshan mts. 27.5.1993 Vít Kubán leg. / Holotypus $0^{\top}$ Lathrobium sexspinosum sp. n. det. V. Assing 2013" (NHMW).

\section{Etymology:}

The specific epithet (Latin, adjective) alludes to the presence of six sclerotized spines in the internal sac of the aedeagus.

\section{Description:}

Species of moderate size; body length $6.3 \mathrm{~mm}$; length of forebody $3.1 \mathrm{~mm}$. External characters (Fig. 206) as in L. lijiangense.

$0^{\pi}$ : sternites III-VI unmodified; sternite VII (Fig. 207) distinctly transverse, symmetric, with shallow median depression posteriorly, this impression with sparse, moderately modified black setae, posterior margin very weakly concave; sternite VIII (Fig. 208) symmetric, weakly transverse, with weakly modified black setae in postero-median portion, middle of posterior third without setae, posterior margin only indistinctly concave in the middle; aedeagus (Figs 209-210) $1.1 \mathrm{~mm}$ long, symmetric; ventral process strongly curved subapically and with long, very acute apex in lateral view; dorsal plate with long, distinctly sclerotized apical portion and with short, weakly sclerotized basal portion; internal sac with pair of apical sclerotized spines and with additional two pairs of moderately long, distinctly sclerotized basal spines.

o: unknown.
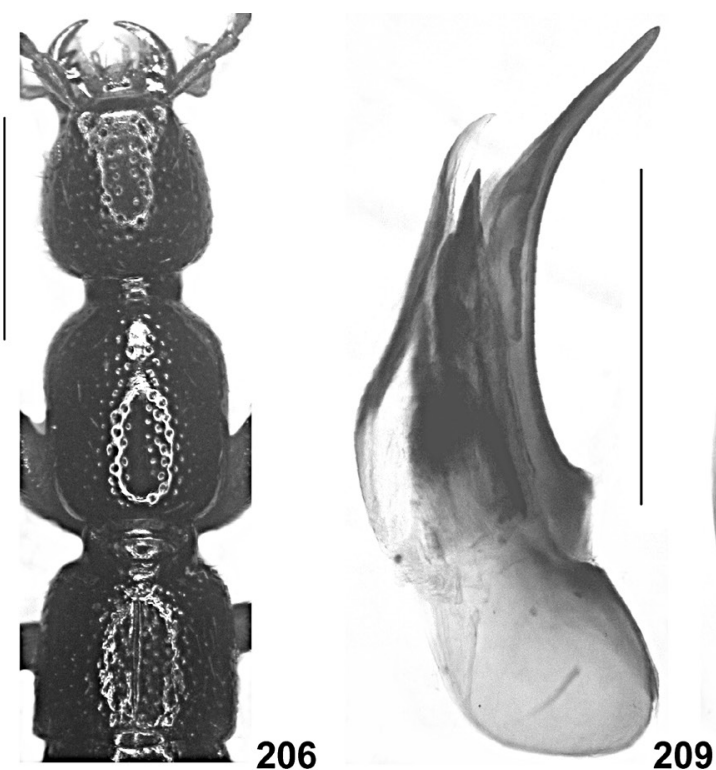

Figs 206-210: Lathrobium sexspinosum: forebody (206); male sternite VII (207); male sternite VIII (208); aedeagus in lateral and in ventral view (209-210). Scale bars: 206: $1.0 \mathrm{~mm}$; 207-210: $0.5 \mathrm{~mm}$.

\section{Comparative notes:}

Lathrobium sexspinosum is closely allied to L. lijiangense and L. seriespinosum, as is suggested not only by male sexual characters, particularly the presence of the pair of apical spines and additional pairs of basal spines in the internal sac of the aedeagus. Among the species of the L. lijiangense complex, L. sexspinosum is characterized by the shape and chaetotaxy of the male sternite VIII, by the conspicuously long, slender, and acute apex of the ventral process, and by the internal structures of the aedeagus; the basal spines are distinctly longer than in L. lijiangense.

\section{Distribution and natural history:}

Like L. seriespinosum, L. sexspinosum is probably endemic to the Yulongxue Shan. Both species were apparently found together at an altitude between 3500 and $4100 \mathrm{~m}$.

\subsubsection{The L. yulongense subgroup \\ 4.1.10.1 Lathrobium yulongense Peng \& LI, 2012 (Figs 188-189, Map 6)}

\section{Material examined:}

China: Yunnan: $10^{\star}, 4$ ㅇ $~+35 \mathrm{~km}$ N Lijiang, Heishui, $27^{\circ} 13^{\prime} \mathrm{N}, 100^{\circ} 19^{\prime} \mathrm{E}, 1 .-19 . \mathrm{VII} .1992$, leg. Becvar (NHMW); $2 o^{\top} o^{*}, 1$ 옹 same data, but 18.VI.-4.VII.1993 (cAss); $10^{*}$, 1 , Yulong Shan, Ganhaizi pass, $27^{\circ} 06^{\prime} \mathrm{N}, 100^{\circ} 15^{\prime} \mathrm{E}, 3000-$ 3500 m, 18.-23.VII.1990, leg. Kubáň (NHMW, cAss).

\section{Comment:}

The original description is based on a single male from "Yulongxueshan Mountain / $27^{\circ} 06^{\prime} \mathrm{N}, 100^{\circ} 06^{\prime} \mathrm{E} /$... / the similar external characters, but especially also by the 
alt. 3,200 m" (PEng et al. 2012). The species is probably endemic to the Yulongxue Shan (Map 6). For illustrations of the habitus and the male sexual characters see PENG et al. (2012). The previously unknown female sexual characters are as follows:

ㅇ: sternite VIII (Fig. 188) approximately $1.0 \mathrm{~mm}$ long and moderately oblong, posterior margin convex, in the middle weakly concave; tergite IX (Fig. 189) with very short median portion and with long postero-lateral processes, antero-median portion with median suture; tergite $\mathrm{X}$ (Fig. 189) weakly convex in cross-section, nearly reaching anterior margin of tergite IX, approximately 10 times as long as antero-median portion of tergite IX.

\subsubsection{The L. hirsutum subgroup}

\subsubsection{Lathrobium hirsutum sp. n. (Figs 211-219, Map 6)}

\section{Type material:}

Holotype ơ: "CHINA: Yunnan [CH07-08], Dali Bai Auton. Pref., Diancang Shan 43 km NW Dali, 3078 m,
2559'35"N, 9952'06"E, W pass, Rhodod., oaks, bamboo, sifted, 29.V.2007, M. Schülke / Holotypus ơ Lathrobium hirsutum sp. n. det. V. Assing 2013" (cSch). Paratypes:

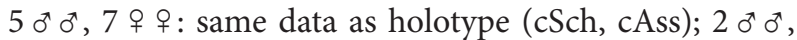
4 우 우 [3 teneral]: "China: N-Yunnan, Dali Bai Aut. Pref. Diancang Shan, E pass, $43 \mathrm{~km}$ NW Dali, 25⒌ $59^{\prime} 50^{\prime N}$, $100^{\circ} 00^{\prime} 30^{\prime \prime E}, 2700 \mathrm{~m}$, secondary pine forest, litter, moss and mushrooms sifted, 23.VIII.2009, leg. M. Schülke" (cSch); $30^{\star} o^{\star}, 3$ ㅇ 우 : same data, but leg. Wrase (cSch, cAss); 1 q : "CHINA (Yunnan) Dali Bai Aut. Pref., Diancang Shan, pass $43 \mathrm{~km}$ NW Dali, $3104 \mathrm{~m}$ (oak shrubs, Rhod., bamboo, litter sifted) $25^{\circ} 59^{\prime} 33.5^{\prime \prime} \mathrm{N}, 99^{\circ} 52^{\prime} 12.5^{\prime \prime} \mathrm{E}$ 23.VIII.2009 D.W. Wrase [01A]" (cSch).

\section{Etymology:}

The specific epithet (Latin, adjective: setose) alludes to the conspicuous chaetotaxy of the female sternite VIII.

\section{Description:}

Small species; body length 4.7-6.5 mm; length of forebody 2.2-2.6 mm. Habitus as in Fig. 211. Coloration: body reddish-brown to dark-brown; legs and antennae reddish.

Head (Fig. 212) approximately 1.05 times as long as broad; punctation moderately coarse and moderately

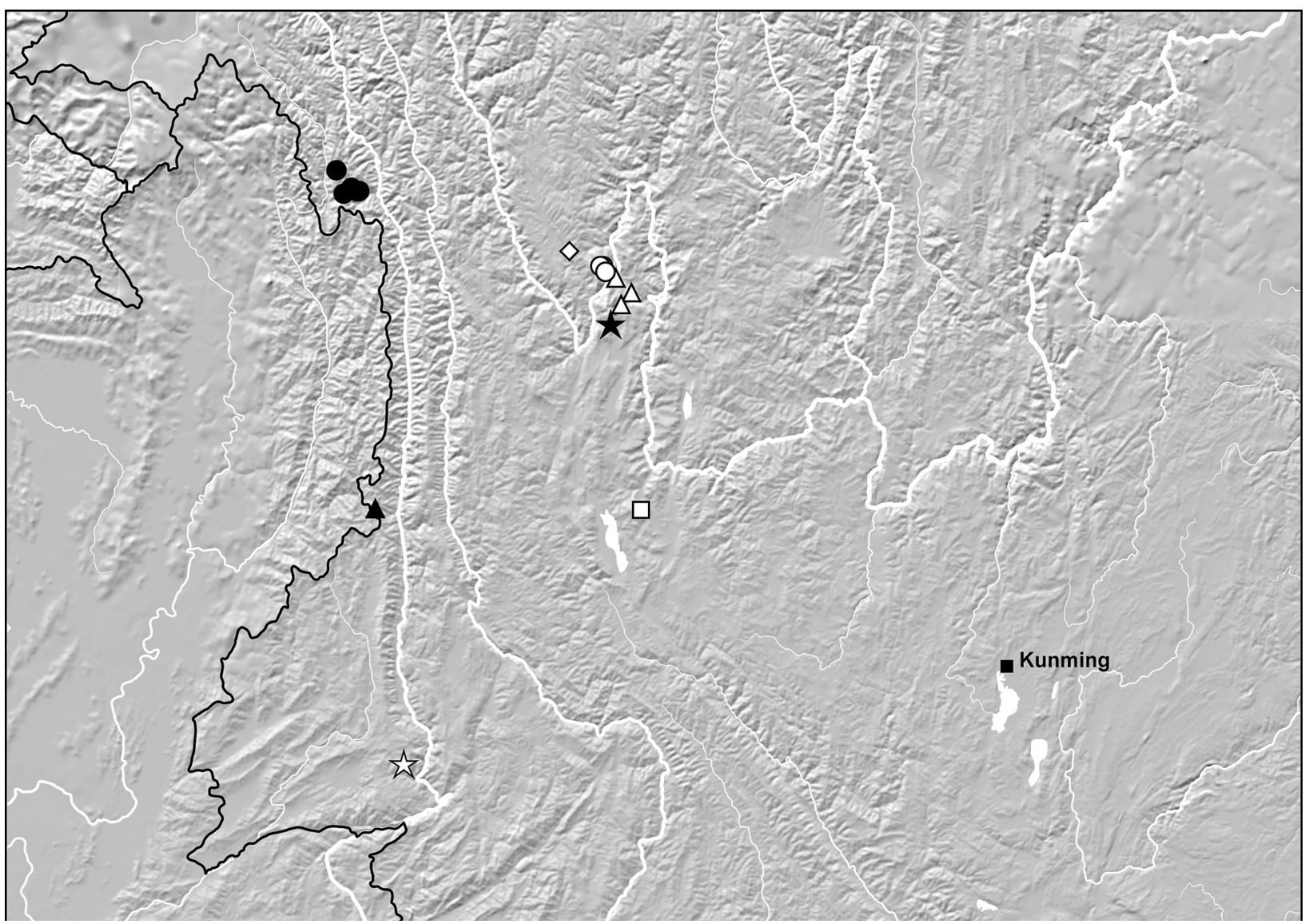

Map 7: Distribution of the species of the L. lijiangense (filled star), the L.celere (other filled symbols), the L. squamosum (open star), and the L. curvatissimum (other open symbols) (sub-)groups: L. seriespinosum and L. sexspinosum (black star); L. squamosum (white star); L. glandulosum (black circles); L. acre (black triangle); L. incurvatum (white diamond); L. stipiferum (white circles); L. yinae (white triangles); L. curvatissimum (white square). 
dense, only slightly sparser in median dorsal portion; interstices with fine, but distinct microreticulation. Eyes small, approximately one fourth the length of postocular region in dorsal view and composed of approximately 25 ommatidia. Antenna 1.2-1.4 mm long.
Pronotum (Fig. 212) distinctly convex in cross-section, approximately 1.25 times as long as broad, or nearly so, and about 1.05 times as broad as head; punctation similar to that of head; interstices without microsculpture and glossy; impunctate midline rather broad.
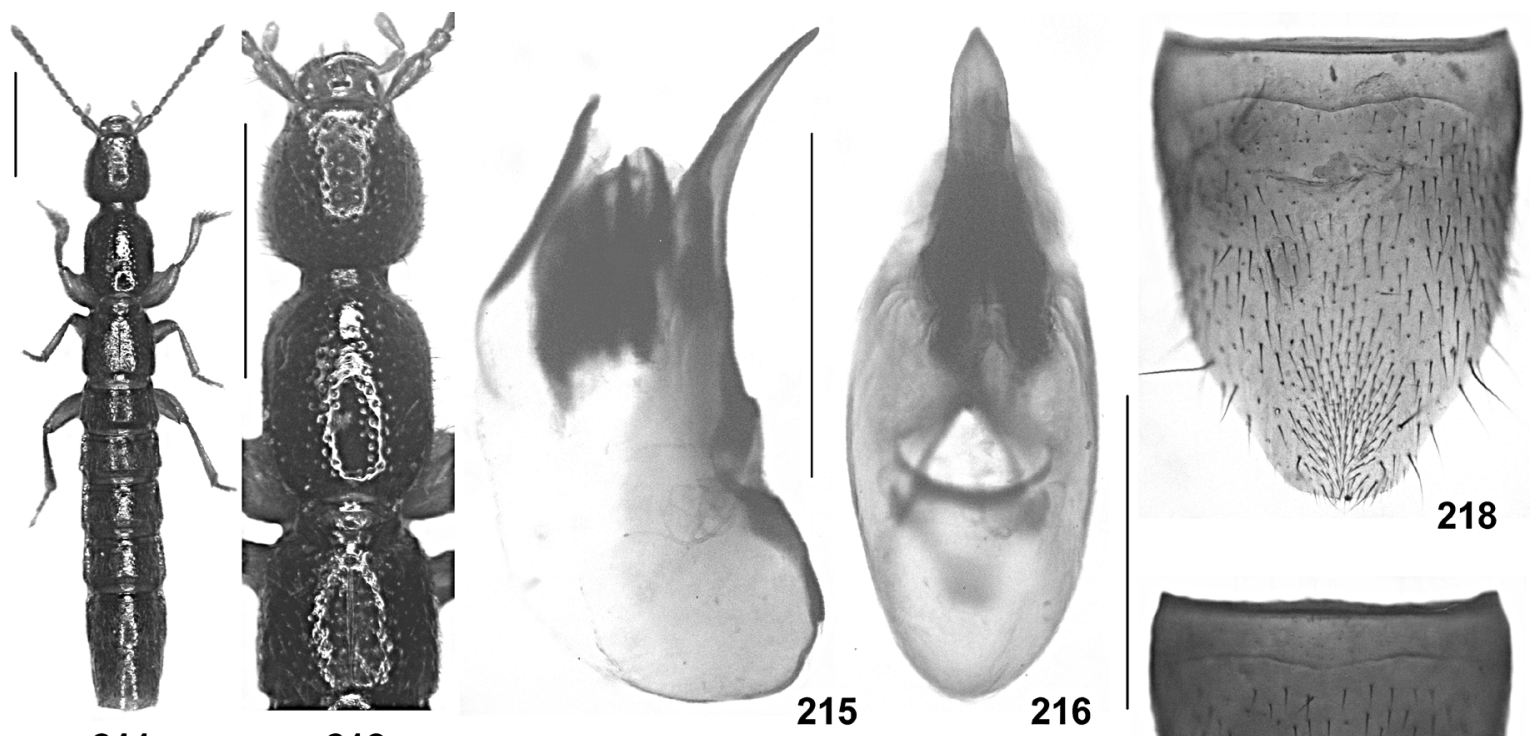

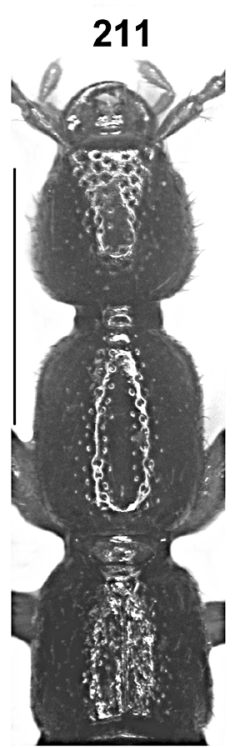

220

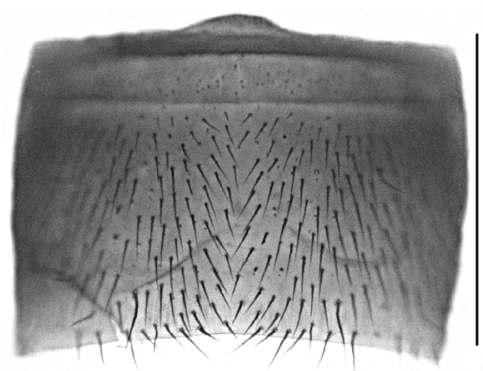

221

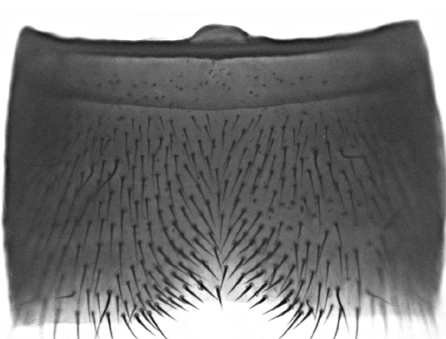

213

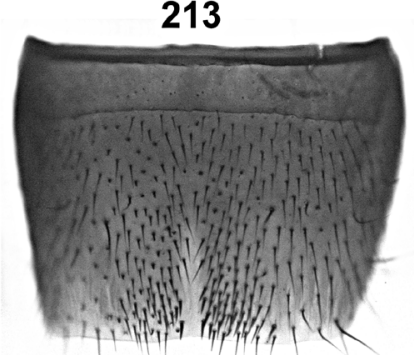

214

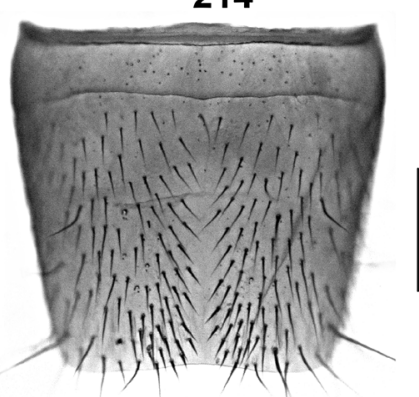

222

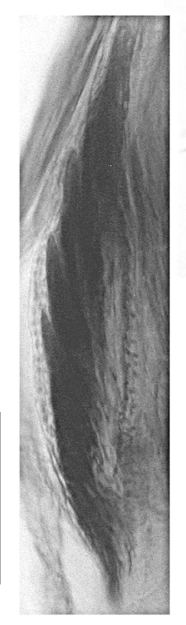

224

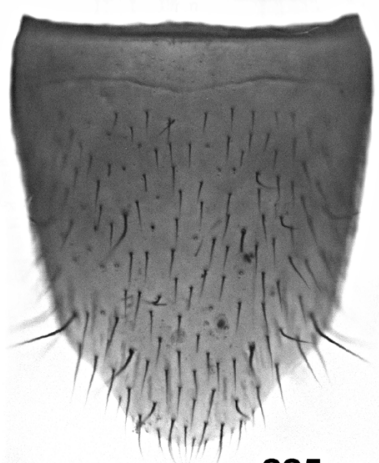

225
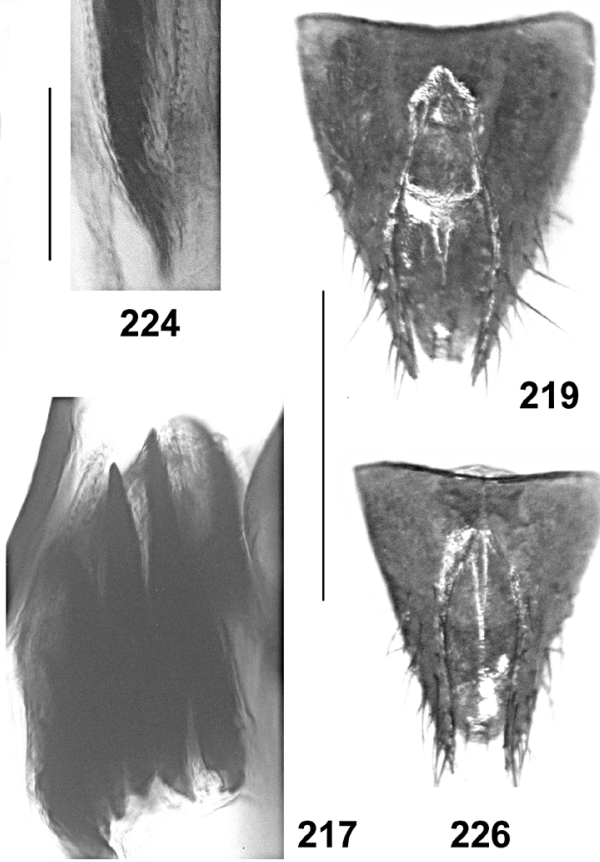

Figs 211-226: Lathrobium hirsutum (211-219) and L. baizuorum (220-226): habitus (211); forebody (212, 220); male sternite VII $(213,221)$; male sternite VIII $(214,222)$; aedeagus in lateral and in ventral view $(215-216,223)$; internal structures of aedeagus in lateral view $(217,224)$; female sternite VIII $(218,225)$; female tergites IX-X $(219,226)$. Scale bars: 211-212, 220: 1.0 mm; 213-216, 218-219, 221-223, 225-226: $0.5 \mathrm{~mm} ; 217,224: 0.1 \mathrm{~mm}$. 
Elytra (Fig. 212) 0.55-0.60 times as long as pronotum; punctation shallow and fine. Hind wings completely reduced. Protarsi with distinct sexual dimorphism.

Abdomen 1.10-1.15 times as broad as elytra; punctation fine and rather dense; interstices with shallow, but distinct microsculpture; posterior margin of tergite VII without palisade fringe; tergite VIII without appreciable sexual dimorphism, posterior margin convex to indistinctly pointed in the middle.

$0^{\star}$ : sternites III-VI unmodified; sternite VII (Fig. 213) moderately transverse, symmetric, with median impression of triangular shape posteriorly, this impression with weakly modified black setae, posterior margin concave in the middle; sternite VIII (Fig. 214) symmetric, distinctly transverse, middle of sternite narrowly without setae in posterior half, on either side of middle with numerous weakly modified black setae in posterior portion, posterior margin weakly concave in the middle, but without distinct excision; aedeagus (Figs 215-216) 1.0-1.1 mm long, symmetric, with conspicuously slender and apically acute ventral process, dorsal plate with flat and distinctly sclerotized apical portion and with short and weakly sclerotized basal portion; internal sac with pair of clusters of sclerotized spines (Fig. 217).

o : sternite VIII (Fig. 218) approximately $0.9 \mathrm{~mm}$ long, distinctly oblong, distinctly produced posteriorly, and with cluster of short setae in posterior median portion (unique among Chinese Lathrobium); tergite IX (Fig. 219) with short median portion and with moderately long postero-lateral processes, median portion with fine suture; tergite X (Fig. 219) with median elevation at posterior third, otherwise flat, and nearly four times as long as median portion of tergite IX.

\section{Comparative notes:}

Lathrobium hirsutum is evidently the sister species of L. baizuorum, as can be inferred from the extremely similar external morphology and particularly from the similar male and female sexual characters. It differs from L. baizuorum by the distinctly larger and stouter aedeagus, the different shape and chaetotaxy of the male sternite VII, the chaetotaxy of the male sternite VIII, the modified pubescence of the female sternite VIII and the different shape of the female tergite $\mathrm{X}$ (with posterior, not anterior elevation).

\section{Distribution and natural history:}

Lathrobium hirsutum is known only from three geographically close localities to the northwest of Dali old town in the Diancang Shan (Map 6). The specimens were sifted from leaf litter in shrub habitats with oak and rhododendron and in a pine forest at altitudes of 2700-3100 m, together with L. elevatum. Some specimens collected at the end of August are teneral.

\subsubsection{Lathrobium baizuorum WATANABE \& XIA0, 2000 (Figs 220-226, Map 6)}

\section{Material examined:}

China: Yunnan: $13 o^{\star} o^{\star}, 9$ ㅇ ㅇ [1 teneral], Dali Bai Nat. Aut. Pref., Diancang Shan, W Dali, $25^{\circ} 41^{\prime} \mathrm{N}, 100^{\circ} 06^{\prime} \mathrm{E}$, $3160 \mathrm{~m}$, small creek valley, litter and debris sifted, 27.V.2007, leg. Pütz, Schülke \& Wrase (cPüt, cSch, cAss); $3 o^{\top} \sigma^{\top}$, Diancang Shan, W Dali, $25^{\circ} 42^{\prime} \mathrm{N}, 100^{\circ} 06^{\prime} \mathrm{E}, 2960 \mathrm{~m}$, sifted from litter, moss, and flood debris, 6.IX.2009, leg. Schülke (cSch, cAss); 1 ㅇ, Diancang Shan, W Dali, $25^{\circ} 42^{\prime} \mathrm{N}, 100^{\circ} 07^{\prime} \mathrm{E}, 3016 \mathrm{~m}$, moist escarpment, litter sifted, 28.V.2007, leg. Pütz (cPüt); 4 ㅇ $~+$, Diancang Shan, W Dali, $25^{\circ} 40^{\prime} \mathrm{N}, 100^{\circ} 08^{\prime} \mathrm{E}, 2730 \mathrm{~m}$, sifted, 13.V.2010, leg. Grebennikov (CAS, cSme); $30^{\star} \sigma^{\star}, 4$ 우 우 [2 slightly teneral], Diancang Shan, W Dali, $25^{\circ} 40^{\prime} \mathrm{N}, 100^{\circ} 06^{\prime} \mathrm{E}, 3890 \mathrm{~m}$, sifted, 19.V.2010, leg. Grebennikov (CAS, cSme, cAss).

\section{Comment:}

The original description is based on eleven type specimens from "Xueren Fen, Diancang Shan Mts." (Watanabe \& XiAO 2000).

\section{Redescription: \\ External characters (Fig. 220) as in L. hirsutum.}

$\sigma^{\star}$ : sternites III-VI unmodified; sternite VII (Fig. 221) moderately transverse, symmetric, with very shallow median impression posteriorly, this impression with rather sparse and very weakly modified black setae, posterior margin almost truncate, without concavity in the middle; sternite VIII (Fig. 222) symmetric, weakly transverse, in the middle narrowly without setae, with very weakly modified black setae on either side of middle, and without posterior excision; aedeagus (Fig. 223) approximately $0.8 \mathrm{~mm}$ long, symmetric, with very slender and apically very acute ventral process; dorsal plate with lamellate sclerotized apical portion and with short and weakly sclerotized basal portion; internal sac with pair of series of sclerotized spines (Fig. 224).

ㅇ: sternite VIII (Fig. 225) $0.8 \mathrm{~mm}$ long, oblong, posteriorly convexly produced in the middle, pubescence unmodified; tergite IX (Fig. 226) with short anteromedian portion, median portion with fine suture; tergite $\mathrm{X}$ (Fig. 226) with convex (cross-section) median elevation in anterior two thirds and flattened in posterior third, approximately 3.5 times as long as antero-median portion of tergite IX.

\section{Comparative notes:}

For characters distinguishing this species from the highly similar L. hirsutum see the comparative notes in the preceding section.

\section{Distribution and natural history:}

Lathrobium baizuorum is probably endemic to the southern part of the Diancang Shan (Map 6). The specimens 
were sifted from leaf litter and debris at altitudes of 2730 $3890 \mathrm{~m}$, partly together with L. aokii. Two specimens collected in May are teneral. One of the dissected females found in May had two mature eggs in the ovaries.

\subsection{The L. tentaculatum species group}

\subsubsection{Lathrobium tentaculatum sp. n. (Figs 227-235, Map 6)}

\section{Type material:}

Holotype ơ: "CHINA: Yunnan, Pu'er Pref., Ailao Shan, $37 \mathrm{~km}$ NW Jingdong, $24^{\circ} 45^{\prime} 12^{\prime \prime} \mathrm{N}, 100^{\circ} 41^{\prime} 24.5^{\prime \prime} \mathrm{E}, 2300 \mathrm{~m}$, devastated forest remnant, litter \& dead wood sifted, 13.IX.2009, leg. M. Schülke [CH09-48] / Holotypus o* Lathrobium tentaculatum sp. n. det. V. Assing 2013" (cSch). Paratypes: $10^{\star}, 1$ [teneral]: same data as holotype (cAss).

\section{Etymology:}

The specific epithet (adjective: with tentacles) alludes to the apically bifid ventral process of the aedeagus.

\section{Description:}

Species of large size and stout habitus (Fig. 227); body length 9.5-11.0 mm; length of forebody 4.5-4.8 mm. Coloration: body black; legs blackish-brown with paler tarsi; antennae dark-reddish to brown.

Head (Fig. 228) large, approximately 1.1 times as broad as long; punctation moderately coarse and rather dense, somewhat sparser in median dorsal portion; interstices with fine and very shallow microreticulation. Eyes relatively large, nearly half as long as postocular region in dorsal view and composed of $>60$ ommatidia. Antenna approximately $2.7 \mathrm{~mm}$ long.

Pronotum (Fig. 228) short and broad, approximately 1.15 times as long as broad and 1.05 times as broad as head; punctation similar to that of head; interstices without microsculpture and glossy; impunctate midline rather narrow.

Elytra (Fig. 228) approximately 0.55 times as long as pronotum and rather broad; punctation dense and defined. Hind wings completely reduced. Protarsi with moderately pronounced sexual dimorphism.

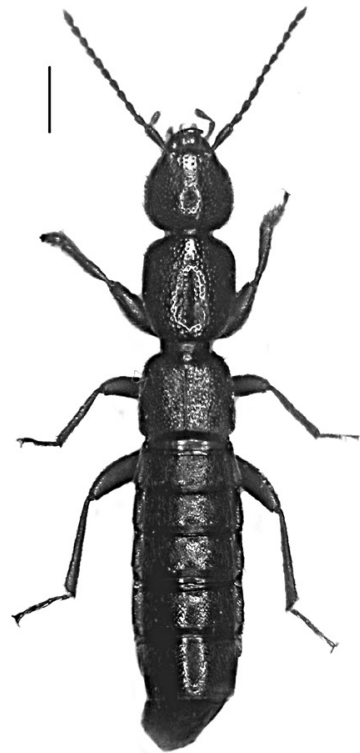

227

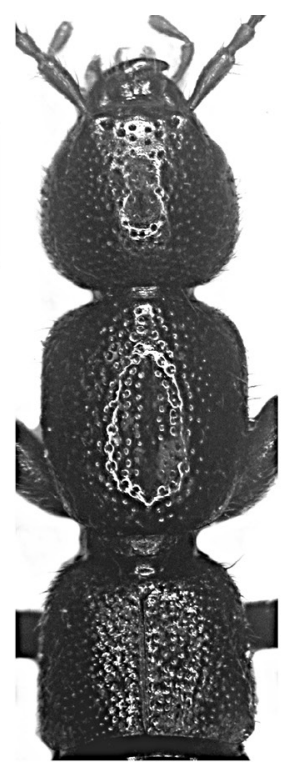

228

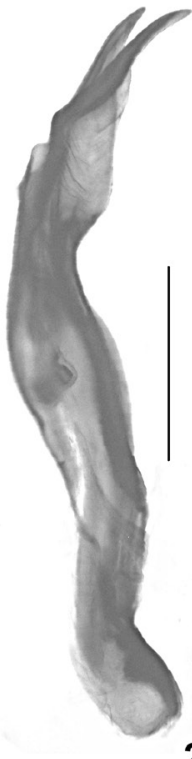

231
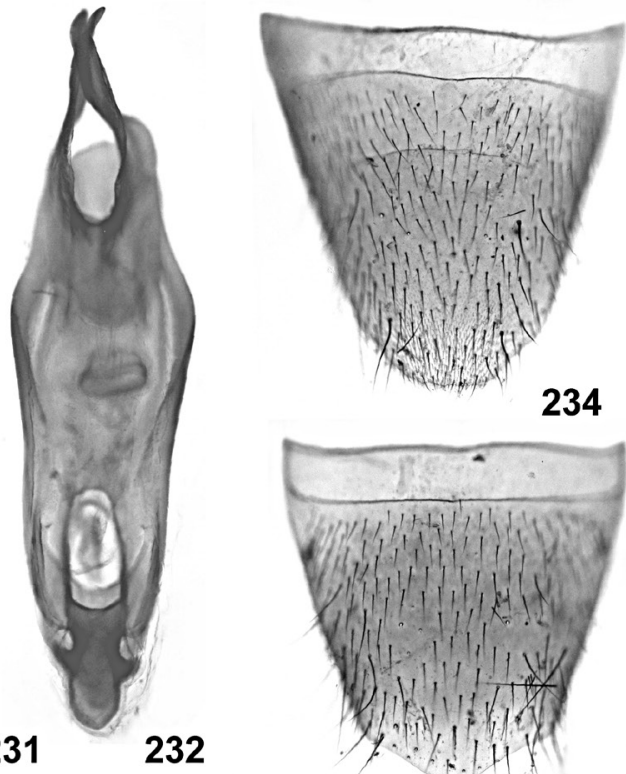

234

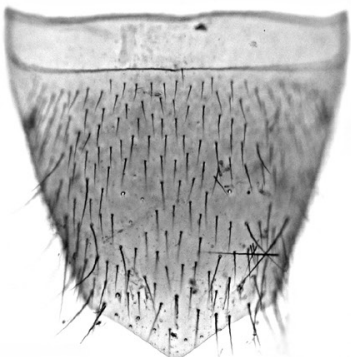

233
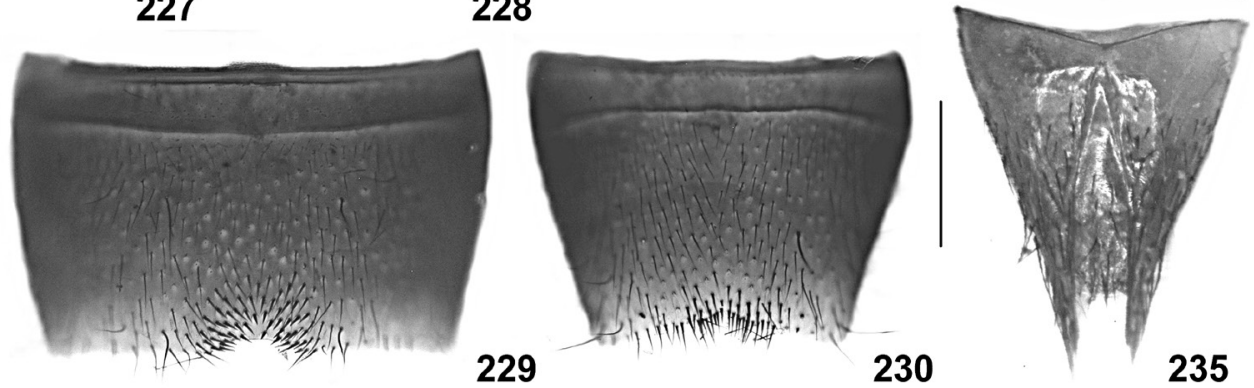

Figs 227-235: Lathrobium tentaculatum: habitus (227); forebody (228); male sternite VII (229); male sternite VIII (230); aedeagus in lateral and in ventral view (231-232); female tergite VIII (233); female sternite VIII (234); female tergites IX-X (235). Scale bars: 227-228: $1.0 \mathrm{~mm}$; 229-235: $0.5 \mathrm{~mm}$. 
Abdomen 1.10-1.15 times as broad as elytra; punctation fine and very dense on tergites III-VI, sparser on tergites VII and VIII; interstices with shallow microsculpture; posterior margin of tergite VII without palisade fringe; tergite VIII without sexual dimorphism, posterior margin angularly produced in the middle (Fig. 233).

$0^{\text {Tे: }}$ sternites III-VI unmodified; sternite VII (Fig. 229) distinctly transverse, symmetric, with shallow and rather small median impression posteriorly, this impression with cluster of moderately modified black setae, posterior margin distinctly concave in the middle; sternite VIII (Fig. 230) symmetric, near posterior excision with dense, weakly modified black setae, posterior excision very small and shallow; aedeagus (Figs 231-232) 1.9-2.0 mm long, somewhat asymmetric, dorso-ventrally compressed, and with small basal portion; ventral process apically extending into two lamellate and somewhat asymmetric processes; dorsal plate with moderately sclerotized and relatively short apical portion and with short basal portion; internal sac without distinct structures, apart from the usual membranous circular structure.

ㅇ: sternite VIII (Fig. 234) approximately $1.3 \mathrm{~mm}$ long, approximately as broad as long, and with strongly convex posterior margin; tergite IX (Fig. 235) with very short antero-median portion, and with moderately long and straight postero-lateral processes, antero-median portion with median suture; tergite X (Fig. 235) flat, more than ten times as long as antero-median portion of tergite IX.

\section{Comparative notes:}

Among the Lathrobium species known from Yunnan, L. tentaculatum is readily identified not only based on the male sexual characters, particularly the distinctive morphology of the aedeagus, but also based on external characters (large and broad body; large transverse head with rather large eyes; long antennae; dense and defined punctation of the elytra; posterior margin of tergite VIII angularly produced in the middle). The derived morphology of the aedeagus does not suggest a closer relationship to any other Lathrobium species recorded from Yunnan; only the morphology of the female tergites IX and $\mathrm{X}$ suggests that L. tentaculatum may be affiliated to the L. daliense group.

\section{Distribution and natural history:}

The type locality is situated in the Ailao Shan, to the northwest of Jingdong (Map 6). The specimens were sifted from leaf litter in a forest remnant at an altitude of $2300 \mathrm{~m}$, together with L. rastellatum. The female paratype is distinctly teneral.

\subsection{The L. celere species group}

\subsubsection{Lathrobium glandulosum sp. n. (Figs 236-245, Map 7)}

\section{Type material:}

Holotype ơ: "CHINA: Yunnan [CH07-24], Nujiang Lisu Aut. Pref., Gaoligong Shan, valley $18 \mathrm{~km}$ W Gongshan, $3020 \mathrm{~m}, 27^{\circ} 47^{\prime} 54^{\prime \prime} \mathrm{N}, 98^{\circ} 30^{\prime} 13^{\prime \prime} \mathrm{E}$, mixed forest, litter, moss, wood sifted, 7.VI.2007, M. Schülke / Holotypus o Lathrobium glandulosum sp. n. det. V. Assing 2013" (cSch). Paratypes: $10^{\star}, 8$ 우: same data as holotype (cSch, cAss); 4 ㅇ + : same data, but leg. Pütz (cPüt, cAss); 1 ㅇ: "CHINA: Yunnan [CH07-21], Nujiang Lisu Aut. Pref., Gaoligong Shan, pass $22 \mathrm{~km}$ W Gongshan, N slope, 3350-3400 m, 27 $46^{\prime} 27^{\prime \prime} \mathrm{N}, 98^{\circ} 26^{\prime} 50^{\prime \prime E}$, fern, moss, litter, sifted, 6.VI.2007, M. Schülke” (cSch); 1 ㅇ: same data, but leg. Pütz (cAss); 2 o $^{\star}$, 9 ㅇ ㅇ: "CHINA: N-Yunnan [200516], Nujiang Lisu Aut. Pref., Gongshan Co., Gaoligong Shan, sidevalley, $3000-3050 \mathrm{~m}, 27^{\circ} 47.90^{\prime} \mathrm{N}, 98^{\circ} 30.19^{\prime} \mathrm{E}$, conif. forest with Rhododendron, broad leaved bushes, litter, moss, dead wood sifted along creek and snowfields, 21.VI.2005, M. Schülke [2005-16]" (cSch, cAss); 1 ơ, 2 ㅇ ㅇ: "CHINA: N-Yunnan Nujiang Lisu Aut. Pr., Gongshan Co., Gaoligong Shan, valley at 3000-3050 m, $27^{\circ} 47.90^{\prime} \mathrm{N} 98^{\circ} 30.19^{\prime} \mathrm{E}, 21 . \mathrm{VI} .2005$ A. Smetana [C169]" (cSme, cAss); 1 ơ, 2 우 ㅇ: "P.R. CHINA, Yunnan, E slope N Gaoligongshan, N27²6.782' E98³3.087', 14.vi.2009, 2956 m, sifting04, V. Grebennikov" (CAS, cSme, cAss); 1 ơ, 1 ㅇ: "P.R. CHINA, Yunnan, E slope N Gaoligongshan, N27 47'22.1" E98³2'17.7", 24.v.2010, 3027 m, sifting20, V. Grebennikov" (cSme, cAss); $3 o^{\star} o^{\star}, 2$ 우 우: "P.R. CHINA, Yunnan, E slope N Gaoligongshan, $\mathrm{N} 27^{\circ} 46.8^{\prime}$ E98 33.1', 12-15.vi.2009, 200-3000 m [sic], sifting1-7, V. Grebennikov" (CAS, cSme, cAss); $10^{\text {: }}$ : "P.R. CHINA, Yunnan, E slope N Gaoligongshan, N27 $53.626^{\prime}$ E98 ${ }^{\circ} 24.168^{\prime}$, 08.vi.2009, $2500 \mathrm{~m}$, sifting01, V. Grebennikov" (cAss).

\section{Etymology:}

The specific epithet (Latin, adjective: with numerous glands) refers to the presence of numerous hypothesized gland openings on the male sternites VII and VIII, one of the synapomorphies of the L. celere group.

\section{Description:}

Species of moderately large, rather variable size and slender habitus (Fig. 236); body length 8.0-10.5 mm; length of forebody 3.8-4.6 mm. Coloration: body dark-brown, usually with dark reddish elytra; legs and antennae reddish-brown to brown.

Head (Fig. 237) distinctly oblong, usually approximately 1.1 times as long as broad, lateral margins subparallel; punctation rather coarse and rather dense; interstices with distinct microreticulation and nearly matt. Eyes rel- 
atively small, $0.25-0.35$ times as long as postocular region in dorsal view and composed of approximately $50 \mathrm{omma}-$ tidia. Antenna 2.2-2.5 mm long.

Pronotum (Fig. 237) slender, approximately 1.3 times as long as broad and approximately as broad as head; punc- tation rather sparse and fine, distinctly finer than that of head; interstices without microsculpture and glossy; impunctate midline moderately broad.

Elytra (Fig. 237) approximately 0.55 times as long as pronotum; punctation shallow and ill-defined. Hind wings

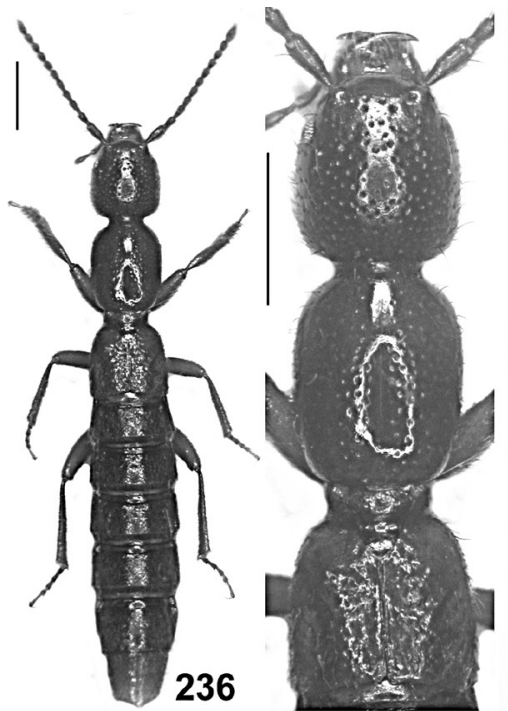

237

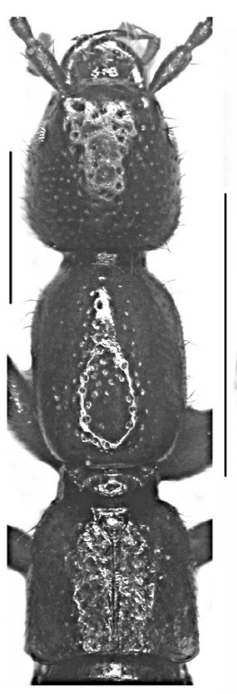

246

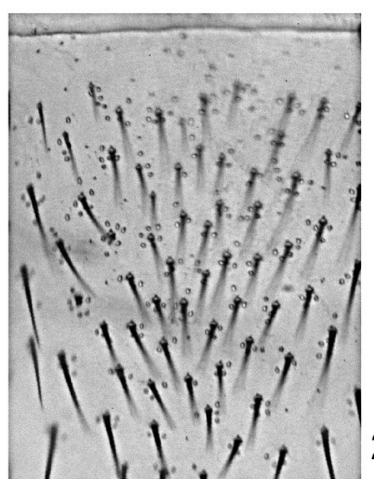

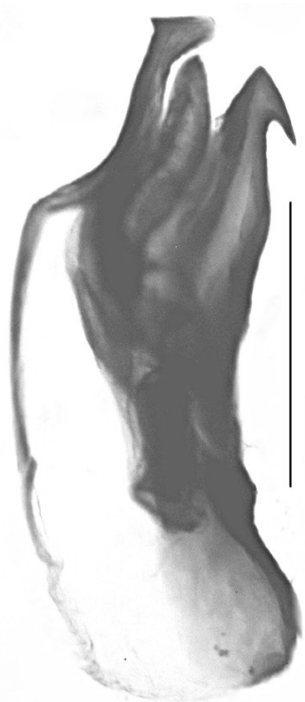

242
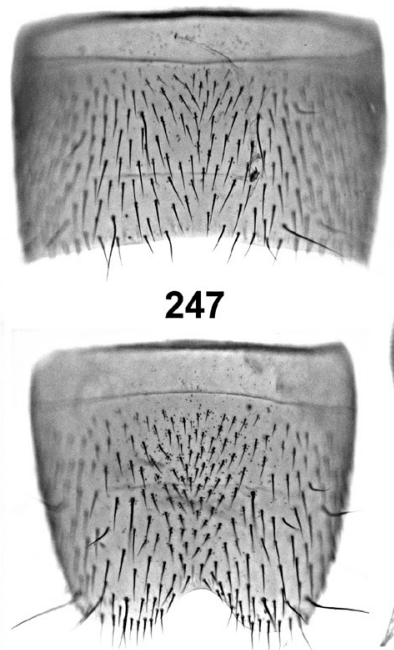

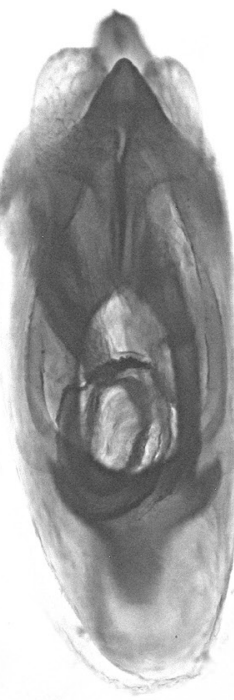

243

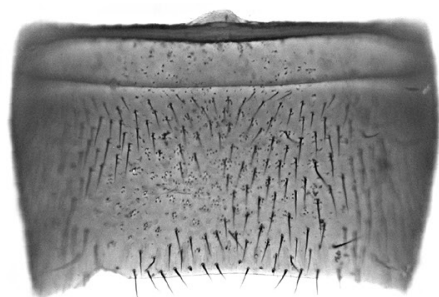

238

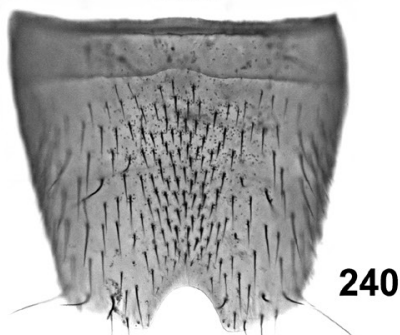

247

248

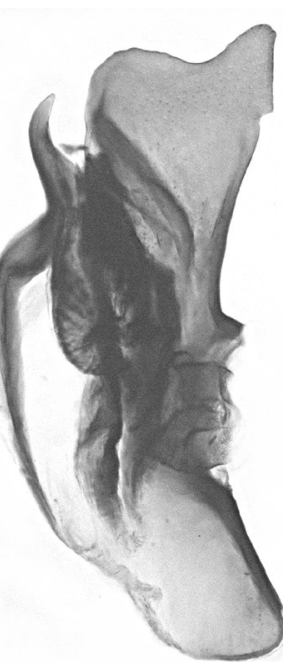

250

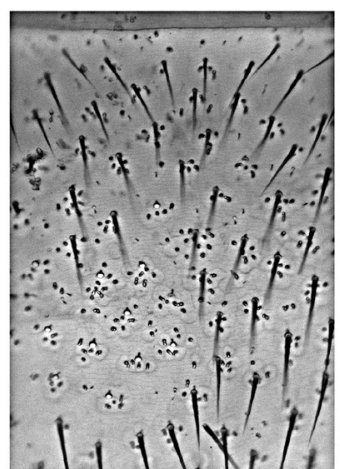

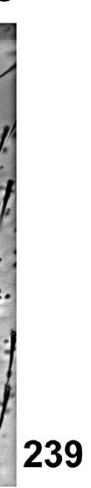

239
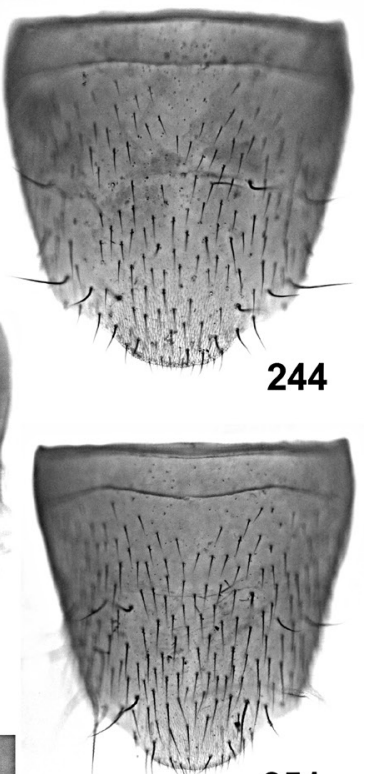

251

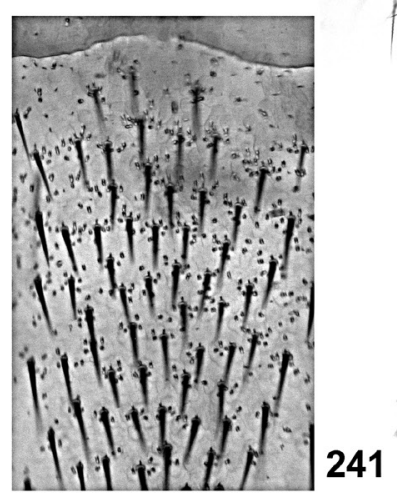

241

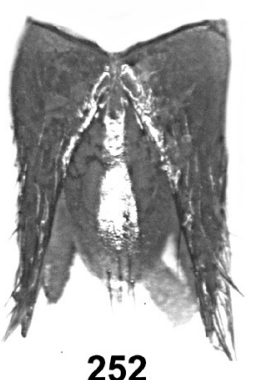

Figs 236-252: Lathrobium glandulosum (236-245) and L. secans (246-252): habitus (236); forebody (237, 246); male sternite VII $(238,247)$; anterior median portion of sternite VII (239); male sternite VIII $(240,248)$; anterior median portion of male sternite VIII $(241,249)$; aedeagus in lateral and in ventral view $(242-243,250)$; female sternite VIII $(244,251)$; female tergites IX-X (245, 252). Scale bars: 236-237, 246: $1.0 \mathrm{~mm}$; 238, 240, 242-245, 247-248, 250-252: $0.5 \mathrm{~mm} ; 239,241,249: 0.1 \mathrm{~mm}$. 
completely reduced. Protarsi without appreciable sexual dimorphism.

Abdomen slightly broader than elytra; punctation fine and moderately dense; microsculpture very shallow, on anterior tergites usually almost obsolete; posterior margin of tergite VII without palisade fringe; tergite VIII without sexual dimorphism, posterior margin obtusely angular in the middle.

$0^{*}$ : sternites III-VI unmodified; sternite VII (Fig. 238) distinctly transverse and symmetric, with numerous minute gland openings (Fig. 239), pubescence not distinctly modified, posterior margin broadly concave; sternite VIII (Fig. 240) symmetric and moderately transverse, with numerous minute gland openings in antero-median portion (Fig. 241), along the middle with rather dense, weakly modified short black setae, posterior excision almost semicircular; aedeagus (Figs 242-243) approximately $1.2 \mathrm{~mm}$ long, symmetric, and of highly distinctive shape; ventral process short, stout, and apically hooked; apical portion of dorsal plate short, broad (dorsal view), strongly sclerotized, bisinuate in lateral view, and apically pointed, basal portion lamellate, nearly straight, and much longer than apical portion; internal sac with long and dark membranous structures.

क: sternite VIII (Fig. 244) approximately $1.1 \mathrm{~mm}$ long and approximately as broad as long, posterior margin convexly produced in the middle; tergite IX (Fig. 245) with very short antero-median portion with median suture, and with moderately long postero-lateral processes extending slightly beyond apex of tergite $\mathrm{X}$; tergite X (Fig. 245) weakly convex in cross-section, approximately ten times as long as antero-median portion of tergite IX.

\section{Comparative notes:}

As can be inferred particularly from the shared and evidently synapomorphic presence of gland openings on the male sternites VII and VIII, L. glandulosum is allied to L. celere Assing, 2013 from the Gongga Shan in Sichuan. Both species additionally share a similar external morphology (slender habitus, oblong head, relatively long legs, coarse puncation and distinct microsculpture of the head) and similar sexual characters (absence of a sexual dimorphism of the protarsi; similar shapes and chaetotaxy of the male sternite VII and VIII, compact symmetric aedeagus with a short dorsal plate, similar shapes of the female sternite VIII and tergites IX and $\mathrm{X})$. Both species differ by the absence of a distinct sexual size dimorphism in L. glandulosum (pronounced in L. celere), the morphology of the aedeagus, the shape of the female sternite VIII (L. celere: distinctly oblong and more broadly convex posteriorly), and the length of the antero-median portion of the female tergite IX (longer in L. celere). For illustrations of L. celere see Assing (2013).
Distribution and natural history:

The species is known from several geographically close localities in the Gaoligong Shan, to the west of Gongshan (Map 7). The specimens were sifted from leaf litter, some of them in a mixed and a coniferous forest at altitudes of 2500-3400 m, partly together with L. abscisum, as well as the closely related L. secans or L. bidigitulatum. The sex ratio is biased in favour of females $\left(11 o^{*} o^{*}\right.$ : 29 우 우).

\subsubsection{Lathrobium secans sp. n. (Figs 246-252, Map 5)}

\section{Type material:}

Holotype ơ: "CHINA: N-Yunnan [2005-16], Nujiang Lisu Aut. Pref., Gongshan Co., Gaoligong Shan, sidevalley, $3000-3050 \mathrm{~m}, 27^{\circ} 47.90^{\prime} \mathrm{N}, 98^{\circ} 30.19^{\prime} \mathrm{E}$, conif. forest with Rhododendron, broad leaved bushes, litter, moss, dead wood sifted along creek and snowfields, 21.VI.2005, M. Schülke [2005-16] / Holotypus ơ Lathrobium secans sp. n. det. V. Assing 2013” (cSch). Paratypes: 1 o', 1 우 [1 teneral]: same data as holotype (cSch, cAss); $30^{*} 0^{*}$, 3 우 우 [3 teneral]: "CHINA: Yunnan [CH07-24], Nujiang Lisu Aut. Pref., Gaoligong Shan, valley 18 km W Gongshan, $3020 \mathrm{~m}, 27^{\circ} 47^{\prime} 54^{\prime \prime} \mathrm{N}, 98^{\circ} 30^{\prime} 13^{\prime \prime} \mathrm{E}$, mixed forest, litter, moss, wood sifted, 7.VI.2007, M. Schülke" (cSch, cAss); 1 ○े [teneral]: “CHINA: Yunnan [CH07-22], Nujiang Lisu Aut. Pref., Gaoligong Shan, valley $21 \mathrm{~km}$ W Gongshan, $3320 \mathrm{~m}, 27^{\circ} 47^{\prime} 03^{\prime \prime} \mathrm{N}, 98^{\circ} 27^{\prime} 39^{\prime \prime} \mathrm{E}$, moss, alder, bamboo, Rhodod., sifted, 6.VI.2007, M. Schülke" (cSch).

\section{Etymology:}

The specific epithet (present participle of the Latin verb secare: to cut) alludes to the laterally strongly compressed, blade-like ventral process of the aedeagus.

\section{Description:}

Species of moderate size and slender habitus; body length 7.8-9.0 mm; length of forebody 3.6-4.2 mm. Coloration: forebody reddish-brown to blackish-brown, usually with dark reddish elytra; abdomen reddish-brown to dark brown; legs and antennae reddish to reddish-brown. Head usually weakly dilated posteriorly, usually 1.051.08 times as long as broad. Other external characters (Fig. 246) as in L. glandulosum.

$\sigma^{*}$ : sternites III-VI unmodified; sternite VII (Fig. 247) distinctly transverse and symmetric, with sparse minute gland openings, pubescence not distinctly modified, posterior margin broadly concave; sternite VIII (Fig. 248) symmetric and distinctly transverse, with numerous minute gland openings in antero-median portion (Fig. 249), along the middle with somewhat denser, weakly modified, shorter black setae, posterior excision 
almost semicircular; aedeagus (Fig. 250) approximately $1.1 \mathrm{~mm}$ long, symmetric, and of highly distinctive shape; ventral process short, strongly compressed laterally, and subapically notched in lateral view; apical portion of dorsal plate short, broad (dorsal view), strongly sclerotized, strongly curved in lateral view, and apically acute, basal portion lamellate, nearly straight, and much longer than apical portion; internal sac with long and dark membranous structures.

ㅇ: sternite VIII (Fig. 251) approximately $1.0 \mathrm{~mm}$ long and very weakly transverse, posterior margin convexly produced in the middle; tergite IX (Fig. 252) with very short antero-median portion with median suture, and with rather long postero-lateral processes extending distinctly beyond apex of tergite X; tergite X (Fig. 252) weakly convex in cross-section, approximately ten times as long as antero-median portion of tergite IX.

\section{Comparative notes:}

Lathrobium secans is undoubtedly closely allied to L. glandulosum and other species of the L. celere group, as is suggested by the similar external and sexual characters, particularly the synapomorphic presence of gland openings on the male sternites VII and VIII. It is distinguished from the similar syntopic L. glandulosum by slightly smaller average body size, the slightly shorter and often posteriorly slightly dilated head, the more transverse male sternite VIII, the completely different shapes of the ventral process and the dorsal plate of the aedeagus, and the relatively long postero-lateral process of the female tergite IX.

\section{Distribution and natural history:}

The species was found in two geographically close localities in the Gaoligong Shan, to the west of Gongshan (Map 5). The specimens were sifted from leaf litter in a mixed and a coniferous forest at altitudes of 3000-3320 m, together with L. abscisum and the closely related L. glandulosum. Several specimens are teneral.

\subsubsection{Lathrobium acre sp. n. \\ (Figs 253-260, Map 7)}

\section{Type material:}

Holotype o": "CHINA (Yunnan) Nujiang Lisu Aut. Pref., Gaoligong Shan, pass $21 \mathrm{~km}$ NW Liuku, $3150 \mathrm{~m}$, $25^{\circ} 58^{\prime} 22^{\prime \prime N}, 98^{\circ} 41^{\prime} 00^{\prime \prime E ~(b a m b o o, ~ s h r u b s, ~ u n d e r ~ s t o n e s ~}$ along road) 9.VI.2007 D.W. Wrase [26] / Holotypus o Lathrobium acre sp. n. det. V. Assing 2013" (cAss).

\section{Etymology:}

The specific epithet (Latin, adjective: sharp) alludes to the laterally conspicuously compressed, blade-like ventral process of the aedeagus.

\section{Description:}

Species of rather large size and slender habitus (Fig. 253); body length $9.7 \mathrm{~mm}$; length of forebody $4.6 \mathrm{~mm}$. Coloration: whole body, including appendages, dark-reddish.

Head (Fig. 254) as broad as long; punctation moderately coarse and rather sparse; interstices with distinct fine microreticulation and subdued shine. Eyes approximately one fourth as long as postocular region in dorsal view and composed of approximately 40 ommatidia. Antenna $2.7 \mathrm{~mm}$ long.

Pronotum (Fig. 254) 1.25 times as long as broad and approximately as broad as head; punctation similar to that of head; impunctate midline moderately broad; interstices without microreticulation.

Elytra (Fig. 254) 0.55 times as long as pronotum; punctation shallow and weakly defined. Hind wings completely reduced.

Abdomen approximately 1.15 times as broad as elytra; punctation fine and rather sparse; interstices with very shallow microsculpture; posterior margin of tergite VII without palisade fringe.

$\sigma^{*}$ : protarsomeres I-IV strongly dilated; posterior margin of tergite VIII very weakly convex; sternites III-VI unmodified; sternite VII (Fig. 256) strongly transverse and symmetric, with minute gland openings, pubescence not distinctly modified, posterior margin broadly concave; sternite VIII (Fig. 256) symmetric and distinctly transverse, with numerous minute gland openings in antero-median portion (Fig. 257), pubescence not distinctly modified, slightly shorter and denser along the middle, posterior excision almost U-shaped; aedeagus (Figs 258-259) approximately $1.7 \mathrm{~mm}$ long, symmetric, and of highly distinctive shape; ventral process rather short, strongly compressed laterally, and with two distinct notches in lateral view; apical portion of dorsal plate moderately, broad (dorsal view), strongly sclerotized, strongly curved in lateral view, and apically extending into slender process (Fig. 260), basal portion lamellate, short, and very weakly sclerotized; internal sac with long and dark membranous structures.

\section{ㅇ: unknown}

\section{Comparative notes:}

Lathrobium acre clearly belongs to the L. celere group and is probably most closely related to L. secans, as is suggested by the similarly laterally compressed ventral process of the aedeagus. The species differs from both L. glandulosum and L. secans by the broader and less densely punctate head, the smaller eyes, the longer antennae, the narrower posterior excision of the male sternite VIII, the more strongly dilated protarsomeres 
I-IV, as well as by the different morphology of the ventral process and the dorsal plate of the much larger aedeagus.
Distribution and natural history:

The type locality is situated in the Gaoligong Shan, to the northwest of Liuku (Map 7). The holotype was sifted from litter in vegetation composed of bamboo and shrubs at an altitude of $3150 \mathrm{~m}$, together with $L$. desectum.

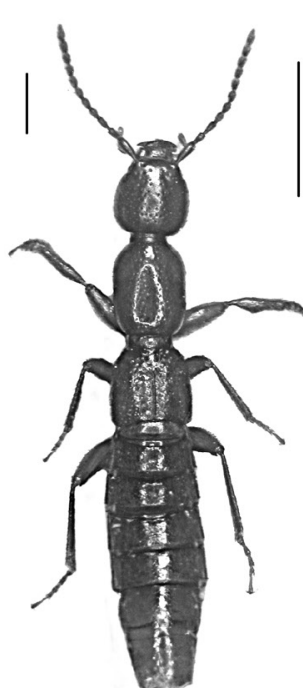

253

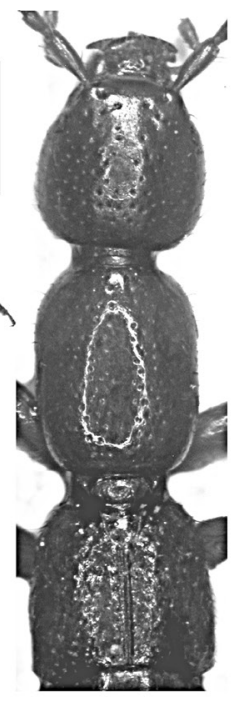

254

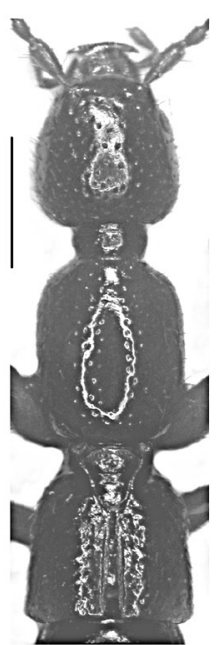

261

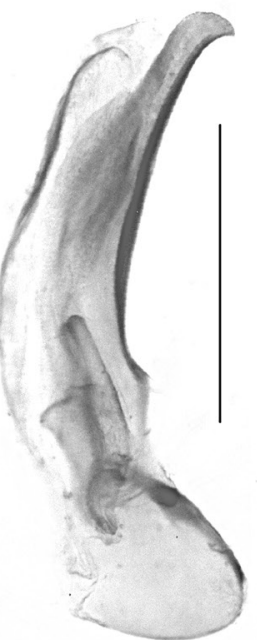

265
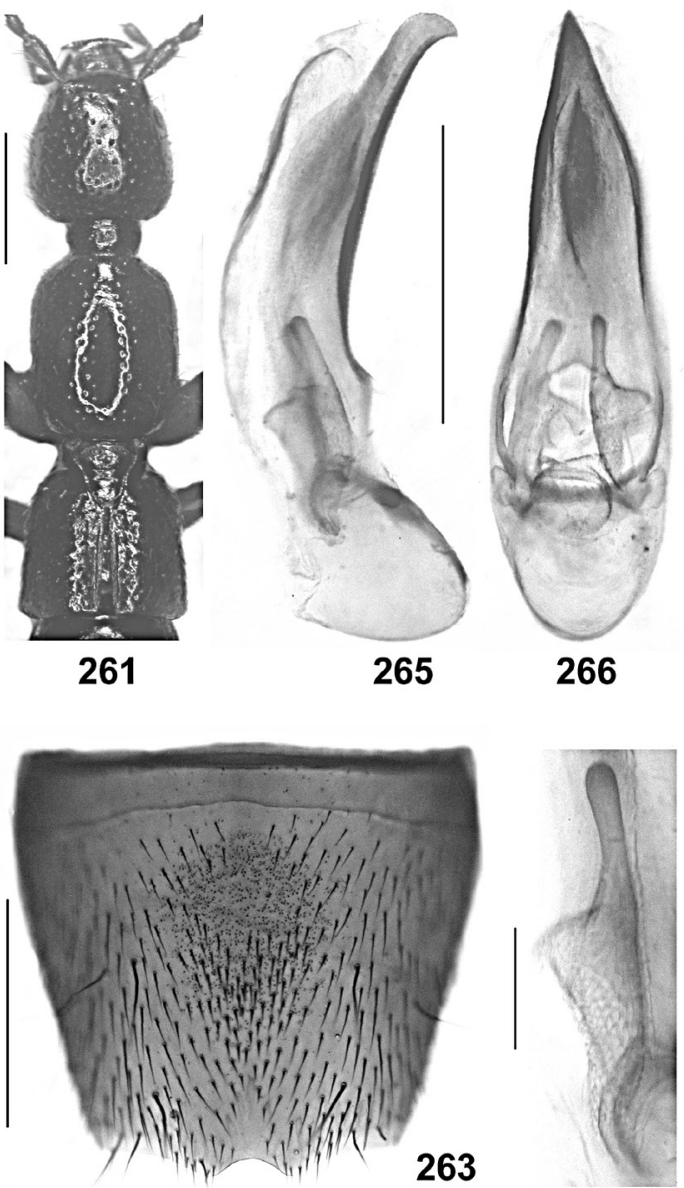

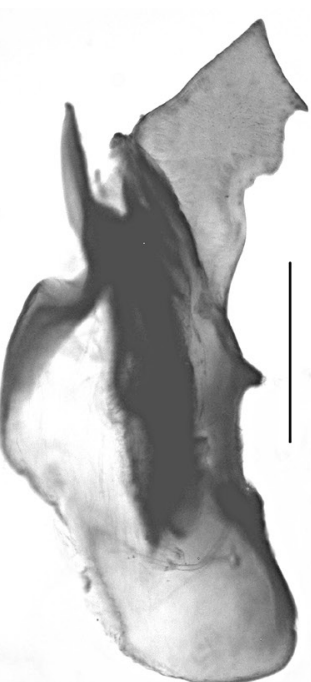

258

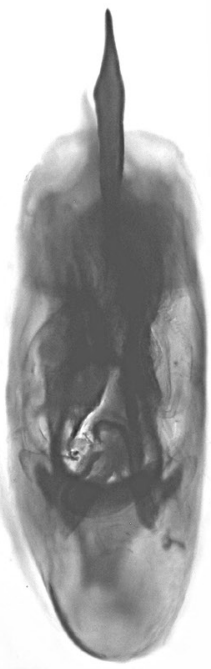

259

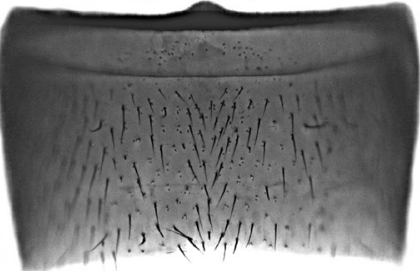

255

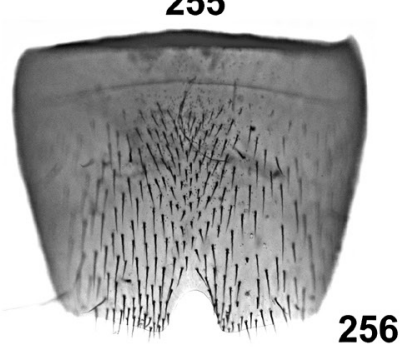

256
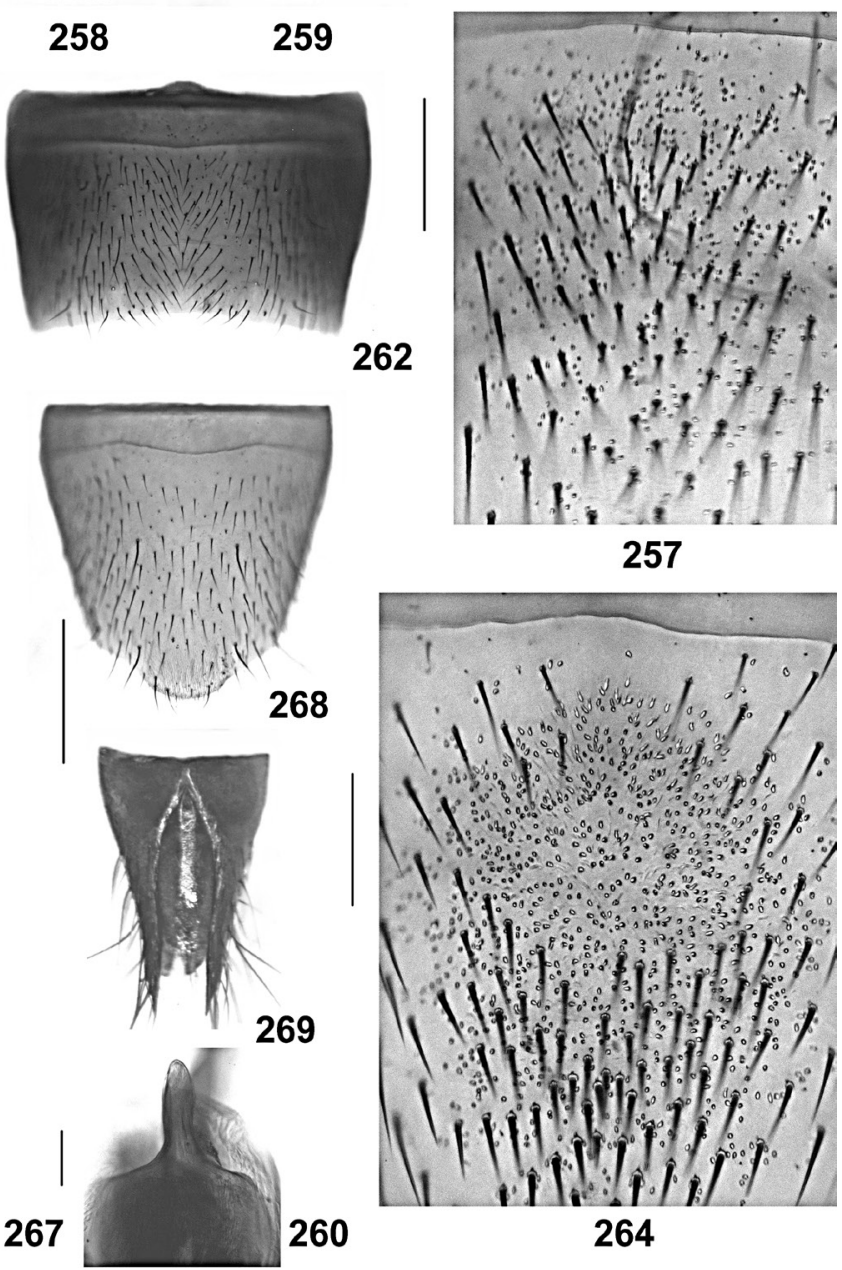

Figs 253-269: Lathrobium acre (253-260) and L. bidigitulatum (261-269): habitus (253); forebody (254, 261); male sternite VII (255, 262); male sternite VIII $(256,263)$; anterior median portion of male sternite VIII $(257,264)$; aedeagus in lateral and in ventral view (258-259, 265-266); apical portion of dorsal plate of aedeagus in dorsal view (260); internal structures of aedeagus in lateral view (267); female sternite VIII (268); female tergites IX-X (269). Scale bars: 253-254, 261: 1.0 mm; 255-256, 258-260, 262-263, 265-269: $0.5 \mathrm{~mm} ; 257,264: 0.1 \mathrm{~mm}$. 


\subsubsection{Lathrobium bidigitulatum sp. $\mathrm{n}$. (Figs 261-269, Map 6)}

\section{Type material:}

Holotype ơ: "P.R. CHINA, Yunnan, E slope N Gaoli-

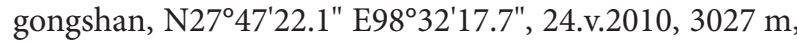
sifting20, V. Grebennikov / Holotypus o Lathrobium bidigitulatum sp. n. det. V. Assing 2013" (CAS). Paratypes: $1 \sigma^{*}$ : same data as holotype (cAss); $1 \sigma^{\top}, 1$ ㅇ: same data, but "sifting21" (cSme, cAss); $100^{\top} \sigma^{\top}, 8$ ㅇ o : "P.R. CHINA, Yunnan, E slope N Gaoligongshan, N27 $46.8^{\prime} \mathrm{E} 98^{\circ} 33.1^{\prime}$, 12-15.vi.2009, 2000-3000 m, sifting1-7, V. Grebennikov" (CAS, cSme, cAss); 1 \%: "CHINA: Yunnan [CH07-24], Nujiang Lisu Aut. Pref., Gaoligong Shan, valley 18 km W Gongshan, $27^{\circ} 47^{\prime} 54^{\prime \prime} \mathrm{N}, 98^{\circ} 30^{\prime} 13^{\prime \prime} \mathrm{E}, 3020 \mathrm{~m}$, mixed forest, litter, moss, wood sifted, 7.VI.2007, A. Pütz" (cPüt).

\section{Etymology:}

The specific epithet is composed of the Latin prefix bi(two) and an adjective derived from the Latin noun digitulum (small finger) and refers to the presence of a pair of finger-shaped structures in the internal sac of the aedeagus.

\section{Description:}

Species of moderately large, rather variable size and rather slender habitus; body length 7.5-10.0 mm; length of forebody 3.6-4.4 mm. Coloration: body dark-brown to blackish-brown, usually with slightly paler elytra; legs reddish to dark-brown; antennae reddish to reddish-brown.

Head (Fig. 261) approximately as long as broad, usually slightly dilated posteriad; punctation rather coarse and rather sparse, particularly in median dorsal portion; interstices with distinct microreticulation and nearly matt. Eyes moderately small, of somewhat variable size, on average approximately one third as long as postocular region and composed of more than 50 ommatidia. Antenna 2.0-2.4 mm long.

Pronotum (Fig. 261) moderately slender, approximately 1.25 times as long as broad and slightly broader than head; punctation rather sparse and fine, similar to that of head or slightly finer; interstices without microsculpture and glossy; impunctate midline moderately broad.

Elytra (Fig. 261) approximately 0.55 times as long as pronotum; punctation shallow and usually weakly defined. Hind wings completely reduced. Protarsi with very weak sexual dimorphism.

Abdomen slightly broader than elytra; punctation fine and dense; microsculpture shallow; posterior margin of tergite VII without palisade fringe; tergite VIII without sexual dimorphism, posterior margin weakly angular in the middle. $\sigma^{*}$ : sternites III-VI unmodified; sternite VII (Fig. 262) distinctly transverse and symmetric, without gland openings, pubescence not distinctly modified, posterior margin broadly concave; sternite VIII (Fig. 263) symmetric and weakly transverse, with cluster of numerous minute gland openings without interspersed setae in antero-median portion (Fig. 264), anterior to this cluster with somewhat shorter setae, pubescence otherwise unmodified, posterior excision small and shallow, posterior margin on either side of this excision slightly produced; aedeagus (Figs 254-266) small in relation to body size, approximately $1.0 \mathrm{~mm}$ long and symmetric; ventral process relatively short, not laterally compressed, and subapically hooked; dorsal plate with moderately long, moderately sclerotized, lamellate apical portion and with moderately long, very thin, and weakly sclerotized basal portion; internal sac with two moderately sclerotized, somewhat finger-shaped internal structures (Fig. 267).

\%: sternite VIII (Fig. 268) approximately 1.0-1.1 mm long and approximately as broad as long, posterior margin convexly produced in the middle; tergite IX (Fig. 269) with very short antero-median portion with median suture, and with moderately long postero-lateral processes extending distinctly beyond apex of tergite $\mathrm{X}$; tergite X (Fig. 269) nearly flat, approximately ten times as long as antero-median portion of tergite IX.

\section{Comparative notes:}

The presence of gland openings on the male sternite VIII indicates that L. bidigitulatum, too, belongs to the L. celere species group. It differs from other representatives of this group by the completely different shape of the aedeagus, the shape and chaetotaxy of the male sternite VIII (particularly the shape of the posterior excision and the defined and dense cluster of gland openings without interspersed setae), and the shape of the female sternite VIII, from most species also by the less oblong pronotum, the sparser punctation of the head, the shorter, usually somewhat wedge-shaped head, and the larger eyes.

\section{Distribution and natural history:}

The species is known only from a small area in the northern Gaoligong Shan (Map 6), where the specimens were sifted from leaf litter at an altitude of approximately $3030 \mathrm{~m}$, as well as somewhere between 2000 and $3000 \mathrm{~m}$, together with L. abscisum and the closely related L. glandulosum. 


\subsection{The L. curvatissimum species group}

\subsubsection{Lathrobium curvatissimum sp. n. (Figs 270-275, Map 7)}

\section{Type material:}

Holotype o [teneral]: "CHINA: Yunnan, Dali Bai Aut. Pref., Jizu Shan, path to cable car, $37 \mathrm{~km}$ NE Dali, $25^{\circ} 58^{\prime} \mathrm{N}$, $100^{\circ} 23^{\prime} \mathrm{E}, 2450 \mathrm{~m}$, mixed forest, sifted from litter, moss \& pine apples, 5.IX.2009, leg. M. Schülke [CH09-29] / Holotypus o Lathrobium curvatissimum sp. n. det. V. Assing 2013" (cAss). Paratypes: $10^{\star}$ [teneral]: same data as holotype (cSch); 2 + + : "CHINA: Yunnan province, Shanzhi env., 22.-24.VI.2007, Jizu Shan Mt., 2180-2580 m, along the path to the summit, $27^{\circ} 57.7-8^{\prime} \mathrm{N}$ [evidently erroneous; probably $25^{\circ}$ ], $100.22 .1-23.6^{\prime} \mathrm{E}, \mathrm{J}$. Hájek \& J. Růžička leg. / sifted detritus and leaves, dense mixed forest (with dominant Quercus, Pinus and Rhododendron) near stream [Ch45-47]" (cSch, cAss).

\section{Etymology:}

The specific epithet (Latin, adjective) alludes to the strongly curved ventral process of the aedeagus.

\section{Comment:}

The two females were not collected together with the males and are slightly smaller. Nevertheless, they are hypothesized to be conspecific based on the otherwise similar external characters. Sexual size dimorphisms are not uncommon among the Lathrobium species of China (Assing in press a). Lathrobium celere, too, is subject to a pronounced sexual dimorphism (Assing 2013)

\section{Description:}

Species of moderate size, apparently with sexual size dimorphism; body length 7.3-7.8 $\mathrm{mm}$ ( $\left.\sigma^{\star} \sigma^{\star}\right), 6.7-7.3 \mathrm{~mm}$ ( ㅇ ㅇ ); length of forebody 3.9-4.0 mm ( $\left.\sigma^{\star} \sigma^{\star}\right), 3.4-3.8 \mathrm{~mm}$ (우우). Coloration: body black; legs and antennae reddish.

Head (Fig. 270) approximately as long as broad or weakly oblong; punctation moderately coarse and moderately dense, somewhat sparser in median dorsal portion; interstices with very shallow microreticulation and somewhat glossy. Eyes moderately small, approximately one third the length of postocular region in dorsal view and composed of approximately 40-50 ommatidia. Antenna 1.9 $2.2 \mathrm{~mm}$ long.

Pronotum (Fig. 270) approximately 1.3 times as long as broad and 1.05 times as broad as head; punctation similar to that of head; interstices without microsculpture and glossy; impunctate midline moderately broad, somewhat irregular.
Elytra (Fig. 270) approximately 0.52 times as long as pronotum and rather slender; punctation rather dense and fine. Hind wings completely reduced. Protarsi with pronounced sexual dimorphism.

Abdomen slender, only slightly broader than elytra; punctation fine and very dense; interstices with shallow microsculpture; posterior margin of tergite VII without palisade fringe; tergite VIII without appreciable sexual dimorphism, posterior margin weakly convex.

$\sigma^{\star}$ : sternites III-VI unmodified; sternite VII (Fig. 271) moderately transverse, symmetric, with shallow median impression posteriorly, pubescence very weakly modified, posterior margin broadly and weakly concave, anterior margin without median process; sternite VIII (Fig. 272) symmetric, moderately transverse, posteriorly with weakly modified black setae, posterior margin very weakly concave in the middle; aedeagus (Fig. 273) approximately $1.6 \mathrm{~mm}$ long, symmetric; ventral process conspicuously long, slender, and strongly curved in lateral view; dorsal plate straight in lateral view; internal sac with pair of relatively slender, broad-based, and apically acute spines.

ㅇ: sternite VIII (Fig. 274) approximately $1.2 \mathrm{~mm}$ long, distinctly oblong, and convexly produced posteriorly; tergite IX (Fig. 275) with long and undivided median portion without suture, and with moderately long postero-lateral processes; tergite X (Fig. 275) flat, slightly shorter than antero-median portion of tergite IX.

\section{Comparative notes:}

Lathrobium curvatissimum is readily distinguished from the syntopic L. jizushanense by the distinctly more slender pronotum, the more slender elytra, the different shapes of the male sternites VII and VIII, the much more oblong female sternite VIII, the anteriorly much longer and undivided antero-median portion of the female tergite IX, the flat and much shorter female tergite $\mathrm{X}$, and particularly by the completely different morphology of the aedeagus. It differs from the sympatric L. zhangi by larger size and by the different morphology of the aedeagus. For illustrations of L. jizushanense and L. zhangi see Figs 56-63 and WatANABE \& XiaO (1997).

Distribution and natural history:

Lathrobium curvatissimum was collected in two geographically close localities in the Jizu Shan, to the northeast of Dali (Map 7). The specimens were sifted from leaf litter in mixed forests at an altitude of 2180-2580 m, together with L.jizushanense. The two male types are teneral. 
4.4.2 Lathrobium yinae WATANABE \& XIA0, 1997 (Figs 276-282, Map 7)

Material examined:

China: Yunnan: $2 \sigma^{\top} \sigma^{\top}, 1+, 35 \mathrm{~km} \mathrm{~N}$ Lijiang, Heishui, $27^{\circ} 13^{\prime} \mathrm{N}, \quad 100^{\circ} 19^{\prime} \mathrm{E}, \quad 18 . \mathrm{VI} .-4 . V I I .1993$, leg. S. Becvar (NHMW, cAss); $10^{*}$ [teneral], 1 ㅇ, $50 \mathrm{~km} \mathrm{~N}$ Lijiang,
Yulongxue Shan Nature Reserve, 24.-29.VI.1993, leg. Jendek \& Sausa (NHMW, cAss); 1 ㅇ, Lijiang Naxi Aut. Co., $30 \mathrm{~km} \mathrm{~N}$ Lijiang, E Yulongxue Shan, $27^{\circ} 09.0^{\prime} \mathrm{N}$ $100^{\circ} 14.9^{\prime} \mathrm{E}, 2800-2900 \mathrm{~m}, 13 . \mathrm{VIII} .2003$, leg. Smetana (cSme).

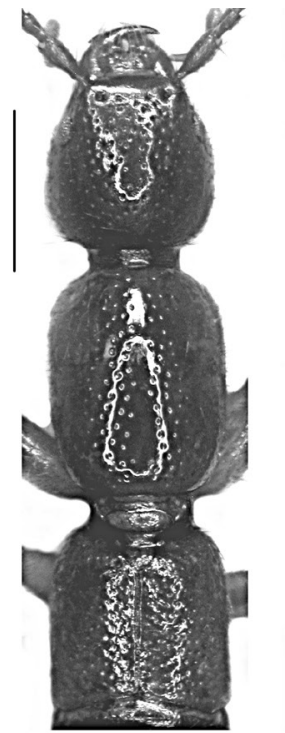

270

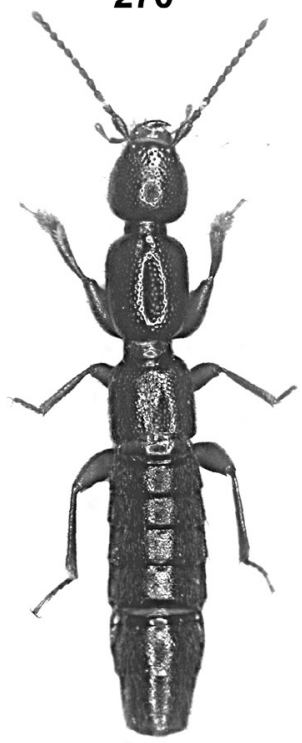

276

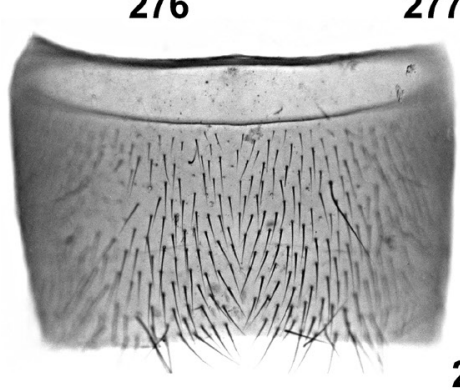

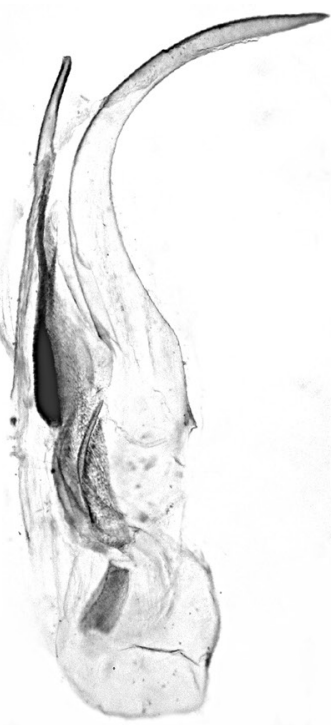

273

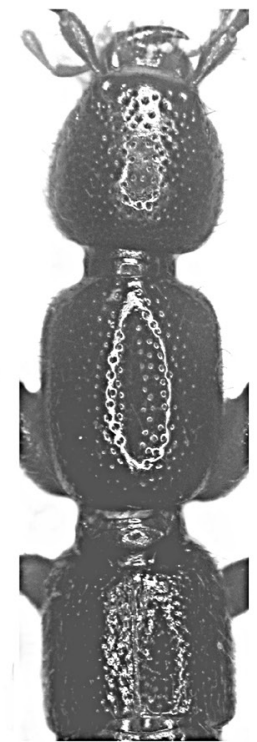

277

271

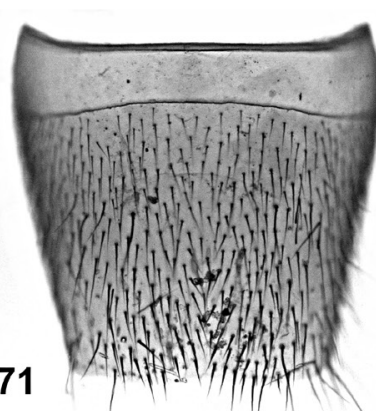

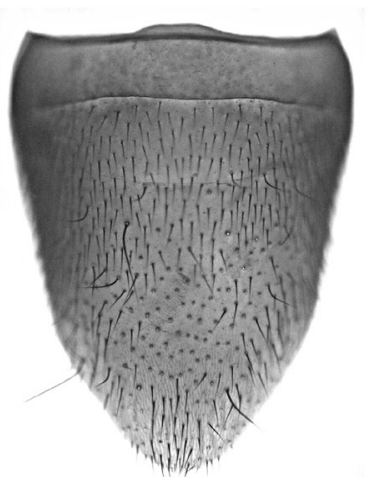

281

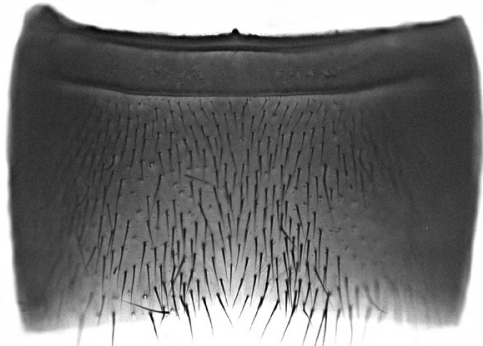

278

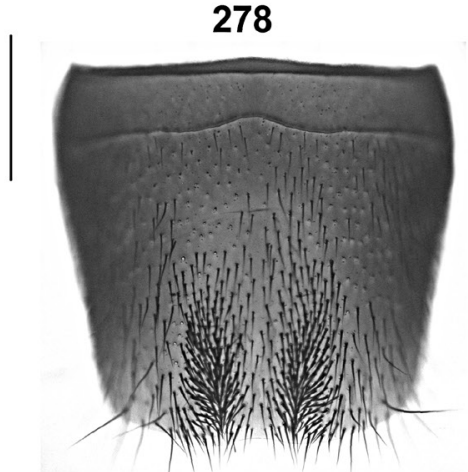

279

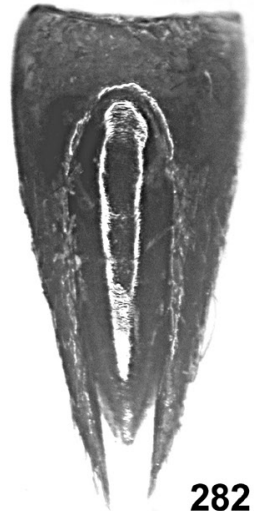

282
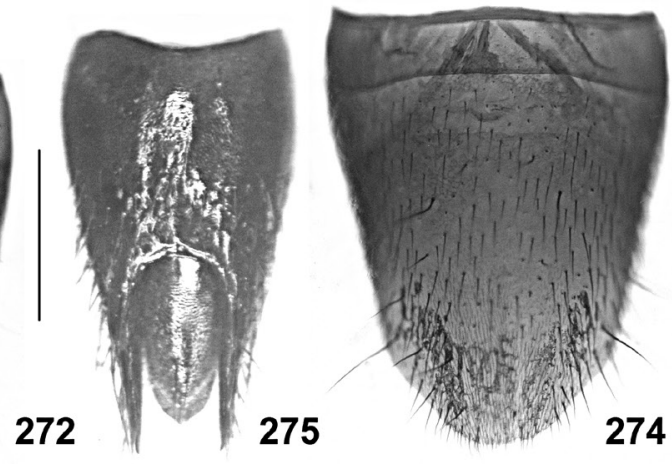

Figs 270-282: Lathrobium curvatissimum (270-275) and L. yinae (276-282): forebody (270, 277); male sternite VII (271, 278); male sternite VIII $(272,279)$; aedeagus in lateral view $(273,280)$; female sternite VIII $(274,281)$; female tergites IX-X $(275,282)$; habitus (276). Scale bars: 270, 276-277: $1.0 \mathrm{~mm} ; 271-275,278-282: 0.5 \mathrm{~mm}$. 


\section{Comment:}

The original description is based on a male holotype and two paratypes (a teneral male and a female) from "Mt. Yulongxue Shan, Lijiang Xian" (Watanabe \& Xiao 1997). The measurements of the body and the forebody (“6.5-7.0 mm" and "2.9-3.1 mm", respectively) indicated in the description, as well as the scale provided with the drawings of the aedeagus (suggesting a length of $0.9 \mathrm{~mm}$ ) are undoubtedly inaccurate. According to photos of a non-type male of L. yinae from the Yulonxue Shan sent to me by Zhong Peng, which are in complete agreement with the illustrations provided by WATANABE \& XIAO (1997), the aedeagus of that particular specimen is $2.4 \mathrm{~mm}$ long.

The aedeagus of the examined material is $2.2-2.3 \mathrm{~mm}$ long and has the ventral process somewhat more strongly curved in lateral view than illustrated in the original description and in the photo of the non-type male. However, additional differences were found neither in external characters (photo of the habitus of the holotype examined), nor in the shapes and chaetotaxy of the male sternites VII and VIII (based on a comparison with the original description and with photos of the additional male). Therefore, the observed differences in the shape of the ventral process of the aedeagus are attributed to intrarather than interspecific variation.

\section{Description:}

Species of rather large size; body length $8.5-10.0 \mathrm{~mm}$; length of forebody 4.5-4.9 mm. Habitus as in Fig. 276. Coloration: body black; legs and antennae dark-reddish to brown.

Head (Fig. 277) 1.00-1.05 times as broad as long; punctation moderately coarse and rather dense, somewhat sparser in median dorsal portion; interstices with fine microreticulation. Eyes moderately small, approximately 0.4 times as long as postocular region in dorsal view and composed of $>50$ ommatidia. Antenna 1.9$2.1 \mathrm{~mm}$ long.

Pronotum (Fig. 277) approximately 1.3 times as long as broad and 1.05 times as broad as head; punctation similar to that of head; interstices without microsculpture and glossy; impunctate midline moderately broad.

Elytra (Fig. 277) approximately 0.53 times as long as pronotum and not particularly broad; punctation rather dense and fine. Hind wings completely reduced. Protarsi with moderately pronounced sexual dimorphism.

Abdomen approximately 1.15 times as broad as elytra; punctation fine and very dense; interstices with shallow microsculpture; posterior margin of tergite VII without palisade fringe; tergite VIII without sexual dimorphism, posterior margin weakly convex. $o^{*}$ : sternites III-VI unmodified; sternite VII (Fig. 278) distinctly transverse, symmetric, with shallow median impression posteriorly, pubescence very weakly modified, posterior margin broadly and weakly concave, anterior margin with minute median process; sternite VIII (Fig. 279) symmetric, weakly transverse, with pair of oblong clusters of moderately modified, very dense black setae in posterior half, posterior margin convex, in the middle very weakly concave; aedeagus (Fig. 280) 2.2$2.3 \mathrm{~mm}$ long, symmetric, and with small basal portion; ventral process long, slender, and smoothly curved in lateral view; dorsal plate with very long, slender, apically acute, basally strongly curved, and distinctly sclerotized apical portion, and with minute basal portion; internal sac with long dark membranous structures.

ㅇ: sternite VIII (Fig. 281) approximately $1.6 \mathrm{~mm}$ long, distinctly oblong, and with strongly convex posterior margin; tergite IX (Fig. 282) slender, with rather short antero-median portion without median suture, and with conspicuously long and straight postero-lateral processes; tergite X (Fig. 282) very long and slender, moderately convex in cross-section, apically acute, and approximately five times as long as antero-median portion of tergite IX.

\section{Comparative notes:}

The similar morphology of the aedeagus (long and curved ventral process; long apical portion of dorsal plate) and the similar shapes of the male sternite VIII and of the female tergite IX (slender shape; antero-median portion undivided, without suture), as well as the similar external appearance suggest that L. yinae is affiliated to L. curvatissimum, from which it differs by distinctly larger size, larger eyes, and the sexual characters.

\section{Distribution and natural history:}

Lathrobium yinae was collected in several geographically close localities in the Yulongxue Shan, to the north of Lijiang. One of the examined specimens was found at an altitude of 2800-2900 m; the labels of the remaining specimens do not indicate any altitudes. One of the specimens collected in June is teneral.

\subsubsection{Lathrobium stipiferum sp. n. (Figs 283-289, Map 7)}

Type material:

Holotype $o^{\star}$ : "CHINA: Yunnan province, $1 \mathrm{~km} \mathrm{~W}$ of Haba, 19.VI.2007, Haba Xueshan Mts., 27²2.3'N, $100^{\circ} 07.7^{\prime} \mathrm{E}$, 2750 m, J. Hájek \& J. Růžička leg. [CH36] / sifted wet detritus and leaves under rocks, margin of mixed forest (with dominant Pinus, Aesculus) near small stream close to village / Holotypus $\sigma^{*}$ Lathrobium stipiferum sp. n. det. V. Assing 2013” (cSch). Paratypes: $10^{\star}$ : same data as holotype (cAss); 1 o: "CHINA: Yunnan province, $3 \mathrm{~km}$ SW of Haba, 19.VI.2007, Haba Xueshan Mts., 
$27^{\circ} 22.3^{\prime} \mathrm{N}, 100^{\circ} 06.5^{\prime} \mathrm{E}, 3200$ m, J. Hájek \& J. Růžička leg. [CH38] / sifted wet detritus, leaves and mosses in more humid depressions, margin of sparse mixed forest (with dominant Pinus, Abies, Quercus) (cAss); 1 i: "YUNNAN 3000-3800 m, 27.20N 100.09E, Habashan mts., E slope 13-17.7.92, David Král leg." (NHMB).

\section{Etymology:}

The specific epithet (Latin, adjective: carrying a pole) alludes to the conspicuously long, straight, and massive dorsal plate of the aedeagus.

\section{Description:}

Species of rather large size; body length 9.0-10.0 mm; length of forebody 4.3-4.5 mm. Habitus as in Fig. 283 . Coloration: body black; legs and antennae dark-reddish to brown.
External characters (Figs 283-284) as in L. yinae, except for the slightly smaller eyes and the slightly less dense punctation of the abdomen.

${ }^{*}$ : sternites III-VI unmodified; sternite VII (Fig. 285) distinctly transverse, symmetric, with shallow median impression posteriorly, pubescence not distinctly modified, posterior margin broadly and weakly concave, anterior margin with minute median process; sternite VIII (Fig. 286) symmetric, distinctly transverse, with a pair of weakly defined clusters of weakly modified, moderately dense black setae in posterior half, posterior margin weakly concave; aedeagus (Fig. 287) approximately $1.9 \mathrm{~mm}$ long, symmetric, and with small basal portion; ventral process long, slender, subapically curved, and apically hooked in lateral view; dorsal plate with conspicuously long, massive, straight, and strongly sclero-

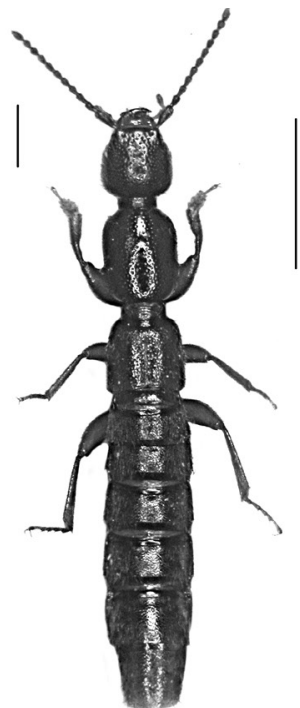

283

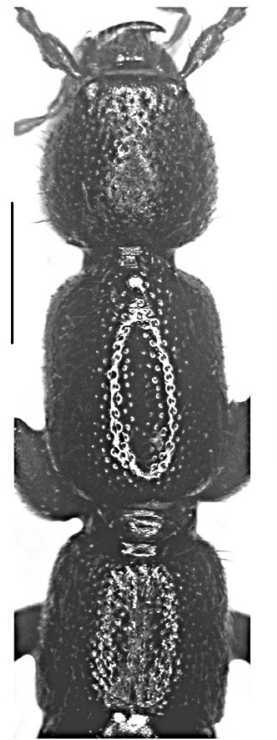

290

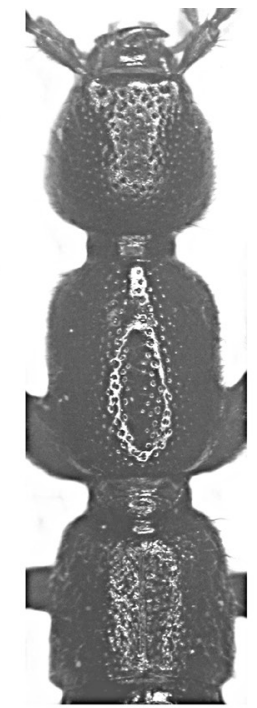

284

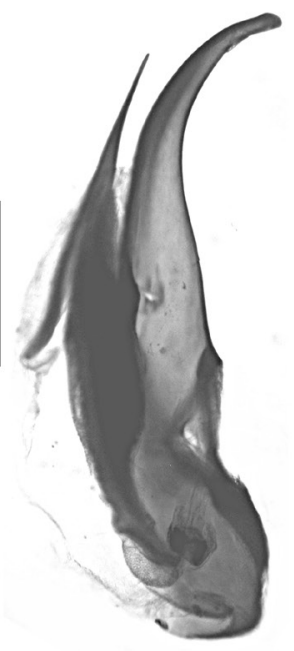

293

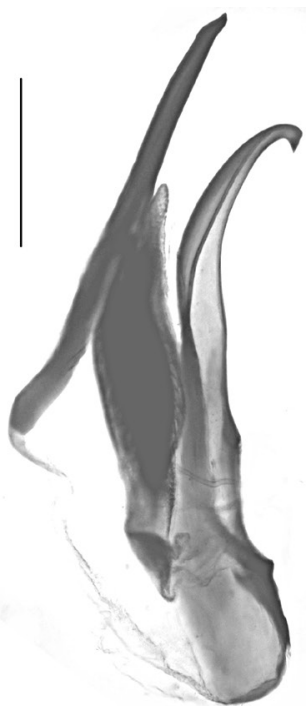

287

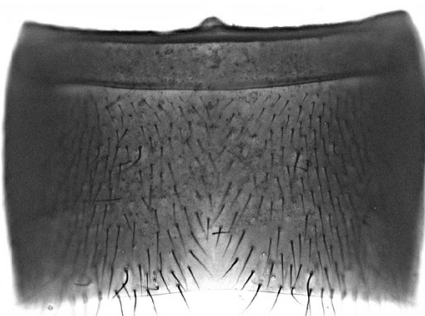

291

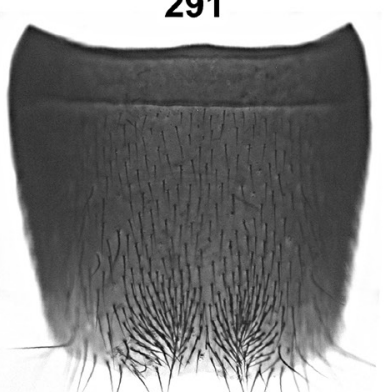

292

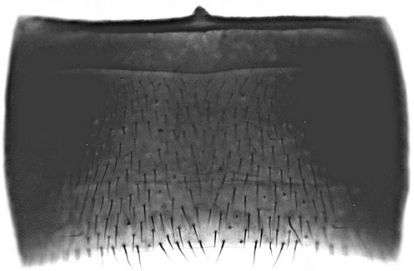

285
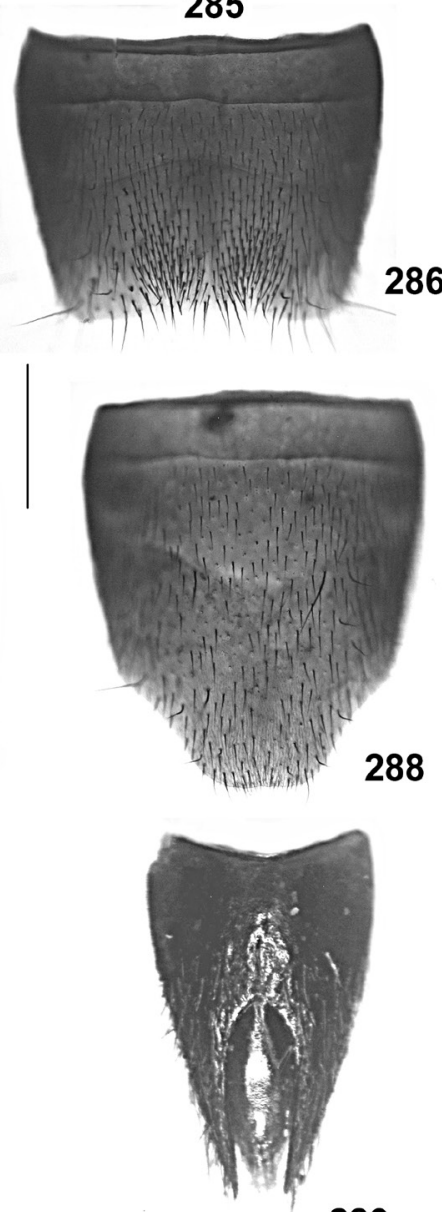

289

Figs 283-293: Lathrobium stipiferum (283-289) and L. incurvatum (290-293): habitus (283); forebody (284, 290); male sternite VII $(285,291)$; male sternite VIII $(286,292)$; aedeagus in lateral view $(287,293)$; female sternite VIII $(288)$; female tergites IX-X (289). Scale bars: 283-284, 290: $1.0 \mathrm{~mm}$; 285-289, 291-293: $0.5 \mathrm{~mm}$. 
tized apical portion and with very short, fine, and almost unsclerotized basal portion; internal sac with large dark membranous structure.

ㅇ: sternite VIII $1.4 \mathrm{~mm}$ long, moderately oblong, and with strongly convex posterior margin; tergite IX (Fig. 289) moderately slender, with long antero-median portion without median suture, and with moderately long postero-lateral processes; tergite X (Fig. 289) weakly convex in cross-section and slightly longer than anteromedian portion of tergite IX.

\section{Comparative notes:}

As can be inferred from the similar morphology of the aedeagus (ventral process long, slender, and curved; long apical portion of dorsal plate), from the similar male and female secondary sexual characters, and from the similar external morphology, L. stipiferum is allied to L. yinae and the distinctly smaller L. curvatissimum. It differs from the externally similar L. yinae particularly by the male and female sexual characters.

Distribution and natural history:

The species was collected in three geographically close localities in the Haba Shan, Yunnan (Map 7). Except for one female without exact data, the specimens were sifted from moist leaf litter in mixed forests at altitudes of 2750 and $3200 \mathrm{~m}$.

\subsubsection{Lathrobium incurvatum sp. n.} (Figs 290-293, Map 7)

Type material:

Holotype ơ: "CHINA: N-Yunnan [C03-05], Zhongdian [today: Shangri-La] Co., $46 \mathrm{~km}$ SSE Zhongdian, $27^{\circ} 27.0^{\prime} \mathrm{N}, 99^{\circ} 54.7^{\prime} \mathrm{E}, 3050-3100 \mathrm{~m}$, creek valley, secondary mixed forest, bamboo, mushrooms, 17.VIII.2003, leg. M. Schülke / Holotypus o Lathrobium incurvatum sp. n. det. V. Assing 2013" (cAss).

\section{Etymology:}

The specific epithet (Latin, adjective) alludes to the distinctly curved ventral process of the aedeagus.

\section{Description:}

Species of large size; body length $10.5 \mathrm{~mm}$; length of forebody $4.9 \mathrm{~mm}$. Eyes rather small, approximately one third as long as postocular region in dorsal view. Other external characters (Fig. 290) as in L. yinae.

$0^{\top}$ : sternites III-VI unmodified; sternite VII (Fig. 291) distinctly transverse, symmetric, pubescence not distinctly modified, posterior margin broadly and weakly concave, anterior margin with minute median projection; sternite VIII (Fig. 292) symmetric, moderately transverse, with pair of ill-defined clusters of moderately modified, dense black setae in posterior half, posterior margin weakly concave in the middle; aedeagus (Fig. 293) $1.9 \mathrm{~mm}$ long, symmetric, and with small basal portion; ventral process stout basally and slender apically, smoothly curved in lateral view; dorsal plate with distinctly sclerotized, long, thin, straight, and apically very acute apical portion in lateral view, and with minute basal portion; internal sac with long dark membranous structures.

\section{ㅇ: unknown}

\section{Comparative notes:}

As can be inferrend from the similar external characters and particularly by the similarly derived male sexual characters (chaetotaxy of the male sternite VIII; large aedeagus with long and curved ventral process and with long apical portion of the dorsal plate), L. incurvatum is closely related to L. yinae and allied species. It is distinguished from them particularly by the morphology of the aedeagus and by the shape and chaetotaxy of the male sternite VIII, from L. yinae additionally by the slightly smaller eyes.

\section{Distribution and natural history:}

The type locality is situated near the Baiyanzi Shan in a mountain range to the south-southeast of Zhongdian (Map 7), where the holotype was sifted from leaf litter in a secondary mixed forest with bamboo at an altitude of 3050-3100 m.

\subsection{The L. squamosum species group}

\subsubsection{Lathrobium squamosum sp. n. (Figs 294-301, Map 7)}

\section{Type material:}

Holotype ơ: "CHINA: Yunnan [CH07-19], Dehong Dai Aut. Pref., mountain range $31 \mathrm{~km}$ E Luxi [= Mangshi], $2280 \mathrm{~m}, 24^{\circ} 29^{\prime} 31^{\prime \prime} \mathrm{N}, 98^{\circ} 52^{\prime} 58^{\prime \prime} \mathrm{E}$, secnd. pine forest with old decid. trees, litter sifted, 3.VI.2007, M. Schülke / Holotypus ơ Lathrobium squamosum sp. n. det. V. Assing 2013" (cSch). Paratypes: $20^{\star} o^{\star}, 3$ i 9 : same data as holotype (cSch, cAss); 1 ㅇ: same data, but leg Wrase (cSch); $3 o^{*} o^{*}$ : same data, but leg. Pütz (cPüt, cAss).

\section{Etymology:}

The specific epithet (Latin, adjective: scaly) alludes to scaly sculpture of the internal structures of the aedeagus.

\section{Description:}

Species of moderate size; body length 7.0-8.0 mm; length of forebody 3.1-3.5 mm. Protarsomeres I-IV without sexual dimorphism, of variable width in both sexes. Other external characters (Fig. 294) as in L. daliense. 
$0^{7}$ : sternites III-VI unmodified; sternite VII (Fig. 295) moderately transverse, symmetric, in posterior median portion with few very weakly modified black setae, posterior margin truncate; sternite VIII (Fig. 296) weakly transverse, symmetric, pubescence not distinctly modified, posterior excision distinct and almost
U-shaped; aedeagus (Figs 297-298) approximately $0.9 \mathrm{~mm}$ long and symmetric; ventral process relatively short and stout, laterally compressed, and apically of distinctive shape; dorsal plate with weakly sclerotized, short, and somewhat convex (cross-section) apical portion, and with unsclerotized, moderately long basal

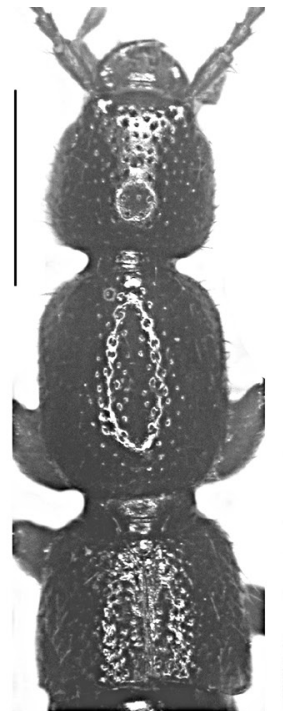

294

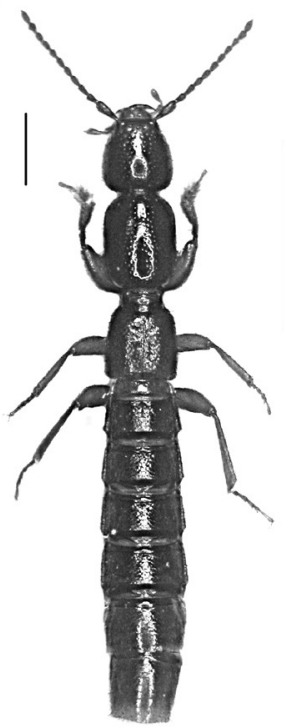

302

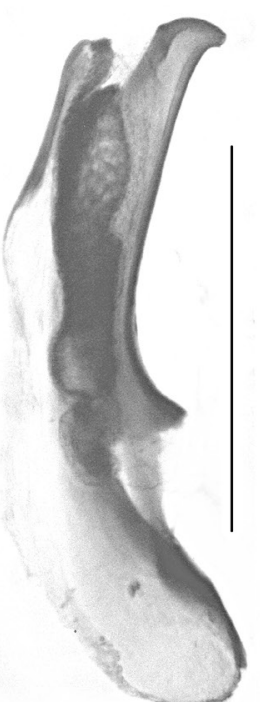

297

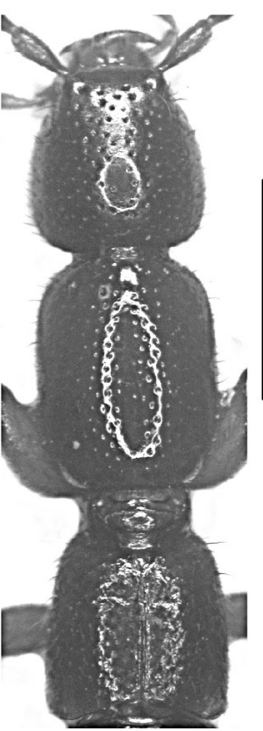

303

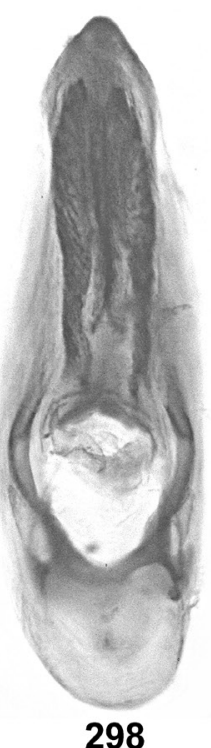

298
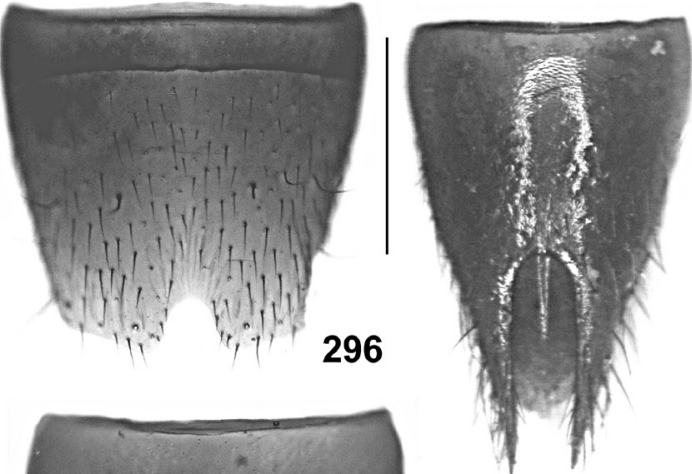

301

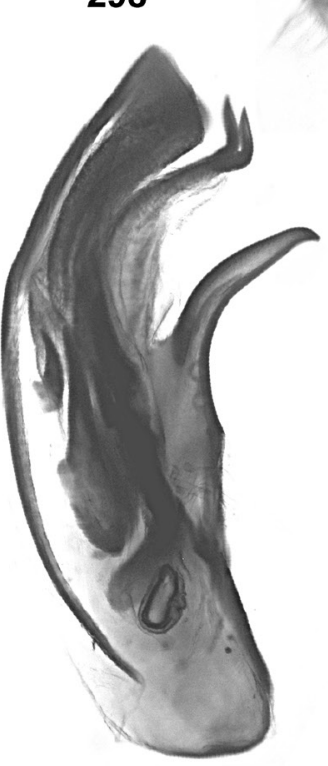

300
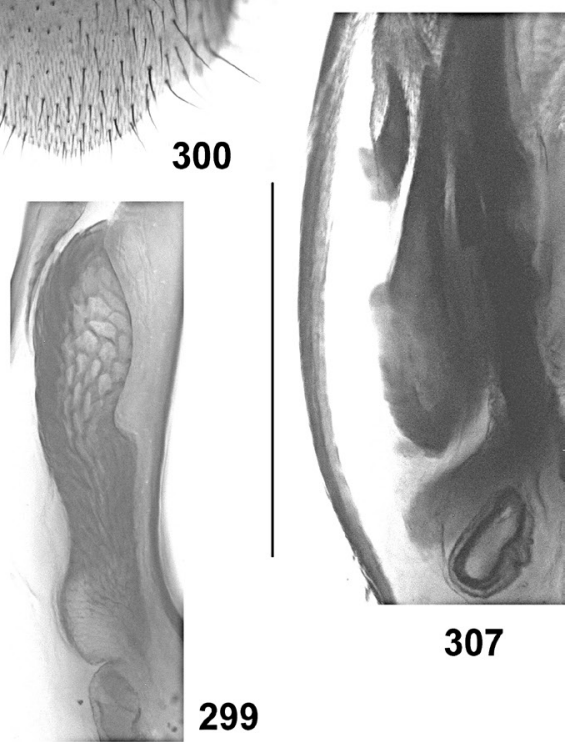

307
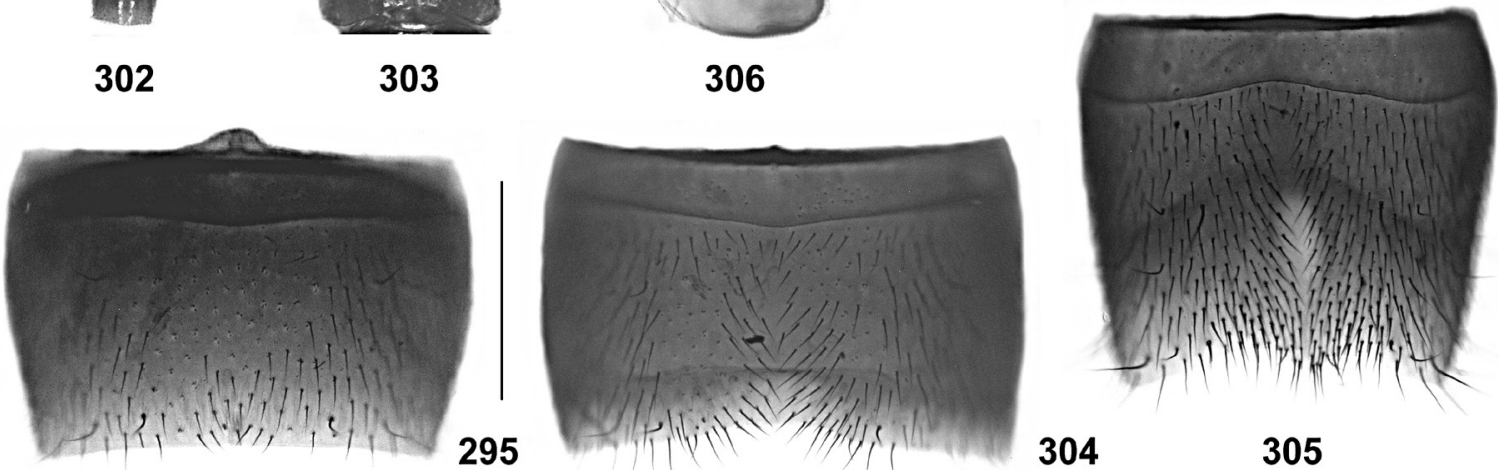

304

305

Figs 294-307: Lathrobium squamosum (294-301) and L. bihamulatum (302-307): forebody (294, 303); male sternite VII (295, 304); male sternite VIII $(296,305)$; aedeagus in lateral and in ventral view $(297-298,306)$; internal structures of aedeagus in lateral view (299, 307); female sternite VIII (300); female tergites IX-X (301); habitus (302). Scale bars: 294, 302-303: 1.0 mm; 295-298, 300-301, 304-307: $0.5 \mathrm{~mm}$; 299: $0.1 \mathrm{~mm}$. 
portion; internal sac with pair of relatively large dark structures with scaly sculpture (Fig. 299).

क : sternite VIII (Fig. 300) approximately $1.2 \mathrm{~mm}$ long and approximately as broad as long; tergite IX (Fig. 301) with long and undivided antero-median portion, and with relatively short postero-lateral processes; tergite X (Fig. 301) distinctly convex, nearly angled in cross-section, slightly shorter than antero-median portion of tergite IX.

\section{Comparative notes:}

Though similar in external appearance to $L$. daliense and allied species, L. squamosum is apparently not closely related to them, as is suggested particularly by the different morphology of the female tergites IX and X. The male and female sexual characters do not indicate closer affiliations with any of the other species known from Yunnan.

\section{Distribution and natural history:}

The type locality is situated in the Ertaipo Shan to the east of Mangshi, Yunnan (Map 7). The specimens were sifted from litter in a secondary pine forest with old deciduous trees at an altitude of $2280 \mathrm{~m}$, together with L. bihamulatum.

\subsection{The L. bihamulatum species group}

\subsubsection{Lathrobium bihamulatum sp. $\mathrm{n}$. (Figs 302-307, Map 8)}

\section{Type material:}

Holotype ơ: "CHINA: Yunnan [C07-19], Dehong Dai Aut. Pref., mountain range $31 \mathrm{~km}$ E Luxi [=Mangshi], $2280 \mathrm{~m}, 24^{\circ} 29^{\prime} 31^{\prime \prime} \mathrm{N}, 98^{\circ} 52^{\prime} 58^{\prime \prime} \mathrm{E}$, secnd. pine forest with old decid. trees, litter sifted, 3.VI.2007, A. Pütz / Holotypus o Lathrobium bihamulatum sp. n. det. V. Assing 2013" (cAss).

\section{Etymology:}

The specific epithet is an adjective composed of the Latin prefix bi- (two) and an adjective derived from the diminutive of the Latin noun hamus (hook). It alludes to the pair of hook-like apical internal structures of the aedeagus.

\section{Description:}

Species of intermediate size and very slender habitus (Fig. 302); body length $8.5 \mathrm{~mm}$; length of forebody $3.8 \mathrm{~mm}$. Coloration: body brown with reddish-brown elytra; legs and antennae dark-reddish.

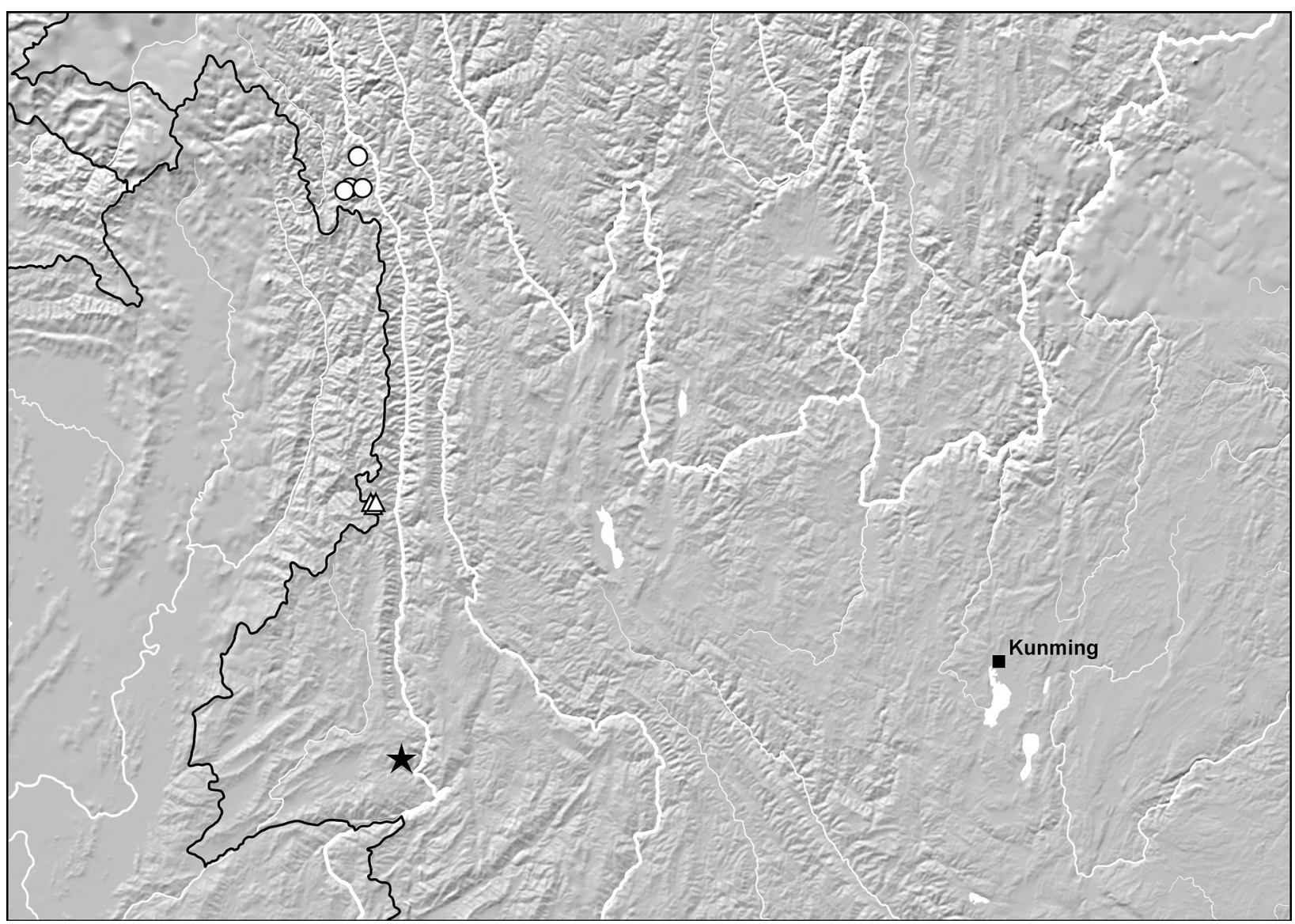

Map 8: Distribution of the species of the L. bihamulatum (filled star) and the L. desectum (open symbols) groups: L. bihamulatum (black star); L. abscisum (white circles); L. desectum, L. sectum, L. amputatum, and L. resectum (all white triangles). 
Head (Fig. 303) approximately as broad as long; punctation moderately coarse and moderately dense; interstices with shallow microreticulation. Eyes small, approximately 0.25 times as long as postocular region and composed of approximately 50 small ommatidia. Antenna $2.5 \mathrm{~mm}$ long.

Pronotum (Fig. 303) approximately 1.3 times as long as broad and 1.02 times as broad as head; punctation similar to that of head; impunctate midline moderately broad; interstices without microreticulation.

Elytra (Fig. 303) 0.53 times as long as pronotum and slender, only as broad as pronotum; punctation fine and relatively sparse. Hind wings completely reduced.

Abdomen long and slender, aproximately 1.2 times as broad as elytra; punctation moderately fine, dense on tergites III-VI, somewhat sparser on tergites VII and VIII; interstices with distinct microsculpture; posterior margin of tergite VII without palisade fringe.

$0^{\star}$ : protarsomeres I-IV strongly dilated; tergite VIII approximately as long as broad, posterior margin weakly angled in the middle; sternites III-VI unmodified; sternite VII (Fig. 304) strongly transverse and with shallow postero-median impression, pubescence not distinctly modified, posterior margin broadly and weakly concave, more distinctly concave in the middle, anterior margin with minute, almost completely reduced median process; sternite VIII (Fig. 305) distinctly transverse and moderately asymmetric, pubescence weakly modified, setae somewhat denser near posterior margin, middle of postero-median impression without setae, posterior margin asymmetrically bisinuate; aedeagus (Fig. 306) $1.3 \mathrm{~mm}$ long, of conspicuous morphology, apical structures of internal sac distinctly extending beyond apex of ventral process; ventral process smoothly and distinctly curved, slender, and apically acute; dorsal plate conspicuously long, apical portion lamellate and distinctly sclerotized, basal portion much longer than apical portion, lamellate, and distinctly sclerotized; internal sac with approximately five strongly sclerotized spines of different sizes and shapes (Fig. 307) and with conspicuous pair of hookshaped apical structures.

†: unknown.

\section{Comparative notes:}

Lathrobium bihamulatum does not seem to have closer affiliations to any of the other species groups recorded from Yunnan. It is characterized by a slender body, particularly the slender elytra (not broader than pronotum; unique among Lathrobium from Yunnan), the slender abdominal tergite VIII, the asymmetrically bisinuate posterior margin of the male sternite VIII (unique among Lathrobium from Yunnan), and by the conspicuous morphology of the aedeagus (apical portion of internal sac strongly extending beyond apex of ventral process; long dorsal plate with a remarkably long and distinctly sclerotized basal portion; shapes of internal structures: presence of sclerotized spines of different shapes and sizes, and an additional conspicuous pair of apical structures).

\section{Distribution and natural history:}

The type locality is situated in the Ertaipo Shan to the east of Mangshi (Map 8). The holotype was sifted from leaf litter in a secondary pine forest with interspersed old deciduous trees at an altitude of $2280 \mathrm{~m}$, together with L. squamosum.

\subsection{The L. desectum species group}

\subsubsection{Lathrobium desectum sp. n. (Figs 308-315, Map 8)}

Type material:

Holotype o": "CHINA: Yunnan [CH07-26], Nujiang Lisu Aut. Pref., Gaoligong Shan, pass $21 \mathrm{~km}$ NW Liuku, $3150 \mathrm{~m}, 25^{\circ} 58^{\prime} 22^{\prime \prime} \mathrm{N}, 98^{\circ} 41^{\prime} 00^{\prime \prime} \mathrm{E}$, bamboo with shrubs, litter sifted, 9.VI.2007, M. Schülke / Holotypus o Lathrobium desectum sp. n. det. V. Assing 2013” (cSch). Paratypes: $5 \sigma^{\star} \sigma^{\star}, 5$ 우 우 : same data as holotype (cSch, cAss); 1 ơ, 2 ㅇ 우: same data, but leg. Pütz (cPüt, cAss); 4 o o o $^{\text {, }}$ 2 우 우 [1 teneral]: "CHINA: Yunnan, Nujiang Lisu Pref., Gaoligong Shan, "Cloud Pass", 21 km NW Liuku, 3150 m, $25^{\circ} 58^{\prime} 21^{\prime \prime} \mathrm{N}, 98^{\circ} 41^{\prime} 01^{\prime} \mathrm{E}$, shrubs \& bamboo, litter sifted, 2.IX.2009, leg. M. Schülke [CH09-22]” (cSch, cAss).

\section{Etymology:}

The specific epithet (past participle of the Latin verb desecare: to cut off) alludes to the truncate posterior margin of the male sternite VIII.

\section{Description:}

Species of moderate size and stout habitus; body length 7.3-8.5 mm; length of forebody 3.1-3.6 mm. Coloration: body blackish; legs reddish to brown; antennae reddish.

Head (Fig. 308) weakly transverse, approximately 1.05 times as broad as long, somewhat wedge-shaped (i.e., dilated posteriad); punctation moderately coarse and relatively sparse; interstices with fine and shallow microsculpture. Eyes relatively large, approximately half as long as postocular region in dorsal view or nearly so, and composed of $>50$ ommatidia. Antenna $1.8-2.0 \mathrm{~mm}$ long.

Pronotum (Fig. 308) short and broad, 1.10-1.15 times as long as broad and 1.10-1.15 times as broad as head; punctation similar to that of head; impunctate midline of variable, often somewhat irregular width; interstices without microsculpture. 
Elytra (Fig. 308) 0.51-0.56 times as long as pronotum; punctation fine, shallow, moderately dense, and somewhat ill-defined. Hind wings completely reduced. Protarsomeres I-IV with pronounced sexual dimorphism.

Abdomen approximately 1.15 times as broad as elytra; punctation fine and dense; interstices with distinct microsculpture; posterior margin of tergite VII without palisade fringe. Tergite VIII without sexual dimorphism, posterior margin weakly convex or indistinctly pointed in the middle.

$0^{\top}$ : sternites III-VI unmodified; sternite VII (Fig. 309) strongly transverse, symmetric, pubescence not distinctly modified, posterior margin broadly and weakly concave, median projection of posterior margin very short and broad; sternite VIII (Fig. 310) symmetric and strongly transverse, approximately 1.3 times as broad as long, somewhat depressed in the middle, but with-

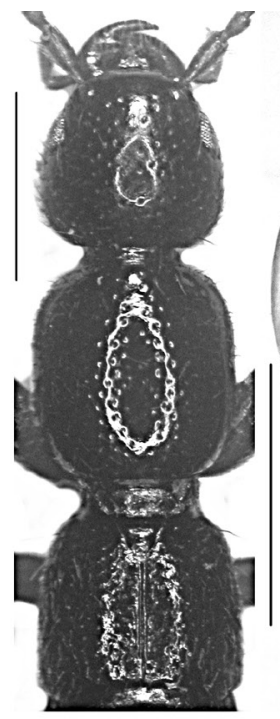

308

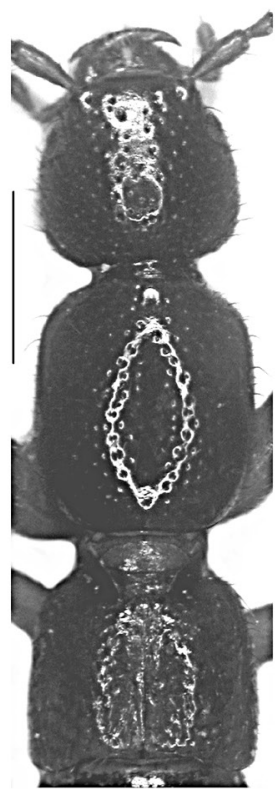

316
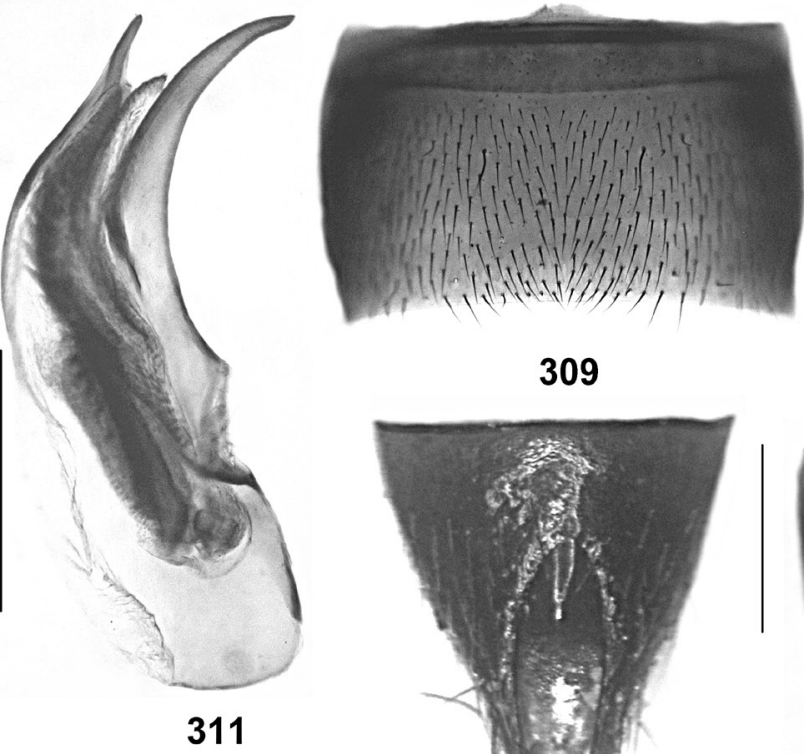

309
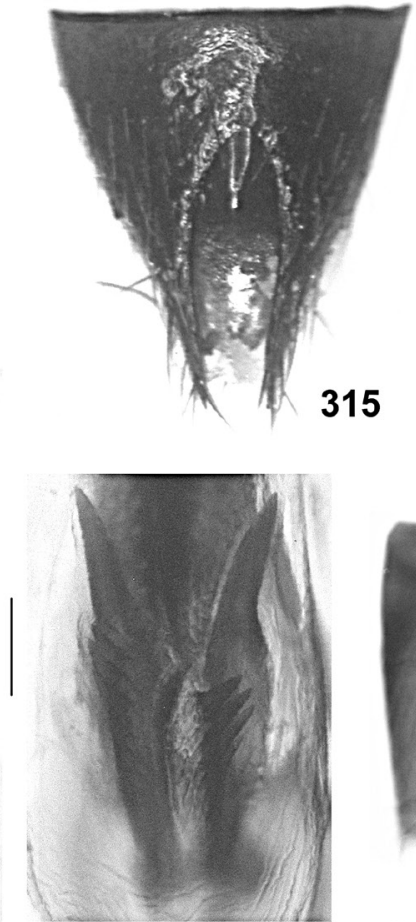

313

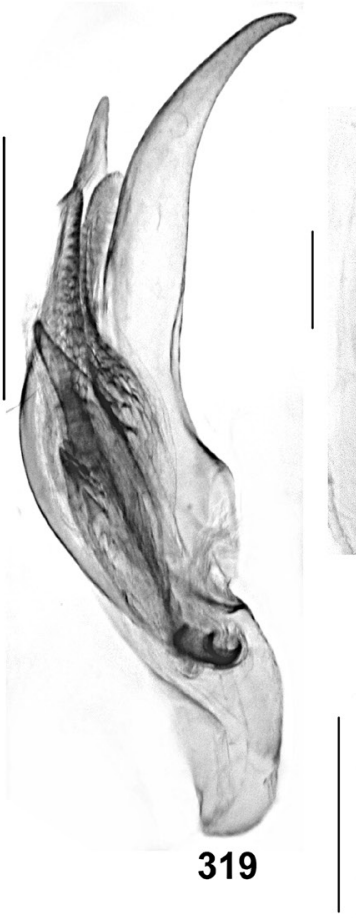

319

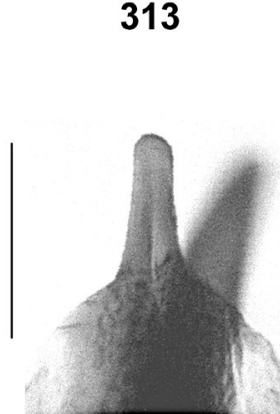

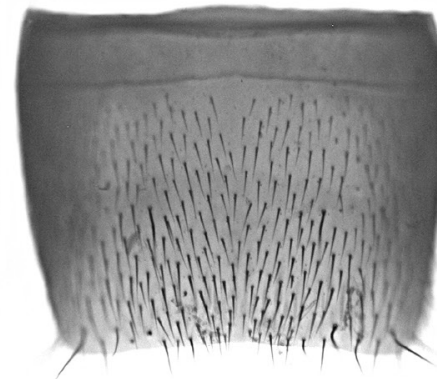

310

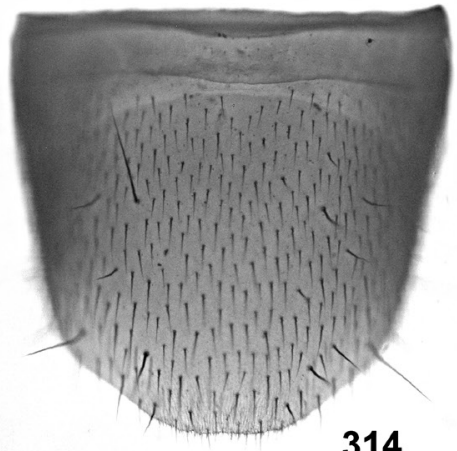

314

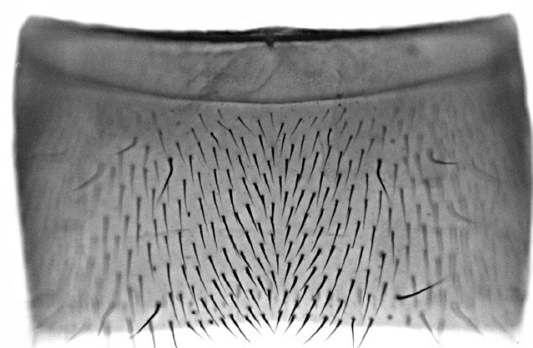

317

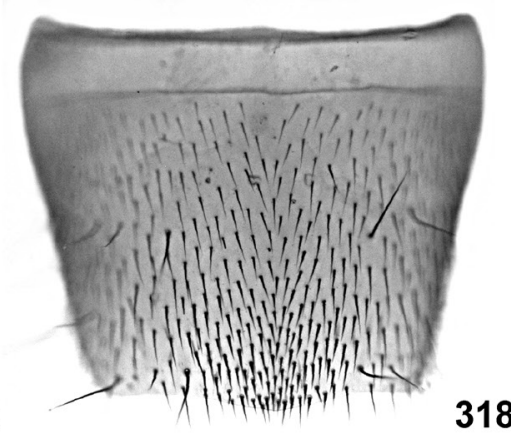

Figs 308-319: Lathrobium desectum (308-315) and L. sectum (316-319): forebody (308, 316); male sternite VII (309, 317); male sternite VIII $(310,318)$; aedeagus in lateral view $(311,319)$; apical portion of dorsal plate of aedeagus in dorsal view $(312)$; internal structures of aedeagus in ventral view (313); female sternite VIII (314); female tergites IX-X (315). Scale bars: 308, 316: 1.0 mm; 309-311, 314-315, 317-319: 0.5 mm; 312-313: $0.1 \mathrm{~mm}$. 
out impression, pubescence short, dense, and unmodified, posterior margin truncate; aedeagus (Fig. 311) 1.2-1.3 mm long and symmetric; ventral process slender, distinctly curved in lateral view, and apically acute; apical portion of dorsal plate lamellate, distinctly sclerotized, nearly straight in lateral view, and with needleshaped apex in dorsal view (Fig. 312), basal portion rather long, but thin, smoothly curved, and moderately sclerotized; internal sac with pair of large spines (Fig. 313) and with additional series of numerous small sclerotized spines.

오 : sternite VIII (Fig. 314) approximately $1.1 \mathrm{~mm}$ long and weakly transverse, posterior margin distinctly convex; tergite IX (Fig. 315) with moderately long anteromedian portion without suture, and with moderately long postero-lateral processes; tergite X (Fig. 315) somewhat convex (cross-section) in anterior half and flat in posterior half, slightly more than twice as long as anteromedian portion of tergite IX.

\section{Comparative notes:}

Lathrobium desectum is reliably distinguished from the following species of the $L$. desectum group only based on the morphology of the aedeagus, particularly the shape of the aedeagus.

\section{Distribution and natural history:}

The type locality is situated in the Gaoligong Shan in western Yunnan province, close to the border with Myanmar (Map 8). The specimens were sifted from leaf litter in bamboo vegetation with shrubs at an altitude of $3150 \mathrm{~m}$. One of the paratypes collected in the beginning of September is teneral.

\subsubsection{Lathrobium sectum sp. n. (Figs 316-319, Map 8)}

Type material:

Holotype $\sigma^{*}$ [teneral]: "CHINA: Yunnan, Nujiang Lisu Pref., Gaoligong Shan, W "Cloud Pass", 24 km NW Liuku, $25^{\circ} 59^{\prime} 02^{\prime \prime} \mathrm{N}, 98^{\circ} 39^{\prime} 56.5^{\prime \prime} \mathrm{E}, 2940 \mathrm{~m}$, small cleft, wet moss \& litter sifted, 3.IX.2009, leg. M. Schülke [CH09-24] / Holotypus o Lathrobium sectum sp. n. det. V. Assing 2013" (cAss).

\section{Etymology:}

The specific epithet (past participle of the Latin verb secare: to cut) alludes to the nearly truncate posterior margin of the short male sternite VIII.

\section{Description:}

Species of moderately large size and stout habitus; body length $8.8 \mathrm{~mm}$; length of forebody $4.1 \mathrm{~mm}$; length of antenna $2.4 \mathrm{~mm}$. Eyes approximately 0.4 times as long as postocular region in dorsal view. Other external characters (Fig. 316) as in L. desectum.

$\sigma^{7}$ : tergite VIII with weakly convex posterior margin; sternites III-VI unmodified; sternite VII (Fig. 317) strongly transverse, symmetric, pubescence somewhat shorter and denser in the shallow postero-median impression than elsewhere, posterior margin broadly and weakly concave, median projection of anterior margin completely reduced; sternite VIII (Fig. 318) symmetric and distinctly transverse, approximately 1.25 times as broad as long, somewhat depressed in the middle, but without impression, pubescence shorter and denser in postero-median portion than elsewhere, posterior margin weakly convex in the middle; aedeagus (Fig. 319) $1.6 \mathrm{~mm}$ long and symmetric; ventral process slender, moderately curved in lateral view, and apically acute; apical portion of dorsal plate lamellate, nearly straight in lateral view, and with needle-shaped apex in dorsal view, basal portion longer than apical portion, thin, smoothly curved, and moderately sclerotized; internal sac with pair of large spines and with additional series of numerous small sclerotized spines.

†: unknown.

\section{Comparative notes:}

Lathrobium sectum is readily distinguished from other representatives of the $L$. desectum group by its larger body size alone. In addition it is characterized by the male sexual characters, particularly the larger aedeagus, the long dorsal plate, the internal structures, as well as the shapes and chaetotaxy of sternites VII and VIII.

\section{Distribution and natural history:}

The type locality is situated in the Gaoligong Shan in western Yunnan province, close to the border with Myanmar (Map 8). The slightly teneral holotype was sifted from wet moss and leaf litter at an altitude of $2940 \mathrm{~m}$, together with L. amputatum.

\subsubsection{Lathrobium amputatum sp. n. (Figs 320-327, Map 8)}

Type material:

Holotype $0^{\star}$ : "CHINA: Yunnan, Nujiang Lisu Pref., Gaoligong Shan, W “Cloud Pass”, 24 km NW Liuku, $25^{\circ} 59^{\prime} 02^{\prime \prime} \mathrm{N}, 98^{\circ} 39^{\prime} 56.5^{\prime \prime} \mathrm{E}, 2940 \mathrm{~m}$, small cleft, wet moss \& litter sifted, 3.IX.2009, leg. M. Schülke [CH09-24] / Holotypus o Lathrobium amputatum sp. n. det. V. Assing 2013" (cSch). Paratypes: $2 o^{\star} o^{\star}, 2$ ㅇ ㅇ [1 teneral]: same data as holotype (cSch, cAss). 
Etymology:

The specific epithet (past participle of the Latin verb amputare: to cut off) refers to the short male sternite VIII with a truncate posterior margin.

\section{Description:}

Species of moderate size and stout habitus; body length 6.5-7.5 mm; length of forebody 3.2-3.5 mm. Posterior margin of tergite VIII weakly convex in both sexes. Other external characters (Fig. 320) as in L. desectum.

$0^{*}$ : sternites III-VI unmodified; sternite VII (Fig. 321) distinctly transverse, symmetric, pubescence not distinctly modified, posterior margin broadly and weakly concave, median process of anterior margin broad and short; sternite VIII (Fig. 322) symmetric and distinctly

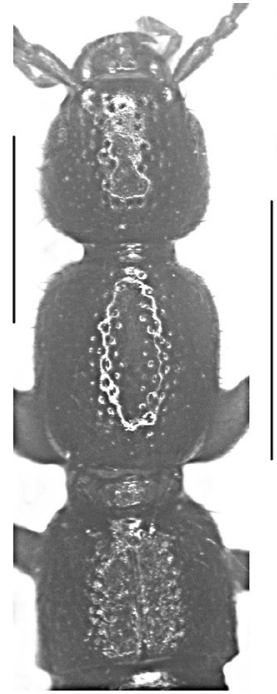

320

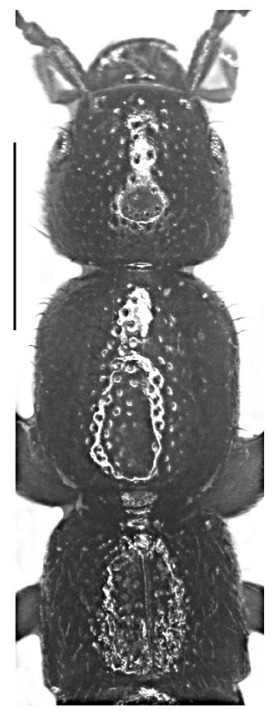

328

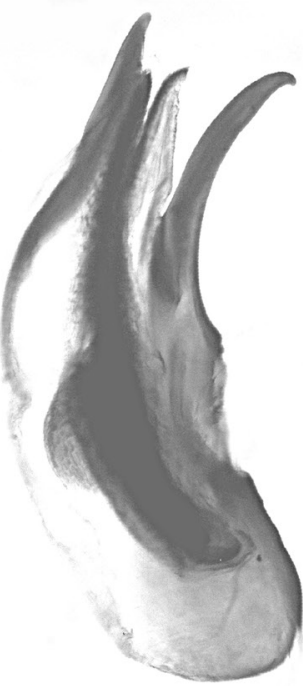

323

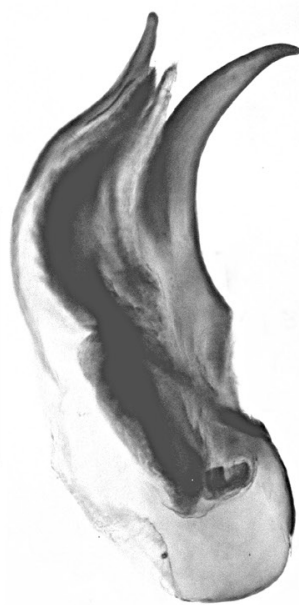

331
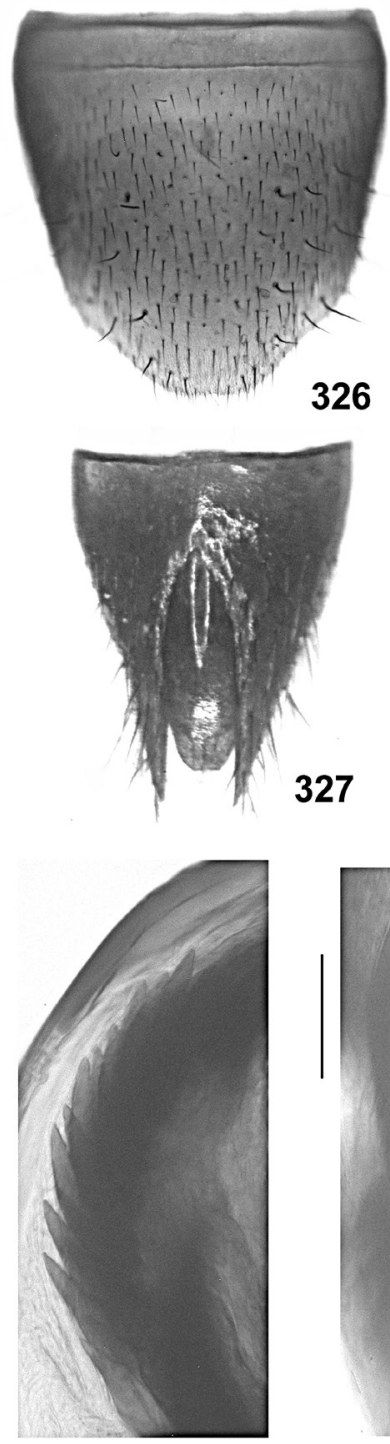

332

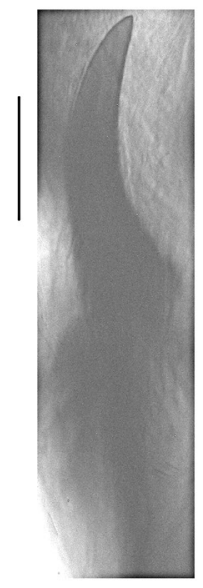

333

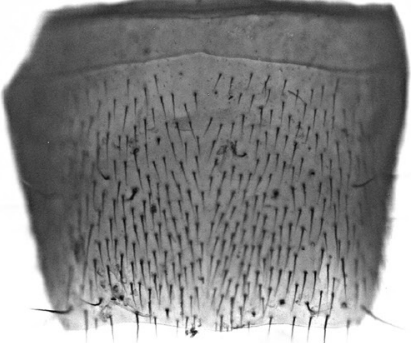

322

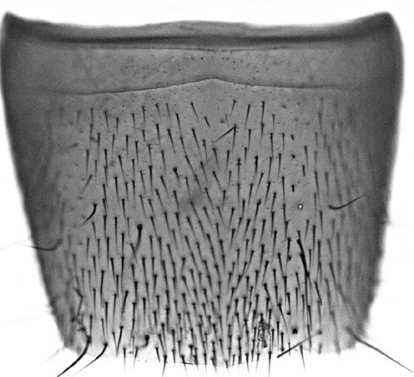

330

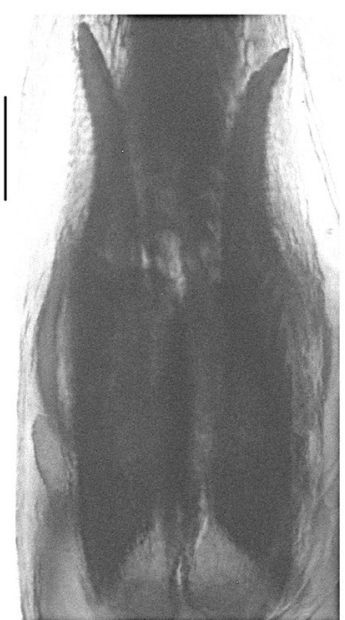

325
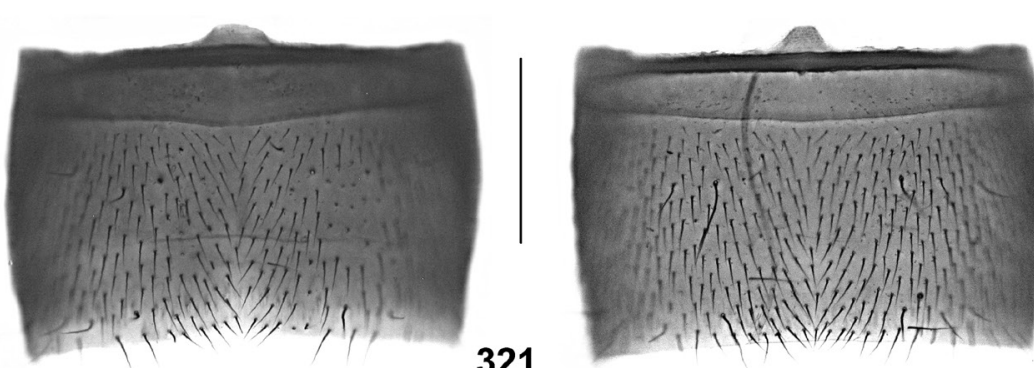

321
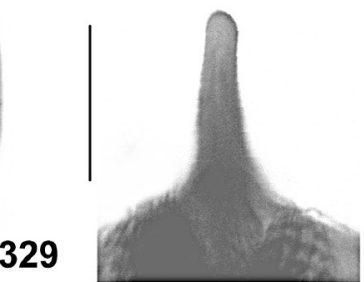

324

Figs 320-333: Lathrobium amputatum (320-327) and L. resectum (328-333): forebody (320, 328); male sternite VII (321, 329); male sternite VIII $(322,330)$; aedeagus in lateral view $(323,331)$; apical portion of dorsal plate of aedeagus in dorsal view (324); basal internal structures of aedeagus in ventral view (325); female sternite VIII (326); female tergites IX-X (327); internal structures of aedeagus in lateral view (332-333). Scale bars: 320, 328: $1.0 \mathrm{~mm}$; 321-323, 326-327, 329-331: 0.5 mm; 324-325, 332-333: 0.1 mm. 
transverse, approximately 1.25 times as broad as long, somewhat depressed in the middle, but without impression, pubescence dense and short, not distinctly modified, posterior margin truncate; aedeagus (Fig. 323) approximately $1.2 \mathrm{~mm}$ long and symmetric; ventral process slender, relatively short, weakly curved in lateral view, and apically acute; apical portion of dorsal plate rather large, distinctly sclerotized, very weakly sinuate in lat- eral view, and with needle-shaped apex in dorsal view (Fig. 324), basal portion short, much shorter than apical portion, thin, distinctly curved, and weakly sclerotized; internal sac with pair of large spines (Fig. 325) and with additional series of numerous small sclerotized spines.

ㅇ: sternite VIII (Fig. 326) approximately $1.1 \mathrm{~mm}$ long and approximately as long as broad; tergite IX (Fig. 327)

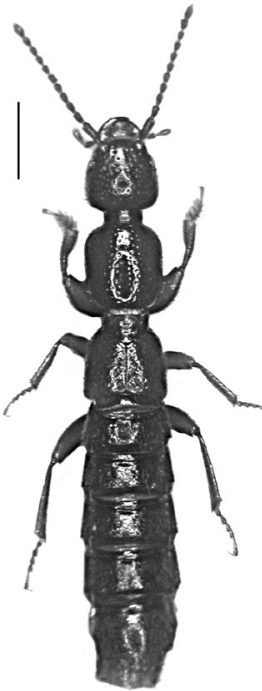

334

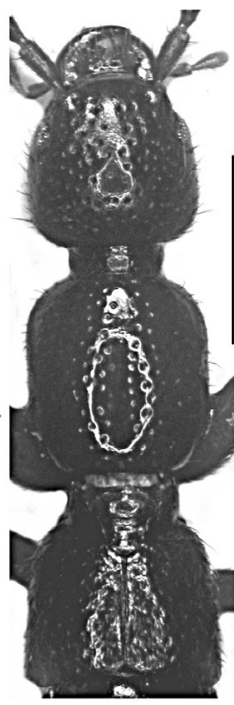

335

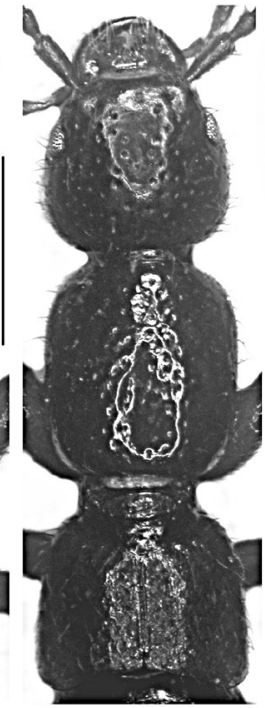

336

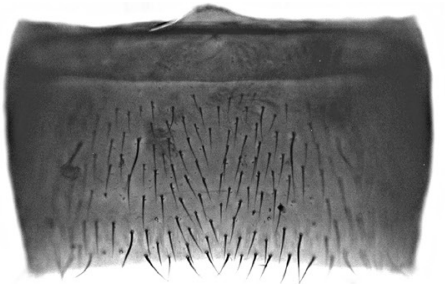

337

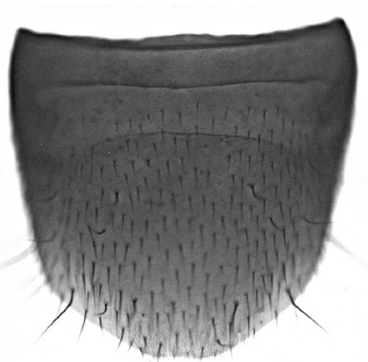

346
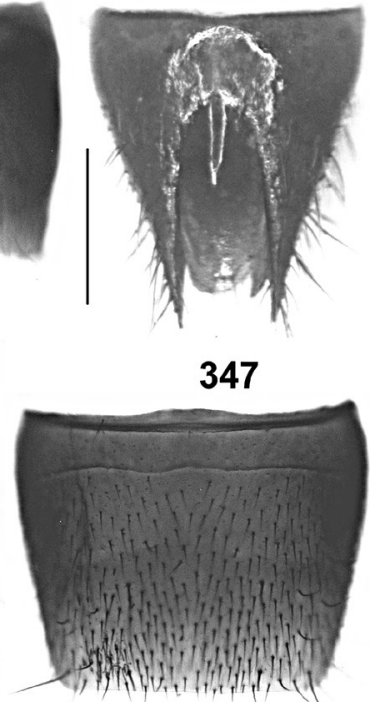

338
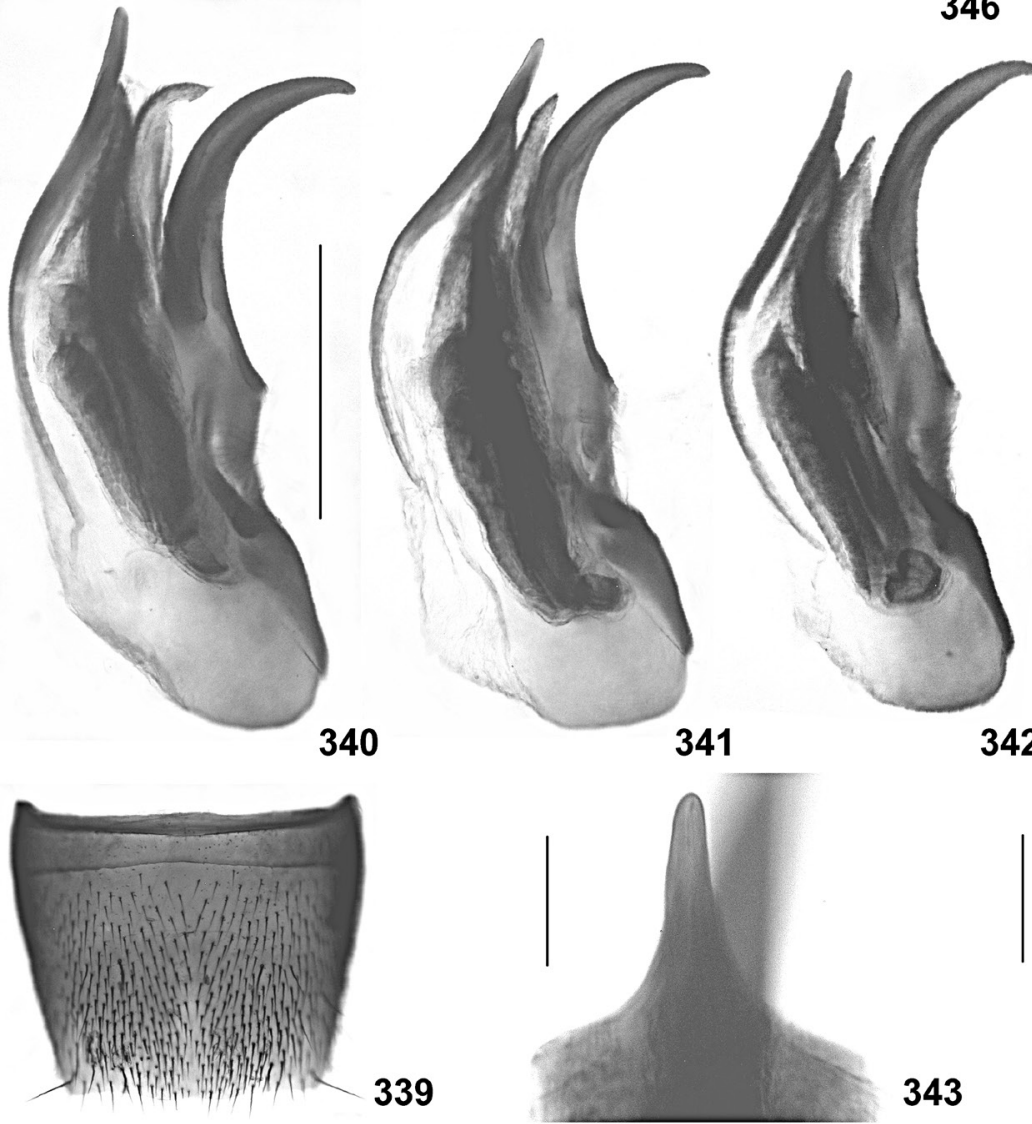

342
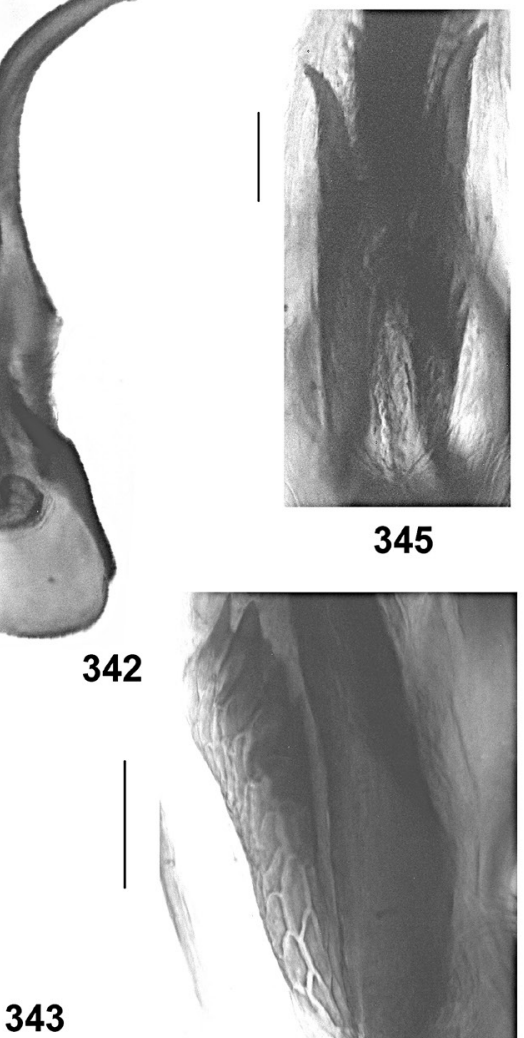

345

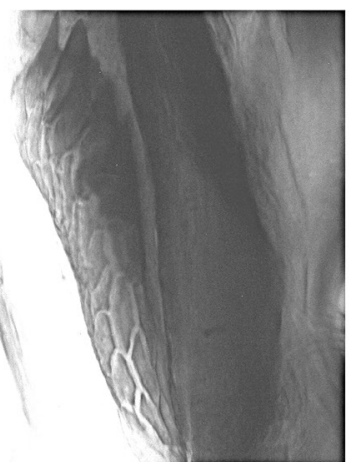

Figs 334-347: Lathrobium abscisum: habitus (334); forebody (335-336); male sternite VII (337); male sternite VIII (338-339); aedeagus in lateral view (340-342); apical portion of dorsal plate of aedeagus in dorsal view (343); internal structures of aedeagus in lateral view (344); basal internal structures of aedeagus in ventral view (345); female sternite VIII (346); female tergites IX-X (347). Scale bars: 334-336: $1.0 \mathrm{~mm}$; 337-342, 346-347: $0.5 \mathrm{~mm}$; 343-345: $0.1 \mathrm{~mm}$. 
with moderately short and undivided antero-median portion without suture and with moderately long postero-lateral processes; tergite X (Fig. 327) moderately convex in cross-section, slightly more than twice as long as antero-median portion of tergite IX.

\section{Comparative notes:}

Lathrobium amputatum differs from other representatives of the L. desectum group by the shorter and less curved ventral process of the aedeagus, the large apical portion and the short basal portion of the aedeagus, the shape of the female sternite VIII, and the shape of the female tergite $\mathrm{X}$. It is additionally distinguished from the syntopic L. sectum by much smaller body size.

\section{Distribution and natural history:}

The type locality is situated in the Gaoligong Shan in western Yunnan province, close to the border with Myanmar. The specimens were sifted from wet moss and leaf litter at an altitude of $2940 \mathrm{~m}$, together with L. sectum. One of the paratypes is teneral.

\subsubsection{Lathrobium resectum sp. n. (Figs 328-333, Map 8)}

\section{Type material:}

Holotype ơ: "CHINA: Yunnan [CH07-27], Nujiang Lisu Aut. Pref., Gaoligong Shan, creek valley $20 \mathrm{~km}$ NW Liuku, 255' $49^{\prime \prime} \mathrm{N}, 98^{\circ} 41^{\prime} 48^{\prime \prime} \mathrm{E}, 3000 \mathrm{~m}$, bamboo, shrubs, litter sifted, 9.VI.2007, M. Schülke / Holotypus ơ Lathrobium resectum sp. n. det. V. Assing 2013” (cSch). Paratype $\mathrm{o}^{\top}$ : same data as holotype (cAss).

\section{Etymology:}

The specific epithet (past participle of the Latin verb resecare: to cut off) alludes to the short male sternite VIII with a truncate posterior margin.

\section{Description:}

Species of moderate size and stout habitus; body length 7.6-8.5 mm; length of forebody 3.3-3.5 mm. Body reddish-brown to blackish. Other external characters (Fig. 328) as in L. desectum.

$\sigma^{7}$ : sternites III-VI unmodified; sternite VII (Fig. 329) strongly transverse, symmetric, pubescence not distinctly modified, posterior margin broadly and weakly concave, median process of anterior margin rather pronounced; sternite VIII (Fig. 330) symmetric and strongly transverse, approximately 1.2 times as broad as long, somewhat depressed in the middle, but without impression, posterior margin almost truncate; aedeagus (Fig. 331) approximately $1.1 \mathrm{~mm}$ long and symmetric; ventral process slender, distinctly curved in lateral view, and apically acute; apical portion of dorsal plate lamellate, distinctly sclerotized, sinuate in lateral view, and with needleshaped apex in dorsal view, basal portion long, approximately as long as apical portion, thin, distinctly curved, and weakly sclerotized; internal sac with pair of large spines (Fig. 333) and with additional series of numerous small sclerotized spines (Fig. 332).

q: unknown.

\section{Comparative notes:}

Lathrobium resectum differs from the geographically close L. desectum particularly by the less transverse male sternite VIII and the shorter aedeagus with a stouter and more strongly curved ventral process, a sinuate dorsal plate (lateral view), and differently shaped internal structures.

Distribution and natural history:

The type locality is situated in the Gaoligong Shan in western Yunnan province, close to the border with Myanmar (Map 8). The specimens were sifted from leaf litter in vegetation composed of bamboo and shrubs at an altitude of $3000 \mathrm{~m}$.

\subsubsection{Lathrobium abscisum sp. n. (Figs 334-347, Map 8)}

\section{Type material:}

Holotype ơ: "CHINA: Yunnan [CH07-22], Nujiang Lisu Aut. Pref., Gaoligong Shan, valley $21 \mathrm{~km}$ W Gongshan, $3320 \mathrm{~m}, 27^{\circ} 47^{\prime} 03^{\prime \prime} \mathrm{N}, 98^{\circ} 27^{\prime} 39^{\prime \prime} \mathrm{E}$, moss, alder, bamboo, Rhodod., sifted, 6.VI.2007, M. Schülke / Holotypus ơ Lathrobium abscisum sp. n. det. V. Assing 2013" (cSch). Paratypes: $20^{\top} o^{\top}$ : same data as holotype (cSch, cAss); $20^{\top} o^{\top}, 2$ ㅇ 우 : “CHINA: Yunnan [CH07-24], Nujiang Lisu Aut. Pref., Gaoligong Shan, valley $18 \mathrm{~km}$ W Gongshan, $3020 \mathrm{~m}, 27^{\circ} 47^{\prime} 54^{\prime \prime} \mathrm{N}, 98^{\circ} 30^{\prime} 13^{\prime \prime} \mathrm{E}$, mixed forest, litter, moss, wood sifted, 7.VI.2007, M. Schülke" (cSch, cAss); $30^{\star} 0^{\star}$, 2 우 우 [1 slightly teneral]: "CHINA: N-Yunnan [200516], Nujiang Lisu Aut. Pref., Gongshan Co., Gaoligong

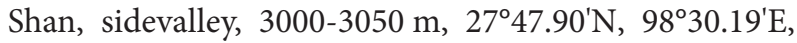
conif. forest with Rhododendron, broad leaved bushes, litter, moss, dead wood sifted along creek and snowfields, 21.VI.2005, M. Schülke [2005-16]" (cSch, cAss); 1 ơ, 1 우 "CHINA: N-Yunnan Nujiang Lisu Aut. Pr., Gongshan Co., Gaoligong Shan, valley at $3000-3050 \mathrm{~m}, 27^{\circ} 47.90^{\prime} \mathrm{N}$ $98^{\circ} 30.19^{\prime}$ E, 21.VI.2005 A. Smetana [C169]” (cSme, cAss); 7 ๙๐ $^{\star}, 3$ 우 우: “P.R. CHINA, Yunnan E slope N Gaoligongshan, N27 59'01.0"E98 32'56.9", 27.v.2010, 3018 m, sifting22, V. Grebennikov" (CAS, cSme, cAss); $3 \sigma^{*} \sigma^{*}$ : same data, but "sifting23" (CAS, cSme, cAss); 5 o $^{\star}$ o $^{\star}, 3$ 우 우 [1 क with mature egg in ovaries]: "P.R. CHINA, Yunnan, E slope N Gaoligongshan, N27²46.8' E98 33.1', 12-15. vi.2009, 2000-3000 m, sifting1-7, V. Grebennikov" (CAS, cSme, cAss); 1 o': "P.R. CHINA, Yunnan, E slope N Gaoli- 
gongshan, N27²47'51.7 E98³4'56.4", 01.vi.2010, 2100 m, sifting25, V. Grebennikov" (cAss).

\section{Etymology:}

The specific epithet (past participle of the Latin verb abscidere: to cut off) alludes to the short male sternite VIII with a truncate posterior margin.

\section{Description:}

Species of moderate size and stout habitus; body length 7.0-8.5 mm; length of forebody 3.3-3.8 mm. Habitus as in Fig. 334. Punctation of head and pronotum rather coarse and moderately dense (Figs 335-336). Other external characters as in L. desectum.

$\sigma^{*}$ : sternites III-VI unmodified; sternite VII (Fig. 337) strongly transverse, symmetric, pubescence not distinctly modified, posterior margin broadly and weakly concave, anterior margin with moderately pronounced median projection; sternite VIII (Figs 338-339) symmetric and strongly transverse, approximately 1.3 times as broad as long, somewhat depressed in the middle, but without impression, posterior margin more or less truncate; aedeagus (Figs 340-342) approximately 1.15$1.25 \mathrm{~mm}$ long and symmetric; ventral process slender, strongly curved in lateral view, and apically acute; apical portion of dorsal plate lamellate, distinctly sclerotized, weakly curved in lateral view, and with needle-shaped apex in dorsal view (Fig. 343), basal portion long, longer than apical portion, but thin, weakly curved, and moderately sclerotized; internal sac with pair of large spines (Fig. 345) and with additional series of numerous small sclerotized spines (Fig. 344).

o : sternite VIII (Fig. 346) approximately as long as broad, posterior margin distinctly convex; tergite IX (Fig. 347) with moderately short antero-median portion without suture and with moderately long postero-lateral processes; tergite X (Fig. 347) strongly convex (cross-section) in anterior half, abruptly sloping ventrad in the middle (forming an angle in lateral view), nearly flat in posterior half, and approximately three times as long as antero-median portion of tergite $\mathrm{X}$.

\section{Comparative notes:}

Lathrobium abscisum differs from other species of the L. desectum group particularly by the more strongly curved ventral process and the internal structures of the aedeagus.

\section{Intraspecific variation:}

The species is rather variable not only regarding the shape of the head and the punctation of the head and pronotum, but also regarding the shape and chaetotaxy of the male sternite VIII (Figs 338-339), as well as the shape of the ventral process of the aedeagus (Figs 340-342). The material labelled "sifting22" and "sifting 23" is distinguished from that collected in the other localities by larger average body size, a larger and more distinctly wedge-shaped head, a slightly larger aedeagus (approximately $1.25 \mathrm{~mm}$ long), and slightly denser pubescence on the male sternite VIII. However, these differences are attributed to intraspecific variation, since they are not pronounced and the aedeagus provides no convincing additional evidence suggesting that these populations should represent distinct species.

\section{Distribution and natural history:}

The species was found in several geographically close localities in the northern Gaoligong Shan. The specimens were sifted from litter in mixed and pine forests, as well as in vegetation composed of alder, bamboo, and rhododendron, at altitudes between 2100 and $3320 \mathrm{~m}$, together with L. secans, L. glandulosum, and/or L. bidigitulatum. One of the paratypes collected in June is slightly teneral. One of the dissected females collected in June had a mature egg in the ovaries.

\subsection{The L. lobrathiforme species group}

\subsubsection{Lathrobium lobrathiforme Assing, 2012}

\section{Material examined:}

China: Yunnan: 5 exs., N-Yunnan, Nujiang Lisu Aut. Pref., Gongshan Co., Gaoligong Shan, $27^{\circ} 48^{\prime} \mathrm{N}, 98^{\circ} 30^{\prime} \mathrm{E}$, valley at 3000-3050 m, 21.VI.2005, leg. Smetana [C169] (cSme, cAss).

\section{Comment:}

The above specimens were collected at the type locality of this species. For illustrations of the habitus and the male sexual characters see Assing (2012b).

\subsection{Unnamed species}

The following, probably undescribed species remain unnamed, since they are represented exclusively by females.

\section{Lathrobium sp. 1}

Material examined:

1 甲, "CHINA (Yunnan) Nujiang Lisu Aut. Pref., Gaoligong Shan, creek valley $20 \mathrm{~km}$ NW Liuku, $3000 \mathrm{~m}$, $25^{\circ} 58^{\prime} 49^{\prime \prime} \mathrm{N}, 98^{\circ} 41^{\prime} 48^{\prime \prime} \mathrm{E}, 3000 \mathrm{~m}$ (bamboo, shrubs, litter sifted) 9.VI.2007 D.W. Wrase [27]” (cSch). 


\section{Comment:}

The above specimen undoubtedly represents an undescribed species distinguished from all other species recorded from Yunnan by the minute eyes, which are composed of only five ommatidia. In addition, it is characterized by relatively small body size (body length $6.7 \mathrm{~mm}$; length of forebody $3.1 \mathrm{~mm}$ ), uniformly palereddish coloration, slender habitus, a relatively large but oblong, densely and rather coarsely punctured head, a long and undivided anterior portion of the female tergite IX, and a short female tergite X (distinctly shorter than antero-median portion of tergite IX). The above specimen was collected together with $L$. resectum.

\section{Lathrobium sp. 2}

Material examined:

1 i: "CHINA (N-Yunnan) Zhongdian [today: ShangriLa] Co., 36 km ESE Zhongdian, 3500-3550 m, 27040.9'N, $100^{\circ} 01.5^{\prime} \mathrm{E}$ (overgrown rock hillside with old mixed forest, bamboo, dead wood, leaf litter) 23.-24.VIII.2003 D.W. Wrase" (cSch); 1 오 : same data, but leg Smetana (cSme).

\section{Comment:}

The above specimens probably represent an undescribed species similar and evidently closely related to L. incurvatum, but distinguished by somewhat smaller body size (body length $8.5-9.5 \mathrm{~mm}$; length of forebody 4.0 $4.1 \mathrm{~mm})$.

\section{Lathrobium sp. 3}

\section{Material examined:}

1 ㅇ: "CHINA: Yunnan, Dali Bai Aut. Pref., Mao Jiao Shan, E pass, $58 \mathrm{~km}$ NE Dali, 2556'41"N, 10040'05"E, $2525 \mathrm{~m}$, second. mixed forest, litter, moss \& mushrooms sifted, 4.IX.2009, leg. M. Schülke [CH09-26]” (cSch).

\section{Comment:}

The above specimen probably represents an undescribed species characterized by moderately large size (body length $8.8 \mathrm{~mm}$; length of forebody $3.8 \mathrm{~mm}$ ) and black coloration. It is additionally characterized by a female tergite IX with a long and undivided antero-median portion and by a relatively short female tergite $\mathrm{X}$ (shorter than anteromedian portion of tergite IX).

\section{Lathrobium sp. 4}

\section{Material examined:}

1 ㅇ: "CHINA: Yunnan, Lincang/Dali Pref., Wuliang Shan, old pass road, N pass, $24^{\circ} 45^{\prime} 16.4^{\prime \prime} \mathrm{N}, 100^{\circ} 29^{\prime} 50.3^{\prime \prime} \mathrm{E}$, $2350 \mathrm{~m}$, forest remnant \& tea plantation, litter, mushrooms, grass sifted, 16.IX.2009, leg. M. Schülke [CH09$55] "(\mathrm{cSch})$.

\section{Comment:}

The above specimen is similar to the geographically close L. magnispinosum, but distinguished by slightly smaller size (body length $9.9 \mathrm{~mm}$; length of forebody $4.7 \mathrm{~mm}$ ), more transverse head, and coarser and denser punctation of the pronotum.

\section{Lathrobium sp. 5}

\section{Material examined:}

3 ㅇ ㅇ: "CHINA (Yunnan) Nujiang Lisu Aut. Pref., side valley $18 \mathrm{~km}$ NW Liuku, $2590 \mathrm{~m}, 25^{\circ} 58^{\prime} 10^{\prime \prime} \mathrm{N}, 98^{\circ} 42^{\prime} 27^{\prime \prime} \mathrm{E}$ (devast. prim. forest, litter sifted) 9.-10.VI.2007 D.W. Wrase [29]" (cSch, cAss).

\section{Comment:}

The above specimens are similar to, but distinctly smaller than L. nuicum (body length 9.0-9.5 mm; length of forebody 4.0-4.2 $\mathrm{mm}$ ).

\section{Lathrobium sp. 6}

Material examined:

1 ㅇ: "CHINA: Yunnan [CH07-30], Nujiang Lisu Aut.

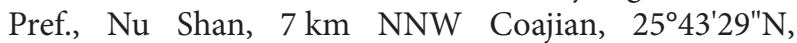
$99^{\circ} 07^{\prime} 57^{\prime E}$, $2420 \mathrm{~m}$, second. pine forest with shrubs, litter, bark sifted, 11.VI.2007, M. Schülke" (cSch); 2 우 우: same data, but leg. Pütz (cPüt, cAss).

\section{Comment:}

The above specimens are externally similar to L. sp. 5 . They were collected together with L. nuicum and L. puetzi.

\section{Lathrobium sp. 7}

\section{Material examined:}

1 \%: "CHINA: Yunnan, Baoshan Pref., Gaoligong Shan, $33 \mathrm{~km}$ SE Tengchong, $2150 \mathrm{~m}, 24^{\circ} 51^{\prime} 22^{\prime \prime} \mathrm{N}, 98^{\circ} 45^{\prime} 36^{\prime \prime} \mathrm{E}$, devast. primery [sic] deciduous forest, litter, wood, mushrooms sifted, 28.VIII.2009, leg. M. Schülke [CH09-08a]" (cSch).

\section{Comment:}

The above specimen is externally similar to L. sp. 6, but slightly smaller.

\section{Lathrobium sp. 8}

\section{Material examined:}

3 우 : “CHINA: Yunnan [CH07-15], Baoshan Pref., Gaoligong Shan, $29 \mathrm{~km}$ ESE Tengchong, $2350 \mathrm{~m}, 24^{\circ} 55^{\prime} 37^{\prime \prime} \mathrm{N}$, $98^{\circ} 45^{\prime} 09^{\prime E}$, dev. decid. forest, litter, wood, fungi sifted, 1.VI.2007, leg. A. Pütz" (cPüt, cAss). 


\section{Comment:}

The above specimens are externally similar to $L$. sp. 5 , but not conspecific. The species is characterized by a conspicuous shape of the female tergite $\mathrm{X}$ (sharply keeled in anterior half).

\section{Lathrobium sp. 9}

\section{Material examined:}

2 우 우 :CHINA (Yunnan) Nujiang Lisu Aut. Pref., creek valley $3 \mathrm{~km}$ SE Gongshan, 27 $43^{\prime} 02^{\prime \prime} \mathrm{N}, 98^{\circ} 41^{\prime} 27^{\prime \prime} \mathrm{E}, 1450$ $1500 \mathrm{~m}$ (litter, moss, sifted) 5.VI.2007 D.W. Wrase [29]" (cSch, cAss).

\section{Comment:}

The above specimens are externally similar to L. rectissimum.

\section{Lathrobium sp. 10}

\section{Material examined:}

1 9 : "CHINA: Yunnan, Nujiang Lisu Pref., Gaoligong Shan, "Cloud Pass", $21 \mathrm{~km}$ NW Liuku, $3150 \mathrm{~m}$, $25^{\circ} 58^{\prime} 21^{\prime \prime N}, 98^{\circ} 41^{\prime} 01^{\prime \prime E}$, shrubs \& bamboo, litter sifted, 2.IX.2009, leg. M. Schülke [CH09-22]” (cAss); 1 ㅇ: same data, but "3.IX.2009 ... [CH09-22a]" (cSch).

\section{Comment:}

The above specimens are externally similar to, but distinctly smaller than L. rectissimum (body length 4.5$4.7 \mathrm{~mm}$; length of forebody 2.3-2.4 mm).

\section{Updated checklist of the Lathrobium species of mainland China and Taiwan}

Including the newly described species, Lathrobium is now represented in mainland China by 156 and in Taiwan by 13 described species.

\section{Acknowledgements}

I am most grateful to the colleagues listed in the material section for the loan of materiaL. In particular, I am indebted to Michael Schülke, Andreas Pütz, and Aleš Smetana for the generous gift of the holotypes of some species. Zhong Peng (Shanghai) and Michael Schülke assisted with the identification of localities; the former also provided photographs of some species described by WatanabE \& XIAO (1997). Lee H. Herman (New York) cross-checked the new names against his unpublished catalogue of Paederinae. Benedikt Feldmann (Münster) proof-read the manuscript.

\section{References}

Assing, V.2012a: Unterfamilie Paederinae Fleming, 1821; pp. 322-369, 380-383. - In: Assing, V. \& Schülke, M. (eds): Freude-Harde-Lohse-Klausnitzer. - Die Käfer Mitteleuropas. Band 4. Staphylinidae I. Zweite neubearbeitete Auflage. Spektrum Akademischer Verlag, Heidelberg and Berlin: I-XII, 1-560.

Assing, V. 2012b: A revision of East Palaearctic Lobrathium (Coleoptera: Staphylinidae: Paederinae). - Bonn Zoological Bulletin 61 (1): 49-128.

Assing, V. 2012c: A revision of the Lathrobium species of the Himalaya (Coleoptera: Staphylinidae: Paederinae). - Bonn Zoological Bulletin 61 (2): 142-209.

Assing, V. 2013: On the Lathrobium fauna of China III. New species and additional records from various provinces (Coleoptera: Staphylinidae: Paederinae). Beiträge zur Entomologie 63 (1): 25-52.

Assing, V. in press a: On the Lathrobium fauna of China I. The species of the Qinling Shan, the Daba Shan, and adjacent mountain ranges (Coleoptera: Staphylinidae: Paederinae). - Bonn Zoological Bulletin 62 (1) (2013).

Assing, V. in press b: On the Lathrobium fauna of China IV. Six new species from Sichuan (Coleoptera: Staphylinidae: Paederinae). - Linzer Biologische Beiträge 45 (1) (2013).

Assing, V. in press c: A revision of Palaearctic Lobrathium. IV. Three new species from Nepal and China, and additional records (Coleoptera: Staphylinidae: Paederinae). - Linzer Biologische Beiträge 45 (1) (2013).

Peng, Z. \& Li, L.-Z. \& ZhaO, M.-J. 2012: A new species of Lathrobium Gravenhorst (Coleoptera: Staphylinidae: Paederinae) from Yulongxueshan Mountain, Southwest China. - Zootaxa 3557: 56-58.

Watanabe, Y. \& XiaO, N.-N. 1994: New apterous Lathrobium (Coleoptera, Staphylinidae) from the Diancang Shan Mountains in Yunnan Province, Southwest China. - Elytra, Tokyo 22 (2): 255-262.

Watanabe, Y. \& Xiao, N.-N. 1996: A new species of the Lathrobium pollens group (Coleoptera, Staphylinidae) from the Mt. Yulongxue Shan in Yunnan Province, Southwest China. - Elytra, Tokyo 24 (1): 61-66.

Watanabe, Y. \& XiaO, N.-N. 1997: New species of apterous Lathrobium (Coleoptera, Staphylinidae) from Yunnan Province, Southwest China. - Elytra, Tokyo 25 (2): 493-508.

Watanabe, Y. \& XiaO, N.-N. 2000: Seven new apterous Lathrobium (Coleoptera, Staphylinidae) from Yunnan, Southwest China. - In: AOKI J.-I.; YIN W.-Y. \& Imadaté, G. (eds): Taxonomical Studies on the Soil Fauna of Yunnan Province in Southwest China. - Tokai University Press: 179-196. 


\begin{tabular}{|c|c|}
\hline Species & Distribution in mainland China and Taiwan \\
\hline abscisum sp. n. & Yunnan: Gaoligong Shan \\
\hline acre sp. n. & Yunnan: Gaoligong Shan \\
\hline acutapicale sp. $\mathrm{n}$. & Yunnan: mountains ESE Zhongdian \\
\hline acutissimum PeNG, Li \& ZHAO, 2012 & Sichuan: Jiajin Shan \\
\hline ailaoshanense WATANABE \& XIAO, 1997 & Yunnan: Ailao Shan \\
\hline amputatum sp. n. & Yunnan: Gaoligong Shan \\
\hline alesi Assing, 2010 & Taiwan: Hsueh Shan \\
\hline alishanum Assing, 2010 & Taiwan: Alishan \\
\hline anmaicum Assing, 2010 & Taiwan: Anmashan \\
\hline aokii WATANABE \& XIAO, 2000 & Yunnan: Diancang Shan \\
\hline appendiculatum Assing, 2013 & Sichuan: N Jinyang \\
\hline aquilinum Assing, in press & Shaanxi: Daba Shan \\
\hline aspinosum Assing, 2013 & Sichuan: Erlang Shan \\
\hline baihualingense WATANABE \& XIAO, 2000 & Yunnan: Gaoligong Shan \\
\hline baishanzuense PENG \& LI, 2012 & Zhejiang: Baishanzu \\
\hline baizuorum WaTANABE \& XiaO, 2000 & Yunnan: Diancang Shan \\
\hline barbiventre Assing, 2013 & Fujian: Wuyi Shan \\
\hline biapicale Assing, in press & Sichuan: Songpan env. \\
\hline bibaculatum Assing, 2013 & Sichuan: Erlang Shan \\
\hline bidigitulatum sp. $\mathrm{n}$. & Yunnan: Gaoligong Shan \\
\hline bifasciatum sp. $\mathrm{n}$. & Yunnan: mountains SSE Zhongdian \\
\hline bifidum Assing, in press & Hubei: Daba Shan \\
\hline biforme Assing, in press & Gansu: Qinling Shan \\
\hline bihamulatum sp. n. & Yunnan: Ertaipo Shan E Mangshi \\
\hline bihastatum Assing, 2013 & Sichuan: Daxiang Ling \\
\hline biseriatum sp. $\mathrm{n}$. & Yunnan: Xue Shan (S Zhongdian) \\
\hline bisinuatum Assing \& PENG, 2013 & Sichuan: Emei Shan \\
\hline bispinigerum AssING, 2013 & Sichuan: Erlang Shan \\
\hline bisuditum Assing, in press & Sichuan: Xiling Xue Shan \\
\hline bivirgatum Assing, in press & Sichuan: Luoji Shan \\
\hline brevilobatum Assing, in press & Shaanxi: Qinling Shan \\
\hline breviseriatum sp. n. & Yunnan: Daque Shan (E Weishan) \\
\hline brevisternale Assing, in press & Sichuan: Min Shan \\
\hline brevitergale Assing, in press & Shaanxi: Qinling Shan \\
\hline celere Assing, 2013 & Sichuan: Gongga Shan \\
\hline concameratum Assing, in press & Shaanxi: Qinling Shan \\
\hline conexum Assing \& Peng, 2013 & Sichuan: Emei Shan \\
\hline coniunctum Assing \& Peng, 2013 & Sichuan: Emei Shan \\
\hline cooteri WATANABE, 1999 & Zhejiang: Linglong Shan \\
\hline cornigerum Assing, 2013 & Jiangxi: Wuyi Shan \\
\hline crassispinosum Assing, in press & Shaanxi/Sichuan: Micang Shan \\
\hline curvatissimum sp. n. & Yunnan: Jizu Shan \\
\hline curvispinosum Assing, in press & Hubei: Daba Shan \\
\hline
\end{tabular}




\begin{tabular}{|c|c|}
\hline Species & Distribution in mainland China and Taiwan \\
\hline dabeiense WatanaBE \& XIAO, 1997 & Yunnan: Gaoligong Shan \\
\hline daliense WatanabE \& XiaO, 1994 & Yunnan: Diancang Shan \\
\hline daocongchaoi PENG \& LI, 2012 & Fujian: Wuyi Shan \\
\hline dayaoshanense PENG \& LI, 2012 & Guangxi: Dayaoshan \\
\hline depravatum Assing, 2013 & Jiangxi: Wuyi Shan \\
\hline declive Assing, in press & Shaanxi: Qinling Shan: Taibai Shan \\
\hline desectum sp. n. & Yunnan: Gaoligong Shan \\
\hline detruncatum Assing, in press & Sichuan: Songpan env. \\
\hline diffissum Assing, in press & Sichuan: Luoji Shan \\
\hline dignum SHARP, 1874 & Hubei, Jiangsu, Liaoning, Gansu?, Shaanxi? \\
\hline effeminatum Assing, in press & Shaanxi: Qinling Shan \\
\hline elevatum sp. $\mathrm{n}$. & Yunnan: Ailao Shan \\
\hline ensigerum Assing \& Peng, 2013 & Sichuan: Emei Shan \\
\hline exspoliatum sp. $\mathrm{n}$. & Yunnan: Wulao (=Xue) Shan (ENE Lincang) \\
\hline extraculum Assing, 2010 & Taiwan: Peitawushan \\
\hline falcatum Assing, in press & Gansu: Qinling Shan \\
\hline fissispinosum Assing, in press & Hubei: Daba Shan \\
\hline follitum Assing, 2010 & Taiwan: Peitawushan \\
\hline formidabile Assing, in press & Sichuan: Hengduan mountains NW Qiaowa \\
\hline fortehamatum sp. n. & Yunnan: Xue Shan (S Zhongdian) \\
\hline fortepunctatum Assing, 2013 & Chongqing: Jinfo Shan \\
\hline fortespinosum sp. n. & Yunnan: mountains N Zhongdian \\
\hline fujianense PENG \& LI, 2012 & Fujian: Junzifeng Shan \\
\hline gansuense Assing, in press & Gansu: Qinling Shan \\
\hline glandulosum sp. n. & Yunnan: Gaoligong Shan \\
\hline grandispinosum sp. $\mathrm{n}$. & Yunnan: Zhemo Shan \\
\hline guizhouense CHEN, Li \& ZHAO, 2005 & Guizhou: Fanjing Shan \\
\hline hailuogouense PENG, LI \& ZHAO, 2012 & Sichuan: Gongga Shan \\
\hline hamulatum Assing, in press & Sichuan: Luoji Shan \\
\hline hastatum Assing \& Peng, 2013 & Sichuan: Emei Shan \\
\hline heteromorphum CHEN, Li \& ZHAO, 2005 & Shaanxi: Qinling Shan \\
\hline hirsutum sp. n. & Yunnan: Diancang Shan \\
\hline houhuanicum Assing, 2010 & Taiwan: Houhuanshan \\
\hline huaense Assing, in press & Shaanxi: Qinling Shan: Hua Shan \\
\hline hunanense WATANABE, 2011 & Hunan: Zhangjiacao \\
\hline iaculatum sp. n. & Yunnan: Gaoligong Shan \\
\hline imadatei WATANABE, 1992 & Zhejiang: Wuyanling \\
\hline immanissimum PeNG \& LI, 2012 & Zhejiang: Baishanzu \\
\hline imminutum Assing, 2013 & Beijing: Dongling Shan \\
\hline incurvatum sp. $\mathrm{n}$. & Yunnan: mountains SSE Zhongdian \\
\hline inflexum Assing, in press & Gansu: mountains SE Longnan \\
\hline involutum Assing, 2010 & Taiwan: Hseuhshan \\
\hline ishiianum WATANABE \& XIAO, 2000 & Yunnan: Gaoligong Shan \\
\hline
\end{tabular}




\begin{tabular}{|c|c|}
\hline Species & Distribution in mainland China and Taiwan \\
\hline itohi WatANABE \& XIAO, 2000 & Yunnan: Gaoligong Shan \\
\hline iunctum Assing \& Peng, 2013 & Sichuan: Emei Shan \\
\hline jinfoicum Assing, 2013 & Chongqing: Jinfo Shan \\
\hline jingyuetanicum Li \& CHeN, 1990 & Jilin: Jingyuetan \\
\hline jiulongshanense PENG \& LI, 2012 & Zhejiang: Jiulong Shan \\
\hline jizushanense WATANABE \& XIAO, 1997 & Yunnan: Jizu Shan \\
\hline kishimotoi Watanabe, 2011 & Hunan: Zhangjiacao \\
\hline labahense Peng, Li \& ZHAO, 2012 & Sichuan: Labahe \\
\hline lentum Assing, in press & Sichuan: Songpan env. \\
\hline lijiangense Watanabe \& Xiao, 1997 & Yunnan: Yulongxue Shan \\
\hline lingae Peng, Li \& ZHAO, 2012 & Zhejiang: Longwang Shan \\
\hline lobrathiforme Assing, 2012 & Yunnan: Gaoligong Shan \\
\hline lobrathioides Assing, 2012 & Chongqing: Jinfo Shan \\
\hline longispinosum Assing, in press & Shaanxi/Sichuan: Micang Shan \\
\hline longwangshanense PENG, Li \& ZHAO, 2012 & Zhejiang: Longwang Shan \\
\hline lunatum Assing, in press & Gansu: Qinling Shan \\
\hline magnispinosum sp. $\mathrm{n}$. & Yunnan: Wuliang Shan \\
\hline maoershanense PENG \& LI, 2012 & Guangxi: Maoer Shan \\
\hline mawenliae PENG \& LI, 2013 & Shaanxi: Qinling Shan \\
\hline miaoershanum WATANABE, 2011 & Guangxi: Maoer Shan \\
\hline minicum Assing, in press & Gansu: Min Shan \\
\hline naxii Watanabe \& XIaO, 1996 & Yunnan: Yulongxue Shan \\
\hline nenkaoicum Assing, 2010 & Taiwan: Nenkaoshan \\
\hline nuicum sp. n. & Yunnan: Nu Shan \\
\hline obstipum PeNG \& LI, 2012 & Zhejiang: Baishanzu \\
\hline parvitergale Assing, 2013 & Zhejiang: Tianmu Shan \\
\hline pilosum Peng \& LI, 2012 & Zhejiang: Baishanzu \\
\hline pium Assing, 2013 & Guizhou: Leigong Shan \\
\hline proprium PENG \& LI, 2012 & Guangxi: Maoer Shan \\
\hline puetzi sp. n. & Yunnan: Nu Shan \\
\hline rastellatum sp. $\mathrm{n}$. & Yunnan: Ailao Shan \\
\hline rastratum sp. $\mathrm{n}$. & Yunnan: Wuliang Shan \\
\hline rectispinosum Assing, in press & Shaanxi: Daba Shan \\
\hline rectissimum sp. n. & Yunnan: Gaoligong Shan \\
\hline resectum sp. n. & Yunnan: Gaoligong Shan \\
\hline restinctum sp. n. & Yunnan: mountains ESE Zhongdian \\
\hline reticolle sp. n. & Yunnan: Haba Shan \\
\hline rougemonti WATANABE, 1999 & Zhejiang: Tianmu Shan \\
\hline schuelkei sp. n. & Yunnan: Laobie Shan \\
\hline secans sp. $\mathrm{n}$. & Yunnan: Gaoligong Shan \\
\hline sectum sp. n. & Yunnan: Gaoligong Shan \\
\hline semistriatum SCHEERPELTZ, 1962 & Shandong: Tai Shan \\
\hline seriespinosum sp. n. & Yunnan: Yulongxue Shan \\
\hline
\end{tabular}




\begin{tabular}{|c|c|}
\hline Species & Distribution in mainland China and Taiwan \\
\hline serrilobatum Assing, in press & Shaanxi/Sichuan: Micang Shan \\
\hline sexspinosum sp. $\mathrm{n}$. & Yunnan: Yulongxue Shan \\
\hline shaanxiense CHEN, Li \& ZHAO, 2005 & Shaanxi: Qinling Shan \\
\hline shaolaiense WATANABE, 1998 & Taiwan: Ta-hsüeh Shan \\
\hline shengtangshanense PENG \& LI, 2012 & Guangxi: Shengtang Shan \\
\hline sheni PENG \& LI, 2012 & Zhejiang: Jiulong Shan \\
\hline shuheii WatanABE \& XIAO, 2000 & Yunnan: Gaoligong Shan \\
\hline $\begin{array}{l}\text { sinense HERMAN, } 2003 \\
=\text { chinense BERNHAUER, } 1935\end{array}$ & Gansu, Shaanxi, Hubei, N-Sichuan, Jiangsu \\
\hline sociabile Assing, in press & Shaanxi: Qinling Shan \\
\hline spinigerum Assing, in press & Shaanxi: Micang Shan \\
\hline squamosum sp. n. & Yunnan: Ertaipo Shan E Mangshi \\
\hline stipiferum sp. n. & Yunnan: Haba Shan \\
\hline tamurai WATANABE, 1992 & Zhejiang: Wuyanling \\
\hline tangi Peng \& LI, 2012 & Zhejiang: Baishanzu \\
\hline tarokoense Assing, 2010 & Taiwan: Taroko Nature Reserve \\
\hline tectiforme Assing, in press & Shaanxi: Qinling Shan \\
\hline tentaculatum sp. n. & Yunnan: Ailao Shan \\
\hline tianmushanense WATANABE, 1999 & Zhejiang: Tianmu Shan, Longwang Shan \\
\hline tricuspidatum sp. n. & Yunnan: Haba Shan \\
\hline trifidum Assing, in press & Shaanxi/Chongqing: Daba Shan \\
\hline triquetrum sp. n. & Yunnan: Bangma Shan \\
\hline tsuifengense WATANABE, 2005 & Taiwan: Tsuifeng \\
\hline uncum Peng, Li \& ZhaO, 2012 & Zhejiang: Longwang Shan \\
\hline utriculatum Assing, 2010 & Taiwan: Peinantashan \\
\hline varisternale Assing, in press & Shaanxi: Qinling Shan \\
\hline ventricosum Assing, 2013 & Sichuan: Gongga Shan \\
\hline verminatum Assing, in press & Sichuan: Xiling Xue Shan \\
\hline watanabei SCHÜLKE, 2002 & Sichuan: Daxue Shan \\
\hline wuesthoffi КосH, 1939 & Beijing; Hebei/Nei Mongol \\
\hline wuicum Assing, 2013 & Jiangxi: Wuyi Shan \\
\hline$x i e i$ Watanabe \& XiaO, 2000 & Yunnan: Gaoligong Shan \\
\hline yasutoshii WATANABE, 2005 & Taiwan: Lishan \\
\hline yinae Watanabe \& XIaO, 1997 & Yunnan: Yulongxue Shan \\
\hline yulongense PENG \& LI, 2012 & Yunnan: Yulongxue Shan \\
\hline yunnanum WATANABE \& XIAO, 1994 & Yunnan: Diancang Shan: Laohu Shan \\
\hline zhangdinghengi PeNG, Li \& ZHAO, 2012 & Guangxi: Huaping Nature Reserve \\
\hline zhangi Watanabe \& XIAO, 1997 & Yunnan: Jizu Shan \\
\hline zhaotiexiongi PENG, Li \& ZHAO, 2012 & Zhejiang: Jiulong Shan, Majian \\
\hline zhemoicum sp. n. & Yunnan: Zhemo Shan \\
\hline zhujianqingi PENG \& LI, 2012 & Guangxi: Maoer Shan \\
\hline
\end{tabular}

